\title{
Funktionsanalyse der Entwicklungskontrollgene Irx2 und Mash1 in der Maus
}

\author{
Dissertation \\ zur Erlangung des Doktorgrades \\ der Mathematisch-Naturwissenschaftlichen Fakultäten \\ der Georg-August-Universität zu Göttingen
}

vorgelegt von

May-Britt Becker

aus Köln

Göttingen 2002 


\author{
Diese Arbeit wurde am \\ Max-Planck-Institut für biophysikalische Chemie, \\ Karl-Friedrich-Bonhoefer-Institut \\ Abteilung: Molekulare Zellbiologie \\ Direktor: Prof. Dr. Peter Gruss \\ durchgeführt.
}

D7

Referent: Professor Dr. P. Gruss

Korreferent: Professor Dr. U. Ehlers

Tag der mündlichen Prüfung 


\section{INHALTSVERZEICHNIS}

I. Einleitung 1

$\begin{array}{lr}\text { II. Ergebnisse } & 16\end{array}$

$\begin{array}{ll}\text { II.1. Strukturanalyse des Irx2-Gens } & 16\end{array}$

II.1.1. Sequenzanalyse der Irx2-cDNA 16

II.1.2. Irx2-Proteinsequenzanalyse 22

II.1.3. Das Irx2-Antiserum 26

II.1.4. Identifikation des genomischen Klon des Irx2-Gens 28

II.1.4.1 Durchmustern einer genomischen Phagenbank 29

II.1.4.2 Sequenzanalyse des genomischen Irx2-Klons 30

II.1.5. Chromosomale Lokalisation 32

II.2 Erstellung und Analyse der Irx2-Verlustmutante 34

II.2.1 Entwicklung und Durchführung der Schritte zur Klonierung der Irx2- 35

Rekombinationskassette

II.2.2 Gentransfer in ES-Zellen $\quad 37$

$\begin{array}{ll}\text { II.2.3 Morula-Aggregation von ES-Zellen } & 38\end{array}$

II.2.4 Analyse der Mauskolonie von ES-Zellklon 69 41

II.2.5 Untersuchung der Mauskolonie von ES-Zellklon 184

II.2.6 Phänotypanalyse der Mauslinie Irx2-184 44

II.2.6.1 Analyse des Verpaarungsmusters von Irx2-Mutanten 44

2.6.2 Morphologische Untersuchung 51

2.6.3 Humane Lokalisation von Irx2 und das Cri-du-chat Syndrom 54

II.2.7 Entwicklung der mehrfachen Selektion in ES-Zellen und Erstellung der 56

Doppelmutante Irx 1/Irx2

II.3 Expressionsanalyse des Irx2-Gens 
II.3.1 Übersicht über die Irx2-Expression 58

II.3.2 Spezifizierung der Expression von Irx2 während der Larynxentwicklung 65

II.3.3 Expression von Irx2 während der Organogenese am Beispiel der 67 Lungenentwicklung

$\begin{array}{ll}\text { II.4 Analyse der Mash1-Mutante } & 74\end{array}$

$\begin{array}{ll}\text { III. Diskussion } & 84\end{array}$

IV. Material und Methoden 104

$\begin{array}{ll}\text { IV.1. Organismen } & 104\end{array}$

$\begin{array}{ll}\text { IV.1.1 Mäuse und Embryonen } & 104\end{array}$

$\begin{array}{ll}\text { IV.1.2 Bakterien } & 104\end{array}$

$\begin{array}{lc}\text { IV.1.3 ES-Zellen } & 104\end{array}$

$\begin{array}{ll}\text { IV.2 Materialien } & 105\end{array}$

$\begin{array}{ll}\text { IV.2.1 Chemikalien } & 105\end{array}$

$\begin{array}{ll}\text { IV.2.2 Radiochemikalien } & 105\end{array}$

$\begin{array}{ll}\text { IV.2.3 Verbrauchsmaterial } & 105\end{array}$

$\begin{array}{ll}\text { IV.2.4 Enzyme } & 105\end{array}$

$\begin{array}{ll}\text { IV.2.5 Reaktionssets (“Kits”) } & 105\end{array}$

$\begin{array}{ll}\text { IV.2.6 Membranen } & 106\end{array}$

$\begin{array}{ll}\text { IV.2.7 DNA-Bibliotheken } & 106\end{array}$

$\begin{array}{ll}\text { IV.2.8 Vektoren } & 106\end{array}$

$\begin{array}{ll}\text { IV.2.9 Größenmarker } & 106\end{array}$

$\begin{array}{ll}\text { IV.2.10 Oligopeptide } & 107\end{array}$

$\begin{array}{ll}\text { IV.2.11 Filme } & 107\end{array}$

$\begin{array}{ll}\text { IV.2.12 Photoarbeiten und Sequenzbearbeitung } & 107\end{array}$

$\begin{array}{ll}\text { IV.2.13 in-situ-Hybridisierungssonden } & 108\end{array}$

$\begin{array}{ll}\text { IV.2.14 Medien, Nährböden, Standard-Lösungen } & 108\end{array}$

$\begin{array}{ll}\text { IV.3 Methoden } & 109\end{array}$

$\begin{array}{ll}\text { IV.3.1 Isolierung von Plasmid-DNA aus Bakterien } & 110\end{array}$

IV.3.2 Konzentrationsbestimmung von Nukleinsäuren 111

$\begin{array}{ll}\text { IV.3.3 Agarose-Gelelektrophorese } & 111\end{array}$

IV.3.4 Gewinnung von DNA-Fragmenten aus Agarosegelen mit dem QIA- 112 quick Gel Extraction Kit 
IV.3.5 Restriktionsspaltung von DNA

IV.3.6 Aufreinigung von DNA-Lösungen mittels Phenol/Chloroform-

Extraktion

IV.3.7 Ethanolfällung von DNA aus wässrigen Lösungen

IV.3.8 Isopropanolfällung von DNA aus wässrigen Lösungen

IV.3.9 Ligation von DNA-Fragmenten

IV.3.10. "blunt end"-Klonierung

IV.3.11 Transformation von Bakterien

IV.3.12 Sequenzierung ("Cycle sequencing")

IV.3.13 Polymerase-Kettenreaktion (PCR)

IV.3.14 Southern-Blot-Analyse

IV.3.15 Radioaktive Markierung von DNA- und RNA-Blots

IV.3.16 Durchmustern einer cDNA- oder genomischen Maus-DNA-Bibliothek nach rekombinanten Bakteriophagen und deren Isolierung

IV.3.17 Präparation genomischer Maus-DNA

IV.3.18 Arbeiten mit RNA

IV.3.19 Northern Blot

IV.3.20 Radioaktive mRNA-in-situ-Hybridisierung an Schnitten

IV.3.21 mRNA-in-situ-Hybridisierung an ganzen Embryonen ("wholemount"'-Hybridisierungstechnik)

IV.3.22 Nachweis von $\beta$-Galaktosidase (X-Gal-Färbung)

IV.3.23 Methoden zur Arbeit mit eukaryotischen Zellen

IV.3.24 Maus-FISH-Analyse der transgenen ES-Zellen

IV.3.25 Herstellung von Maus-Chimären aus ES-Zellen durch

Morulaaggregation

IV.3.26 Zellbiologische Methoden

IV.3.27 Herstellung von Antisera (Irx l-Antikörper)

IV.3.28 Western-Blot

IV.3.29 Immunhistochemie

IV.3.30 Histologische Methoden 
VII. Literaturverzeichnis 163

VIII. Danksagung

180

IX. Publikationen

182

X. Lebenslauf

184 


\section{EINLEITUNG}

Tiere entwickeln sich in der Regel aus einer befruchteten Eizelle, aus der die embryonalen Zellen hervorgehen, die nach vielen Mitosen die zelluläre Grundlage des Organismus bilden. In einer erstaunlichen Meisterleistung der Selbstorganisation bilden sich diese Zellen zu einem vollständigen Organismus. Der grundlegende Aufbau ist im Prinzip dabei gleich, nicht aber das Ergebnis: Menschen, Mäuse oder Fliegen repräsentieren die unterschiedlichsten Ausprägungen ihrer Baupläne. Angesichts des breiten Spektrums morphologischer Gestaltungsmöglichkeiten ist der Befund überraschend, dass es eine molekulare Verwandtschaft der Entwicklung gibt. Verschiedene Gruppen von interagierenden Faktoren, wie z. B die homeotischen Gene agieren sowohl in den Wirbellosen wie auch in den Wirbeltieren als Regulatoren des Körperaufbaus. Es ist zu erwarten, dass neben diesem System, das z.B. Positionen in der Längsachse festlegt, sich auch weitere genetische Kontrollnetze im Laufe der Jahre wenig verändert haben. Die Entdeckung dieser universellen molekularen Architektur ist die Grundlage für die Suche nach orthologen Genen in anderen Tierarten. Dabei ist die Vergleichbarkeit der Nukleotidsequenzen die Grundlage für die Entdeckung von funktionellen Übereinstimmungen wie auch von tierspezifischen Besonderheiten das Ziel der Untersuchung.

Heute sind nahezu alle Gene des Menschen und der Maus sequenziert. Interessant ist, dass das Genom der Maus rund 2,6 Milliarden Basenpaare umfaßt und damit nur etwa 300 Millionen Basenpaare kleiner ist als das menschliche Erbgut. Die neue Herausforderung besteht nun im Verständnis der molekularen Mechanismen, welche die selektive Aktivität dieser Gene steuern. Wahrscheinlich werden alle Gene im Laufe des Lebens eines Organismus zumindest einmal transkribiert, dabei ist die räumliche und zeitliche Verteilung der Genaktivität von entscheidender Bedeutung. 


\section{I.1. GENREGULATION UND TRANSKRIPTIONSKONTROLLE}

Alle Zellen eines Embryos entstammen der befruchteten Eizelle. Daraus folgt, dass sie alle - bis auf wenige Ausnahmen - das gleiche Genom wie die totipotente Zygote enthalten, und dennoch entwickeln sich unterschiedliche Zelltypen. Insofern geht es zentral um die Frage, welche Gene unterschiedliche Zellschicksale bedingen können.

Die Entwicklung, die Morphologie, die Physiologie und auch der Metabolismus einer Zelle hängen im Wesentlichen von den zelleigenen Proteinen ab. Sie bilden die Strukturund Funktionselemente der Zelle und bestimmen damit ihre möglichen Fähigkeiten. Gewebespezifische Proteine sorgen für die spezifische funktionelle Ausgestaltung einer Zelle, während die "Haushaltsproteinen" (housekeeping proteins) für die Lebenserhaltung der Zelle unverzichtbar sind, da sie alle biochemischen Reaktionswege zur Erzeugung der zelleigenen Energie, der DNA-Erneuerung und des Zellzyklus ermöglichen. Obwohl die Haushaltsgene qualitativ und quantitativ je nach Zelle variieren, spielen sie in der Entwicklung der Organismen nur eine untergeordnete Rolle. Es sind vielmehr die gewebespezifischen Proteine, welche die Zellunterschiede in den Vielzellern vermitteln. Die Zelle verfügt über verschiedene Mechanismen, die Bildung von Proteinen zu kontrollieren. Die Expression eines Gens wird durch die koordinierte Wirkung der regulatorischen Transkriptionsfaktoren gesteuert. Dabei entscheidet häufig nicht ein Transkriptionsfaktor allein über den Aktivitätsstatus eines Gens, sondern das spezifische Zusammenspiel mehrerer Faktoren. Die Kontrolle der Genexpression und Proteinsynthese erfolgt jedoch nicht allein auf der Ebene der Transkription. Die Konformation der DNA kann ebenfalls zur Regulation beitragen. Die Bedeutung des sterischen Effekts für die Expression der genetischen Information ist darin begründet, dass die Transkriptions-maschinerie nur starten kann, wenn sie Zugang zur DNA hat (Cavalli, 1998).

Festzuhalten bleibt, dass für die Entwicklung eines Organismus die Steuerung der differentiellen Genexpression grundlegend ist. Für die Analyse der Embryonalentwicklung sind daher die Gene der Transkriptionsfaktoren von besonderem Interesse, denn sie bewirken den spezifischen Wechsel von Genaktivitätsmustern. 


\section{I.2. IDENTIFIZIERUNG VON ENTWICKLUNGSKONTROLLGENEN}

Die Identifizierung von Entwicklungsgenen ist ein zentrales Anliegen der Entwicklungsbiologie. Anhand von Phänotyp-Analysen natürlicher Mutanten und der Lokalisation der dazugehörigen genetischen Veränderung wurden die ersten Entwicklungskontrollgene identifiziert. Zu ihnen gehört die Homeodomänen-Genfamilie (Gehring, 1985)(Gehring, 1994). Diese Familie umfaßt eine große Gruppe von Transkriptionsfaktoren mit einer ähnlichen DNA-bindenden Domäne, die Homeodomäne. Sie enthält das Helix-Schleife-Helix-Motiv, das für viele DNAbindenden Faktoren charakteristisch ist. Kodiert wird diese Domäne von einer ca. 180 bp langen Nukleotidsequenz, der sog. Homeobox. Viele Mitglieder dieser Gen-Familie spielen eine wichtige Rolle im Prozeß der Embryonalentwicklung. Ursprünglich sind die Homeoboxgene bei der Fruchtfliege D. melanogaster entdeckt worden, bei der sie wesentlich an der Steuerung der Musterbildung beteiligt sind. Die Bezeichnung "Homeobox" leitet sich daraus ab, dass Mutationen in einigen dieser Gene zu sog. homeotischen Veränderungen führen. Bei diesen Mutationen wird ein ganzer Körperabschnitt durch einen anderen ersetzt. So werden bei der natürlich vorkommenden Fliegenmutante Antennapedia (McGinnis, 1985; McGinnis et al., 1984), anstelle der Antennen im Kopfsegment Extremitäten ausgebildet.

In Drosophila ist gezeigt worden, dass Kluster (eine festgelegte Abfolge von Genen) von homeotischen Genen an der Festlegung der Segmentidentitäten beteiligt sind. Ähnliche Gengruppen sind inzwischen bei vielen anderen Tieren entdeckt worden. Bei den Wirbeltieren werden sie als Hox-Kluster bezeichnet. Im Genom der Maus gibt es vier Kluster von Hoxgenen, die vermutlich durch mehrfache Verdopplung aus einer ursprünglichen Gengruppe hervorgegangen sind. Gene, die so durch Divergenz und Verdoppelung innerhalb einer Spezies entstehen, werden als paraloge Gene bezeichnet.

Die hohe Konservierung von Sequenzen, Genen und ihren Funktionsorten erlaubt es, im Rahmen von Evo-Devo-Studien (evolution und development) Vorhersagen und Arbeitshypothesen für mögliche funktionelle Zusammenhänge aufzustellen, immer beachtend, dass diese Vorhersagbarkeit Grenzen hat. Der Fund und Vergleich der HoxKluster in vielen Tierarten ist daher sehr bedeutend gewesen. Denn neben den strukturellen Ähnlichkeiten in der Nukleotidsequenz, der Ausrichtung der Proteine als 
DNA-bindende Transkriptionsfaktoren, zeigen sie eine äußerst erstaunliche Übereinstimmung in ihrer Funktion. In den so verschiedenen Tieren wie der Fruchtfliege als Vertreterin der Invertebraten und der Maus, der Wirbeltiervertreterin, scheint es ein gemeinsames Prinzip in der Entwicklung zu geben. Darüber hinaus wird sogar ein im starken Maße vergleichbares Repertoire an Genen in der Embryonalentwicklung genutzt. Die Homeoboxgene stellen damit ein beeindruckendes Beispiel für die weitverbreitete Konservierung von Entwicklungsgenen dar. In allen bisher untersuchten Arten spielen sie als Transkriptionsfaktoren eine Schlüsselrolle in der regionalen Spezifizierung (McGinnis and Krumlauf, 1992; Weisblat, 1994).

\section{I.3. ENTDECKUNG EINER NEUEN GENFAMILIE: DIE IROQUOIS-GENE.}

Die Suche nach dieser Genfamilie beginnt mit den interessanten Ergebnissen, die in der Analyse der neuralen Entwicklung in der Fruchtfliege Drosophila melanogaster gewonnen wurden (Dambly-Chaudière and Leynes, 1992; Leyns et al., 1996). Entdeckt wurde die Iroquois-Mutante anhand des sichtbaren Verlust aller lateralen Sinnesborsten auf dem Notum ("Rücken der Fliege"), auf dem nur ein mittlerer Streifen an Sinneshaaren zurück blieb. Dieses Erscheinungsbild erinnerte an die Haartracht des Indianerstammes der Iroquesen und so erhielt der Lokus der vorliegenden Mutation seinen Namen. Der Iroquois-Komplex (Iro-C) besteht aus drei Genen - araucan, caupolican und mirror (Gómez-Skarmeta et al., 1996; McNeill et al., 1997). Phantasievoll ist auch die Namensgebung für die einzelenen Gene: Araucan ist der Name eines Indianerstammes in Südamerika, dessen Anführer Caupolican hieß.

Die Iroquois-Gene sind Mitglieder einer konservierten Genfamilie von Homeodomänen-kodierenden Transkriptionsfaktoren (Gómez-Skarmeta et al., 1996), die in der embryonalen Musterbildung und Regionalisierung eine wesentliche Rolle spielen (Gómez-Skarmeta et al., 1998). Auf die molekulare Charakterisierung der Fliegengene folgte die Suche nach orthologen Vertretern insbesondere in der Maus und in weiteren Vertebraten.

Von den Iroquois homeobox- (Irx-) Genen sind bisher sechs Familienmitglieder in der Maus beschrieben worden - Irx1, Irx2, Irx3, Irx4, Irx5 und Irx6 (Bosse et al., 1997; Bosse et al., 2000; Peters et al., 2000; Cohen et al., 2000; Bruneau et al., 2000). 
Innerhalb der Iroquois-Genfamilie zeichnet sich die Homeodomäne dadurch aus, dass ihre einzelnen Aminosäurebausteine während der Evolution äußerst konserviert beibehalten worden sind. Diese evolutive Identität begründet die Zusammenfassung der Iroquois-Gene zu einer Familie innerhalb der großen Gruppe der Transkriptionsfaktoren. Außerdem besitzen ausschließlich die Mitglieder der Iroquois-Genfamilie die "Iro-Box" - eine weitere konservierte Domäne, deren Funktion noch nicht geklärt ist.

Der Fund konservierter Iroquois-spezifischer Domänen weist auf eine wichtige funktionelle Bedeutung dieser Gene hin und läßt erwarten, dass auch in weiteren Wirbeltieren orthologe Gene existieren, so wie es beispielsweise sechs humane Irx-Gene gibt (Lewis et al., 1999; Bruneau et al., 2000). Aus der Analyse des humanen Irx2-Gens liegen erste funktionelle Hinweise vor, die auf eine Beteiligung in der Entstehung von humanem Brustkrebs hinweisen (Lewis et al., 1999).

Weitere Analysen in Vertebraten wurden in Xenopus laevis, Gallus gallus und in Zebrafisch (Danio rerio) durchgeführt. Bisher bekannt sind fünf orthologe Irx-Gene aus Xenopus laevis (Bellefroid et al., 1998; Gómez-Skarmeta et al., 1998). Im Huhn wurden bisher cIrx2 (Goriely et al., 1999), cIrx3 (Funayama et al., 1999) und cIrx4 (Bao et al., 1999) identifiziert, sowie mehrere Irx-Gene in Zebrafisch, deren Zuordnung noch weiter analysiert werden muß (Tan et al., 1999).

Die Entdeckung der Iroquois-Familie in den verschiedensten Tierarten ermöglicht es nun, Hinweisen auf funktionale Übereinstimmungen bei gleichzeitiger Berücksichtigung der gruppenspezifischen Besonderheiten nachzugehen.

\section{I.3.1 FUNKTIONEN DER IROQUOIS-GENE IN DER ENTWICKLUNG VON FLIEGEN}

Iro wurde genetisch als die $T p(3,3)$ iro $^{1}$-Mutante beschrieben. Die rezessive Mutation führt zur Abwesenehit der achaete-scute- (as-sc-) exprimierenden proneuralen Zellgruppen und damit zum Fehlen der lateralen sensorischen Borsten auf dem Notum (Dambly-Chaudière and Leynes, 1992; Leyns et al., 1996). Diese Borsten und Haare auf der Körperoberfläche der Fruchtfliege Drosophila melanogaster sind mechanosensorische Sinnesorgane, die Berührungen sowie Luftwiderstände wahrnehmen. Bevor der Mechanorezeptor gebildet werden kann, muß zuvor der Ort der Entstehung definiert sein. Es zeigte sich, dass seine genaue Position exakt festgelegt ist. 
In der Imaginalscheibe der Mutante ist das "Vormuster" (prepattern) der Genexpression gestört. Dieses bewirkt auch eine Störung der zeitlich aufeinander folgenden Aktivitäten der proneuralen Gene und des Notch-Delta-Signalweges (Posakony, 1994; Simpson, 1997), die im Wildtyp die Entstehung des sensorischen Organs aus der Vorläuferzelle (SOM; sensomotoric mother cell) ermöglicht hätten.

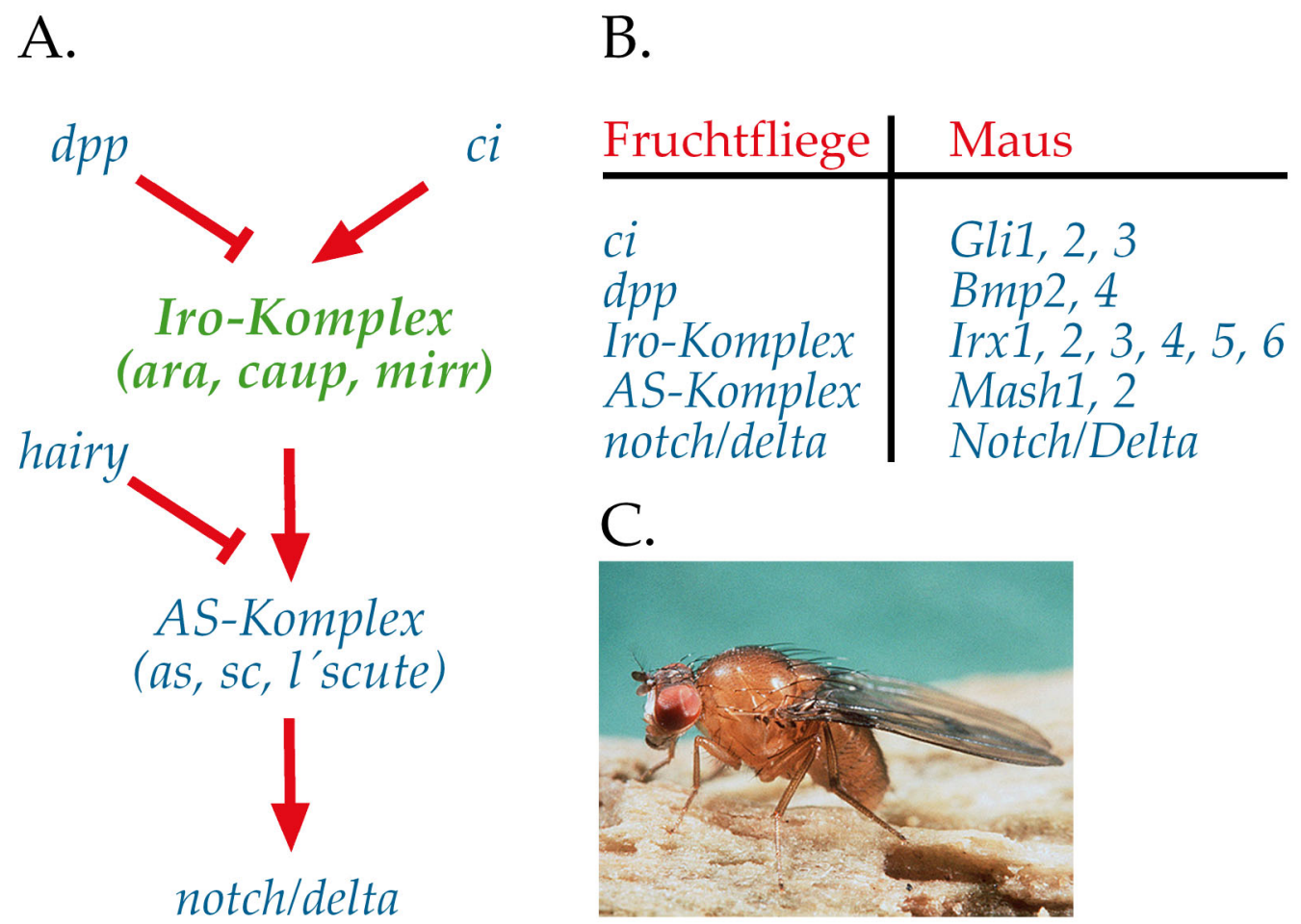

\begin{abstract}
Abb.1: Genetische Regulation der Sinnesborsten der Fruchtfliege Drosophila melanogaster
\end{abstract}

A. Darstellung der aktivierenden und reprimierenden genetischen Interaktionen während der Bildung der Sinnesborstenzellen der Fruchtfliege.

B. Alle essentiellen Gene dieser funktionellen Kaskade haben orthologe Verwandte im Genom der Vertebraten.

C. Die Identifizierung der Iroquois-Genfamilie begann mit Drosophila melanogaster.

Neben der Spezifizierung der Positionen der Sinnesborsten auf dem Notum der Fliege, agieren die Iroquois Gene bei der Einteilung von Kompartimenten auf den Augen- und Flügel-Imaginalscheiben. In der Augen-Imaginalscheibe setzen die Iroquois-Gene die vom Organisator induzierte Unterteilung in dorsal und ventral um. 
Als Leitmotiv der Iroquois-Aktivität könnte gelten, dass diese Gene große Regionen im Embryo in Untereinheiten unterteilen und anschließend für entsprechend unterschiedliche Genaktivitätsmuster sorgen (Cavodeassi et al., 2001).

\section{Drosophila}

Auge Notum

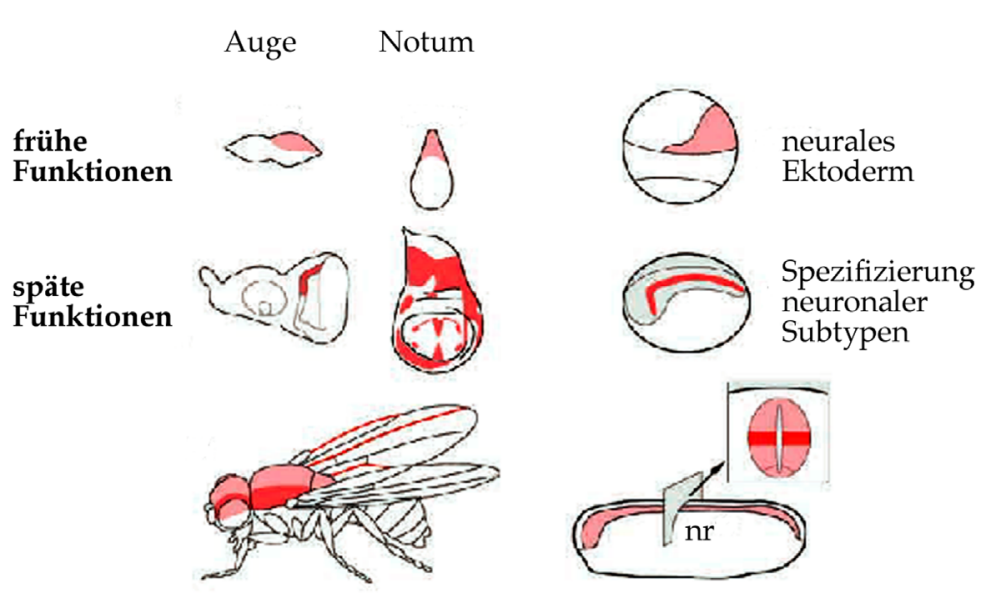

\section{Xenopus}

Abb. 2: Vergleich von frühen und späten Funktionen der Iroquois-Gene in $D$. melanogaster und Xenopus (entnommen aus (Cavodeassi et al., 2001)

Die frühe Funktion besteht in der Spezifizieung großer Regionen wie Auge, Notum oder Neuralektoderm. Die späte Funktion bewirkt die Ausbildung an musterbildenden Elementen, wie z.B. die Haarsinneszellen, die Flügel oder die neuronalen Untergruppen im Neuralrohr (nr).

\section{I.3.2. FUNKTIONEN DER IROQUOIS-GENE IN VERTEBRATEN}

Die Ergebnisse der Funktionsstudien in Xenopus weisen den Iroquois-Genen eine besondere, wenn auch redundante Funktion während der Neurogenese zu (Bellefroid et al., 1998; Gómez-Skarmeta et al., 1998). Die frühe Funktion liegt in der Spezifizierung des prospektiven Ektoderms während der Gastrulation. Die Förderung der neuralen Entwicklung findet auf molekularer Ebene in einer gegenseitigen Repression von Xiro und Bmp4 statt. Xiro kann die mesoderm-induzierende Funktion des bone morphogenetic protein 4 (Bmp4) verhindern. In einer späteren Phase der Entwicklung beschränkt sich die Xiro Genaktivität auf spezifische Einzelbereiche, in denen die Entwicklung einer bestimmten Subgruppe an Neuronen induziert wird (GómezSkarmeta et al., 2001). 
Erste Hinweise zeigen, dass das Hühnergen cIrx4 eine wichtige Rolle während der Herzentwicklung spielt und cIrx3 in der Coelombildung von Bedeutung ist (Bao et al., 1999; Funayama et al., 1999).

\section{I.3.3. BISHER BEKANNTE IROQUOIS-FUNKTIONEN IN DER MAUS}

Die Maus nimmt wie jedes Tier ihren Anfang in einer Zelle - der befruchteten Eizelle. Nach erfolgter Befruchtung benötigt der Mausembryo 19 Tage bis zur Geburt. Dabei weicht die frühe Phase der Entwicklung der Amnioten stark von der anderer Wirbeltiere ab, denn die Entwicklung im Mutterleib stellt spezifische Erfordernisse an das Überleben des Embryos. Die Eier sind sekundär dotteram und der Embryo bezieht die Nahrung von der Mutter über die Plazenta. Dies bedeutet, dass die Embryonen zwangsläufig sehr früh mit der Mutter Kontakt aufnehmen, um ihre Versorgung sicherzustellen (Tam and Behringer, 1997; Hogan et al., 1994). Dieser Kontakt wird durch die Blastozystenimplantation hergestellt. Anschließend setzt bei E6,5 (=embryonales Stadium 6,5 Tage nach der Befruchtung) die Gastrulation ein, deren gezielte Zellwanderungen die Entstehung der drei Keimblätter Ektoderm, Mesoderm und Endoderm ermöglichen.

In der Irx 1-Verlustmutante sind diese frühen embryonalen Vorgänge gestört (Zülch, 2001). Die Gastrulation ist so stark beeinträchtigt, dass anstelle der verschiedenen mesodermalen Zellen ausschließlich extraembryonales Mesoderm gebildet wird. Dieser Fehler führt zum Tod der Mutanten noch während der Gastrulation.

Von allen Mitgliedern der murinen Iroquois-Genfamilie ist bisher neben der eben erwähnten Funktion des Irxl-Gens nur bekannt, dass der Verlust der Irx4 Funktion zu veränderten Genexpressionsmuster weiterer Gene im Herzventrikel führt (Bruneau et al., 2000).

Alle Iroquois-Gene in der Maus zeigen ein hoch spezifisches wie auch dynamisches Genaktivitätsmuster im sich entwickelnden Nervensystem. Neben diesen mit Drosophila vergleichbaren neuralen Aktivitätsbereichen liegen im embryonalen Mesoderm und in den Herzanlagen neue Domänen möglicher Funktionen. 


\section{I.4. DIE SPEZIFISCHE FUNKTION EINES GENS KANN IN DER MAUS UNTERSUCHT WERDEN.}

Die Funktion eines Gens kann auf gentechnologischem Wege mit Hilfe der Gewinnund Verlustmutanten in der Maus untersucht werden.

Gewinnmutanten werden so konstruiert, dass sie einen Überschuss des Genprodukts ("gain-of-function") enthalten bzw. Aktivität an zusätzlichen Stellen zeigen. Die Überexpression von Zielgenen erzeugt ektopische Genaktivitäten, deren Auswirkungen anhand morphologischer Auffälligkeiten analysiert werden können. Diese Methode eignet sich gut, um Veränderung in den Genaktivitätsmustern zellulärer Zielgene zu zeigen. Die Untersuchung der Funktion eröffnet den Blick auf die Reaktionen des Gesamtorganismus, bei der die zufällige Integration des Zielgens in das Genom zu bedenken ist. Durch die Integration könnten unbekannte Gene gestört werden bzw. die inserierte DNA unter fremde Kontrolle geraten. Der Vergleich einer großen Anzahl von Tieren erlaubt korrekte Schlußfolgerungen, da Gemeinsamkeiten im Phänotyp, die bei verschiedenen Integrationsereignissen entstanden sind, auf die eingeführte Veränderung zurückzuführen sind.

Bei Verlustmutanten dagegen wird das zu untersuchende Gen ausgeschaltet ("loss-offunction, knock-out"). Zu unterscheiden sind die gezielte und die zufallsgenerierte Mutagenese. Bei der zufälligen Mutagenese inseriert die Genkassette in völlig unbekannte Genloci. Danach ist sie über ihre Markergene nachweisbar. Zusätzlich kann sie den offenen Leserahmen des getroffenen Gens unterbrechen und somit seine Funktion stören. Anhand des Phänotyps kann dann die entwicklungsbiologische Relevanz des "getroffenen" Gens ermittelt werden. Der Erfolg dieser Methode gründet sich auf die Anzahl der untersuchten Tiere und die gewählten Suchmasken, d.h. das Auswahlverfahren, mittels dessen mögliche positive Kandidaten anhand von Genexpressions-mustern des Markergens und des resultierenden Pänotyps identifiziert werden können.

Die Methode der gezielten Geninaktivierung über homologe Rekombination liefert die direkteste und beste Funktionsanalyse. In vitro werden funktionell wichtige Bereiche des jeweiligen Gens entfernt und durch Markergene ersetzt. Diese veränderten DNABereiche werden mittels homologer Rekombination in das Genom von embryonalen Stammzellen (ES-Zellen) eingebracht. Diese ES-Zellen werden mit Wildtyp- 
Stammzellen aggregiert, in eine Leihmutter eingebracht und bilden einen kompletten neuen Embryo. Im positiven Fall bilden die veränderten Stammzellen Keimbahnzellen, so dass der transgene Embryo später auch transgene Nachkommen hat. Dies ist die Grundlage für den Aufbau einer Mauskolonie und somit auch der funktionellen Analyse. Der resultierende Phänotyp gibt Aufschluß über die Funktion des untersuchten Gens (Mansouri, 2000; Mansouri, 2001).

\section{I.5. DIE MAUS IST DAS BESTE MODELL FÜR DIE UNTERSUCHUNG DER GRUNDLAGEN HUMANER KRANKHEITEN.}

Die Forschung an humanen Krankheiten versucht die grundlegenden Auslöser zu identifizieren. Problematisch ist, dass ausschließlich die Folge-symptomatik bei den betroffenen Patienten zur Untersuchung verfügbar ist. Zudem steht die Hilfe für die Patienten absolut im Vordergrund der Behandlung und nicht die maximal mögliche wissenschaftlich Analyse. Für die dauerhafte Heilung bzw. maßgeschneiderte Behandlung ist natürlich die Entschlüsselung der auslösenden Ursachen essentiell. Die derzeit besten Möglichkeiten bestehen in der Forschung an Zellkultursystemen und Tiermodellen. Zellkultursysteme ermöglichen den direkten Zugriff auf klare, unidirektionale Fragen und Antworten. Dieses System gibt allerdings keine Auskunft über die Übertragbarkeit der Ergebnisse auf den Gesamtorganismus. Die Forschung an Tiermodellen gibt auf diese Fragen Antwort. Hier ist es nämlich möglich, organismusübergreifende Fragestellungen zu betrachten. Ein gutes Beispiel ist die Untersuchung von Diabetis. Nach Identifizierung des Mausgens, das für die Bildung der Insulin-produzierenden Zellen in der Bauchspeicheldrüse verantwotlich ist, konnte mittels gezielter, homologer Rekombination dieses Gens - Pax4 - zerstört werden. Die resultierende Maus-Verlustmutante ist die Grundlage für die weitere Forschung an Diabetis (St. Onge et al., 1997; Sosa-Pineda et al., 1997).

Entscheidend ist die exzellente Vergleichbarkeit von physiologischen Vorgängen zwischen Maus und Mensch, die es ermöglichen, die Grundlagen von humanen Krankheiten zu studieren. So können alle säugerspezifischen Fragen, wie auch die genomische Prägung, untersucht werden. 
EINE BESONDERHEITEN IN DER SÄUGERENTWICKLUNG IST DIE GENOMISCHE PRÄGUNG VON CHROMOSOMEN

Die Untersuchungen von Gregor Mendel konnten von der Hypothese ausgehen, dass jedes Gen zweimal vorhanden ist, und zwar eines von der Mutter und eines vom Vater. Bei der Merkmalsausprägung spielt die Herkunft keine Rolle. Doch die Natur hält Überraschungen bereit. Es kann zum Beispiel ausschließlich das maternale vererbte Allel aktiv sein, während das paternale Allel des entsprechenden Genes inaktiv ist. Dieser Effekt wird als genomische Prägung bezeichnet (Greally and John, 2000). Generell steht dieser Mechanismus im Gegensatz zum Verhalten der großen Mehrheit der Gene, bei denen beide Allele unabhängig von ihrer Herkunft aktiviert werden können.

Das erste Anzeichen für die Existenz des Mechanismus der Markierung der Gameten entstand in Transplantationsexperimenten an Mäusen in den frühen 80er Jahren. Die Kerne befruchteter Eizellen wurden entfernt und durch zwei haploide Kerne aus Spermien oder Eizellen ersetzt. Somit entstanden Embryos, die einen diploiden Chromosomensatz besitzen, der jedoch nicht zu gleichen Teilen von Vater und Mutter abstammt, sondern rein androgynetisch (vom Vater) bzw. rein gynogenetisch (von der Mutter) ist. Trotz des diploiden Chromosomensatzes konnten die Embryonen nicht überleben. Im Gegensatz zu dem beschriebenen, fast 100jährigen Dogmas Mendels zeigen diese Experimente, dass mütterliche und väterliche Chromosomen nicht stets funktionell identisch sind. Die Herkunft der Chromosomen kann für die Entwicklung des Embryos ebenso wichtig sein wie ihre Anzahl.

Bis zum heutigen Tag konnten durch die Analyse uniparentaler Disomien über 50 Gene mit genomischer Prägung identifiziert werden (Harwell, http// :www.mgu.har.mrc.ac.uk/imprinting). Insofern drängen sich zwei Fragen in den Vordergrund, die sowohl theoretisch wie auch experimentell zu klären sind: Wie kann eine stabile, aber nicht irreversible Inaktivierung eines Lokus erreicht werden? Aus welchem Grund ist dieser Mechanismus entstanden?

Zunächst ist es wichtig zu betonen, dass die Markierung der Chromosomen reversibel sein muß, denn ein maternal vererbtes Chromosom muß sich z.B. im Aktivitätsstatus in den geprägten Genen ändern, wenn es in der nächsten Generation durch die mänliche Keimbahn geht. Ist dieser Wechsel (Switch) gestört, kann zum Beispiel das humane 
Prader Willi- und Angelmann-Syndrom entstehen. Da schon sehr kleine Deletionen diese "Switch"-Syndrome auslösen können, wird vermutet, dass es bestimmte gamentenspezifische DNA-Bereiche gibt, die die Prägung initiieren können.

Die DNA in den Chromosomen tritt in unterschiedlichen Zuständen auf. Im Heterochromatin ist sie eng aufgedrillt und nicht zugänglich für die Transkriptionsmaschinerie. Begünstigt wird diese Form durch einen hohen Methylierungsgrad der DNA sowie die Deacetylierung der Histone im Heterochromatin. In der frühen Entwicklung, das heißt in den primordialen Keimzellen der Maus, in ihren embryonalen Stammzellen und auch in den Zellen der Blastozyste sind keine Methylierungen an der DNA festzustellen. Erst im Moment der beginnenden Differenzierung scheint die selektive DNA-Methylierung das Genom in aktive und inaktive Bereiche zu unterteilen. Dabei darf nicht außer Acht gelassen werden, dass ein hoher Grad an Methylierung nicht mit einer Inaktivierung gleichzusetzten ist. Die Inaktivierung des zweiten X-Chromosoms ist zum Beispiel unabhängig von DNAMethylierungen. Ein unterschiedlicher Methylierungszustand beider Chromosomen stellt folglich nicht die Ursache, aber dennoch eine häufige Begleiterscheinung zum Auftreten von genomischer Prägung dar. Die Methylierung bei den Säugern findet am fünften Kohlenstoff-Atom des Cytosins innerhalb von CpG-Dinukleotiden statt.

Eine veränderte Prägung kann zu verschiedenen Krankheiten führen. Beispiele sind das Fragile X-Syndrom, das phänotypisch einen variablen Schweregrad an geistiger Beeinträchtigung zeigt wie verschiedene Formen von Autismus. Vererbt wird das Fragile X-Syndrom ausschließlich von der Mutter. Die genetische Grundlage ist eine zunehmende Veränderung im FFMRl-Gen. Es enthält eine Wiederholung von CGGTrinukleotiden im 5'-Bereich des Gens. Mit zunehmender Länge der Wiederholung steigt ebenfalls die Schwere der Krankheit. Entsprechend der Länge der Wiederholungen tritt eine zunehmende Anzahl an aberranten de novo-Methylierungen von DNA und Deacetylierugen von Histone auf, was zur Stilllegung des FMRl-Gens führt.

Vor zwanzig Jahren wurden erstmalig derartige Erbgänge mit genomischer Prägung beschrieben. Seit den neunziger Jahren mehren sich die Hinweise auf ihre genetischen und biochemischen Grundlagen. Seit einigen Jahren entstehen Hypothesen, die bisher jedoch nur Teilaspekte des Phänomens erklären können. Die biologische Grundlage der genomischen Prägung ist weiterhin umstritten. Immerhin haben Untersuchungen der 
letzten Jahre gezeigt, dass dieser Effekt erstmals mit der Entwicklung der Säuger aufgetreten ist. Dementsprechend ist davon auszugehen, dass die genomische Prägung nach der Trennung der Protortheria von den therischen Säugern entstanden ist, also vor ca. 150 Millionen Jahren. Das Gen für den Wachstumsfaktor Igf2 ist beispielsweise im Opossum, in der Maus und im Menschen monoallelisch aktiv, wohingegen die Mitglieder der eierlegenden Monotremata, wie das Schnabeltier Platypus keine genomische Prägung an diesem Lokus zeigen (Killian et al., 2001). Die Mehrzahl der genetischen Untersuchungen unterstützen die "Theria Hypothese". Sie hält eine frühe Trennung der Monotremata von den Marsupialia und Theria für wahrscheinlich (Marshall, 1979).

Die Frage nach dem Nutzen der Entwicklung von genomischer Prägung ist noch nicht abschließend geklärt. Entstanden ist sie parallel zu der intra-uterinen Entwicklung der Säuger. Diese evolutive Neuerung in der Gruppe der Säuger bedingt eine enge Verbindung zwischen Mutter und Kind in Hinsicht auf die Versorgung. Grundlage vieler Hypothesen ist die unterschiedliche Beteiligung der Eltern an der Aufzucht bzw., genetisch gesprochen, an der Weitergabe des eigenen Genpools in die nächste Generation. Dabei wird ein Kampf der Geschlechtern um die mütterlichen Ressourcen (battle of sex, sexual tug-a-war) postuliert (Moore, 1991). Einer alternativen Hypothese (" Ovarian time bomb hypothesis" = Ovarien Zeitbomben Hypothese) liegt die Annahme zugrunde, dass es wichtig ist, das Risiko einer spontanen parthenogenetischen Entwicklung zu minimieren, da sie das Leben der Mutter gefährdet. Weitere Ideen beziehen sich auf die Verhinderung der Integration parasitärer DNA ins Genom und der Erleichterung meiotischer Prozesse (Killian and al., 2001).

Ziel der vorliegenden Doktorarbeit ist die detaillierte Expressionsanalyse des Irx2Gens in der Maus, die Gewinnung des genomischen Klons und die Erstellung der Irx2defizienten Mutante. Damit umfaßt diese Arbeit die Identifizierung und Untersuchung der Irx2-Genstruktur sowie des zeitlichen und räumlichen Expressionsmusters durch RNA in-situ-Analysen. Die gezielte Mutagenese des Irx2-Gens durch homologe Rekombination bildet die Grundlage der Funktionsanalyse. Im Tiereich ist die IroquoisGenfamilie zentral an neuralen Spezifizierungsprozessen beteiligt. Damit gehört Irx2 nicht nur in die Gruppe der Transkriptionsfaktoren, sondern auch zu der Familie von 
essentiellen Entwicklungskontrollgenen. Ebenfalls zu den wichtigen Kontrollgenen gehört Mash1. Die Analyse der Mash1-Verlustmutante ist von großem Interesse wie auch die mögliche genetische Interaktion zwischen Irx2 und Mash1. Alle Fragen zur speziellen Funktion des murinen Irx2-Gens werden mit Hinblick auf die evolutive Abstammung untersucht, um konservierte Aspekte zu identifizieren und neue Aufgaben aufzudecken. 


\section{ERGEBNISSE}

Das Ziel dieser Arbeit ist die Analyse der funktionellen Relevanz des Irx2-Gens in der Maus. Meine Arbeit baut auf den Ergebnissen meiner Diplomarbeit auf, in der ich die Identifizierung sowie die ersten Schritte der Iroquois homeoboxgene 2 (Irx2) Analyse beschrieben habe (Becker, 1997). Die detaillierte Beschreibung der Genexpressionsbereiche des Irx2-Gens ermöglicht die Auswahl der zu untersuchenden Organen, sowie der entscheidenen Entwicklungsstadien. Um die Funktion zu studieren, wird die gezielte Verlustmutante mittels homologer Rekombination hergestellt. Dazu ist es notwendig, die genomische Organisation des Irx2-Gens zu ermitteln. Anhand der Nullmutante läßt sich die Funktion des Irx2-Gens während der Entwicklung der Maus entschlüsseln.

\section{II.1. STRUKTURANALYSE DES IRX2-GENS}

Die Analyse der vollständigen kodierenden Sequenz wie auch der genomischen Organisation des Irx2-Gens ist von grundlegender Bedeutung für die Funktionsuntersuchung.

\section{II.1.1. SEQUENZANALYSE DER IRX2-CDNA}

Um die vorhandene Irx2-cDNA-Sequenz (Becker, 1997) zu vervollständigen, wurde eine E10,5-Maus-cDNA-Bibliothek (Stratagene) mit ca. 200.000 Phagen ausplattiert. Die Phagenbank deckt das 6-fache des Mausgenoms ab. Mit einer Mischung aus einer weit 5' gelegenen (Sonde 5') und einer längeren Irx2-spezifischen Sonde (Sonde 31), die 
die Intensität des Nachweissignals verstärkt, wurde nach Irx2-positiven Klonen in der Phagenbank gesucht. Durch Hybridisierung mit hoher Stringenz und anschließender Subklonierung der hybridisierenden Fragmente konnten 3 Klone isoliert werden, die die vorhandenen Sequenz am 5'-Ende verlängerten. Die gewonnene Klone wurde aus den Phagenvektoren in Plasmidvektoren (pBSKS) umkloniert, denn nur Plasmidvektoren können in Bakterien vervielfältigt und verändert werden. Zudem enthalten sie die notwendigen Startsequenzen für die anstehenden Sequenzierungen. Die vollständige kodierende Sequenz des Irx2-Gens umfaßt 1422 bp und ist in der folgenden Abbildung dargestellt (im folgenden Irx2-13 genannt):

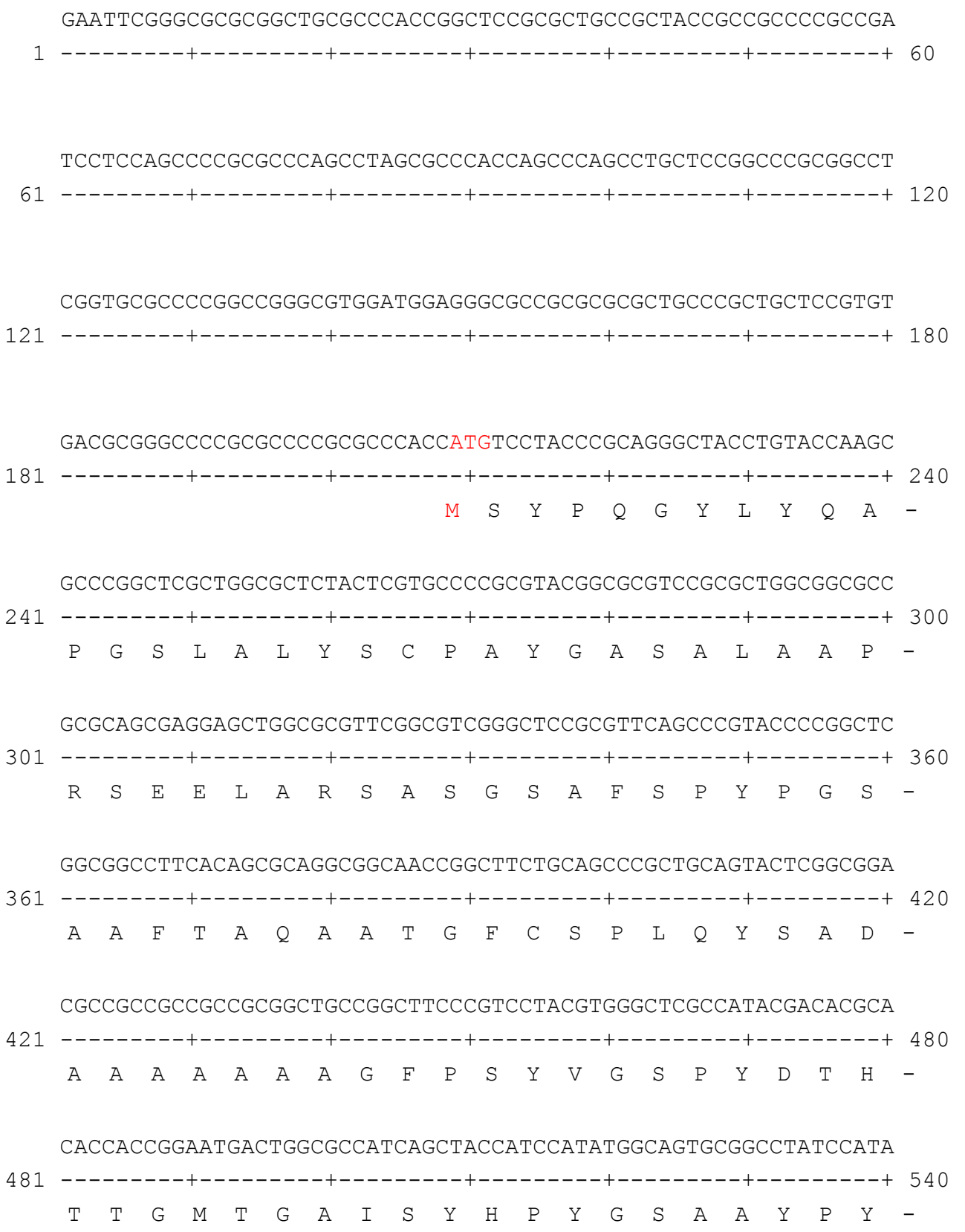




\section{ERGEBNISSE}

CCAGCTCAACGACCCCGCGTACCGTAAGAACGCTACGCGGGACGCCACTGCCACACTGAA $541--------+--------+--------+--------+--------+---------+600$

$\begin{array}{lllllllllllllllllllllllllllllllll}Q & \mathrm{~L} & \mathrm{~N} & \mathrm{D} & \mathrm{P} & \mathrm{A} & \mathrm{Y} & \mathrm{R} & \mathrm{K} & \mathrm{N} & \mathrm{A} & \mathrm{T} & \mathrm{R} & \mathrm{D} & \mathrm{A} & \mathrm{T} & \mathrm{A} & \mathrm{T} & \mathrm{L} & \mathrm{K} & -\end{array}$

AGCCTGGCTCAACGAACACCGAAAGAACCCGTACCCCACCAAGGGAGAGAAGATCATGCT

$601---------+--------+--------+---------+--------+---------+660$

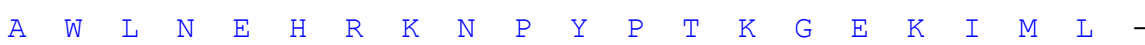

GGCCATCATCACCAAGATGACCCTCACGCAGGTCTCCACCTGGTTCGCCAACGCGCGCCG

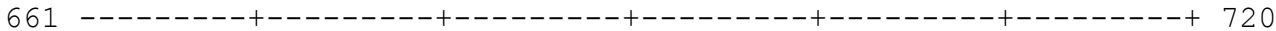

$\begin{array}{llllllllllllllllllllllllllllll}A & I & I & T & K & M & T & L & T & Q & V & S & T & W & F & A & N & A & R & R & -\end{array}$

ACGTCTCAAGAAGGAGAACAAAATGACCTGGGCCCCAAGGAACAAAAGCGAGGATGAGGA

$721--------+--------+--------+--------+--------+--------+780$

$\begin{array}{llllllllllllllllllllll}\mathrm{R} & \mathrm{L} & \mathrm{K} & \mathrm{K} & \mathrm{E} & \mathrm{N} & \mathrm{K} & \mathrm{M} & \mathrm{T} & \mathrm{W} & \mathrm{A} & \mathrm{P} & \mathrm{R} & \mathrm{N} & \mathrm{K} & \mathrm{S} & \mathrm{E} & \mathrm{D} & \mathrm{E} & \mathrm{D} & -\end{array}$

CGAGGACGAGGGAGATGCTTCCAGAAGCAAGGAGGAGAGTTCAGACAAGGCACAGGATGG

$781---------+---------+---------+---------+---------+---------+840$

$\begin{array}{llllllllllllllllllllll}E & D & E & G & D & A & S & R & S & K & E & E & S & S & D & K & A & Q & D & G & -\end{array}$

CACAGAGACCTCTGCGGAGGACGAAGGGATCAGTCTACACGTCGACTCGCTCACGGACCA

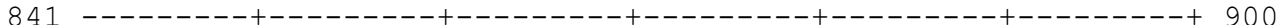

$\begin{array}{lllllllllllllllllllllllllllllll}T & E & T & S & A & E & D & E & G & I & S & L & H & V & D & S & L & T & D & H & -\end{array}$

CTCGTGCTCAGCGGAGTCAGATGGGGAAAAATTGCCCTGCCGCGCCGGGGATGCCTTGTG

$901--------+--------+--------+--------+--------+---------+960$

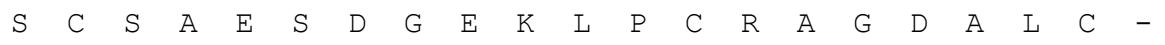

CGAATCAGGCTCAGAGTGTAAGGACAAGTTTGAGGACCTGGAGGACGAGGAGGACGAGGA

$961--------+--------+--------+--------+---------+---------+1020$

$\begin{array}{llllllllllllllllllllllllllll}E & S & G & S & E & C & K & D & K & F & E & D & L & E & D & E & E & D & E & E & -\end{array}$

AGACGAGTGCGAGCGGGACCTGGCGCCACCCAAGCCCGTAACCTCCTCGCCTCTCACCGG

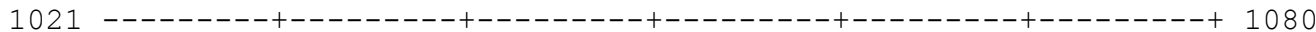

$\begin{array}{lllllllllllllllllllll}\mathrm{D} & \mathrm{E} & \mathrm{C} & \mathrm{E} & \mathrm{R} & \mathrm{D} & \mathrm{L} & \mathrm{A} & \mathrm{P} & \mathrm{P} & \mathrm{K} & \mathrm{P} & \mathrm{V} & \mathrm{T} & \mathrm{S} & \mathrm{S} & \mathrm{P} & \mathrm{L} & \mathrm{T} & \mathrm{G} & -\end{array}$

CGTGGAGGCACCCCTGCTGAGCCCGGCGCCCGAAGCCGCGCCGCGCGGTGGCAGCGGTGG

$1081--------+--------+--------+---------+--------+---------+1140$

$\begin{array}{lllllllllllllllllllllllllllllllll}V & E & A & P & L & L & S & P & A & P & E & A & A & P & R & G & G & S & G & G & -\end{array}$

CAAGACGCCCCTAGGCAGCCGGACGTCGCCAGGAGCGCCGCCGCCCGCCAGCAAACCCAA

$1141-------+-------+-------+--------+-------+--------+1200$

$\begin{array}{lllllllllllllllllllllllllll}K & T & P & L & G & S & R & T & S & P & G & A & P & P & P & A & S & K & P & K & -\end{array}$

GCTGTGGTCGCTGGCCGAGATAGCCACGTCGGACCTCAAGCAACCAAGCTTGGGCCCGGG

$1201--------+--------+--------+--------+--------+--------+1260$

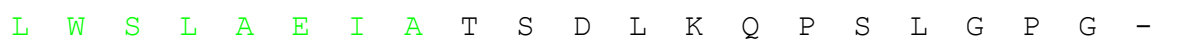

TTGCGGGCCTCCGGGGCTGCCTGCTGCCGCCGCGCCTGCCTCGACTGGGGCCCCTCCGGG

$1261--------+--------+--------+--------+--------+--------+1320$ 


\section{ERGEBNISSE}

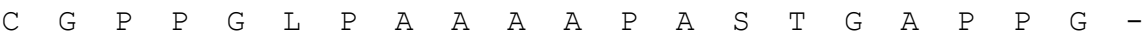
AGGCTCGCCCTACTCTGCTTCGCCCCTGCTGGGCCGCCACCTCTATTACACGTCCCCTTT

$1321--------+--------+--------+--------+--------+---------+1380$

$\begin{array}{lllllllllllllllllllll}G & S & P & Y & S & A & S & P & \text { L } & \text { L } & G & R & H & \text { L } & Y & Y & \text { T } & \text { S } & \text { P } & \text { F } & -\end{array}$

CTATGGCAACTACACAAACTACGGGAACTTAAACGCAGCGCTGCAAGGCCAGGGCCTTCT

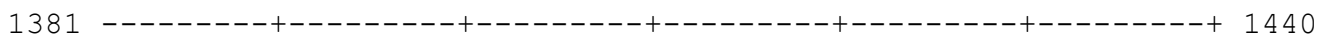

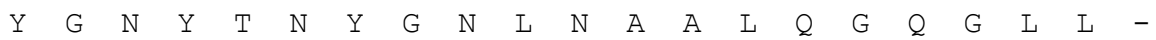

GCGGTACAATACCGCGGCCTCCTCACCAGGCGAGACACTGCACGCCATGCCCAAGGCGGC

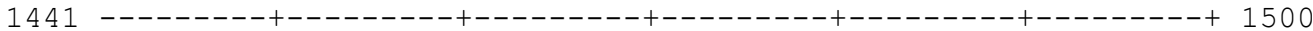

$\begin{array}{lllllllllllllllllllll}R & Y & N & T & A & A & S & S & P & G & E & T & \text { L } & H & A & M & P & K & A & A & -\end{array}$

CAGCGACACGGGCAAGGCGGGCTCGCATTCACTGGAGTCCCACTACAGGCCTCCGGGCGG

$1501--------+--------+--------+--------+--------+---------+1560$

$\begin{array}{lllllllllllllllllllllllllllllll}S & D & T & G & K & A & G & S & H & S & L & E & S & H & Y & R & P & P & G & G & -\end{array}$

CGGCTACGAGCCCAAGAAAGATACCAGTGAGGGCTGTGCAGTTGTTGGTGCAGGCGTCCA

$1561-------+--------+--------+-------+--------+--------+1620$

$\begin{array}{lllllllllllllllllllllllllllllllll}G & Y & E & P & K & K & D & T & S & E & G & C & A & V & V & G & A & G & V & Q & -\end{array}$

GACCTACCTATAGGAGGGCCAAGGTCAGCAGTGCAAGTAGGTGTCACAATTGCTTTGGAA

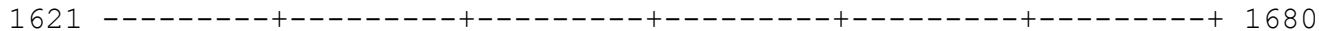

T Y L *

AAAAAAGTCAGGAGGCTATTCTCCCTTCCCAAGTTCATAAATACACAGATACAAACCCCA

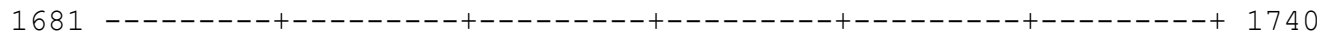

GATGTGGAAACCCGGACCACATTTTGTGCCACTGTATAAGAAGATGCACAACTGCACTGG

1741 --------+---------+--------+---------+--------+---------+ 1800

CAACCCACAGACTTTAAGGACTGGACACACGTTGTTTGGGCATATGAGAACTTGTTGTCA

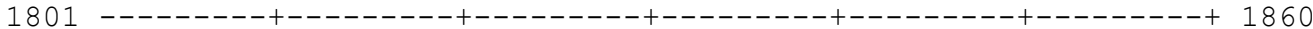

TAGTACAGCTTCCCTATGTTTGTGTGACTTTTGGAAACAATCTGTTTTTTCTCAGGATAT

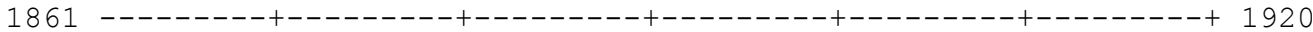

CCTCATCACTTCATTGCCACGGTATATATTCTATAGGTGTGATAGGACTTGCTGTAAAAT

$1921---------+---------+---------+---------+---------+---------+1980$

TTATTTGTAAAAAAAAATGTACACGGTAGAACTAACGTGATTGAAGAACTTGAGTCCTTC

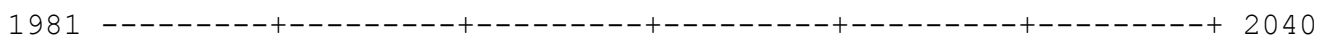

AGAAGTGGAAACAAATTTGATATTTATTTTTATAATGATATAAAGCTTCTAGTAATTTAT 
Abb. 3: Nukleotid- und Aminosäuresequenz des Transkript Irx2-13

Das erste ATG liegt bei 209 bp, das zweite bei 491 bp. Als Stop-Kodon wird TAG bei 1631 bp genutzt. Die Homeobox erstreckt sich von 551 bp bis 720 bp und das Sequenzmotiv der IroBox liegt bei 1184 bp. Die Nukleotide TGTGAT kennzeichnen die K-Box an Position 1958 bp.

Im Northern-Blot hybridisieren zwei Fragmente mit einer Irx2-spezifischen Sonde (=13Sal). Dies bedeutet, dass von Irx 2 zwei alternativ gespleißte Formen existieren. Ihre Größen sind im Northern Blot 2,6 kb und 1,9 kb, wobei die analysierten cDNA-Klone mit 2,2 kb und 1,8 kb kleiner sind (Abb. 4). Der Größenunterschied zwischen dem Northern Blot und den Sequenzdaten beruhen auf dem Fehlen des poly-A-Schwanzes in den sequenzierten Klonen.

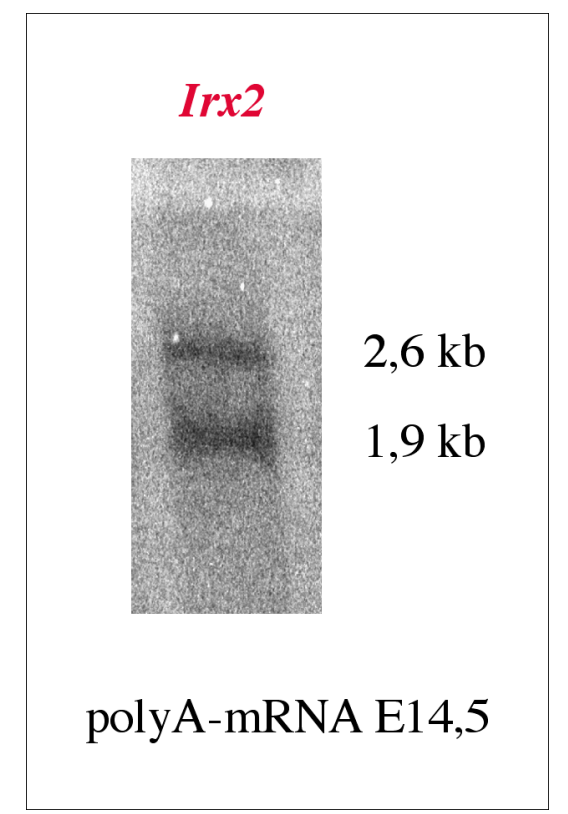

Abb. 4: Northern-Blot mit $m R N A$ von Embryonen an Tag E14,5 
Zwei Fragmente der $m R N A$ hybridiseren mit der Sonde 13Sal. Sie entsprechen den Transkripten der Größen 2,6 kb und 1,9 kb.

Der Translationsstart (ATG) des längeren Irx2-Transkriptes liegt an der Position 209 bp. Dieses ATG ist eingebettet in der sog. Kozak-Konsensus-Sequenz (GCCGCCA/ GCCATG), die darauf hinweist, dass diese Position mit hoher Wahrscheinlichkeit dem Translationsstart des Proteins entspricht (Abb. 5). Das alternativ genutzte ATG liegt bei 491 bp. Die Transkripte unterscheiden sich in der Proteinlänge und hinsichtlich verschiedener Wiederholungen von Stopsignalen im nicht-translatierten (UTR = untranslated region) $3^{\prime}$-Bereich.

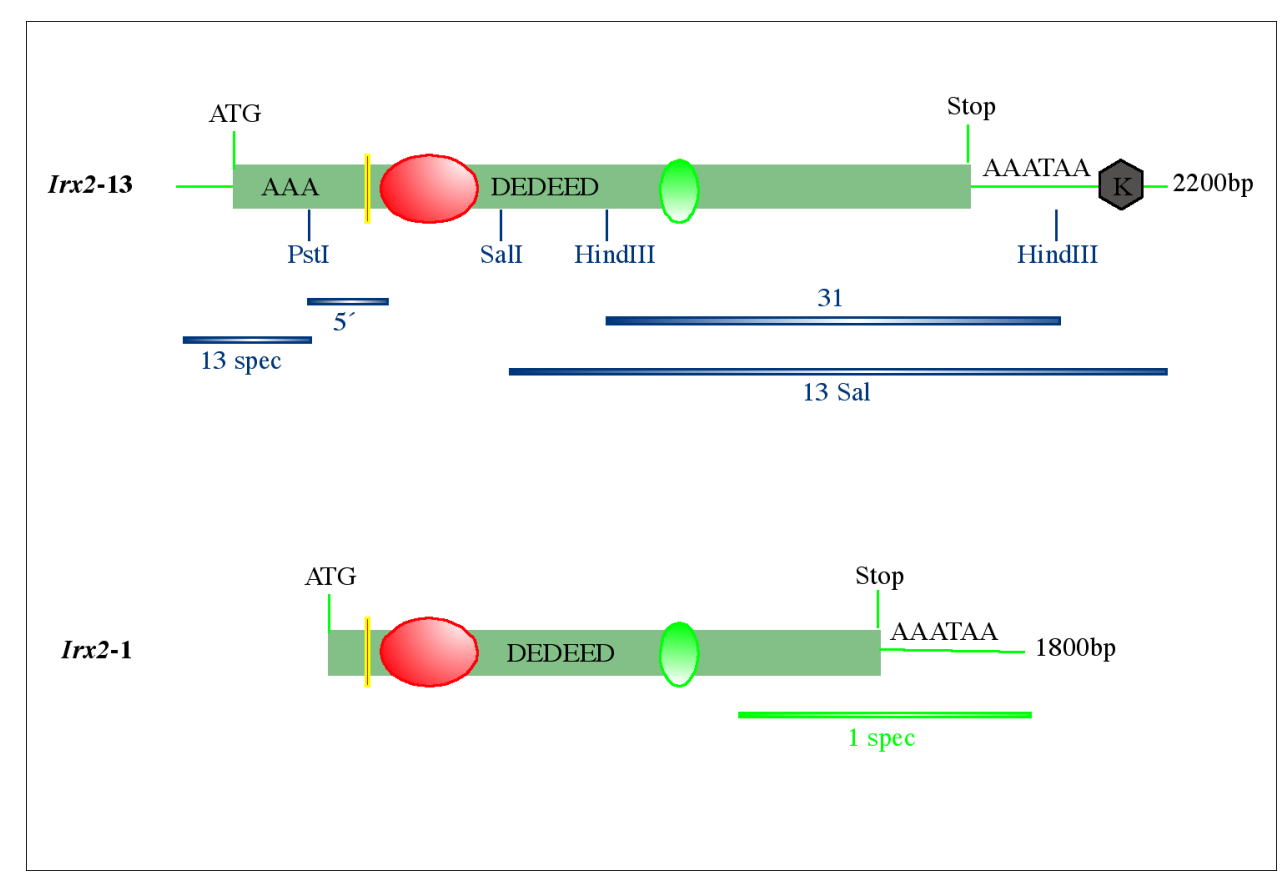

Abb. 5: Schematische Darstellung der beiden Transkripte, Irx2-13 und Irx2-1.

Funktionell bedeutsamen Regionen sind: rot markiert ist die Homeobox, grün die IroBox und schwarz die K-Box. Im 5'-Bereich liegt in Transkript Irx2-13 eine Wiederholung von Adenin (AAA) vor. DEDEED kennzeichnet eine saure Region. Die Sequenzen beider Transkripte enthalten Polyadenylierungsstellen. Angegeben sind verschiedenen Sonden, die in folgenden Experimenten verwendet werden.

Im Folgenden werde ich daher ausschließlich auf das längere Transkript, Irx2-13, eingehen. Das Irx2-Gen weist eine Homeobox (Gehring, 1994) auf, die sich von 551 bp bis $720 \mathrm{bp}$ erstreckt. Ferner beinhaltet die kodierende Irx2-Sequenz bei 1184 bp bis 1224 bp im 3'-Bereich das Motiv der Iro-Box (Abb. 5) (Bürglin, 1997). Das erste Stop-Kodon 
(TAG) liegt bei 1631 bp. Im 3'-UTR liegt eine K-Box mit der Sequenz TGTGAT bei 1958 bp.

\section{II.1.2 IRX2-PROTEINSEQUENZANALYSE}

Das Irx2-Gen kodiert wahrscheinlich für ein Protein aus 474 Aminosäuren (=aa) mit einem Molekulargewicht von $52 \mathrm{kDa}$. Die Iroquois-2 Proteine verschiedener Tiere zeigen einen sehr hohen Grad an Konservierung der Aminosäuresequenz, was auch außerhalb der Homeodomäne $\mathrm{zu}$ beobachten ist. So liegt bei dem Vergleich der kompletten Aminosäuresequenzen der Irx2-Proteine von Mensch, Maus und Frosch eine Aminosäureidentität von $79 \%$ vor (Abb. 6).

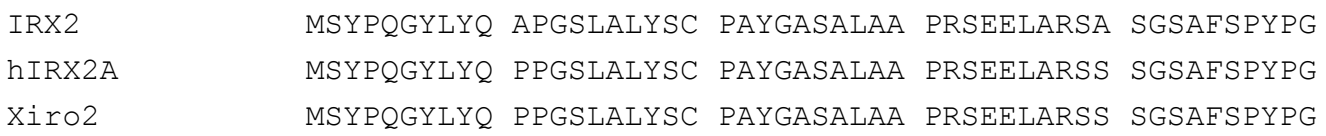

SAAFTAQAAT G.FCSPLQYS ADAAAAAAAG FPSYVGSPYD THTTGMTGAI 


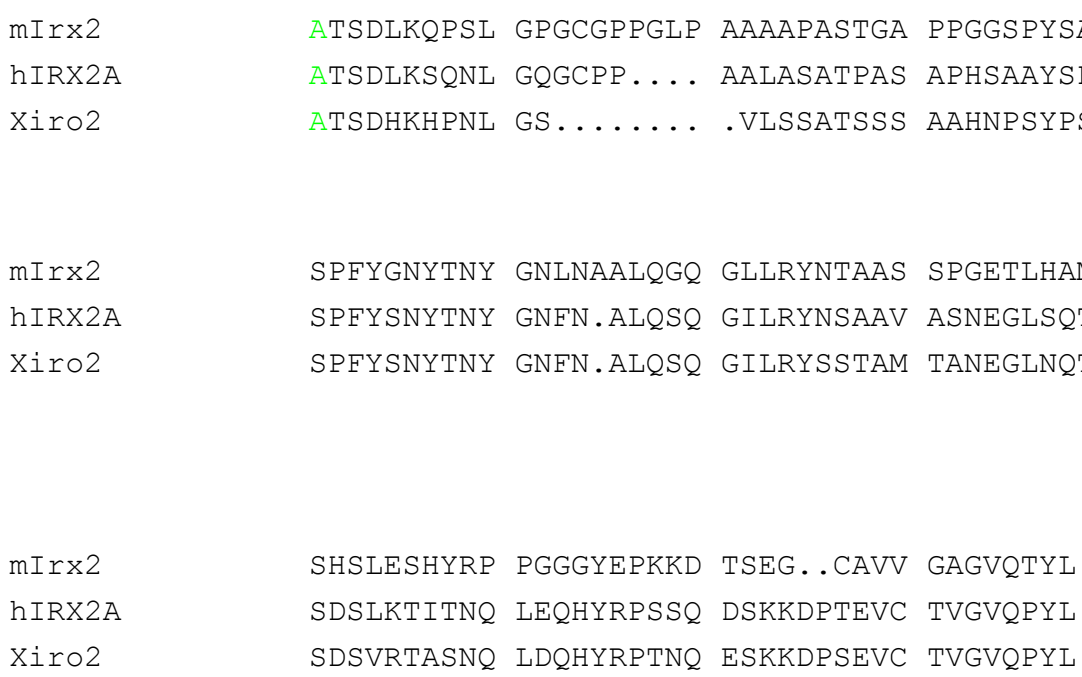

Abb. 6: Vergleich der Irx2-Proteine von Maus (mIrx2), Mensch (hIRX2) und Frosch (Xiro2).

Bei Vergleich der Aminosäuresequenzen zeigt sich eine Übereinstimmung von $79 \%$. Die Homeodomäne (rot markiert) und die Iro-Domäne (grün markiert) sind $100 \%$ identisch.

Mittels der Berechnungen mit dem Chou-Fassmann-(CF) und dem GanierOsguthhorpe-Robson (GOR)-Algorhythmus (Chou and Fasman, 1978; Garnier et al., 1978) konnte eine potentielle Sekundärstrukturvorhersage für das Irx2-Protein getroffen werden (Becker, 1997). Aus diesen Berechnungen ergibt sich im Bereich der Homeodomäne eine Helix-Schleife-Helix-Struktur. Diese Helixstruktur stellt ein klassisches Motiv von Transkriptionsfaktoren dar und dient der spezifischen DNABindung. Ferner läßt sich diese Homeodomäne in die Gruppierung der TALE-Familie von Homeoproteinen (Bürglin, 1997) einordnen. Grundlage dieser Einordnung ist eine leicht veränderte Homeodomäne, welche eine Verlängerung der Schleife zwischen der ersten und der zweiten Helix um die drei Aminosäuren Prolin-Tyrosin-Prolin (TALE steht für "three aminoacid loop extension") umfaßt. Damit hat die Homeodomäne eine Länge von 63 statt 60 Aminosäuren. Die Position 50 der Homeodomänen ist entscheidend an der DNA-Bindung beteiligt und wird zumeist von polaren Aminosäuren eingenommen (Treisman et al., 1989). Typischerweise haben alle Mitglieder der Iroquois-Proteinfamilie an der Aminosäureposition 53 der Homeodomäne ein Alanin. Die Position 50 entspricht der Position 53 in der Homeobox von TALE-Mitgliedern. Das 
Vorhandensein einer ungeladenen Aminosäure an dieser Position spezifiziert die Iroquois-Gene zu einer eigenen Subfamilie innerhalb der Superfamilie der HomeoboxGene. Das Irx2-Protein weist weiterhin einen Alanin-reichen Bereich (71 - 77 aa) und einige saure Aminosäurenbereiche im mittleren Teil (186 - 194 und 260 - 279 aa) auf. Im Bereich der Iro-Box sind potentielle $\beta$-Faltblattstrukturen auszumachen, die auf einem vermehrten Auftreten von Prolin begründet sind. Die Iro-Domäne zeigt ebenfalls eine sehr hohe Konservierung der Maus-Irx-Gene auch zu so evolutiv entfernten Vertretern wie der Fliege D. melanogaster und dem Wurm C. elegans (Bürglin, 1997).

\section{Aminosäurevergleich der murinen Iroquois-Genfamilie:}

1

Irx1 ..GTAELGA. . .GAGAAAVT SVLGM.Y.AA AG.PYAGAPN YSAFLPYAAD

Irx3 GAGASELAA. . SGSLSNVLS SVYGAPYAAA AA.AAAAAQG YGAFLPYATE

Irx2 AYGASALAAP RSEELARSAS GSAFSPYPGS AAFTAQAATG FGSPLQYSAD

Irx5 AYSTSVISGP RTDELGRSSS GSAFSPYAGS TAFTA.PSPG YNSHLQYGAD

Irx4 VYESRLLATA RHELNSAAAL GVYGSPYGS. .......SQG YGNYVTYGSE

Irx6 PYDSRLLGSA RPEL..GAAL GIYGAPYAA. .......AQS YPGYLTYGPE

Irx1 LSLF.SQMGS QYELKDNPGV . HPA.TFAA. . HTTPA PY GQFQY....

Irx3 LPIF.PQLGA QYELKDSPGV QHPA.TAAAF PHPHPA YPY GQYQF.....

Irx2 AAAA.AAAGF P.SYVGSPYD THTT.GMTGA IS GSAA YPYQL.....

Irx5 PAAA.AAAAF ..SYVGSPYD .HTP.GMAGS LG APPL GSYPY.....

Irx4 ASAFY.SLN. SFESKDGTGS SHAGLPPTAA AA EPAL SQYPYDRYGT

Irx6 PPTLCGALNP QYEFKDAAGS FAPSL..TQP GA ETTL GQYQYDRYGG

151

Irx1 ...GDPGRPK NATRESTSTL KAWLNEHRKN PYPTKGEKIM LAIITKMTLT Irx3 ...GDPSRPK NATRESTSTL KAWLNEHRKN PYPTKGEKIM LAIITKMTLT Irx2 ...NDPAYRK NATRDATATL KAWLNEHRKN PYPTKGEKIM LAIITKMTLT Irx5 ...GDPAYRK NATRDATATL KAWLNEHRKN PYPTKGEKIM LAIITKMTLT Irx4 VD..SGTRRK NATRETTSTL KAWLQEHRKN PYPTKGEKIM LAIITKMTLT Irx6 VELSSAGRRK NATRESTSAL KAWLHEHRKN PYPTKGEKIM LAIITKMTLT

Irx1 QVSTWEANAR RRLKKENKVT WGARSKDQED GALFGSDTEG DPEKAEDDEE Irx3 QVSTWFANAR RRLKKENKMT WAPRSRTDEE GNAYGSEREE EDEE.EDEEE Irx2 QVSTWFANAR RRLKKENKMT WAPRNKSEDE DEDEG.DASR SKEESSDKAQ Irx5 QVSTWEANAR RRLKKENKMT WTPRNRSEDE EEEENIDLEK NDEDEPQKPE Irx4 QVSTWEANAR RRLKKENKMT WPPRNKCADE KRPYGEGEEE EAGEEESREE Irx6 QVSTWFANAR RRLKKENKMT WAPKNK........GGEER KADSGEDSLG

Irx1 I.DLE.SIDI DQIDERDG. ..... . DQSNE DEE....... . DKAEAPRA

Irx3 S.KRELEMEE EELAGRGGGH GGRGAGRRRR DEEIDL...E NLDSAAAGSE

Irx2 D.GTETSAED EGISLHVDSL TDHSCSAESD GEKLPCRAGD ALCESGSECK

Irx5 D.KGDLEGPE SG...GAEQK ATAGCE.RLQ GPLSP..AGK ETEGSLSDSD 
Irx4 PLKSAKSEGH AGKDDKELEL SDLEDFDPLD AETSECELKT PFQSLDSGPE

Irx6 CLNGDTKDAT ASQEARGLRL SDLED... LE EEEEEEEAEE .. EAAVSAAR

$$
301
$$

Irxl RVPPPASARD QS...S.PLS AAETLKSQDS .......PLG LVK....... Irx3 LTLAGAAHRN GDFGLG.PIS DCKTSDSDDS SEGLEDRPLS VLSLAPPPPP Irx2 DKFEDLEDEE DEEDEC.ER. . DLAPPKPVT S..SPLTGVE APLLSPAPEA Irx5 FKESSSEGRH DELPRP. PRA GESSPAGPAT ARLAEDAGPH YPASVPAPGP Irx4 RIPASSDGPG TGKEASTTLR MPLGTAGGAV MDGDLERARN CLRSTVVVPD Irx6 RL........ ADFQKST... QPLPAPCAAA QEGCLE.SRE C...GLGLPR

$$
351
$$

Irxl ....EVSEPG S..TRLLSPG AAAVGLQGAP HSKPKIWSLA ETATSPDGAP

Irx3 VARAPASPPS P..PSSLDPC APAPAPSSA. LQKPKIWSLA ETATSPDN.P Irx2 APRG.....G SGGKTPLGSR TSPGAPP..P ASKPKLWSLA EIATSDLKQP Irx5 HPSAGELPPG SGGSSVIHSP PPPPPPPPAV LAKPKLWSLA EIATSSDKVK Irx4 SGAEGGPPAC EAKLTFAQAG APPNL..... ETKPRIWSLA HTATAAAATA Irx6 FSFTEAPQSG EADFITAEPG GPTMILHYPS GHKPRIWSLA HTAAASAVES

401

Irxl KASPPPP..S SHASA...HG PPS..GSPLQ HPAFLPSHGL YTCHIGKFSN Irx3 RRSPPGAGGS PPGAA...VA PPTLQLSPAA AAAAAAAHRL VSAPLGKFPA Irx2 SLG.............. PGC P....PGL PAAAAPASTG APPGGSPYSA Irx5 DGG.GGSEGS PCPPC...PG PMGGQTLGGS RASPAPAPAR SPSAQCPFPG Irx4 LSQT....EF PSC.MLKRQG PTGVSATTPA SSPAVTAPSG ALDRHQDSPV Irx6 APSTPPRAQS PECHMIPRQ. PSSIRRLLVP RDSEGEEDSP AAKAFGNSTF

Irxl WT..NGA..F LA..QGSLLN MRSFLGVSAP HAAPHGPHLT APPPPQPPVQ Irx3 WT..NRP..F PGPPAGPRPH PLSMLG.SAP Q......HLL GLPG..... Irx2 SPLLGRHLYY TSPFYGNYTN YGNLNAALQG QGLLRYNTAA SSPGETLHAM Irx5 GTVLSRPLYY TAPFYPGYTN YGSFGHLHGH PGPGPSPTA. . GPGSHFNGL Irx4 TSLRNWVDGV FHDPILRHST LN. QAWATAK GALLDPGPLG RNLGAGTNVL Irx6 T.LQGLPLNC APYPRRREPE VRFQYPSGAE G 501

Irx1 VATGVLH.GE KASARSSPAL PE..RDLVTR PDSPPQQLKS PFQPVRDNSL Irx3 .AAG. .HPAA AAAAYARPAE PESGTDRCSA LEVEKKLLKT AFQPV...PR Irx2 PKA.A...SD TGKAGSHSLE SHYR...PPG GGYEPKKDTS EGCAVVGAGV Irx5 NQT.VLNRAD VLAKDPKMLR SQSQLDLCKD SPYELKKGMS DI

Irx4 TTPLACSFPP TVPQDVPPAG ASRELLATPK AGGKPFCT

\begin{tabular}{|c|c|c|}
\hline & 551 & 568 \\
\hline $\operatorname{Irx} 1$ & APQE ..GTPR & ILAALPSA \\
\hline $\operatorname{Ir} x 3$ & RPQNRLDAAL & VLSALSSS \\
\hline $\operatorname{Ir} x 2$ & $\mathrm{QTYL} \sim \sim \sim \sim \sim$ & $\sim \sim \sim$ \\
\hline $\operatorname{Irx} 5$ & $\sim \sim \sim \sim \sim \sim \sim \sim \sim \sim$ & $\sim \sim$ \\
\hline $\operatorname{Irx} 4$ & 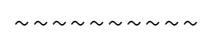 & $\sim \sim \sim$ \\
\hline $\operatorname{Lrx} 6$ & 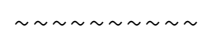 & $\sim \sim \sim$ \\
\hline
\end{tabular}

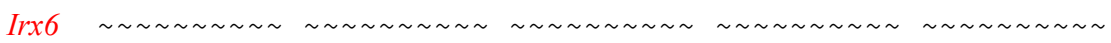

Abb. 7: Aminosäurevergleich der sechs Iroquois-Proteine der Maus.

In der Homeodomäne weisen die Irx-Gene eine 90\%ige Übereinstimmung in der Aminosäuresequenz auf (grün markiert). Dabei ist das Alanin an Position 53 der Homeodomäne (rot markiert), sowie die Verlängerung von drei Aminosäuren PYP (rot markiert) bemerkenswert. Die Proteine weisen weiterhin Bereiche auf mit hoher Übereinstimmung der Aminosäuresequenz (blau markiert). Im aminoterminalen Bereich der Proteine befindet sich die konservierte Iro-Box (rot markiert). Es sind die Adenin-Wiederholungen (türkis markiert) und die YYPY-Aminosäuregruppe vor der Homeodomäne (gelb markiert) zu erwähnen. 


\section{II.1.3. DAS IRX2-ANTISERUM}

Zur Herstellung eines spezifischen Antiserums gegen das Irx2-Protein wurden Proteinfragmente in E. coli überexprimiert, die zur Immunisierung von Kaninchen benutzt werden sollten. Die Überexpression des gesamten Proteins erwies sich in Bakterien als nicht praktikabel, da es nur in sehr geringer Menge hergestellt werden konnte. Um diesem Umstand zu umgehen, wurden Oligopeptide zur Immunisierung benutzt.

Zwei Gesichtspunkte sind bei der Auswahl der Proteinbereiche zur Herstellung von Antikörpern zu bedenken. Wichtig sind zum einen die Spezifität des Antikörpers, der keine Kreuzreaktionen hervorrufen soll. Zum anderen ist darauf $\mathrm{zu}$ achten, dass der Antikörper nicht gegen ein falsches Protein in den Kaninchen gebildet wird. Denn werden nur Fragmente oder Oligopeptide genutzt, zum Beispiel um konservierte Proteinregionen auszusparen, dann kann es zu nicht nativen Faltungen des gebildeten Proteinfragments kommen. Eine veränderte Konformation kann die Bildung von Antikörpern zu Bereichen der Peptide bewirken, die im nativen Protein vielleicht nicht zugänglich sind.

Die Verwendung von Peptiden bietet den Vorteil, dass ausschließlich Proteinbereiche gewählt werden können, die eine geringe Übereinstimmung in ihrer Sequenz zu den andere Proteinen zum Beispiel der Iroquois-Familie aufweisen.

Es wurden zwei verschiedene Oligopeptide synthetisiert: M1: CKD KFE DLE DEE DEE D und M2: PGG GYE PKK DTS EGC entsprechend Sequenzen im carboxyterminalen Bereich des Irx2-Proteins, die weder die Homeo- noch die IroDomäne enthalten. Die Oligopeptide wurden synthetisiert, gereinigt und in Kaninchen injiziert. Über einen Monat wurden Blutproben aufgefangen, aufgereinigt und konzentriert, wobei später hauptsächlich das aufgereinigte Serum der letzten Blutung verwandt wurde. Zum Testen der Spezifität wurden COS-Zellen mit dem Plasmid CMVIrx2-GFP transfiziert, so dass mittels GFP-Markierung die Effizienz der Transfektion ermittelt werden konnte (Abb. 8A). Die Spezifität des Antikörpers wurde auf Proteinextrakten getestet, der aus COS-Zellen isoliert wurde (Abb. 8B). 


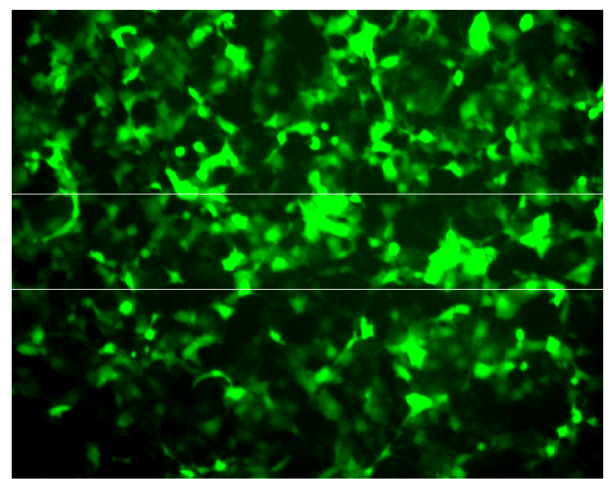

A. COS-Zellen

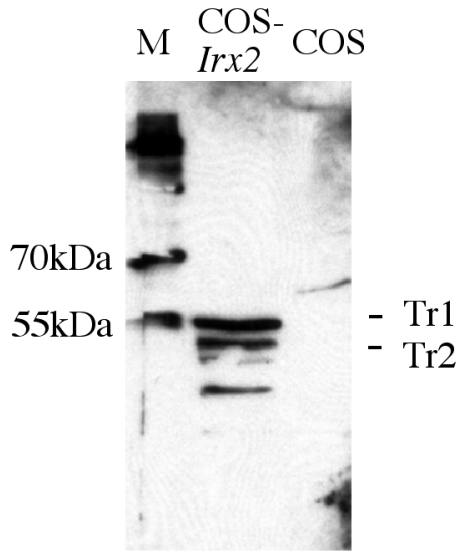

B. Westernblot

Abb. 8: Irx2-Antikörper

(A) GFP-Färbung von COS-Zellen, die CMV-Irx-GFP2 überexprimieren.

(B) Western-Blot aus Proteinextrakt aus transfizierten COS-Zellen. Der Irx2Antikörper erkennt beide Irx2-Proteine (Tr1 und Tr2). Die schwächere dritte Bande entspricht einem Abbauprodukt oder einer unspezifischen Färbung.

Die Immunisierung führte zu einem funktionellen Antiserum mit guten Ergebnissen bei der Analyse von Western-Blots (Abb. 8). Bei der Verwendung des Serums in der Histologie, vorrangig bei der immunohistochemischenAnalyse von Gefrierschnitten, erwies sich der Antikörper jedoch nur als bedingt geeignet, da Hintergrundreaktionen auftraten (Daten nicht gezeigt).

\section{II.1.4. IDENTIFIKATION DES GENOMISCHEN KLON DES IRX2-GENS}

Für alle keimbahnrelevanten Manipulationen muß der genomische Bereich des entsprechenden Gens vorliegen. Dieser sollte kloniert sein, um ihn in weiteren Schritten manipulieren zu können. Somit stellt der genomische Irx2-Klon die Grundlage für die funktionelle Analyse. Der 13kb große Klon wurde aus einer genomischen Phagen-Bank isoliert, in einen Bakterienvektor umkloniert und mittels Restriktionskartierung analysiert und sequenziert. 


\title{
II.1.4.1 DURCHMUSTERN EINER GENOMISCHEN PHAGENBANK
}

Verwendet wurde eine Phagenbank mit genomischer DNA des Stammes Ola 129Sv. Die DNA wurde aus der Leber isoliert und über Sau3a partiell verdaut und in den $\lambda$ Gem-Vektor über XhoI inseriert (Ola 129- $\lambda$ Gem/tm-12 genomic bank). Das Durchmustern verläuft methodisch analog zur Suche nach cDNA-Fragmenten. Die Phagen wurden mit einer Mischung der beiden Sonden 5' und 31 (Abb. 5) hybridisiert. Diese enthalten keine Homeobox, da ansonsten mit Kreuzreaktionen und falschpositiven Klonen gerechnet werden müßte. Nach vier Runden der wiederholten Suche bei zunehmender Verdünnung wurden 14 Irx2-positive Klone, 4.1 bis 4.14, ermittelt.

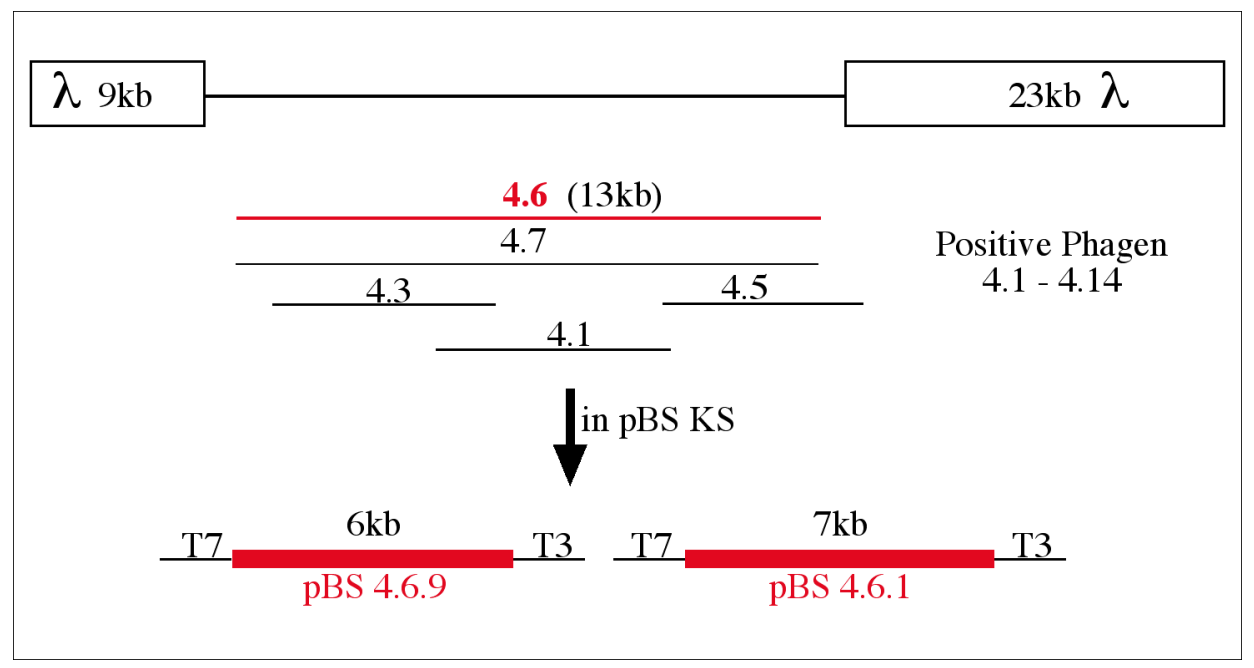

Abb. 9: Gewinnung des genomischen Irx2-Klons aus einer Phagen-Bibliothek.

\begin{abstract}
Zwischen beiden Phagenarmen wurden DNA-Fragmente von einer durchschnittlichen Größe von $14 \mathrm{~kb}$ eingebaut. Grundlage aller folgenden Analysen ist der genomische Phagenklon 4.6 mit einer Größe von 13 kb. Er wurde mit EcoRI verdaut und in zwei Teilen in den Bakterienvektor pBSKS kloniert. Es entstehen die Subklone pBS 4.6.1 mit $7 \mathrm{~kb}$ und pBS 4.6 .9 mit $6 \mathrm{~kb}$.
\end{abstract}

Für alle weiteren Schritte wurde der Phagenklon 4.6 verwendet. Er wurde ausgewählt, da er das größte Insert enthielt, so wie die vollständige kodierende Sequenz. Desweiteren gab es einen zweiten Klon, 4.7, der identisch in Größe und Schnittmuster bei der Restriktionskartierung war. Es gibt bei Phagenbanken das Problem, dass chimäre Klone bei der Erstellung der Bank entstehen können. Chimäre Klone entstehen bei der Ligation der partiell verdauten DNA in die Phagenarme, d.h, dass in einem Phagenklon Sequenzen benachbart sein können, die es im Genom nicht sind. Dieses Risiko ist für 4.6 
bzw. 4.7 minimiert, denn die Wahrscheinlichkeit ist sehr gering, dass zweimal ein identischer chimärer Klon entsteht.

Die Klonierung des genomischen Irx2-Bereichs war eine große Herausforderung. Wurde das $13 \mathrm{~kb}$ große Insert des genomischen Klons 4.6 in einem Bakterienvektor inseriert, so führte das zum Absterben der Bakterien. Weder der Wechsel des Bakterienstammes noch des Vektors zeigten eine Verbesserung. Die Klonierung des Gesamtklons in zwei einzelnen Fragmenten war dagegen stabil. Hierfür wurde das Insert in zwei Teilen über EcoRI aus den Phagenarmen geschnitten, so dass die Subklone pBS 4.6.1 und pBS 4.6.9 entstanden, mit denen weitergearbeitet wurde. Die gelelektrophoretische Auftrennung der großen Fragmenten der Phagenarmen (23 kb und $9 \mathrm{~kb})$ sowie der Irx2-EcoRI-Insertfragmente $(7 \mathrm{~kb}$ und $6 \mathrm{~kb})$ bedingt, dass ein geringprozentiges Gel $(0,3$ bis $0,6 \%)$ gewählt werden muß. Um den Verlust kleiner Fragmente auszuschließen, wurden Kontrollsequenzierungen durchgeführt. Das Ergebnis zeigte, dass der komplette Klon 4.6 in den Subklonen pBS 4.6.1 und pBS 4.6.9 enthalten ist.

\section{II.1.4.2 SEQUENZANALYSE DES GENOMISCHEN IRX2-KLONS}

Die Analyse des genomischen Irx2-Klons begann zunächst mit der Erstellung einer Restriktionskarte. Hierzu wurden sowohl die Phagen als auch die Subklone pBS 4.6.1 und pBS 4.6.9 jeweils mit 20 vorhandenen Restriktionsendonukleasen allein und in Kombination verdaut.

Die Fragmente wurden gelelektrophoretisch aufgetrennt und mittels Southern Blot für eine Hybridisierung mit unterschiedlichen Sonden (5', 31 und der kompletten cDNA) auf eine Membran transferiert. Nach der Zuordnung der verschiedenen Fragmente wurde eine Restriktionskarte erstellt. Diese Karte gibt den ersten Eindruck über die Organisation des Irx2-Lokus wieder.

Für die Sequenzierung der $13 \mathrm{~kb}$ wurden verschiedene Subklone angefertigt, sowie stets neue Sequenzierprimer definiert, die über die Grenzen der bekannten Sequenz hinausgingen. Einige Regionen des genomischen Klons ließen sich nur bedingt sequenzieren, was auf lange Wiederholungen von Nukleotiden (A, GT, CTTCC) oder Regionen mit einem GC-Gehalt von über $75 \%$ zurückzuführen ist. Verschiedenste Protokolle, die die Gelzusammensetzung und die Amplifikationsbedingungen vor der 
Sequenzierung verändern, wurden getestet. Um ebenfalls die schwierigen Regionen zu sequenzieren, hat sich das "GPS-System" bestens bewährt. Mit Hilfe von Transposonsequenzen werden DNA-Stücke an verschiedenen Stellen inseriert, von denen aus mit besonderen Primern sequenziert werden kann. Statistisch gesehen wird in das zu sequenzierende Plasmid gleichmäßig inseriert, auch in Regionen, die für Sequenzierungen schwer zugänglich sind.

Durch die Bestimmung der Sequenz konnten die genaue Restriktionskarte erstellt und die Exon-Intron-Grenzen im genomischen Klon konkretisiert werden.

Der Irx2-Lokus ist in Intron-Exon-Bereiche organisiert, wobei fünf Exons vorliegen. Das erste Start-Kodon (ATG) liegt in Exon I ( 0 - 399 bp der cDNA-Sequenz), das zweite ATG in ExonII (400 - 550 bp), die Homeobox in Exon III (551 - 720 bp), die Iro-Box und das erste Stop-Kodon in ExonIV (882 - 1651 bp) und alle weiteren Stop-Kodons im letzten Exon Nr.V (1651-2208 bp) (Abb. 10).

Es liegen mehrere CpG-Inseln vor. Sie markieren in Säugergenen häufig das 5'Ende von Genen. Das WWWCPG Programm von Gardiner-Garden und Frommer definiert die CpG-Inseln. Es sind Regionen die auf einer Länge von mehr als 500bp mit einem hohen GC-Gehalt von größer 50\% $(\mathrm{p}(\mathrm{G})+\mathrm{p}(\mathrm{C})$ größer 0,5$)$. Sie enthalten einen $\mathrm{CpG-Gehalt}$ von mindestens 0,6 des erwarteten Wertes. Ebenfalls 5' des ersten Exons sind mehrere Wiederholungen von Typ RSINE2, L1P2.5 und Nukleotidrepeats anzutreffen. 


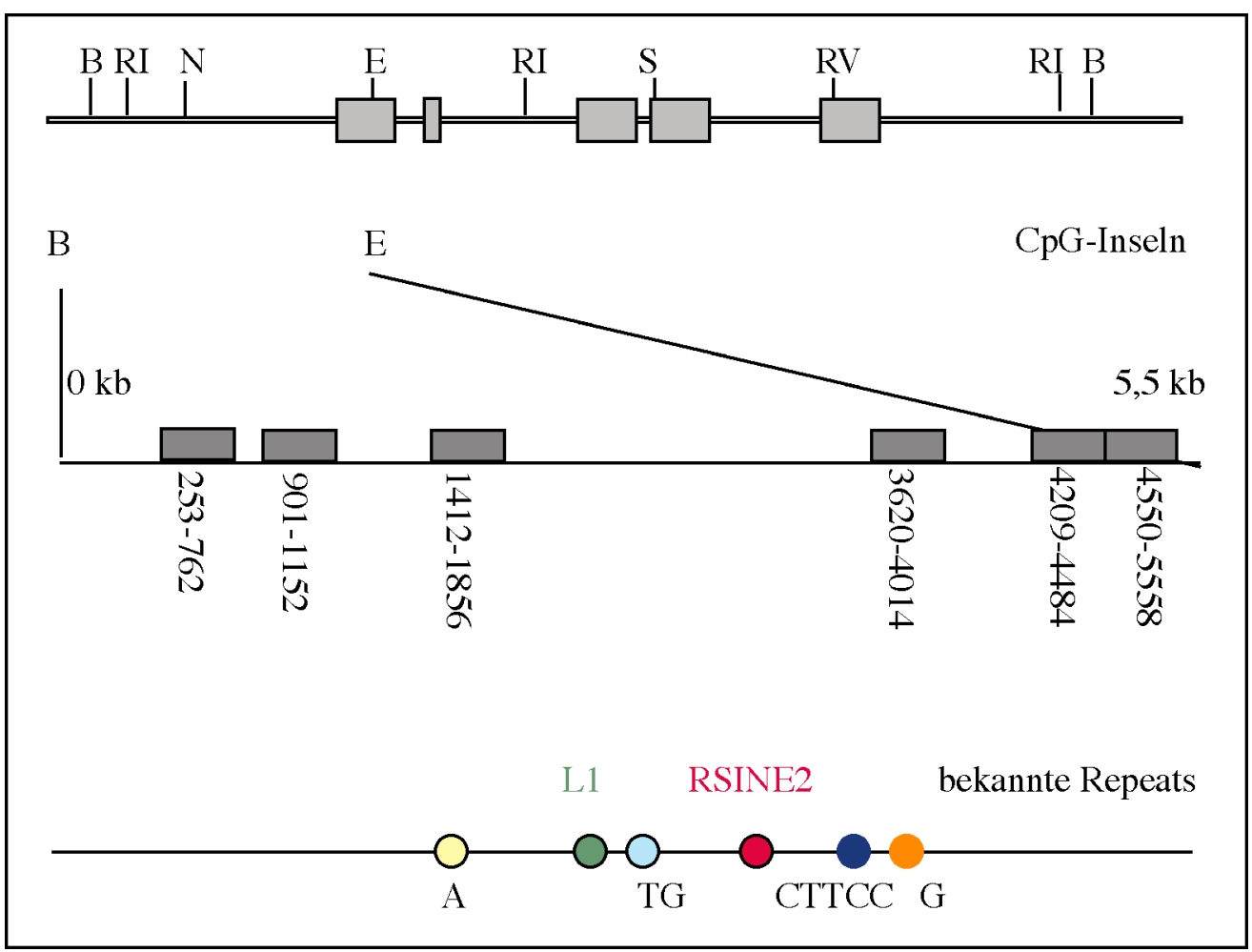

Abb. 10: Darstellung der genomischen Organisation des Irx2-Gens.

Der genomische Irx2-Klon ist in fünf Exons (hellgraue Kästen) organisiert, die über 5 $\mathrm{kb}$ verteilt sind. Ausgewählte Schnittstellen unterteilen den ca. $15 \mathrm{~Kb}$ großen Klon. B: BamHI, RI: EcoRI, N: Ndel, E: Eagl, S: Sall, RV: EcoRV

In den ersten 5,5 kb liegen sechs CpG-Inseln (mit Angabe der bp) und ebenfalls sechs prominente Nukleotid-Wiederholungen. A, G stehen für EinzelnukleotidWiederholungen, TG und CTTCC verweisen auf die Wiederholung ihrer Sequenz und RSINE2 und L1 sind bekannte repetitive Elemente.

\section{II.1.5 CHROMOSOMALE LOKALISATION}

Für die Durchführung der funktionellen Analyse ist die Kenntnis über die chromosomale Organisation von Bedeutung. Die Iroquois-Gene in D. melanogaster sind tandemartig (sog. Kluster) organisiert. Im Kluster kann es zu Wechselwirkungen der Gene untereinander kommen, so dass eine integrierte Rekombinationskassette unter die Kontrolle der benachbarten Gene gelangen kann. Es ist dann möglich, dass das Selektionsgen von anderen Mitgliedern der tandemartigen Organisation mitreguliert wird und damit die Selektion verfälscht wird beziehungsweise zusätzliche Phänotypen verursacht (Meyers et al., 1998). 
Aus diesem Grund wurde die chromosomale Lokalisation des Irx2-Gens mittels FISH in-situ-Analyse bestimmt. Die Chromosomen von Maus-ES-Zellen wurden in der Mitose arretiert, um Metaphasen-Chromosomen zu erhalten. Diese wurden auf Objektträgern gespreizt und mit dem genomischen Irx2-Klon (Mischung aus pBS 4.6.9 und pBS 4.6.1) hybridisiert. Das Mausgen Irx2 liegt auf Chromosom 13 (Abb. 11). Es stellte sich bei diesen Untersuchungen heraus, dass Irx 1 und Irx 2 sehr nah beieinander auf Chromosom 13 lokalisiert sind (A. Zülch, pers. Mitteilung), weshalb zusätzlich eine Abstandsmessung zwischen Irxl und Irx2 mittels einer Fiber-FISH-Analyse durchgeführt wurde (mit freundlicher Unterstützung von W. Engel, Göttingen). Diese Analyse ergab einen Abstand zwischen Irxl und Irx2 von lediglich $200 \mathrm{~kb}$ (Abb. 11). Aus einer Datenbankanalyse konnte ferner ein weiteres Mitglied der IroquoisGenfamilie, Irx4, auf Chromosom 13 lokalisiert werden. Auch hier ist der Abstand zu den anderen Familienmitgliedern mit ca. 400 kb gering (http://www.ncbi.com). 


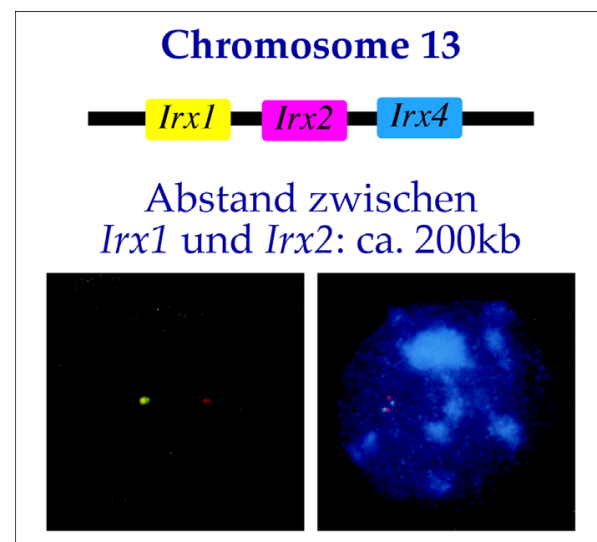

Fiber-FISH-Analyse von $\operatorname{Ir} x 1$ und $\operatorname{Ir} x 2$

Abb. 11 : Chromosomale Lokalisation und Abstandsmessung von Irx2 zu Irx1

In der Maus sind die Gene Irx1 und Irx2 auf Chromosom 13 lokalisiert. Die Fiber-FISH Analyse ergab einen Abstand von Irx1 zu Irx2 von ca. 200 kb, angezeigt durch Fluoreszenssignale (rot: Irx1, grün: Irx2).

\section{II.2 ERSTELLUNG UND ANALYSE DER IRX2- VERLUSTMUTANTE}

Die embryonale Stammzell-(ES-Zell-)-Technologie in Verbindung mit der zelleigenen homologen Rekombination ermöglicht es, eine gezielte Veränderung eines bestimmten Genlokus durchzuführen und diese in der Keimbahn der Maus zu etablieren. Säugerzellen besitzen die enzymatische Maschinerie, welche die homologe Rekombination zwischen eingebrachteten DNA-Molekülen und ihrem endogenen chromosomalen Locus ermöglichen (Doetschman et al., 1988)(Bronson and Smithies, 1994)(Capecchi, 1989). Diese Möglichkeit, gezielt Gene in ES-Zellen (embryonalen Stammzellen der Inneren Zellmasse der Blastozyste) zu mutieren und daraus Verlustmutanten in der Maus herzustellen, wurde im Laufe der Jahre technisch verfeinert, um die Häufigkeit der homologen Rekombination zu optimieren. Um ein Gen gezielt auszuschalten, ist ein Rekombinationskonstrukt notwendig, welches in-vitro 
hergestellt wird, das einen Selektionsmarker (in der Regel das Neomycin-Resistenzgen) und ein Reportergen (lacZ, $\beta$-Galactosidase) enthält, welcher flankiert ist von homologen Regionen des genomischen Lokus. In den ES-Zellen wird dann die endogene Sequenz mittels homologer Rekombination gegen die des Rekombinationskonstruktes ausgetauscht.

\section{II.2.1 ENTWICKLUNG UND DURCHFÜHRUNG DER SCHRITTE ZUR KLONIERUNG DER IRX2-REKOMBINATIONSKASSETTE}

Die Intergation des Rekombinationskonstruktes soll bewirken, dass die Funktion eines Zielgens gestört wird. Im Falle von Irx2 bedeutete dies, die funktionell wichtige Homeobox zu entfernen. Es hat sich gezeigt, dass die Größe des flankierenden Homologiebereiches für die Effizienz des Rekombinations-ereignisses von großer Bedeutung ist (Thomas and Capecchi, 1987). Um eine hohe Rekombinationsfrequenz zu erhalten, sollten die homologen Abschnitte in einer Gesamtgröße von 10kb liegen (Mansouri, 2000).

Vor der Herstellung des Irx2-Rekombinationskonstruktes wurde der genomische Klon pBS 4.6.1 modifiziert (Abb. 12). Es wurde ein $1 \mathrm{~kb}$ großer Bereich auf der 3'-Seite als spätere sog. externe Sonde entfernt (BglII, EcoRI) welcher eine entscheidende Rolle bei der späteren Genotypisierung der Mäuse spielte. Die Sequenz der externen Sonde ist nicht im Rekombinationskonstrukt enthalten und nimmt auch nicht an der homologen Rekombination teil. Die externe Sonde diente als Hybridisierungssonde, um die korrekte Integration in den Irx2-Lokus zu überprüfen.

Die zu deletierende Region von 2,5 kb umfasste die Homeodomäne in Exon III und beide Start-Kodons in ExonII und ExonI. Die zu entfernenden Bereiche in den Vektoren pBS 4.6.1 und pBS 4.6.9 waren von ausreichender Sequenz flankiert (Abb. 12). 5'der Deletion befanden sich 4,7 $\mathrm{kb}$ und 3'der Deletion $5 \mathrm{~kb}$ homologe Sequenz. Im verbleibenden genomischen Klon wurde über eine veränderte EagI und SalI Schnittstelle die Selektionskassette pGNA eingesetzt, welche 7,3 kb groß war und sowohl das LacZGen ( $\beta$-Galaktosidase-Gen) als auch das Neomycin-Gen enthielt. 


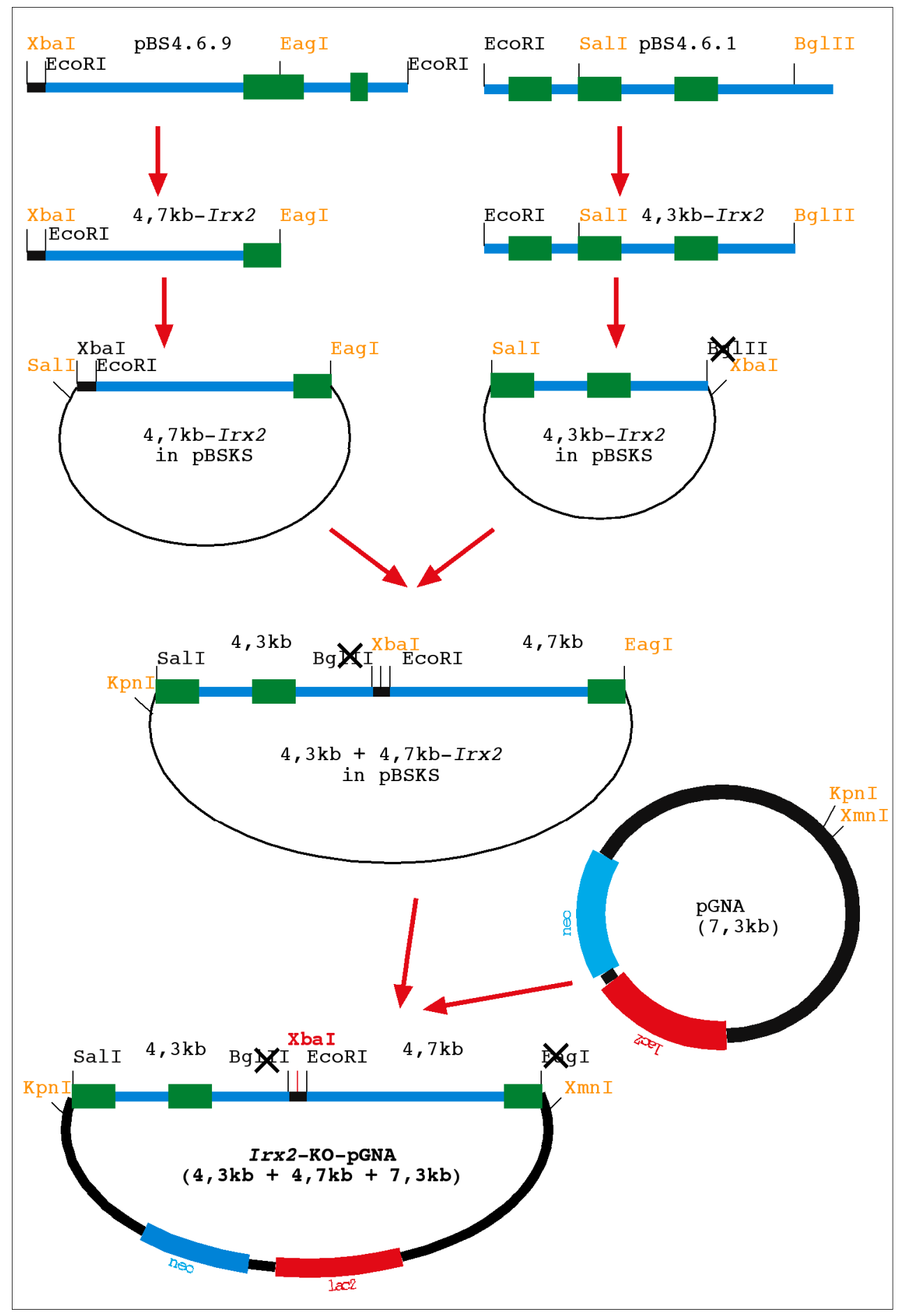

Abb. 12: Klonierungsschema zu Erstellung der Irx2-Rekombinationskassette.

Die schematische Dartsellung beinhaltet alle Angaben zur Größe der Konstrukte, zur Zahl der Exons und zur Verwendung von Schnittstellen und Plasmiden. Der Subklon pBS 4.6.1 wurde zuerst um den Bereich der externen Sonde verkürzt. Anschließend wurden die beiden Subklone getrennt vorbereitet auf die Fusion mit der Rekombinationskassette des pGNA-Vektors. Zur Linearisierung wurde die singuläre Schnittstelle Xbal verwendet. 
Die Integration der Selektionskassette in einen genomischen Klon, der Intron I und/ oder II enthielt, führte zu instabilen Ligationsprodukten in Bakterien. Aufgrund von starken Rekombinationsereignissen war zusätzlich notwendig, die Klonierungen in einem pGNA-Vektor zu erstellen, dessen Replikationsstart (origin of replication) derart modifiziert ist, dass nur wenige Kopien des Plasmids pro Zelle produziert werden. Die Verwendung von reparatur-defizienten Bakterien (XL-10Gold; Stratagene) erwies sich als nützlich.

\section{II.2.2 GENTRANSFER IN ES-ZELLEN}

Embryonale Stammzellen (ES-Zellen) werden aus der inneren Zellmasse der Mausblastozyste des Mausstammes 129Sv gewonnen. Sie können in Kultur ohne Differenzierung gehalten werden. Wenn sie auf embryonalen Fibroblasten und/oder in Anwesenheit von LIF (leukaemia inhibitory factor) kultiviert werden, so dass sie ihre Pluripotenz behalten (Mansouri, 2001). $30 \mu \mathrm{g}$ des Rekombinationskonstruktes wurden in ca. $1 \times 10^{7}$ ES-Zellen der MPI-II-ES-Zellinie elektroporiert.

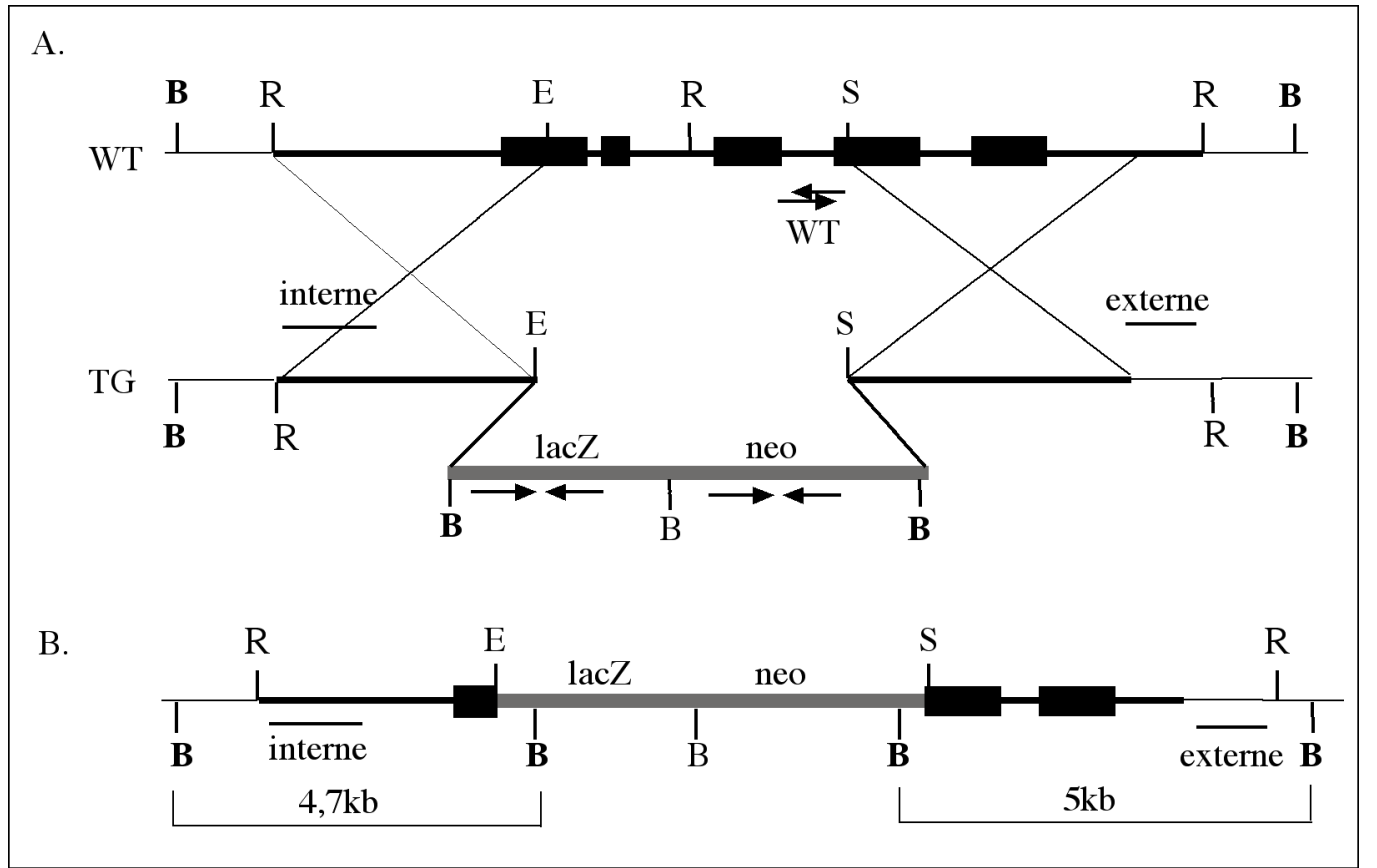

Abb. 13: Schema der erwarteteten homologen Integration zur Erzeugung des transgenen Lokus.

A. Der Irx2-Wildtyp (WT)-Lokus enthält fünf Exons (schwarze Kästen) und liegt zwischen zwei BamHI-Schnittstellen (B). Das erstellte Rekombinationskonstrukt 


\begin{abstract}
enthält homologe Bereiche: auf der 5'Seite von EcoRI (RI) bis Eagl (E) und auf der 3'Seite von Sall (S) bis zum Beginn der Sequenz für die externen Sonde. Angegeben sind die Sonden (externe, interne) und die Stellen für die Genotypisierungs-PCR von Neomycin (neo), lacZ und Wildtyp (WT). Die WT-PCR amplifiziert einen Bereich im deletierten dritten Intron.
\end{abstract}

B. Das homolog integrierte Rekombinationskonstrukt weist bei einer Restriktionsendonucleasebehandlung mit BamHI (B) Fragmentgrößen von 4, 7 Kb bzW. 5 Kb auf.

Die mit dem Irx2-Konstrukt transformierten Zellen wurden daraufhin mit Geneticin (G418) auf ihre Neomycin-Resistenz selektiert. Nach der Selektion konnten über 220 ES-Zell-Klone isoliert werden. Zur Identifizierung des homologen Rekombinationsereignisses wurde genomische DNA aus den ES-Zellen gewonnen. Für deren Analyse werden im Southern-Blot sowohl die externe wie auch eine interne Sonde benutzt (Abb. 13). Der Verdau der genomischen DNA mit BamHI, Gelauftrennung, Southern-Blot-Analyse und anschließender Hybridisierung mit der externen Sonde zeigte eine ca $12 \mathrm{~kb}$ Bande für das Wildtyp-Allel und einer zusätzliche $5 \mathrm{~kb}$ Bande für das homolog rekombinierte Allel. Bei der Hybridisierung mit der internen Sonde entsprach das rekombinierte Allel 4,7 kb. Von den ca. 220 ES-Zell-Klonen zeigten sechs das richtige Rekombinationsereignis (Nr. 5, 69, 184, 185, 198, 217).

\title{
II.2.3 MORULA-AGGREGATION VON ES-ZELLEN
}

Vier der positiven ES-Zellen (Nr. 5, 69, 184, 198) wurden mit Wildtyp-Morulae aggregiert, die aus dem NMRI-Mausstamm gewonnen wurden. Nicht alle Morulae entwickelten sich außerhalb des Körpers, es konnten ca. $90 \%$ der aggregierten Embryonen retransferiert werden. Ebenso entwickelten sich nicht alle transferierten Embryonen zu Chimären. Entscheidend für die Weiterentwicklung sind Faktoren wie die der Synchronisation der Ammenmütter und die Sauberkeit während des Retransfers. Die Chimären entwickeln sich normal und die ES-Zellen beteiligen sich an der Entwicklung aller embryonalen Gewebetypen, einschließlich der Keimbahn (Robertson, 1987).

Nach ca. sechs Wochen wurden die Chimären mit NMRI-Wildtypmäusen verpaart, wobei der Grad des Chimärismus dabei anhand der Fellfarbe erkennbar ist. Je höher dieser Grad, desto höher ist auch die prozentuale Wahrscheinlichkeit, dass die chimäre Maus die transgene Information auch in ihren Keimzellen trägt und somit diese Information an ihre Nachkommen weitergibt. Eine Keimbahntransmission konnte bei 
den Nachkommen anhand der Augenfarbe erkannt werden. Mäuse mit schwarzen Augen entstammten der Keimbahn der transgenen ES-Zellen (Stamm: 129Sv), wohingegen Mäuse mit roten Augen von den nicht-transgenen ES-Zellen (Stamm: NMRI) abstammen. Keimbahn transmittierende Chimären wurden auf dem Inzuchtstamm Sv129 und dem Auszuchtstamm NMRI weitergezüchtet. Der Mausstamm Sv129 bietet die Vorteile eines genetisch reinen Hintergrundes, da auch die ES-Zellen und die genomische DNA im Rekombinationskonstrukt diesem entstammen. Bei Müttern des Stammes 129Sv ist die Zahl der Nachkommen und die Pflegebereitschaft eingschränkt. Diese Einschränkungen treten nicht in einem NMRI-Hintergrund auf. Die folgende Abbildung (Abb. 14) gibt schematisch den Ablauf der Erstellung einer Verlustmutante dar. 


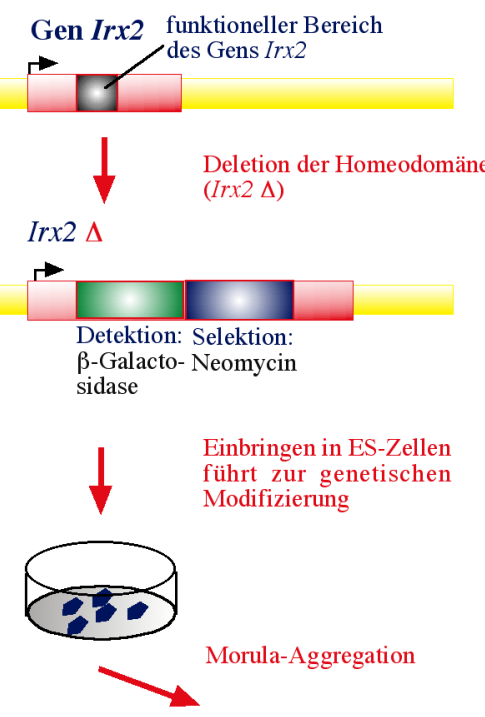

Blastocyste mit transgenen ES-Zellen
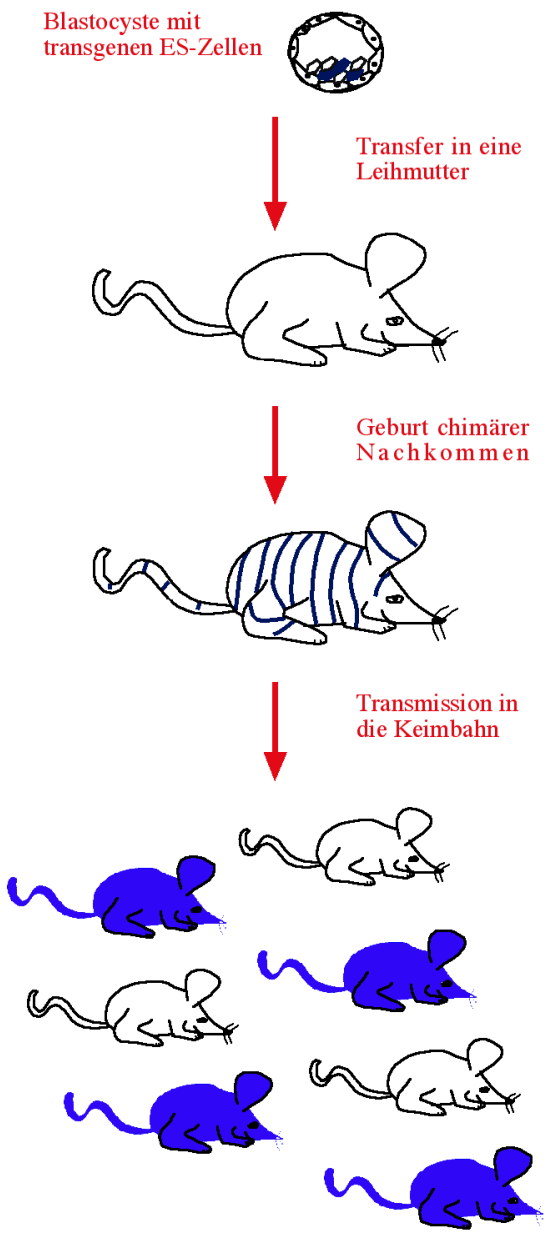

Abb. 14: Schematische Darstellung der Aggregation und des Verpaarungsschemas zur Herstellung einer Irx2-Verlustmutante.

In vitro werden Bereiche des Zielgens ersetzt durch Sequenzen von Selektionsgenen. Daraufhin wird das Rekombinationskonstrukt mittels Elektroporation in ES-Zellen eingeführt, wobei die zelleigenen Prozesse der homologen Rekombination das 
Konstrukt ins Genom der Zellen integrieren. Angezeigt wird das Integrationsereignis durch die Resistenz der Zelle gegen das Gift Geneticin. DNA-Analysen der Zellen geben Auskunft über die Form der Integration. Ist in den Ziellokus, in diesem Fall das Irx2-Gen, inseriert, läßt man die Stammzellen sich zu Morulae entwickeln. Nach der Aggregation werden chimäre Mäuse (F0, blau-weiß) geboren und mit WildtypMäusen verpaart. Die Transmission in die Keimbahn kann über die Fellfarbe (weiß/ blau) nachgewiesen werden. Die Nachkommen sind die F1-Generation.

\section{II.2.4 ANALYSE DER MAUSKOLONIE VON ES-ZELLKLON 69}

Die Aggregation der Klone Nr. 5, 69, 184 und 198 führte zur Keimbahntransmission von Nr. 69. Heterozygote Tiere der Mauslinie Irx2-69 wurden miteinander verpaart. Erwartet wurde eine Verteilung von Wildtypmäusen (WT) zu heterozygoten Tieren (+/-) zu homozygoten Mäusen (-/-) nach der Mendelschen Regel von $1: 2: 1$.

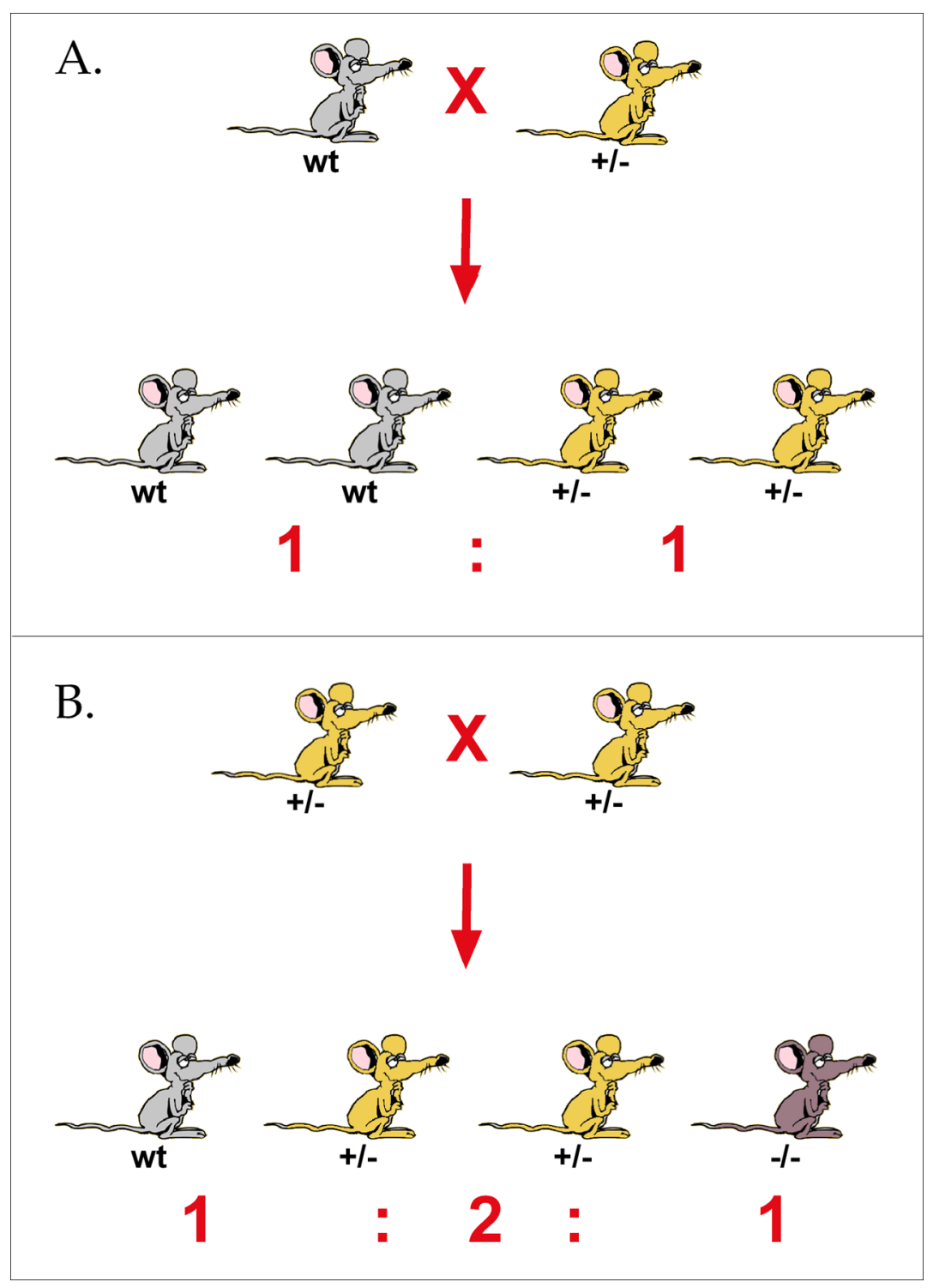


Abb. 15: Bildliche Darstellung der zuerwartenen Verpaarungsergebnissen bei reinen Mendelschen Erbgängen.

A. Werden heterozygote (+/-) Tiere mit wildtyp (+/+) Mäusen verpaart, so entstehen wildtyp und transgene Nachkommen in einem Verhältnis von $1: 1$.

B. Bei Verpaarung von heterozygoten (+/-) Eltern teilen sich die Genotypen in einem Verhältnis von $1: 2: 1$ auf.

Die Genotypisierung der Irx2-Mäuse erfolgte mittels einer Southern-Blot- bzw. einer PCR-Analyse. Der ES-Zellklon Irx2-69 hatte bei Hybridisierung mit der externen Sonde und Verdau der genomischen DNA mit BamHI das erwartete Bandenmuster von $12 \mathrm{~kb}$ für das Wildtyp-Allel und $5 \mathrm{~kb}$ für das transgene Allel ergeben. Die Verwendung der externen Sonde garantiert, dass sich das veränderte Alle im Irx2-Lokus befindet. Das vollständige Rekombinationskonstrukt war homolog in den Irx2-Lokus integriert.

Die Analysen der transgenen Tiere der dazugehörigen Mauskolonie Irx2-69 wichen hiervon ab. Bei der Hybridisierung mit der externen Sonde zeigte das transgene Allel eine unerwartete falsche Bandengröße von $10 \mathrm{~kb}$. Die Integration der Rekombinationskassette führte $\mathrm{zu}$ einem instabilen und nicht $\mathrm{zu}$ analysierenden transgenen Ereignis. Der Zielort ist durch unkontrollierte Rekombinationsereignisse verändert worden und daher wurde die Analyse dieser Mauskolonie eingestellt.

\section{II.2.5 UNTERSUCHUNG DER MAUSKOLONIE VON ES-ZELLKLON 184}

Die Aggregation der Klone Nr. 5, 184 und 198 wurde wiederholt. Zusätzlich wurden die positiven ES-Zellklone Nr. 185 und Nr. 217 aggregiert. Keimbahntransmission wurde für Nr. 184 erreicht.

Die Genotypisierung der Irx2-Mäuse erfolgte mittels der Southern-Blot- bzw. PCRAnalyse. Der ES-Zellklon Irx2-184 hatte nach dem Verdau der genomischen DNA mit BamHI und der Hybridisierung mit der externen Sonde und Verdau der genomischen DNA mit BamHI das erwartete Bandenmuster von $12 \mathrm{~kb}$ für das Wildtyp-Allel und $5 \mathrm{~kb}$ für das transgene Allel ergeben (Abb. 16). Die Analyse von transgenen Tieren der aufgebauten Mauskolonie Irx2-184 zeigte das entsprechend gleiche Muster, wobei die Hauptanalyse auf der Mauskolonie vom Stamm NMRI beruhte. Im folgenden wurde mit einer Kombination aus einer WT-PCR, die Teile des IntronIII amplifiziert, das im 
transgenen Allel deletiert ist und einer TG-PCR, die das Neomycin- oder LacZ-Gen nachweist, genotypisiert. Zur Kontrolle der Stabilität hinsichtlich der intergrierten Rekombinationskassette wurden über den gesamten Verlauf der Untersuchung DNAStichproben der Kolonie sowohl mit der externen wie auch mit der internen Sonde hybridisiert. Es wurde keine Abweichung festgestellt .

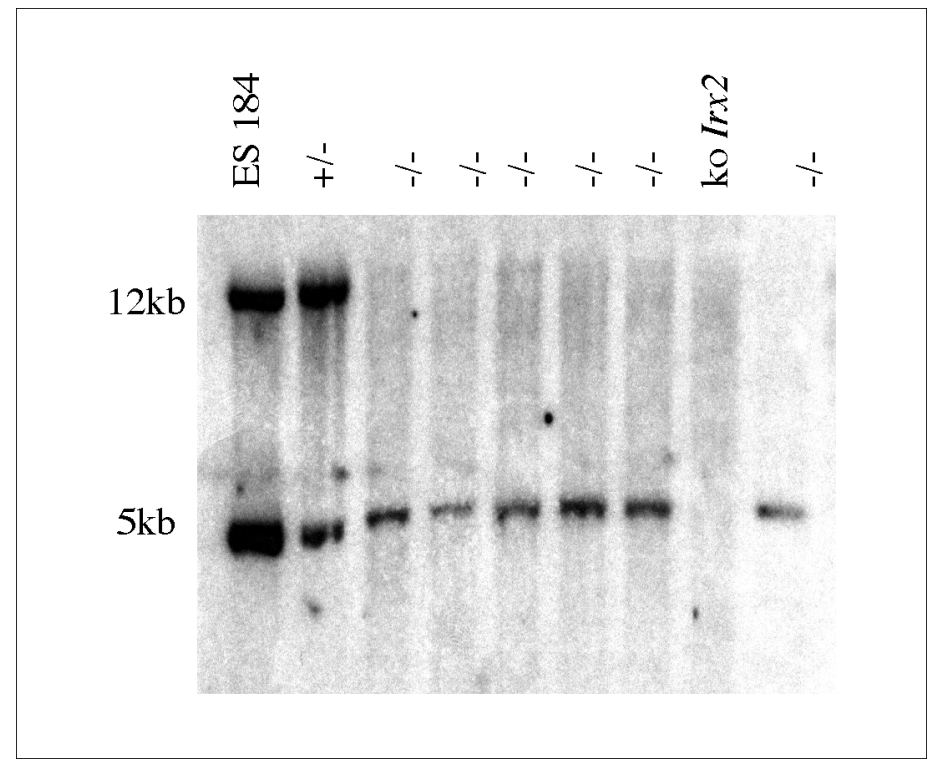

\begin{abstract}
Abb. 16: Southern-Blot-Hybridisierung mit der externen Sonde zum Nachweis der Integration der Rekombinationskassette in den Irx2-Lokus.

Analysiert wurde DNA, isoliert aus den embryonalen Membranen eines heterozygoten und mehrer homozygoter Tiere im Alter von E12,5. Die erste Spur enthält als positive Kontrolle die heterozygote DNA der aggregierten ES-Zelle Nr.184. Spur zwei enthällt DNA eines heterozygoten Tieres. Die Spuren 3-7 und 9 verifizieren das zuvor erhaltene PCR-Ergebnis der Homozygotie für diese Tiere. Die 8. Spur ist als Negativkontrolle anzusehen, da sie das Rekombinationskonstrukt enthält, das nicht mit der externen Sonde hybridisiert. Das Wildtyp-Allel entspricht einer Göße von ca. $12 \mathrm{~kb}$ und das transgene Allel $5 \mathrm{~kb}$. Das Ergebnis der gezeigten Genotypisierung ist wie folgt: Spur 1 und 2 enthalten DNA heterozygoter Enbryos und die Spuren 3 bis 7 und 9 DNA homozygoter Embryos.
\end{abstract}

\title{
II.2.6 PḦ̈NOTYPANALYSE DER MAUSLINIE IRX2-184
}

\section{II.2.6.1 ANALYSE DES VERPAARUNGSMUSTERS VON IRX2-MUTANTEN}

Die Analyse der Irx2-Mutante ergibt eine interessante geschlechtsspezifische Verteilung der inserierten Mutation unter den Nachkomme (Abb. 17). 


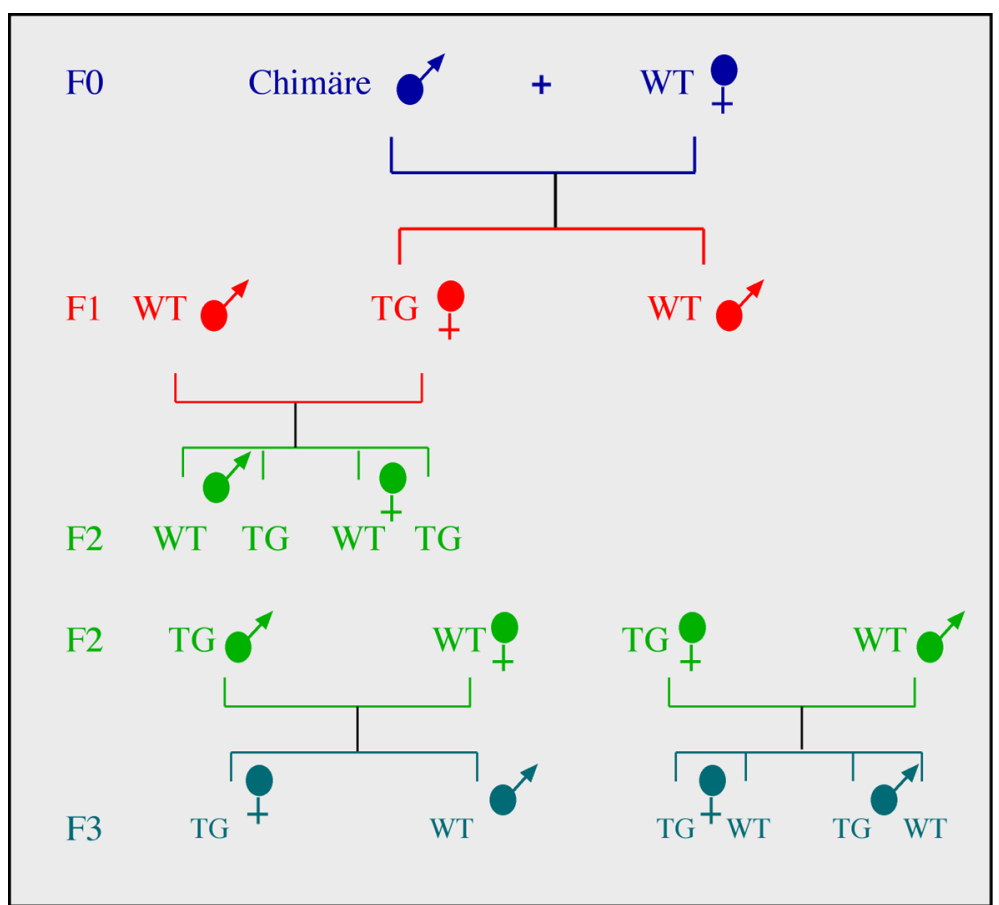

Abb. 17: Vererbungsschema der ersten Generationen der Mauslinie Irx2-184.

Es kommt zu unterschiedlicher Merkmalsausprägung je nachdem, welche Keimbahn vom transgenen Allel durchlaufen wurde, wie in der Abbildung beschrieben wird. F0F3: Generationsfolgen, WT: Wildtyp, TG: Transgenes Tier

Verpaarung von heterozygoten Weibchen mit Wildtyp-Männchen

Bei der Verpaarung von heterozygoten Weibchen mit Wildtyp-Männchen entstanden sowohl männliche als auch weibliche transgene Tiere. Die Verteilung der Genotypen entspricht dem Mendelschen Verhältnis von WT :TG $=1: 1(111: 110$ und $67: 60$ bei den Männchen und 46 : 50 bei den Weibchen)(Abb. 18). 


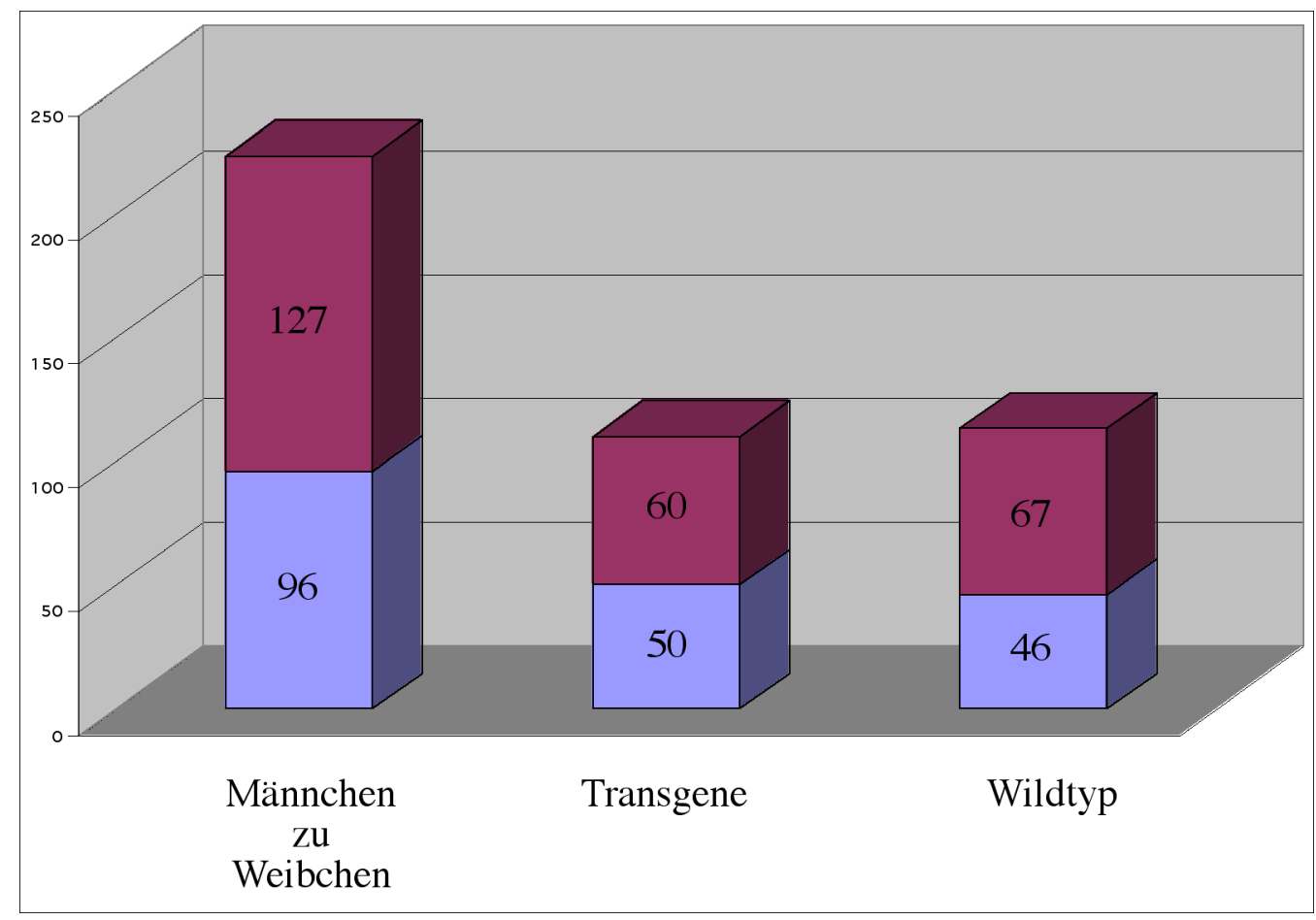

Abb. 18: Irx2-Verpaarungsergebnisse von heterozygoten Weibchen mit WildtypMännchen.

Das Balkendiagramm gibt die Verhältnisse der entstehenden Genotypen in Verbindung zu ihrem Geschlecht an. Die rot markierten Balken entsprechen den Männchen, die blauen den Weibchen. Die Y-Achse gibt die Anzahl der untersuchten Nachkommen an.

Verpaarung von heterozygoten Männchen mit Wildtyp-Weibchen

Die Verpaarung von heterozygoten Männchen der F2 Generation ergab eine bemerkenswerte Verteilung. Die Verteilung der Genotypen entspricht ca. einem Verhältnis von Wt : TG $=1: 1$ oder $59: 44$ Wildtypmäusen zu transgenen Tieren (Abb. 19). Die Analyse der Genotypen in Bezug zum Geschlecht der Tiere zeigte, dass alle transgenen Tiere weiblich sind. 


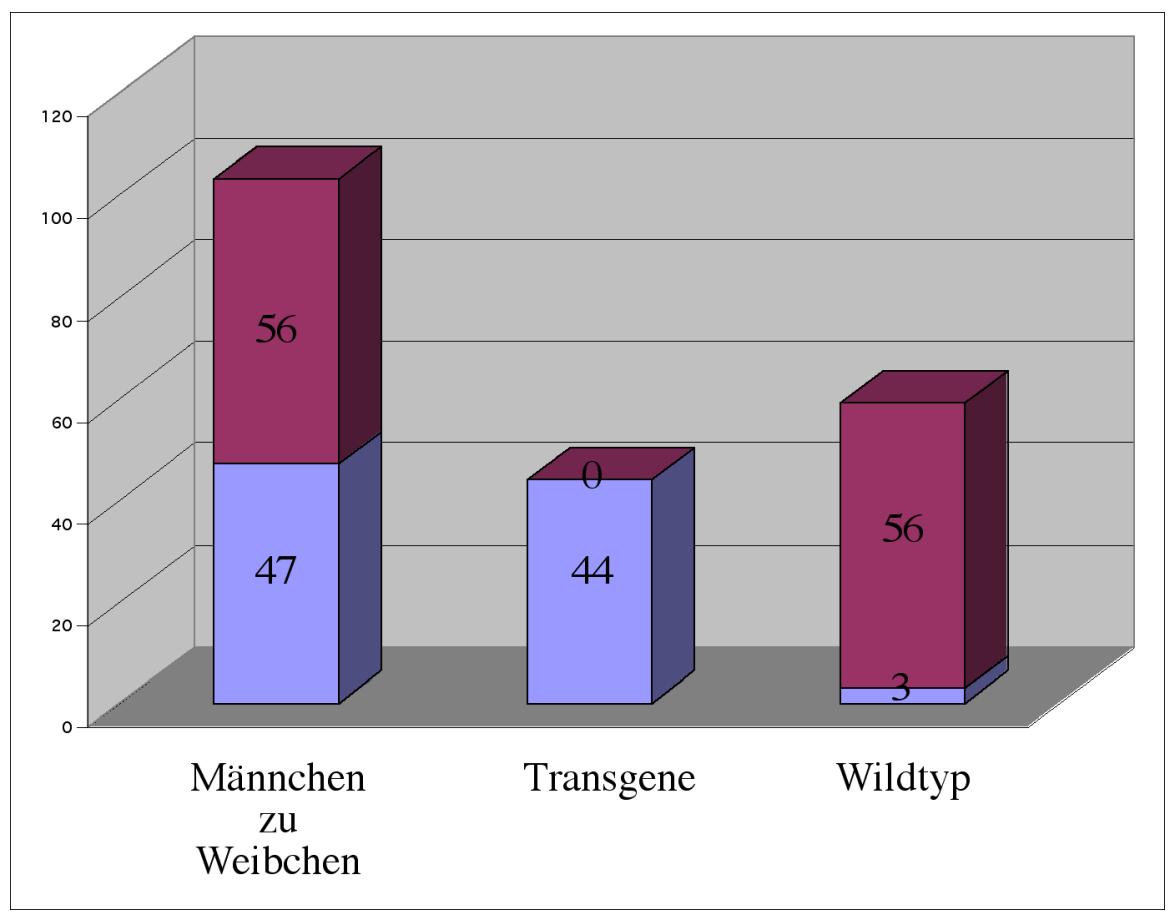

Abb. 19: Irx2-Verpaarungsergebnisse von heterozygoten Männchen mit WildtypWeibchen.

Das Balkendiagramm gibt die Verhältnisse der entstehenden Genotypen in Verbindung zu ihrem Geschlecht an. Die rot markierten Balken entsprechen den Männchen, die blauen den Weibchen. Die erste Säule gibt die Anzahl der untersuchten Männchen zu Weibchen an. Die zweite Säule weist das Ergebnis der Transgenen aus und die dritte das der Wildtypen. Die Y-Achse gibt die Anzahl der untersuchten Nachkommen an.

Parallel zur Analyse der geborenen Würfe wurden Embryonen der Stadien E8,5 bis E18,5 genotypisiert und auf ihr Geschlecht hin getestet. Da die ersten morphologischen Unterschiede in der Entwicklung der Geschlechtsorgane erst ab E14,5 entstehen, fällt die visuelle Geschlechtsbestimmung aus. Stattdessen wurde eine SRY-PCR entwickelt. Das Gen SRY liegt auf dem Y-Chromosom und ist spezifisch für männliche Tiere. Die folgende Abbildung zeigt das Ergebnis der Genotypisierung hinsichtlich des NeomycinGens (obere Reihe) zur Identifizierung der transgenen Tiere und der SRYGeschlechtsbestimmung (untere Reihe). Auch die Analyse embryonaler Würfe bestätigt die auffällige geschlechtsspezifische Verteilung der Genotypen. Es gibt keine männlichen heterozygoten Tiere im Alter zwischen E8,5 bis E18,5 (Abb. 20). 


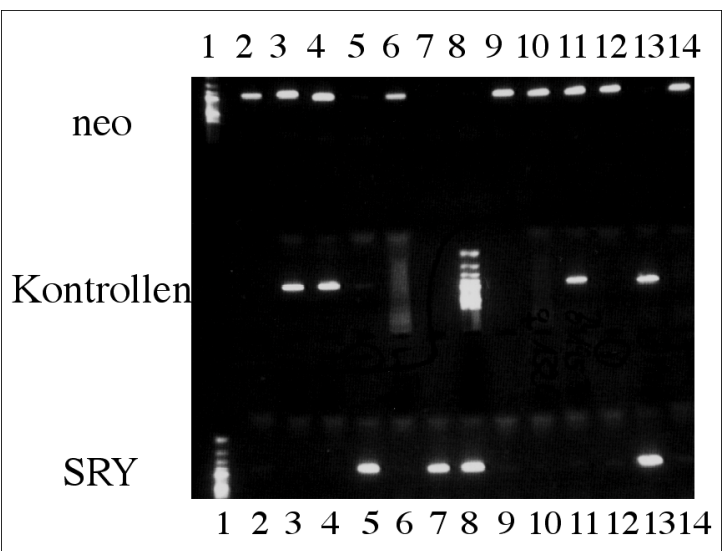

\begin{abstract}
Abb. 20: Genotypisierungsergebnis der Nachkommen eines Wurfes im Alter von E9.0 entstanden aus einer Verpaarung eines heterozygoten Vaters und einer WildtypMutter.
\end{abstract}

Die obere Reihe zeigt den Transgenen-Nachweis. Die Spuren 2 bis 14 enthalten DNA verschiedener Embryonen. Die untere Reihe zeigt den Nachweis des mänlichen Geschlechts. Die Spuren 2 bis 14 enthalten wie in der oberen Reihe die DNA der entsprechenden Embryonen. Die mittlere Reihe enthältt die Kontrollen: Spur 3 bis 6 für die neoPCR: 3: DNA der Spur 2, 4: knock-out Konstrukt, 5: keine DNA, 6: WTDNA und Spur 10 bis 13 für die SRY PCR: 10: DNA der Spur 2, 11: DNA der Mutter, 12, keine DNA, 13: DNA des Vaters.

Die Verpaarungsergebnisse weisen, wie bereits erwähnt, auf einen Genlokus mit monoallelischer Aktivität hin. Die genomische Prägung ist häufig begleitet von differentiellen Methylierungsmustern in der genomischen Sequenz des entsprechenden Gens. Großangelegte Untersuchungen der internationalen Datenbanken haben für das Chromosom 13 der Maus kein differentielles Methylierungsmuster vorhergesagt. Dennoch ist es interessant zu untersuchen, ob vielleicht ausschließlich der Irx2-Lokus Methylierungsunterschiede zeigt. Es gibt Restriktionsenzyme, die ihre Zielsequenzen ausschließlich schneiden, wenn sie nicht methyliert sind. Andere Enzyme sind nicht methylierungssensitiv. Die Enzyme HpaII und MspI sind Isoschizomere, sie erkennen die gleiche Schnittsequenz, aber bei methylierter DNA schneidet MspI nicht. Im Vergleich von DNA-Proben, die mit beiden Enzymen verdaut wurden und anschließender Hybridisierung mit spezifischen Sonden, ist ein unterschiedliches Schnittmuster visualisierbar.

Es wurden männliche und weibliche Wildtyp-DNA getrennt verdaut, die Fragmente aufgetrennt und mit genomischen Fragmenten des 5'Bereiches hybridisiert. Es entstand 
kein differentielles Schnittmuster der Enzyme HpaII und MspI bei verschiedenen Sonden des 5'-Bereichs. Die monoallelische Expression des Irx2-Gens prägt sich in der untersuchten Region $5 \mathrm{~kb}$ vor dem ATG nicht in einem differentiellen Methylierungsmuster an den Schnittstellen der beiden Enzyme aus (Daten nicht gezeigt).

\section{Verpaarung der Heterozygoten}

Insgesammt wurden Nachkommen aus Verpaarung von Elterntieren, die beide heterozygot sind, 396 Nachkommen untersucht (Abb. 21) Die Verteilung der Genotypen ist wie folgt: WT : TG $=1: 3$. Die allgemeine Verteilung ist nicht auffällig. Aber die Bezugnahme auf das Geschlecht der Tiere zeigt, dass es bei den mänlichen Tieren statistisch eine zu große Zahl an wildtyp Tieren (88) im Vergleich zu transgenen (115) gibt. Überraschend ist, dass die Anzahl der Wildtyp-Weibchen mit 11 aus 193 deutlich unter der zu erwartenenen Anzahl liegt.

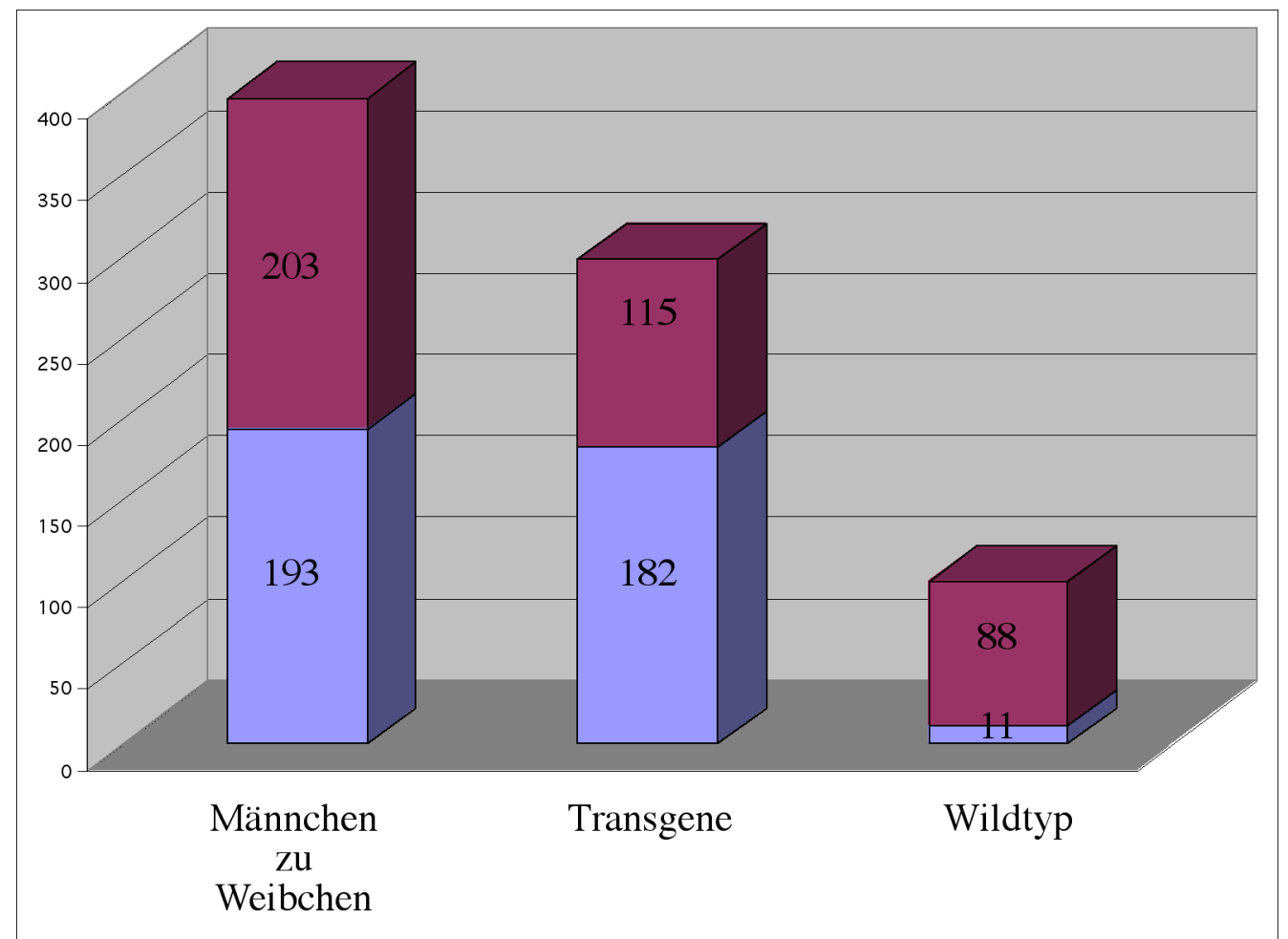

Abb. 21: Ergebnisse der Verpaarung von heterozygoten Irx2-Eltern.

Das Balkendiagramm gibt die Verhältnisse der entstehenden Genotypen in Verbindung zu ihrem Geschlecht an. Die rot markierten Balken entsprechen den Männchen, die blauen den Weibchen. Die erste Säule gibt die Anzahl der untersuchten Männchen zu Weibchen an. Die zweite Säule weist das Ergebnis der 
Transgenen aus und die dritte das der Wildtypen. Die Y-Achse gibt die Anzahl der untersuchten Nachkommen an.

Das ausgeprägte Geschlecht kann durch Mutationen verändert werden und sogar konträr zum Genotyp sein. Das Geschlecht der Nachkommen wurde visuell anhand der sekundären Geschlechtsmerkmale bestimmt. Um die Möglichkeit zu analysieren, ob transgene Tiere bevorzugt weibliche Geschlechtsmerkmale ausbilden und daher die zu große Anzahl an weiblichen Transgenen begründen, wurden die inneren Geschlechtsorgane nach morphologischen Veränderungen untersucht. In den untersuchten Tieren konnten keine morphologisch sichtbaren Veränderungen in der Geschlechtsentwicklung festgestellt werden. Desweitern wurde mittels der PCR-Technik das Vorhandensein des Y-typischen SRY-Gens ermittelt. Genotyp und Phänotyp der Tiere in der Kolonie waren übereinstimmend. Ein Geschlechtswechsel in den transgenen Tieren liegt nicht vor (Daten nicht gezeigt).

Die Verpaarung von heterozygoten Tieren ermöglicht die Bildung von Nachkommen, die die Mutation auf beiden Allelen tragen (= sog. Nullmutante). Sie haben die Funktion des Irx2-Gens vollständig verloren. Bis zum Alter von E18.5 konnten homozygote Tiere nachgewiesen werden, jedoch nicht nach der Geburt. Folglich sterben die homozygoten Tiere mit Irx2-Deletion bei der Geburt.

Die männlichen Chimären der Mauslinie Irx2-184 wurden mit Weibchen der Wildtyp-Stämme 129Sv und NMRI verpaart. Erwartet wurde eine Verteilung von Wildtypmäusen (WT) zu heterozygoten Tieren (+/-) nach der Mendelschen Regel von 1 : 1. Die Analyse zeigte, dass nur +/- Weibchen geboren wurden, nicht aber +/Männchen. Die Verpaarung von heterozygoten Weibchen der F1-Generation mit Wildtyp-Männchen ergab eine Verteilung an heterozygoten Tieren entsprechend den Mendelschen Regeln. Wurden Männchen der F2-Generation weiterverpaart, so wiederholte sich das Ergebnis der F1-Generation, es wurden keine +/- Männchen geboren. Wurden Weibchen der F2-Generation weiterverpaart, so ergab sich eine Verteilung entsprechend den Mendelschen Regeln. Der Phänotyp variiert, je nachdem, ob die Mutation durch die väterliche oder die mütterliche Keimbahn an die Nachkommen weitergegeben wird. Dieses Phänomen der Ungleichheit eines Allels hinsichtlich der elterlichen Abstammung ist ein Anzeichen für genomische Prägung. 


\section{II.2.6.2 MORPHOLOGISCHE UNTERSUCHUNG}

Das mit dem Reporterkonstrukt eingebrachte LacZ-Gen wurde über den IroquoisLokus kontrolliert, daher wurde es räumlich und zeitlich spezifisch wie das Irx2-Gen reguliert. Seine Aktivität ließ sich über eine Farbreaktion nachweisen. Durch die Expressionsanalysen konnte bestimmt werden, das die frühe Irx2-Expression, von E8,5 bis E12,0, von einem eigenen Enhancer gesteuert wurde. Dieser Enhancer mußte in dem deletierten Bereich liegen, der 70bp vor dem ersten ATG begann und drei Introns umfaßte. Dabei wurde dieser Enhancer mit entfernt. Die Genexpressionsbereiche von Irx2 konnten in den Entwicklungsstadien von E8,5 bis E12,0 daher nicht mittes LacZFärbung dargestellt werden, wohingegen die Aktitvität des LacZ-Gens von E12,5 an positiv von den verbleibenden Kontrollregionen von Irx2 beeinflußt wurde. Morphologisch waren keine Störungen im Aufbau der Embryonen zu erkennen (Abb. 22). Die Hirnblasen, das Blutgefäßsystem, die Extremitäten und auch die Rumpflänge entsprach den erwarteten Werten. 


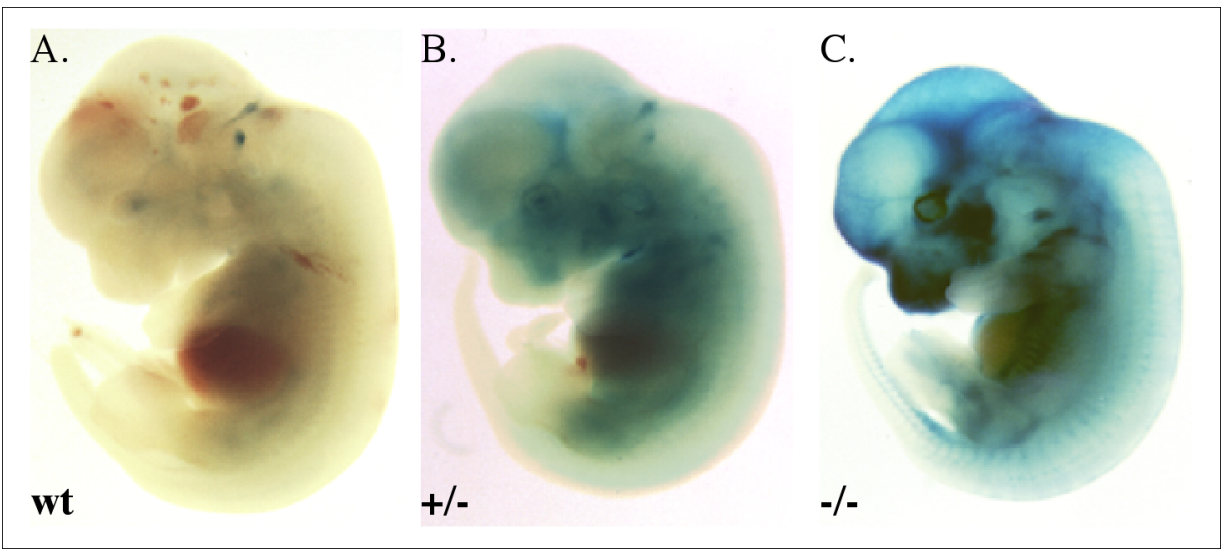

Abb. 22: LacZ- Färbung von Embryonen im Alter von E12.5.

Embryo $A$ ist genetisch Wildtyp und zeigt keine LacZ-Färbung. Die beiden blauen Punkte im Hinterhirn entstehen bei jeder Färbung und sind als unspezifische Hintergrundreaktionen zu betrachten. Embryo B enthält eine Kopie des Transgens und Embryo C zwei Kopien, dementsprechend ist das Signal höher. Der morphologische Aufbau der Embryonen ist nicht gestört und es sind keine Wachstumsdefizite zu erkennen.

Histologische Schnitte von Embryonen verschiedenen Alters wurden angefertigt und untersucht. Es konnte keine Abweichung in der Morphologie entdeckt werden. Die folgende Abbildung vergleicht Schnitte eines Wildtyp-Embryos und eines homozygoten Tieres im Alter von E12,5. Auch sie sind ein Beispiel dafür, dass keine Unterschiede im generellen Aufbau der Organe entstanden sind. Folgende Abbildung zeigt, dass der Aufbau wichtiger Organe wie auch einiger Sinnesorgane nicht gestört ist (Abb. 23). 


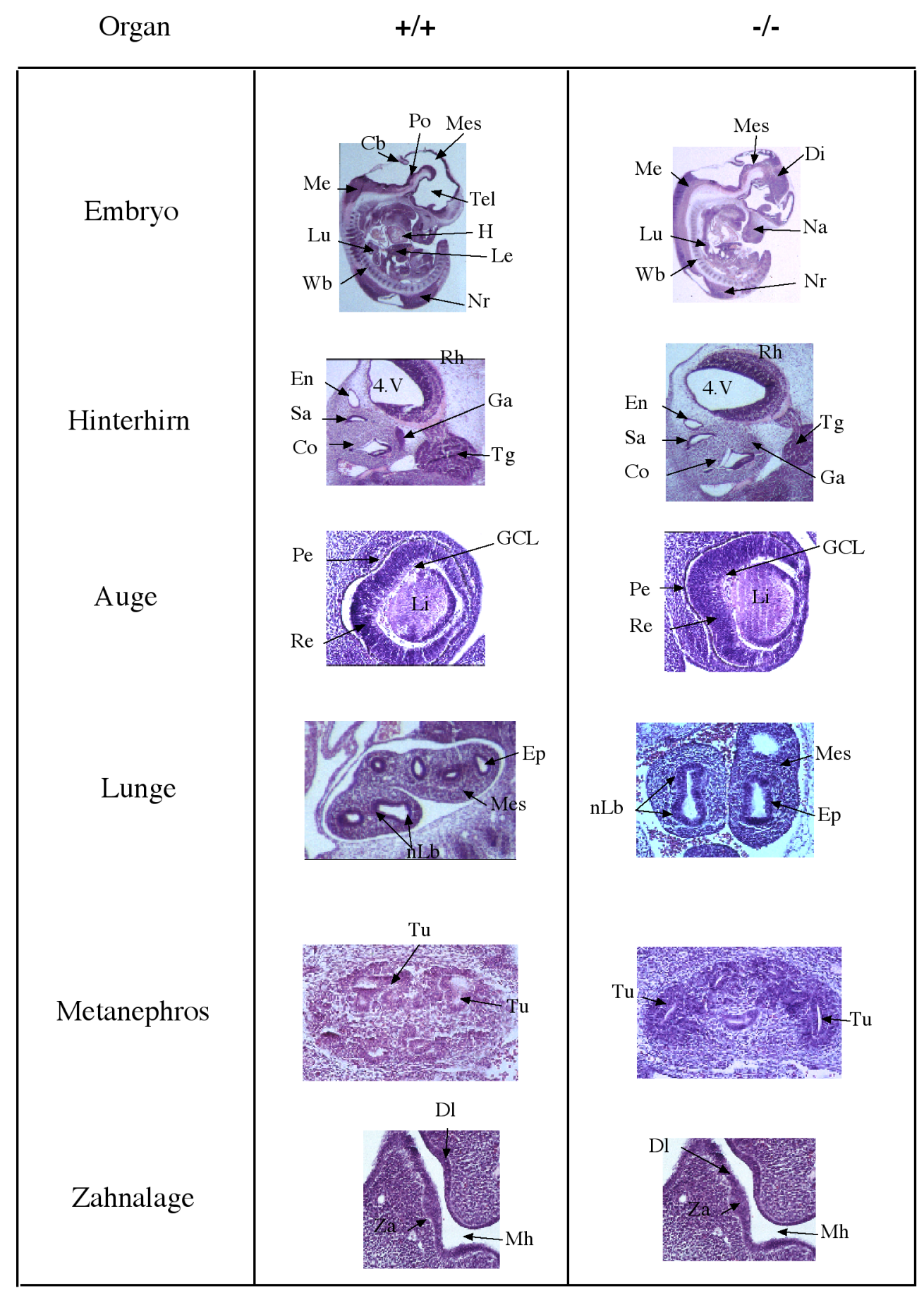

Abb. 23: Histologischer Vergleich ausgewählter Organe von Irx2-Mutanten und Wildtyp-Tieren im Alter E12,5.

gesamter Embryo: Die Körper sind vollständig dreidimensional aufgebaut. Cb: Cerebellum, H: Herz, Le: Leber, Lu: Lunge, Me: Medulla, Na: Nase, Nr: Neuralrohr, Po: Pons, Tel: Telencephalon, Wk: Wirbelkörperanlage

Hinterhirn: Die Orientierung des Hinterhirns mit den wichtigen Nervenverbindungen zum Trigeminus sind aufgebaut. Die Anlagen des Innenohrs liegen vor. Co: Cochlea, 
En: Endolympfsack, Ga: Ganglion des VIII. Hirnnervens, Rh: Rhombische Lippe, Sa: Sacculus, Tg: Trigeminalganglion.

Auge: Es bildet sich zum richtigen Zeitpunkt die Ganglionzellschicht. GCL: Ganglionzellschicht, Pe: Pigmentepithel, Re: Retina

Lunge: Neue Lungenbläschen (nLB) entstehen mit einer klaren Unterteilung in Epithel (Ep) und Mesenchym (Mes).

Metanephros: In sich formenden Metanephros entstehen die typischen Gänge (Tu).

Zahnanlage: Die Verdickung der Dentallamina (DI) hat in der Mundhöhle (Mh) mit der Bildung der Zahnanlage ( $\mathrm{Za}$ ) begonnen.

Die Untersuchung an histologischen Schnitten zu verschiedenen Zeitpunkten ergab keine Hinweise auf den Grund der embryonalen Lethalität der homozygoten Tiere. Die Funktionalität von Organen und des Zentralnervensystems läßt sich morphologisch nur bedingt bewerten.

Der perinatale Tod deutet auf das Versagen von lebenswichtigen Organen wie zum Beispiel des Atemsystems hin.

\section{II.2.6.3 HUMANE LOKALISATION VON IRX2 UND DAS CRI-DU-CHAT SYNDROM}

Um Hinweise auf die Verbindung der Iroquois-Gene zu einem möglichen humanen Syndromen zu analysieren, wurde mittels FISH in situ-Hybridisierung die Lokalisation von Irx2 im Genom des Menschen untersucht. Irx2 liegt auf dem kurzen Arm von Chromosom 5, an die Position 5p15.3. Die tandemartige Organisation der Iroquois-Gene ist auch im Menschen konserviert. So sind die humanen Orthologe (hIrxl, hIrx2 und hIrx4) auf Chromosom 5 (5p15) ebenfalls geklustert. Neben der Nukleotidsequenz ist auch die chromosomale Organisation konserviert. 
Lokalisation des hIrx2 Gens
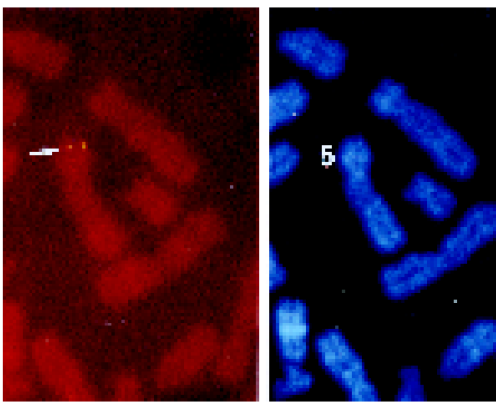

Abb. 24: Chromosomale Lokalisation des humanen Iroquois-Gens hIRX2.

Mittels FISH-in-situ-Analyse mit einer spezifischen Sonde für das humane IRX2-Gen wurde die chromosomale Lokalisation ermittelt auf dem Chromosom 5. Die Fluoreszenzsignale sind mit einem Pfeil hervorgehoben.

Die chromosomale Position 5p15 ist verbunden mit dem menschlichen KatzenschreiSyndrom (cri-du-chat, CDC). Liegt eine heterozygote Deletion in diesem Bereich vor, so entwickelt sich je nach Größe und Position der Veränderung ein unterschiedliches Krankheitsbild. Homozygote Merkmalsträger sind nicht bekannt. Beeinträchtigt sind bei den Patienten neben ihren geistigen Fähigkeiten, die Entwicklung des Kehlkopfes und die Funktionalität von Organen wie Herz, Lunge und Nieren. Die Lokalisation von Irx2 in der kritischen chromosomalen Region des Syndroms macht seine Beteiligung im CDC wahrscheinlich.

Für eine Irx2-Analyse in Bezug auf CDC stand nur eine DNA-Probe eines Patienten zur Verfügung. Sie wurde freundlicherweise von Prof. Dr. W. Engel vom Humangenetischen Institut in Göttingen zur Verfügung gestellt. Dabei wurde analysiert, ob der CDC-auslösende Bruchpunkt im Irx2-Gen liegt. Dieses ist mittels eines veränderten Restriktions-Bandenmuster, gefolgt von einer Hybridisierung mit spezifischen Sonden detektierbar. Das ist im Southern Blot nachweisbar, wenn der Bruchpunkt im Irx2-Gen liegt und damit die Abfolge der Sequenz verändert ist. Allerdings tragen viele Patienten große Deletionen, die eine Zuordnung zu einem speziellen Gen in der kritischen Region unmöglich machen. Die untersuchte DNA des Patienten zeigte eine große Deletion und erwies sich als ungeeignet (Daten nicht 
gezeigt). Aufgrund der chromosomalen Lokalisation ist Irx2 als Kandidatengen für die Auspägung der monochromatischen Stimme der Neugeborenen und der Verzögerung des Spracherlernens einzustufen.

\section{II.2.7 ENTWICKLUNG DER MEHRFACHEN SELEKTION IN ES-ZELLEN UND ERSTELLUNG DER DOPPELMUTANTE IRX1/IRX2.}

Die Gene der Iroquois-Genfamilie sind durch Duplikation jeder aus dem anderen hervorgegangen. Dabei kommt es meist zur Entwicklung neuer, spezifischer Funktionen. Es können aber auch Bereiche mit überlappenden Funktionen entstehen. Um mögliche redundante Phänotypen zwischen Irx 1 und Irx2 auszumachen, wurde der Doppel-Knockout von Irx 1 und Irx 2 durchgeführt. Es wurden diese beiden Gene ausgesucht, da ihre Orte der Genaktivität in der Lunge zum Beispiel vollständig überlappen. Theoretisch wäre es auch interessant gewesen, die paralogen gene Irx2 und $\operatorname{Irx} 5$ in einer Doppelmutante zu untersuchen., jedoch existierte zum Zeitpunkt der Erstellung der Doppelmutante von Irx5 erst ein cDNA -Fragment.

Für die Generierung der Doppelmutante wurden die bereits Irx2-transgenen ESZellen genutzt (Abb. 25). Sie wurden ein zweites Mal elektroporiert mit einem Rekombinationskonstrukt, indem die Homeodomäne von Irxl entfernt wurde. Die Deletionskassette für den Doppel-Knock-out ersetzt den Bereich der Irx 1 Homeobox durch das Puromycin-Gen ( $p K O$-puro; Stratagene). Wichtig ist die Verwendung eines zweiten selektiven Markers. Die Irx2-transgene Zellen sind mittels Neomycin auf die Integration getestet worden. Um die Integration des zweiten Transgens zu kontrollieren, wird das Puromycin-Gen als positiver Selektionsmarker eingesetzt, da ein Vorteil von Puromycin ist, dass es sehr effizient wirkt und die Selektion in weniger als fünf Tagen beendet werden kann. Weiterhin wurde bei dieser Kassette auf der 5'-Seite außerhalb des homologen Bereiches die HSV-Thymidin-Kinase (Tk) als negativer Selektionsmarker eingebaut. Dieser negative Selektionsmarker diente dazu, möglichst viele falsch integrierte Stammzellen zu selektieren und auszuschließen. Bei der nicht homologen Rekombination wird auch das Tk-Gen integriert und dementsprechend das Protein gebildet. Dieses ist allerdings für die Zelle toxisch. Bei homologer Integration des Rekombinationskonstrukts wird hingegen das $T k$-Gen abgeschnitten und intrazellular 
abgebaut. Als Basis der Klonierung für das Irx2-Konstrukt dient der Vektor pKO-\#1908 (Stratagene).

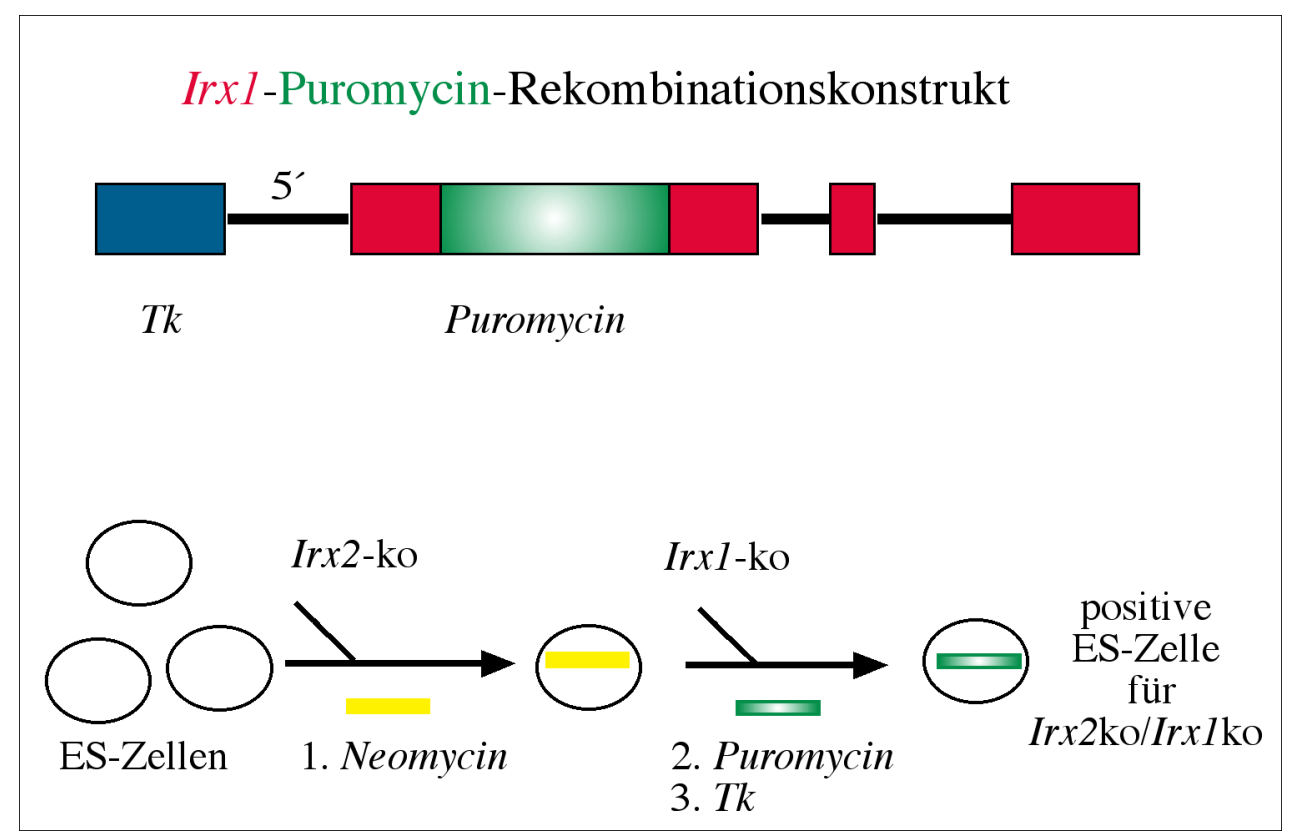

Abb. 25: Skizze über die Strategie der Erstellung des Irx1/Irx2- Doppel-Knock-out.

Die Deletionskassette für den Doppel-Knock-out ersetzt den Bereich der Irx1 Homeobox durch das Puromycin-Gen. Der Ablauf des Experimentes sieht vor, dass ES-Zellen, die bereits das Irx2-Ko-Konstrukt tragen und damit Neomycin resistent sind in einer weitern Elektroporation mit dem Irx2-Ko-Konstrukt transfiziert werden. Dadurch ist die dreifache Selektion auf Neomycin, Puromycin und Tk möglich.

Die Qualität der ES-Zellen hinsichtlich einer Keimbahntransmission nimmt mit zunehmender Anzahl der Passagen ab. In diesem experimentellen Ansatz mußten die ES-Zellen drei verschiedene Selektionen mit der entsprechenden Anzahl an Passagen durchlaufen und überleben. Es wurden mehrere Klone identifiziert, die beide Rekombinationskassetten an homologer Stelle enthalten. Für die Bildung des DoppelKnock-out ist es essentiell, dass beide Kassetten auf demselben Chromosom intergriert werden, da sie ansonsten bei der Verpaarung zur F1-Generation unterschiedlich segregiert werden. Daher wurde eine FISH- in-situ Analyse durchgeführt, um die tatsächliche chromosomale Lokalisation beider Rekombinationskonstrukte festzustellen. Vier ES-Zellklone wurden aggregiert, von denen einer in die Keimbahn gelangte.

Dieses Ergebnis zeigt, dass es möglich ist, die ES-Zellen einer dreifachen Selektion mit der entsprechenden Anzahl an Passagen auszusetzten und trotzdem verlieren sie 
nicht ihr Potential, Keimbahnzellen zu bilden, nicht verloren. Die Analyse der Doppelmutanten wurde frühzeitig beendet, da der Phänotyp des singulären Irx2-Knockouts eine frühe embryonale Lethalität zur Folge hat. Die Embryonen zeigen eine gestörte Gastrulation und sterben um E6.5 ab (Zülch, 2001). Eine überlappende Funktion beider Gene kann es zu diesem Zeitpunkt nicht geben, da Irx2 erst ab E8,5 aktiv ist. Die Erstellung des Doppelknock-out war eine Kollaboration zu gleichen Teilen mit Armin Zülch.

\section{II.3 EXPRESSIONSANALYSE DES IRX2-GENS}

Das Wissen über einen räumlichen und zeitlichen Expressionsverlauf eines Gens gibt wesentliche Anhaltspunkte zu dessen Funktion. Dazu wurde die Irx2-Genaktivität vom embryonalen Alter E8,5 bis zur Geburt untersucht. Neben der Analyse der regional spezifischen Expressionsdomänen wurden zusätzlich einzelne Organe untersucht. Zu der Analyse verschiedener Entwicklungsstadien der Maus wurden Embryonen bis zu einem Alter von E11,5 sowie freipräparierte Organe mit der nicht radioaktiven Gesamtköper (whole-mount-) in-situ-Hybridisierung und ältere Stadien der mausentwicklung auf Paraffinschnitten mittels radioaktiver in-situ-Hybridisierung verwendet.

\section{II.3.1 ÜBERSICHT ÜBER DIE IRX2-EXPRESSION}

Irx2 zeigt eine spezifische, aber auch sehr dynamische Genaktivität während der embryonalen Entwicklung der Maus (Abb. 26). Die Expressionsbereiche lassen sich sowohl zeitlich als auch räumlich unterteilen. Der folgende Abschnitt faßt die wichtigsten Schritte der dynamischen Expression zusammen, um dann auf einzelne regionale Schwerpunkte wie den Schlunddarm und die Lunge einzugehen.

Die frühe Genaktivität von Irx2 von E8,5 bis E12,5 zeigt ein regionalisierendes Muster, wohingegen die späteren Expressionsdomänen an Orten aktiver Zelldifferenzierung lagen (Abb. 26). Generell ist das Irx2-Transkript in Abkömmlingen 
aller drei Keimblätter vorhanden. Die Expression liegt in ektodermalen Derivaten (ZNS, Haut und Zahnanlagen), in mesodermalen (undifferenziertes Mesenchym und Knorpel) und in endodermalen (Lungenepithel) Komponenten vor.
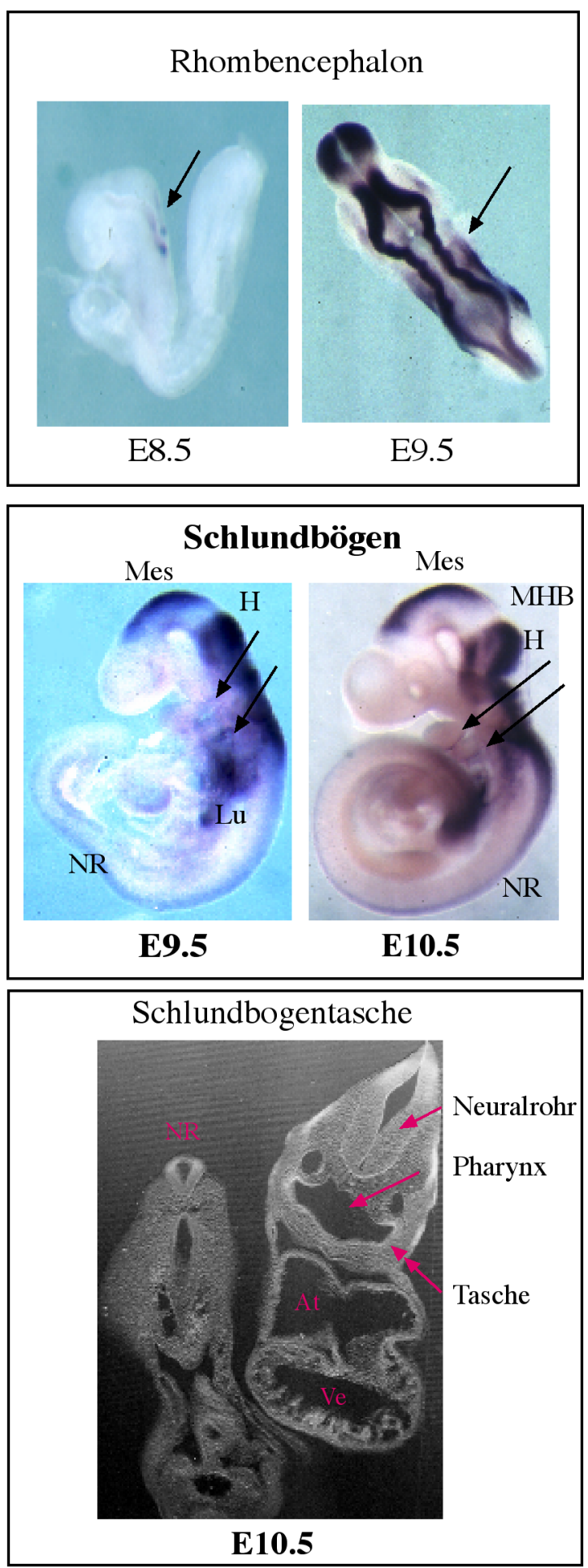

Abb. 26: Darstellung der Irx2-Aktivität in den embryonalen Stadien E8,5 bis E10,5. 
oben: Der Transkriptionsstart des Irx2 Gens liegt zeitlich bei E8,5 und räumlich in Rhombomer vier (Pfeil). Die Expression breitet sich über das ganze Rhombencephalon aus (Pfeil). Ebenfalls beginnt die Aktivität im Mesencephalon bei Tag E9,5.

mitte: Die Expression manifestiert sich im Mittel- und im Hinterhirn. Weiter Orte der Genexpression sind die Lunge (Lu), das Neuralrohr (NR) und die ersten beiden Schlundbögen (Pfeile).

unten: Die frontale Schnittebene ermöglicht den genauen Einblick in die Irx2Expression der Schlundbogentasche, sowohl im Ektoderm als auch im Endoderm des Pharynx.

Die Irx2-Expression beginnt im Embryonalstadium E8,5 und liegt dabei im Hinterhirn (Abb. 26). Die Irx2-Genaktivität ist dort in Rhombomere vier zu finden und breitet sich bis E9.0 über alle Rhombomere aus. Es gibt eine funktionelle Verbindung zwischen dem Aufbau des Rhombencephalons, der Organisation der Hirnnerven und der Zuordnung von auswandernden Neuralleistenzellen bzw. mesodermalen Zellen in die Schlundbögen, ob auf der Höhe des vierten Rhombomers Neuralleistenzellen in den zweiten Schlundbogen entsandt werden. Desweiteren entspringen hier die Wurzeln der beiden Hirnnerven VII (Vestibucochlearer Nerv) und VIII (Glossopharyngealer Nerv).

Irx2 Genaktivität zeigt sich in der Schlundtasche zwischen dem ersten und dem zweiten Schlundbogen im embryonalen Stadium E9,5. An dieser Stelle liegen Ektoderm und Entoderm direkt aufeinander. Diese Furche wird den äußeren Gehörgang und die Paukenhöhle des Mittelohrs bilden, beides sind Orte von Irx2 Expression, besonders im Alter E18,5 (Daten nicht gezeigt). In den Schlundbögen sind jeweils einzelne Zellen Irx2 positiv. Ebenfalls im Alter von E9,5 entsteht im Mesencephalon (Mittelhirn) die zweite zentralnervöse Expressionsdomäne. Das Organisationszentrum im Hinterhirn, die Mittelhirn-Hinterhirn-Grenze (MHB) ist scharf ausgespart.

Die Irx2-Genexpression zeigt sich in den folgenden Entwicklungsstadien im Dien-, im Mesen-, im Meten- und im Myelencephalon, nur der proximalste Teil, das Telencephalon bleibt expressionsfrei. 


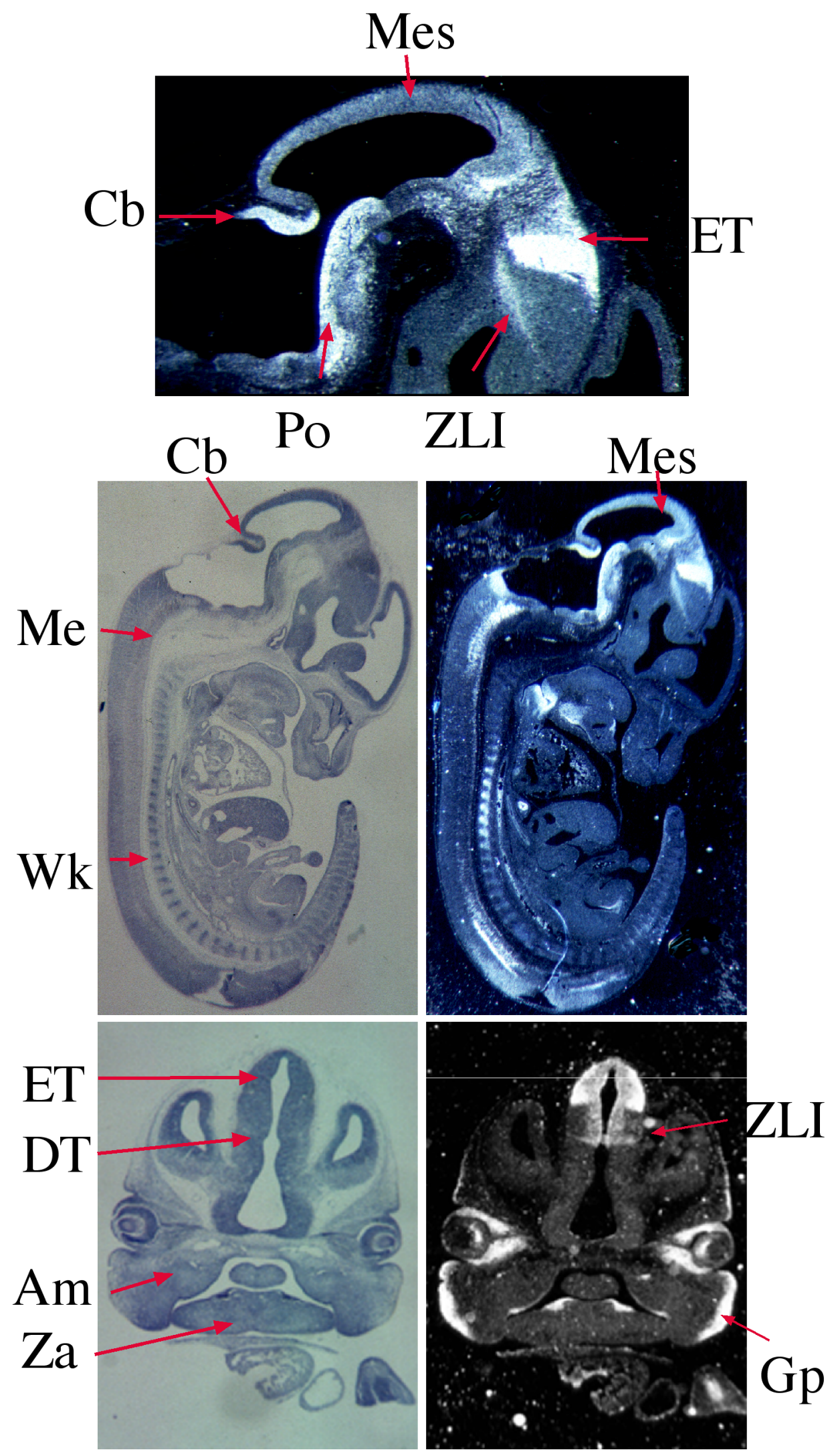

Abb. 27: Zentralnervöse Expression von Irx2 im embryonalen Stadium E12,5, dargestellt auf Gewebeschnitten mittels radioaktiver Markierung der Genaktivität. 
oben: Vergrößerung der sagitalen Ansicht des Gehirns. Die Expression liegt im Epithalamus (ET), der Zona limitans (ZLI), im Mesencephalon (Mes), in der Kleinhirnanlage $(\mathrm{Cb})$ und in der Brücke $(\mathrm{Po})$ vor.

mitte: Sagitale Ganzkörperansicht in Hell- und Dunkelfeld. Im Dunkelfeld ist die Irx2Aktivität durch die weiße Farbmarkierung zu erkennen. Neben den eben beschriebenen Domänen liegt Irx2 Aktivität in der Medulla (Me), dem Thyroidknorpel (Tk), der Lunge (Lu) und den Wirbelkörpern (Wk) vor.

unten: Frontale Kopfansicht in Hell- und Dunkelfeld. Diese Schnittrichtung eröffnet den Blick auf die hochspezifische Expression im Diencephalon. Im Epithalamus (ET) liegt Irx2 Aktivität sowohl im der Ventrikular- wie auch in der Mantelschicht vor. Im Dorsalen Thalamus (DT) ist Aktivität in der Ventrikularschicht zu finden. Weitere Expressionsdomänen sind die Zona limitans (ZLI), das Augenmesoderm (Am), die Retina, die Zahnanlagen (Za) und die epipharyngeale Plakode des Gesichts (Gp).

Die Expression an E12,5 im Diencephalon, das kranial an die Vierhügelplatte (Lamina tecti) grenzt, zeigt sich in der sagittalen Sicht im Epithalamus und in der Zona limitans intrathalamica, die dorsalen und ventralen Thalamus voneinander trennt und später zur Medulla lamina wird. Der Epithalamus, der dem Thalamus dorso-kaudal aufsitzt, entwickelt sich im Adultus zur Epiphyse (Zirbeldrüse). Die Zirbeldrüse enthält speziell differenzierte Neurone, die eine endokrine Funktion zeigen; sie produzieren das Hormon Melatonin, welches als Vermittler der zirkadianen Rhythmik agiert. In der frontalen Ansicht zeigt sich, dass die Ventrikularzone des dorsalen Thalamus eine zusätzliche Region von Irx2-Aktivität ist, die in der sagittalen Ansicht nicht sichtbar ist (Abb. 27). Der Thalamus setzt sich aus vielen Einzelkernen zusammen, die durch zahlreiche Assoziationsfasern eng miteinander verbunden sind. Allgemein kann gesagt werden, dass er das "Tor zur Großhirnrinde" ist, da nahezu alle sensiblen und sensorischen Bahnen im Thalamus kreuzen und von hier aus zur Großhirnrinde verschaltet werden, wobei zahlreiche Integrationsvorgänge und vermutlich sogar eine selektive Auslese der Sinnesinformationen stattfinden.

Die Brücke (Pons), die dem Cerebellum gegenüberliegt und vom Isthmus rhombencephalic bis zur Medulla oblongata reicht, besteht aus der dem Ventrikel zugewandten dorsalen Kernschicht (Pars posteriores pontis) und der ventral liegende Faserschicht (Pars anteriores pontis). Die Brücke und die Medulla oblongata bilden den rautenförmigen Boden und das Cerebellum das Dach des vierten Ventrikels. Die Irx2Genexpression liegt sowohl in der Ventrikularzone, die die pontinen Kerne enthält, als 
auch im Bereich der Nervenfasern vor, die zur pontinen Formatio reticularis (FR) gehören. Diese durchziehen das ganze Hirnstammtegmentum bis ins Rückenmark hinab und sind funktionell für die Verschaltung von Reflexen zuständig. Im Boden der Rautengrube liegen das Brech- und Atemzentrum, im medullaren Bereich das Kreislaufzentrum.

Im Neuralrohr ist Irx2 entlang der anterior-posterioren Achse exprimiert und zwar dabei sowohl im dorsalen Rückenmark in der Schicht der proliferierenden Nervenzellen als auch in den Interneuronen in der ventralen Hälfte. Desweiteren liegt Irx2-Aktivität in den Ganglienzellen der Retina (Abb. 27) und im Ganglion des VIII. Hirnnervs in den Stadien E12,5 bis 18,5 vor (Abb. 28).

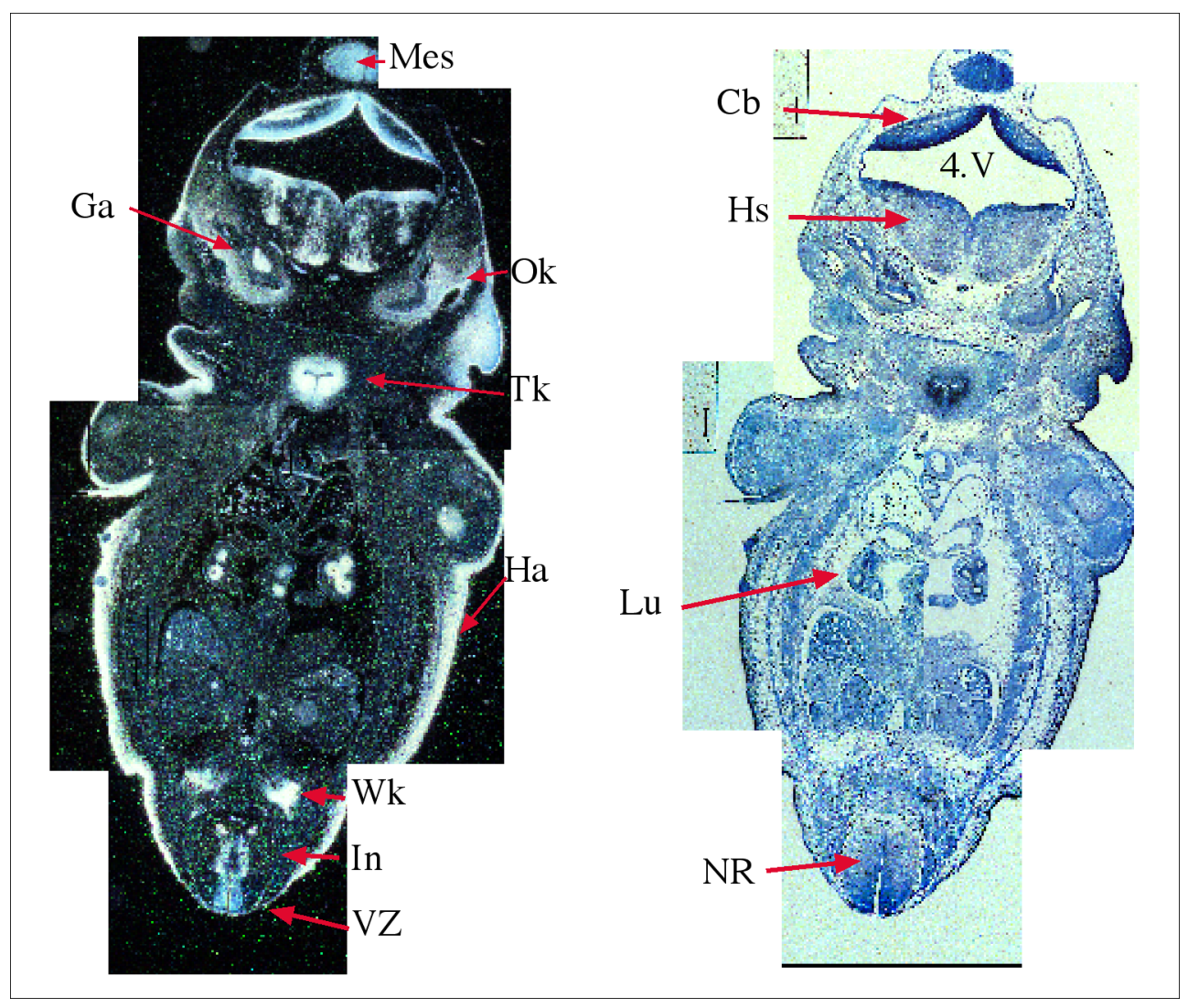

Abb. 28: Expression des Irx2-Gens im Stadium E12,5 (frontaler Schnitt).

Die Irx2-Expression zeigt sich spezifisch in den branchial-motorischen Säulen, der Formatio reticularis, im Hirnstamm (Hs)und in der Cerbellaranlage (Cb). Im Rückenmark ist Irx2 in den Interneuronen (In) und der dorsalen Venrikularschicht (VZ) aktiv. Weiter prominente Orte der Genaktivität sind das Mesencephalon (Mes), die Haut ( $\mathrm{Ha}$ ), die Lunge (Lu), die Wirbelkörper (Wk), die Ohrkapsel (Ok), das Ganglion (Ga) des VIII. Hirnnervens und die Anlage der Thyroidknorpel (Tk). 
Die Haut des Embryos, insbesondere das Gesichtsektoderm der epipharyngealen Plakode, zeigt Irx2-Expresion (Abb. 28). Außerdem zeigt im Stadium E12,5 das Zahnleistenepithel im prospektiven Kiefer Irx2-Genaktivität zum Zeitpunkt der Entwicklung der Stratifizierung des ektodermalen Epithels der Mundbucht. Des weiteren liegt Irx2-Aktivität in Bereichen einiger mesenchymaler Knorpelvorstufen wie den Wirbelkörperanlagen, in der Anlage der Phalangen, in der Ohrkapsel und im Thyroidknorpel vor.

Mit zunehmendem Alter schwindet die breite Aktivität im Hirn und nach der Geburt bleibt sie auf einzelne Bereiche wie den Epithalamus, die superioren Colliculi, die äußere Rindenschicht des Cerebellums, den dorsalen Raphekern und einzelne Kerngebiete im Pons beschränkt (Becker, 1997).

\section{II.3.2 SPEZIEFIZIERUNG DER EXPRESSION VON IRX2 WÄHREND DER LARYNXENTWICKLUNG}

Im Embryo werden die Schlundbögen als transiente Grundelemente des Wirbeltierkörpers angelegt. Ihre ursprüngliche Funktion als Reusendarm oder als Kiemenapparat haben sie verloren. Sie stellen das Zellmaterial für die artspezifische Differenzierung des Viszeralskeletts und des Schlunddarms. Sie entwickeln sich zu Ober- und Unterkiefer, zum Mittelohr, zum Zungenbein und zu den Knorpeln des Kehlkopfes (Larynx). Die Zugehörigkeit von Zellen zu einem der Schlundbögen bestimmt ihr Entwicklungsschicksal. Schon bevor sie auswandern, ist Ihr Bestimmungsort festgelegt. 


\section{Irx2 Expression in der Entwicklung des Kehlkopfes}
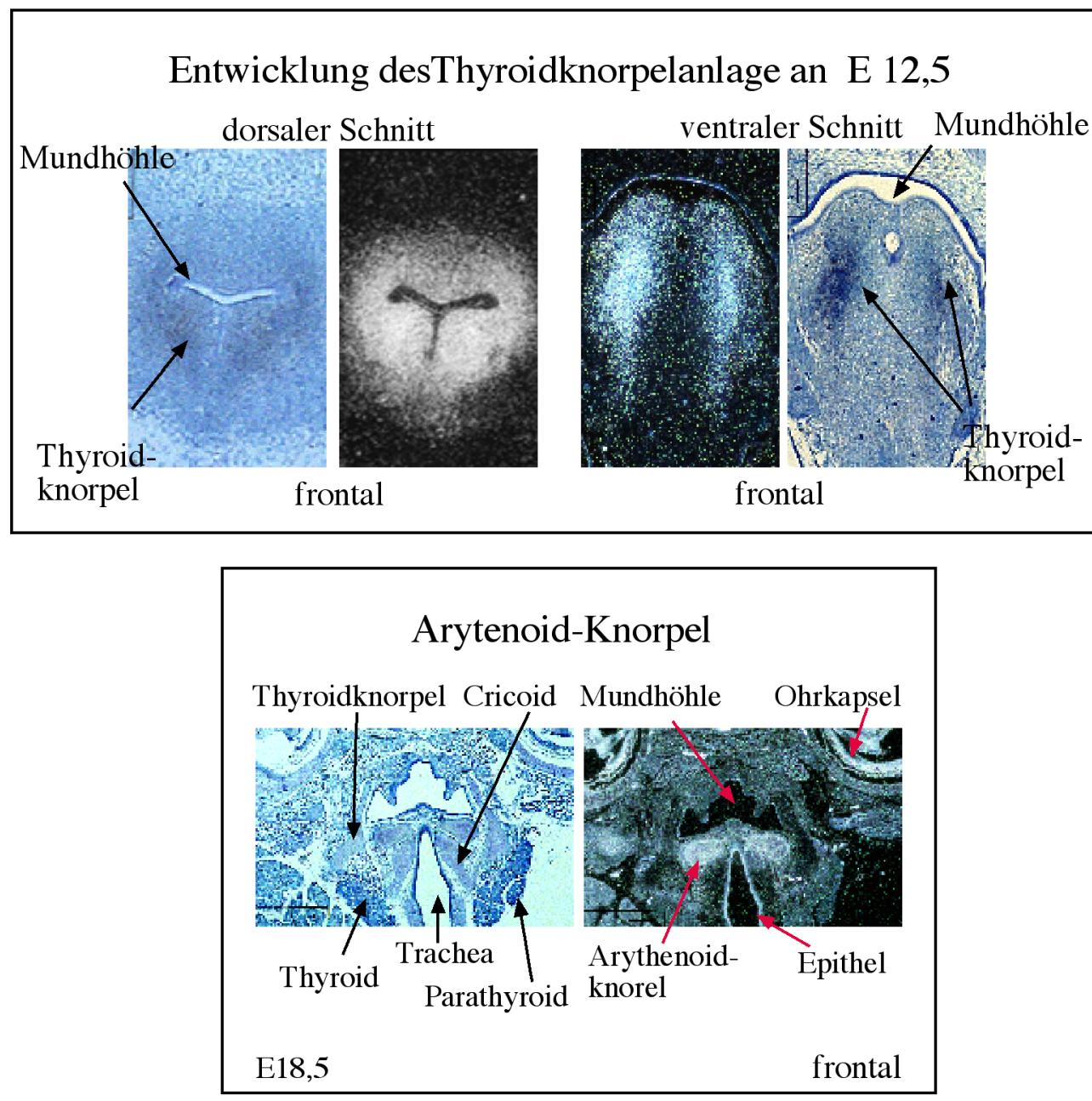

Abb. 29.: Expression von Irx2 während der Entwicklung des Kehlkopfes analysiert an frontalen Gewebeschnitten.

oben: Die undifferenzierte Knorpelanlage für den Kehlkopf zeigt in ihrer gesamten dorso-ventralen Ausdehnung Irx2-Aktivität an E12,5.

unten: Im embryonalen Stadium E18,5 sind die unterschiedlichen Kehlkopfknorpel zu unterscheiden. Irx2-Aktivität liegt spezifisch in den Arytenoidknorpeln und nicht im Schildknorpel oder dem Cricoidknorpel vor.

An E12,5 ist eine massive Expressionsdomäne exakt in den sich entwickelnden Knorpelanlagen des Larynx zu sehen (Abb. 29). Morphologisch unterscheidbar werden die einzelnen Bestandteile des Kehlkopfes nicht vor dem Stadium E14,5 (Abb. 29). Sie entwickeln sich aus Zellen der Schlundbögen vier und sechs. Zellen dieser Bögen entstammen dem lateralen Plattenmesoderm. Kurz vor der Geburt $(E 18,5)$ zeigt sich, 
dass der Kehlkopf aus dem großen Schildknorpel (Thyroidknorpel), dem Cricoid, dem Cuniculat-, dem Cuneiform- und den Arytenoidknorpeln besteht. Irx2-Expression ist ausschließlich in den Knorpeln der Arytenoid zu sehen. Die Arytenoidknorpel bedingen durch ihre Stellung die unterschiedliche Spannung der Stimmbänder und damit Tonlage und Modulation der Stimme.

\section{II.3.3 EXPRESSION VON IRX2 WÄHREND DER ORGANOGENESE AM BEISPIEL DER LUNGENENTWICKLUNG}

Irx2 und auch ein weiteres Mitglied der Iroquois-Genfamilie der Maus, Irx1, sind in spezifischen, nicht neuronalen Organen wie der Lunge aktiv (Becker et al., 2001). Während der frühen Säugerentwicklung bilden sich aus dem Endoderm eine Reihe von Organen wie Leber, Bauchspeicheldrüse und Lunge. Die Lungenknospen entstehen aus dem Vorderdarm der kaudalen Pharynxregion und bestehen aus epithelialen Endodermschichten, die von Mesenchym umgeben sind (Hogan and Yingling, 1998). Zwischen dem Glandularstadium und dem Kanalikularstadium der Lungenentwicklung wachsen die Lungenknospen aus, bilden dabei zuerst zwei Bronchi und später aus diesen beiden viele Bronchiolen, die sich in einem komplexen Muster verzweigen (Ten HaveOpbroek, 1991).

Die Expression von Irx2 beginnt bei E8,5 im anterioren Vorderdarm dorsal des Herzschlauchs. In dieser Phase entwickelt sich die laryngo-tracheale Grube, die sich mehr und mehr einstülpt und zum trachealen Diverticulum wird (Kaufmann and Bard, 1999). Es kommt zur Trennung von Luft- und Speiseweg. Die Abschnürung vom Schlunddarm wächst aus und bildet die Lungenanlage. Der Pharynx teilt sich posterior in die Speiseröhre (Oesophagus) und die Luftröhre (Trachea). Nach der Trennung entstehen aus dem vorderen Teil des Diverticulums die Luftröhre und aus dem distalen die Lungenbläschen. Irx2 markiert die Region der ersten Entstehungsschritte im Vorderdarm. Sobald die ersten Hauptbronchien gebildet sind, ist Irx2 ausschließlich im Epithel der sich bildenden Lungenbläschen aktiv. Keine Genexpression ist in den angrenzenden Strukturen, den Blättern des Brustfells (Pleura pulmonalis et parietalis), dem Ductus de Cuvieri, in den die vordere und die hintere Cardinalvene münden, und dem umliegenden Mesenchym zu verzeichnen. Mit zunehmender Verzweigung konzentriert sich die Hauptmenge des Transkripts auf die distalen Enden 
der Bläschen. Entstehen neue, so bedeckt Irx2 Expression die Trennungszone. Die Genaktivität läßt deutlich in der Phase der Entstehung der terminalen Bronchiolen nach und endet an Tag E14.5.

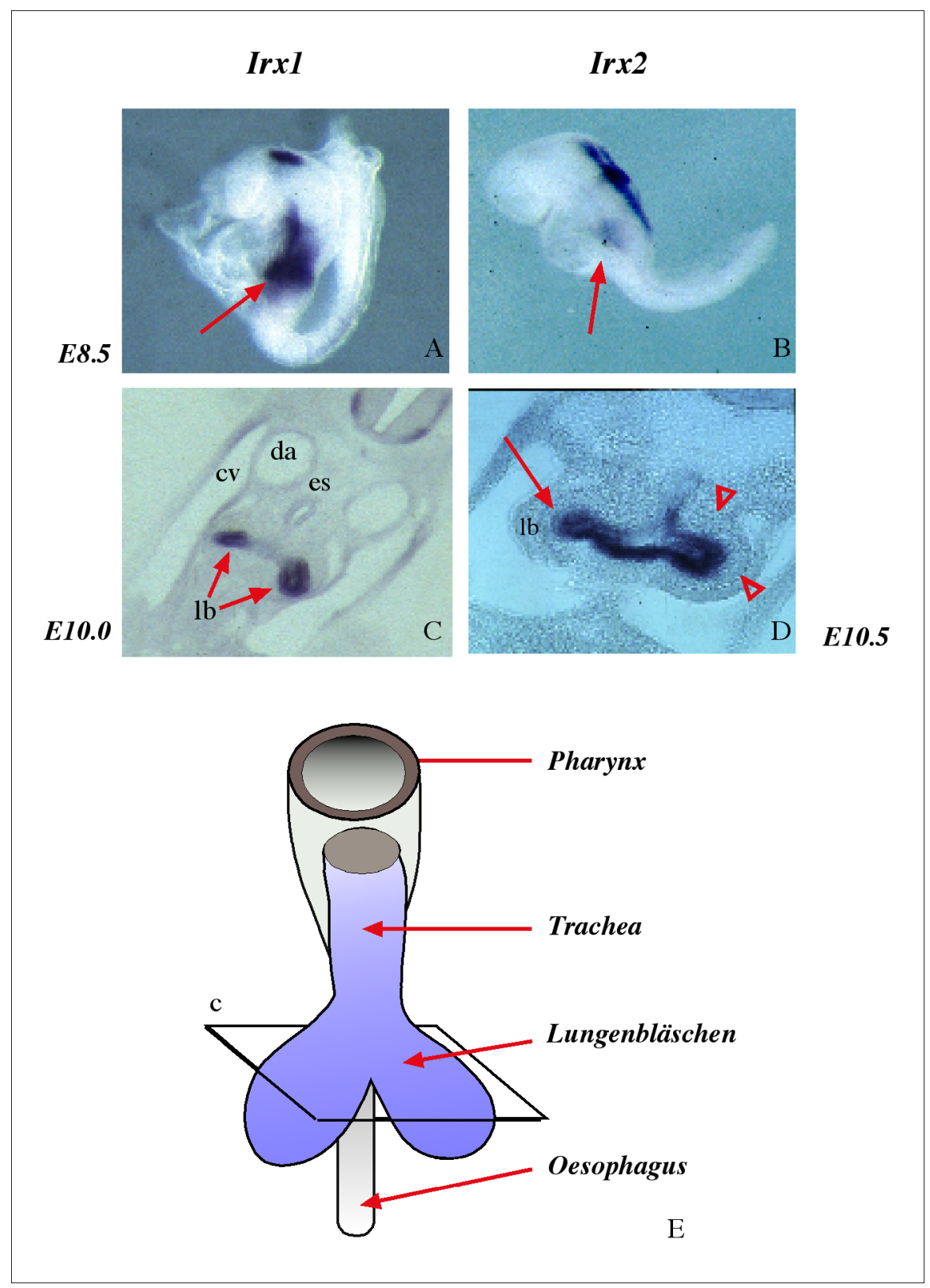

Abb. 30: Die Genaktivität von Irx2 und Irx1 markiert den Bereich der Entstehung der Lungenanlage.

Irx1 ist in einer breiten Domäne im Vorderdarm und im Mesencephalon aktiv (A). Die Lungenexpression (C) läßt sich auf transversalen Schnitten (E) dem Epithel der Lungenbläschen (lb) zuordnen. 
Irx2 ist spezifisch im Vorderdarm (Pfeil) und im Rhombencephalon aktiv (B). Die Lungenexpression (D) zeigt sich auf transversalen Schnitten im Epithel der Lungenbläschen (lb).

In (E) ist die Schnittebene und der Aufbau der Lungenanlage in diesem Stadium angegeben. cv: Cardinalvene, da: dorsale Aorta, es: Ösophagus, lb: Lungenbläschen.

Die Aktivitäten von Irx2 und Irxl liegen in überlappenden Bereichen und Strukturen vor, aber sie zeigten deutliche Unterschiede in der Intensität der Expression. Zudem ist die stets stärkere Expression von Irxl im Stadium E8,5 wesentlich breiter in der Vorderdarmregion ausgeprägt als Irx2. In diesem Stadium beginnt die Irx2-Expression im Vorderdarmbereich in der Region der laryngo-tracheale Falte. Irxl ist im Stadium E10,5 ausschließlich in der Epithelschicht der Lungenknospen, nicht aber in der mesenchymalen Schicht exprimiert. Während der nächsten Entwicklungsphase, dem Kanalikularstadium, bleibt Irxl weiterhin epithelial in den sich entwickelnden Bronchii exprimiert. Im Stadium E12,5 und E13,5 konzentrieten sich die Irx1-Transkripte vorrangig auf den distalen Bereich der sich formenden Lungen. Einen Tag später ist die Expression auf die Randbereiche der Lungen beschränkt. Die Irxl-Aktivität stoppt mit dem Beginn der Alveolarphase. 


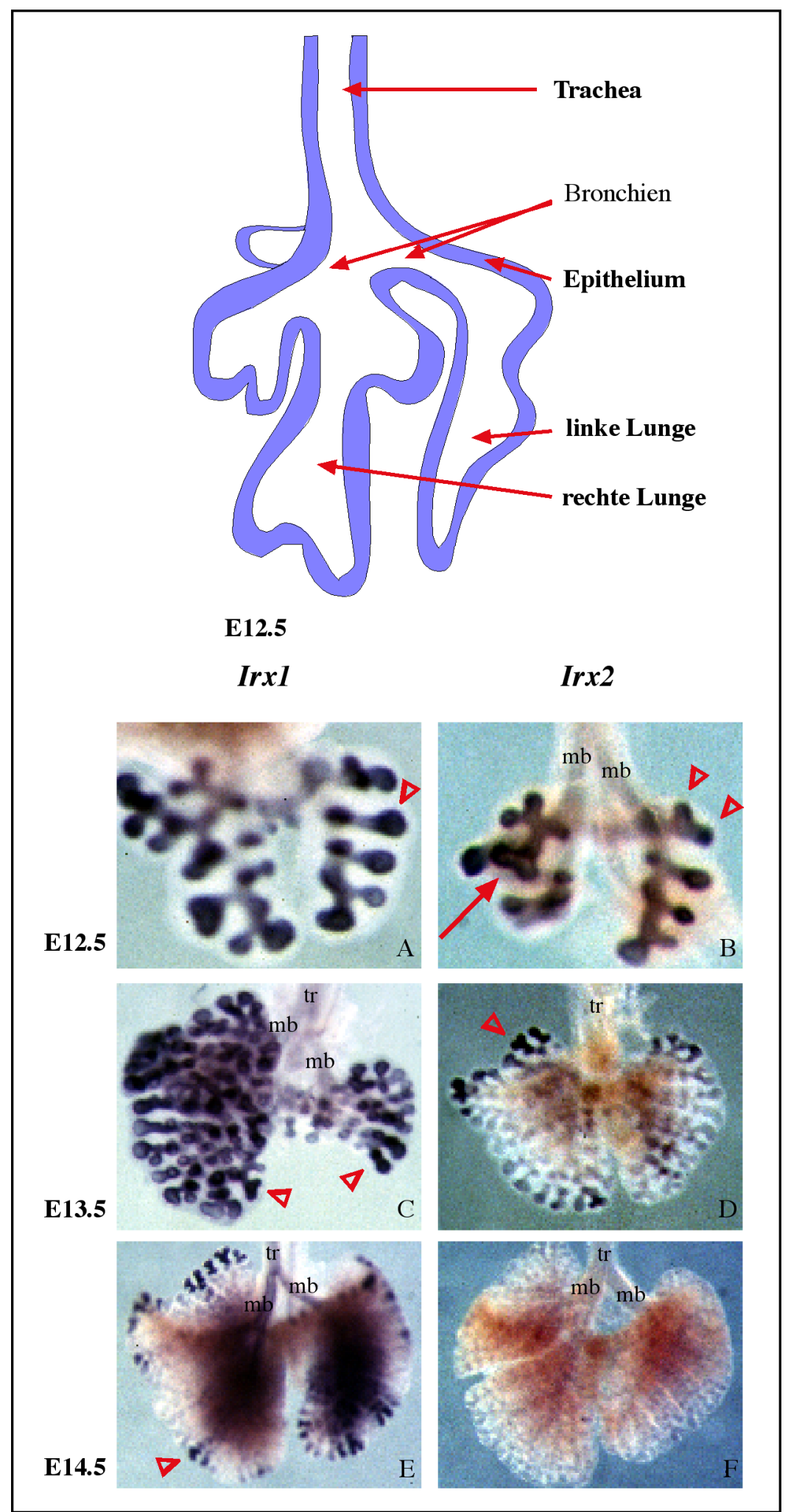

Abb. 31: Spezifische Expression von Irx1 und Irx2 während der Phasen des Lungendifferenzierung.

oben: Skizze des Lungenaufbaus im Stadium E12,5 mit Angabe der Position der fünf Lungenlappen. 
A; C, G: Irx1-Aktivität ist sichtbar in den sich ständig verzwiegenden Lungenbläschen der angegebenen Stadien. Weder in den Hauptbronchien $(\mathrm{mb})$ noch in der Luftröhre (tr) ist das Gen aktiv.

B, D, F: Irx2-Aktivität zeigt sich in den Lungebläschen und markiert das Epithel der neuentstehenden Bläschen. Das Maximum der Aktivität liegt bei E12, 5 und sie kling bis zum Stadium E14,5 ab.

Die Morphogenese der verzweigten Lungenanlage wird gesteuert durch Interaktionen von Faktoren in Epithel und Mesenchym (Spooner et al., 1994). Die Suche nach möglichen Kandidatengenen für die regulative Interaktion mit den Iroquois-Genen in der Lungenentwicklung erfolgt mit Hilfe der Daten aus der Analyse von $D$. melanogaster. Die Iroquois-Gene in der Fliege - araucan, caupolitan und mirror regulieren den achaete-scute Komplex (Gómez-Skarmeta et al., 1996). Ein verwandtes Gen des achaete-scute Komplexes in der Maus ist das Gen Mash1 (Guillemot et al., 1993). Die Gene des Iroquois-Komplexes in der Fliege werden ihrerseits von cubitus interruptus (ci) kontrolliert. Auch für dieses Gen sind verwandte Gene in der Maus entdeckt worden: Gli1, Gli2 und Gli3 (Grindley et al., 1997). Die angesprochenen Faktoren der Regulationskaskade aus Drosophila wurden auf ihre ortsspezifischen Aktivitäten in der Lungenentwicklung getestet. 


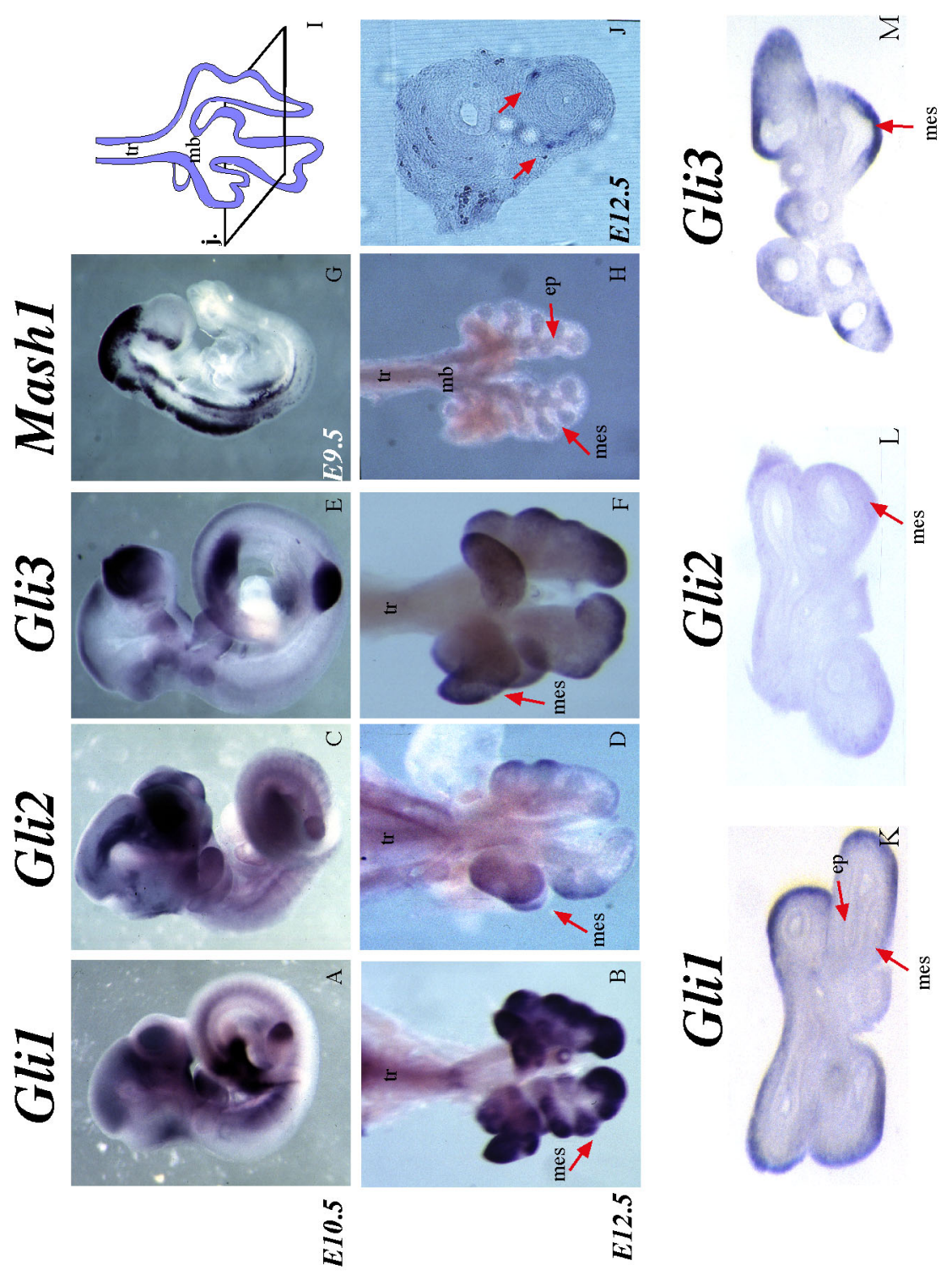

Abb. 32: Expression der drei Gli-Gene und Mash1 in der Lungenentwicklung der Maus.

A, C, E, G: Übersichtsexpression der jeweiligen Gene im Alter E10.5

I: Skizzierter Lungenaufbau mit eingezeichneter Schnittebene des Bildes J.

B, D, F, H: Darstellung der Genexpressionen und Lungenanlagen im Alter von E12.5.

J: Transverse Schnitte durch die Lunge mit Mash1-Genexpression.

K, L, M: Transverse Schnitte, die deutlich mesenchymale Expressionen zeigen. 
Die Gli-Gene sind nicht wie $\operatorname{Irx} 2$ und $\operatorname{Irx} 1$ im Epithel der Lungenbläschen aktiv, sondern im Mesenchym. Die Expression von Glil ist gleichmäßig auf das Randmesenchym verteilt. Das Gli3-Transkript hingegen konzentriert sich auf die Mesenchymbereiche rund um neuentstehende Bläschen. Gli2 folgt der Expression von Gli3, ist aber wesentlich schwächer. Entsprechend der Expressionsdomänen und der Erkenntnisse aus der genetischen Analyse in der Fruchtfliege, sind die Gli-Gene hervorragende Kandidaten für regulative Interaktionen, die das Verzweigungsmuster und die Differenzierung der embryonalen Lunge steuern. Bekannt ist aus Mutantenanalysen, dass in Gli2-Mausmutanten eine Reihe von Skelettdefekten und abnormale Lungen entstehen (Mo et al., 1997)(Motoyama et al., 1998).

Die inhaltliche Grundlage zur Auswahl des Mash1-Gens kommt ebenfalls aus der Analyse der Fruchtfliege. Bei den Genprodukten des Iroquois-Komplexes in Drosophila handelt es sich um Homeobox-Transkriptionsfaktoren, die die bisher einzigen bekannten positiven und direkten Regulatoren des Achaete-Scute-Komplex (AS-K) sind (GómezSkarmeta et al., 1995). So aktivieren auracan und caupolitan den $A S$-Komplex in bestimmten proneuralen Zellgruppen (Gómez-Skarmeta and Modolell, 1996). Da ihre Expression räumlich größer ist, als die des aktivierten $A S-K$, muß es noch weitere Kofaktoren geben, die an der räumlichen Begrenzung beteiligt sind. Die Iroquois-Gene definieren das Vormuster, indem Vorläuferzellen mit neuronaler Kompetenz entstehen. Diese Kompetenz wird vermittelt durch die Aktivität der proneuralen Gene, wie achaete und scute (Simpson, 1997)(Heitzler et al., 1996). Basierend auf diesem Wissen ist ein Genaktivitätsmuster, das auf homologe Funktionen hinweisen könnte, zu erwarten. Außerdem zeigt sich, dass Mash1-Aktivität in ausgesuchten Zellgruppen im Bereich der Irx-Genaktivität vorliegt. Mash1-positive Zellen können ausschließlich in Schnitten detektiert werden (Abb. 32). Sie liegen am epithelialen Rand der IrxExpressionsdomänen und markieren die Vorläufer der neuroendokrinen Zellen der Lunge (Borges et al., 1997). 


\section{II.4 ANALYSE DER MASH1-MUTANTE}

Bei der Analyse der Lungenaktivität von Irx2 und der Schlundbogendifferenzierung gab es deutliche Hinweise auf eine interessante Funktion des Mashl-Gens in diesen Strukturen. Die Verlustmutante Mash1-/- ist von F. Guillemot (Guillemot et al., 1993) erstellt und zur Analyse freundlicherweise zur Verfügung gestellt worden. In der Analyse werden verschiedene embryonale Entwicklungsstadien der Maus im Alter E12,5, E15,5 und E18,5 untersucht. Dabei wurde mit der nicht radioaktiven Gesamtköper- (whole-mount-) in-situ-Hybridisierung und auf Paraffinschnitten von Mausembryonen mittels radioaktiver in-situ-Hybridisierung gearbeitet. Weiterhin dienten Antikörper-Färbungen ebenfalls auf Mausparaffinschnitten, der Analyse.

Im embryonalen Stadium E12,5 ist die Mash1-Genaktivität an Vorderdarmpräparaten zu sehen. Die Aktivität konzerntriert sich auf zwei ovale Strukturen, die Ultimobranchialkörpern. Die Ultimobranchialkörper sind Teil der entstehenden Schilddrüse (Thyroid). Sie besteht ferner aus den Thyroglobulin-produzierenden Zellen (Follikelzellen) und den Calcitonin-prodizierenden Zellen (C-Zellen). Die Entwicklung der Schilddrüse aus zwei Zelltypen unterschiedlichen Ursprungs beginnt mit einer endodermalen Verdickung im Boden des Pharynx kaudal des entstehenden ersten Branchialbogens an Tag E8,5. Dieses endodermale Diverticulum wird die Thyroglobulin-produzierenden Zellen bilden. Desweitern schnüren sich aus der vierten Schlundtasche die Ultimobranchialkörper ab. Im Stadium E15,5 fusionieren sie mit den Follikelzellen. In der folgenden Entwicklung löst sich die ovale Struktur auf und die Schilddrüse entsteht mit der Mischung an Thyroglobulin-produzierenden und Calcitonin-prodizierenden Zellen. Als vergleichende Marker für die transienten Strukturen werden das Ttfl-Gen (Lazzaro et al., 1991), das Pax9-Gen (Peters, 1998) und c-ret (Lo et al., 1991) benutzt. Die Aktivität von Ttfl findet sich in allen Vorläuferzellen der Schilddrüse. $\operatorname{Pax} 9$ ist aktiv in den Derivaten der dritten und vierten Schlundbogentasche, d.h. in Thymus, Parathyroid und den Ultimo-branchialkörpern. Als allgemeiner Marker für Zellen, die von Neuralleistenzellen abstammen, dient c-ret. 


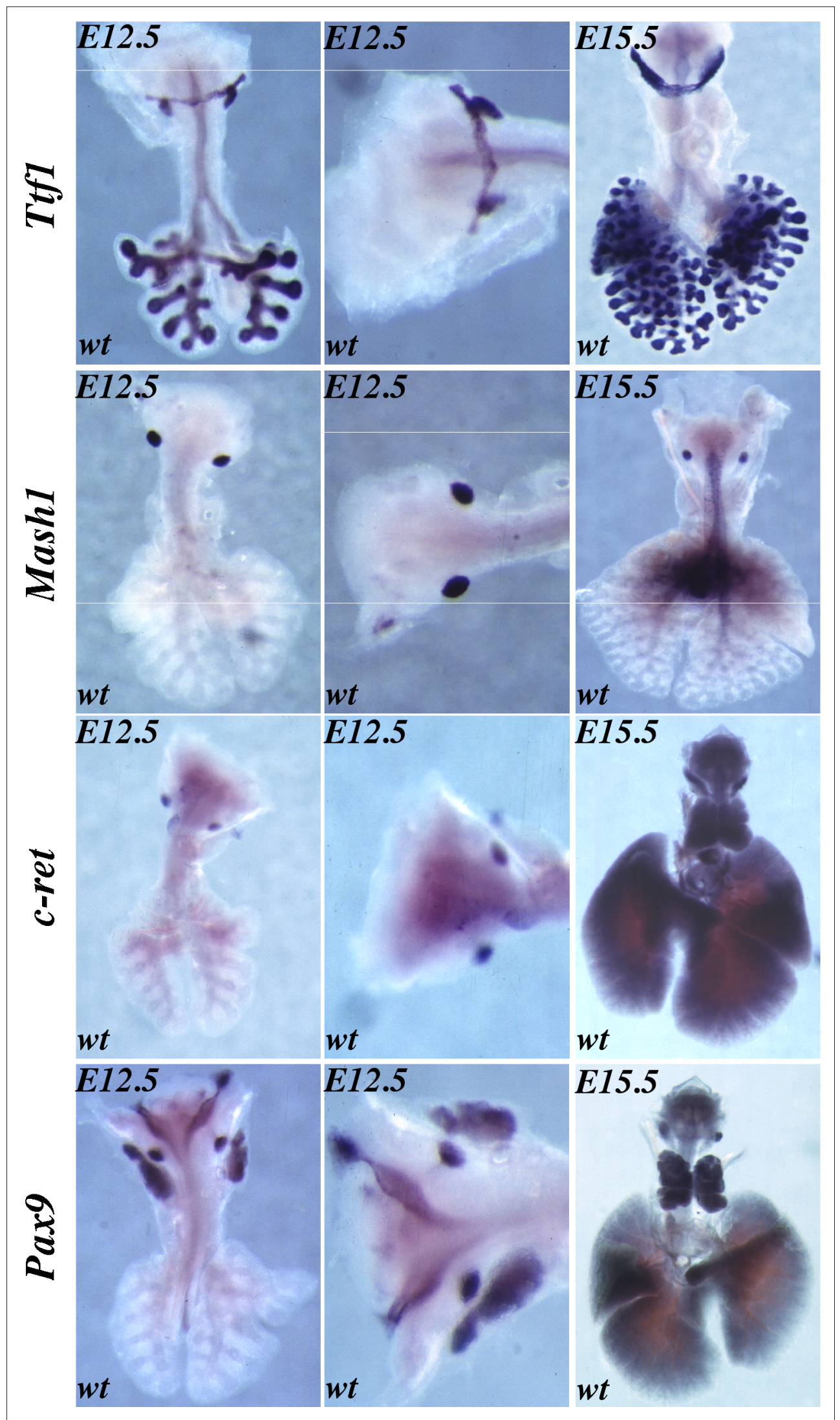

Abb. 33: Vergleich der Genaktivitäten von Ttf1, Mash1, c-ret und Pax9 in WildtypMäusen an E12,5 und E15,5. 
Vorderdarmpräparate von Wildtyp-Mäusen (wt) wurden auf Genaktivität von Mash1, Ttf1, Pax9 und c-ret getestet.

Ttf1 markiert die Vorläuferzellen der Schilddrüse, die Ultimobranchialkörper und die Follikelzellen. Mash1 ist spezifisch in den Ultimobranchialkörpern und c-ret in den Neuralleistenzellen aktiv. Die Genaktivität von Pax9 mmarkiert die Entstehung und Wanderung der Ultimobranchialkörper des Parathyroids und des Thymus.

Die Fragestellung der folgenden Untersuchung zielt auf die Funktionalität der CZellen in der Mash1-Mutante. Für die Analyse wurden Paraffin-Schnitte der Schilddrüse von Mash1-/- Mäusen präpariert und Antikörper-Nachweisreaktionen unterzogen. Wobei die Gewebeproben im Alter E18,5 von Wildtyp-Mäusen eine Färbung mit dem Anti-Thyroglobulin-Antikörper zeigen. Die Follikelzellen stellen den größten Teil der Schilddrüse und produzieren Thyroglobulin, die verstreut liegenden, einzelnen C-Zellen reagieren auf den Anti-Calcitonin-Antikörper. In der Mutante sind morphologisch keine Unterschiede in Größe und Form des Thyroids zu erkennen. Die spezifische Färbung mit Anti-Thyroglobulin zeigt, dass das Organ vorhanden ist. Es lassen sich jedoch keine CZellen mit Anti-Calcitonin nachweisen. In der Mash1-Mutante fehlen spezifisch die Calcitonin-produzierenden Zellen. 


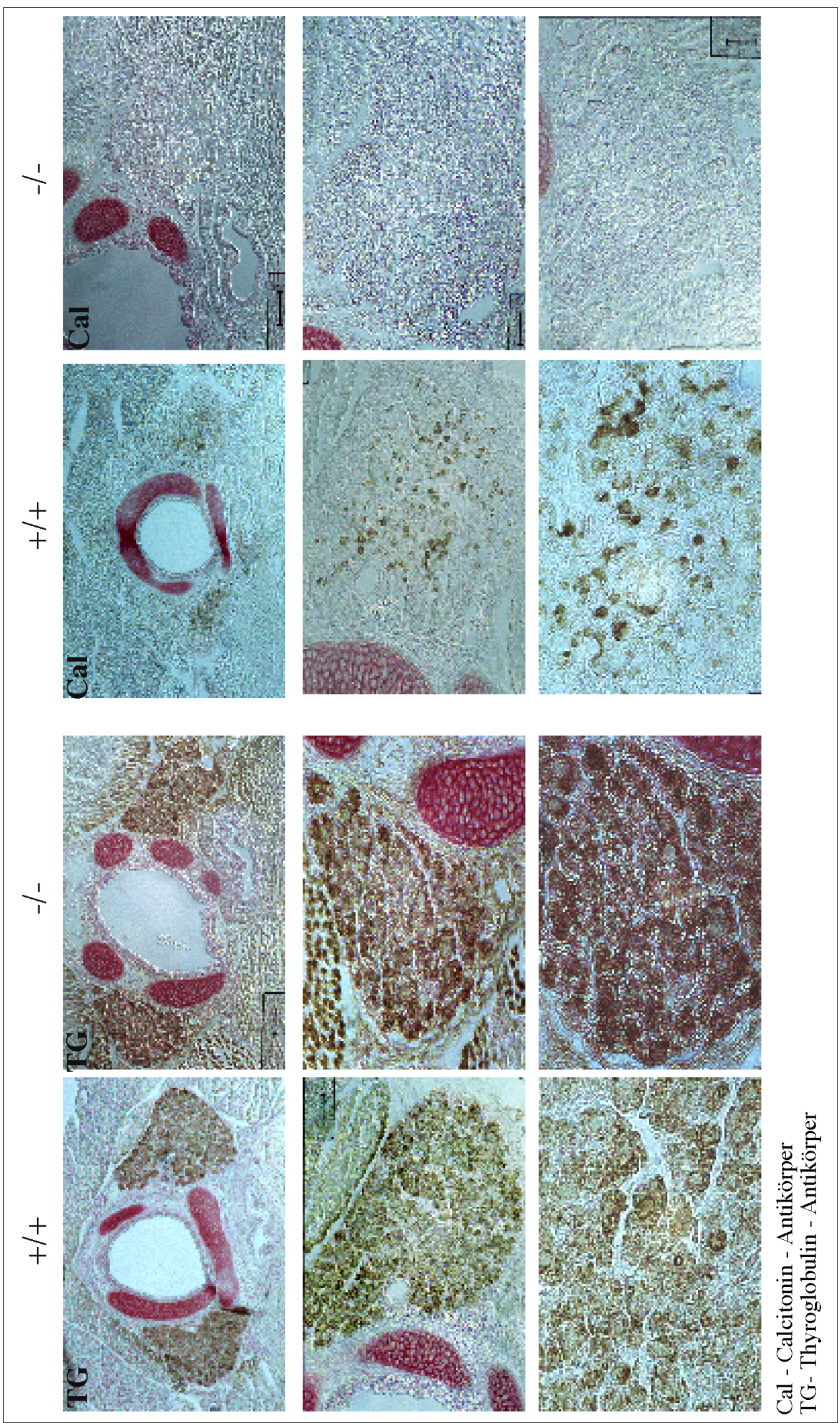

Abb. 34: Darstellung von hormon-produzierenden Zelltypen in der Schilddrüse von Wildtyp- und Mash1- defizienten Tieren im Alter E18,5. 
Sowohl im Wildtyp (WT) als auch in der Mash1-Mutante werden mit Thyroglobulin (TG) die Follikelzellen markiert. Calcitonin-produzierende Zellen können nur im WT nachgewiesen werden.

Im Stadium E12,5 ist sowohl in den Gewebeschnitten der Mutante wie auch im Wildtyp-Vergleichstier das Genprodukt von Ttf1 lokalisierbar, d.h. dass die Vorläufer der Follikelzellen und die Ultimobranchialkörper vorhanden sind.

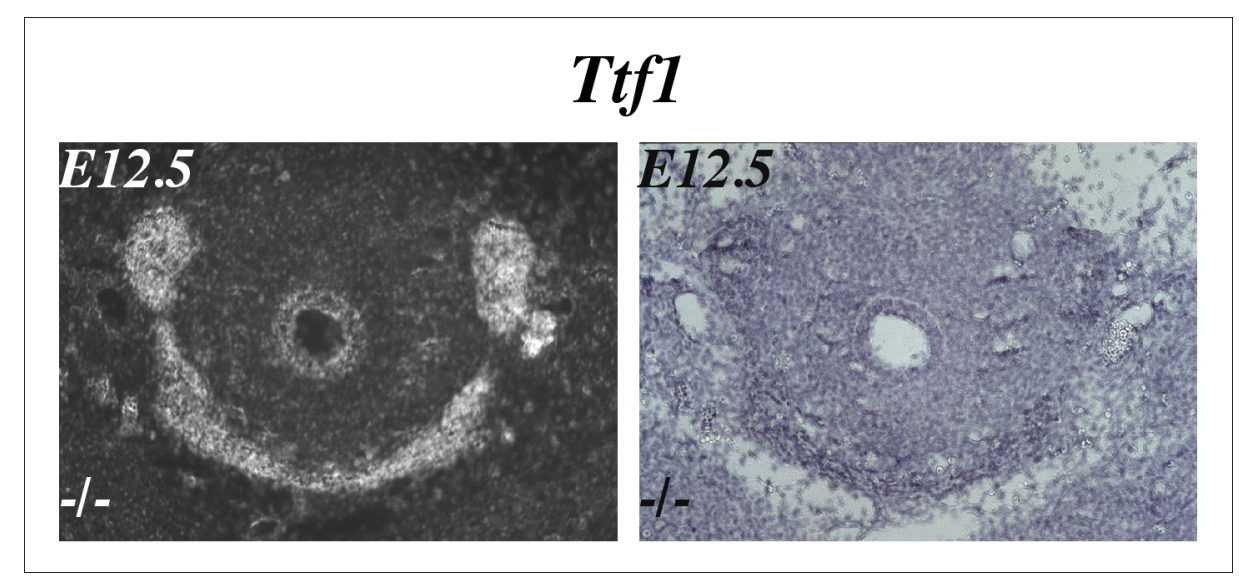

Abb. 35: Expression von Ttf1 in der Mash1-Mutante.

In der sagitalen Schnittebene zeigt sich die Genaktivität von Ttf1 sowohl in den Ultimobranchialkörpern wie auch in den Follikelzellvorläufern.

Die Frage nach der Auflösung der Ultimobranchialkörper in den Thyroidanlage wird untersucht mittels in-situ Analyse an Tag E15,5 der Enbryonalentwicklung an sagitalen und transversalen (cross) Gewebeschnitten. 


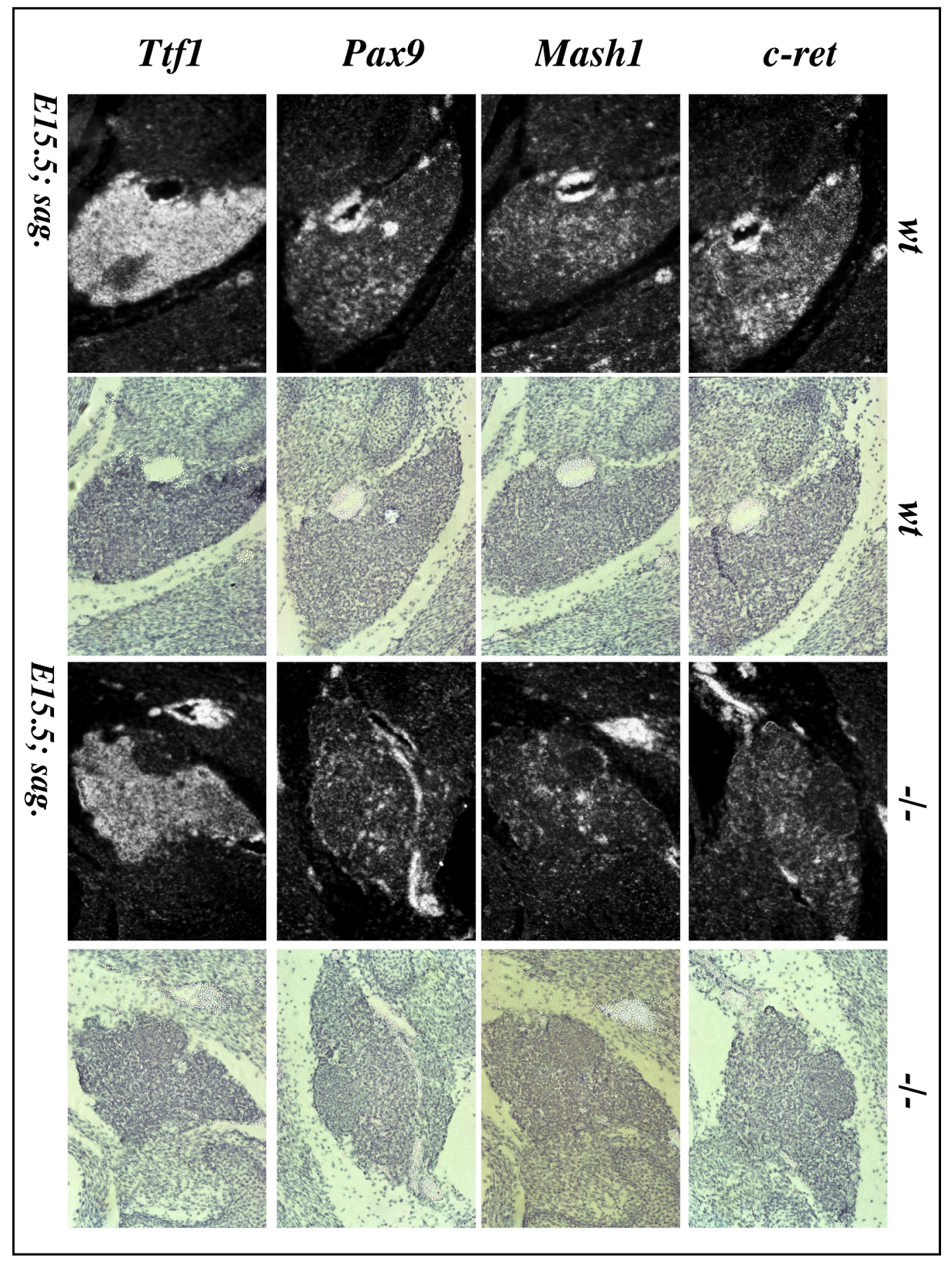

Abb. 36: Genexpressions- und Strukturnachweis in Wildtyp-Mäusen und homozygoten Mash1-Mutanten in sagitalen Schnitten.

Die Struktur des Thyroids wird deutlich in der Expression des Ttf1-Gens. Diese Struktur ist in der Mutante nicht verändert. Alle untersuchten Gene zeigen Aktivität in der Schilddrüse der Mash1-Mutante. 
Es zeigte sich anhand des Ttf1 Transkriptnachweises, dass die Vorläufer der Follikelzellen vorhanden sind. $\operatorname{Pax} 9$ positive Zellen, die den Ultimobranchialkörper entstammen, liegen ebenfalls vor. Ebenso können Neuralleistenzellen mittels der Sonde c-ret nachgewiesen werden. Verwendet wurde auch die Mashl-Sonde, denn in der Mash1-Verlustmutante liegt zwar kein funktionsfähiges Mash1-Protein vor, aber es existiert aber eine verkürtzte, nicht funktionelle Form der mRNA, die mittels in-situ Experimenten nachgewiesen werden kann. Die in ihrer Aussage übereinstimmenden histologischen Schnitte der sagitalen wie transversalen Ebenen belegen, dass im Entwicklungsstadium E15,5 die Zellen der Ultimobranchialkörper in der Schilddrüse vorliegen. 


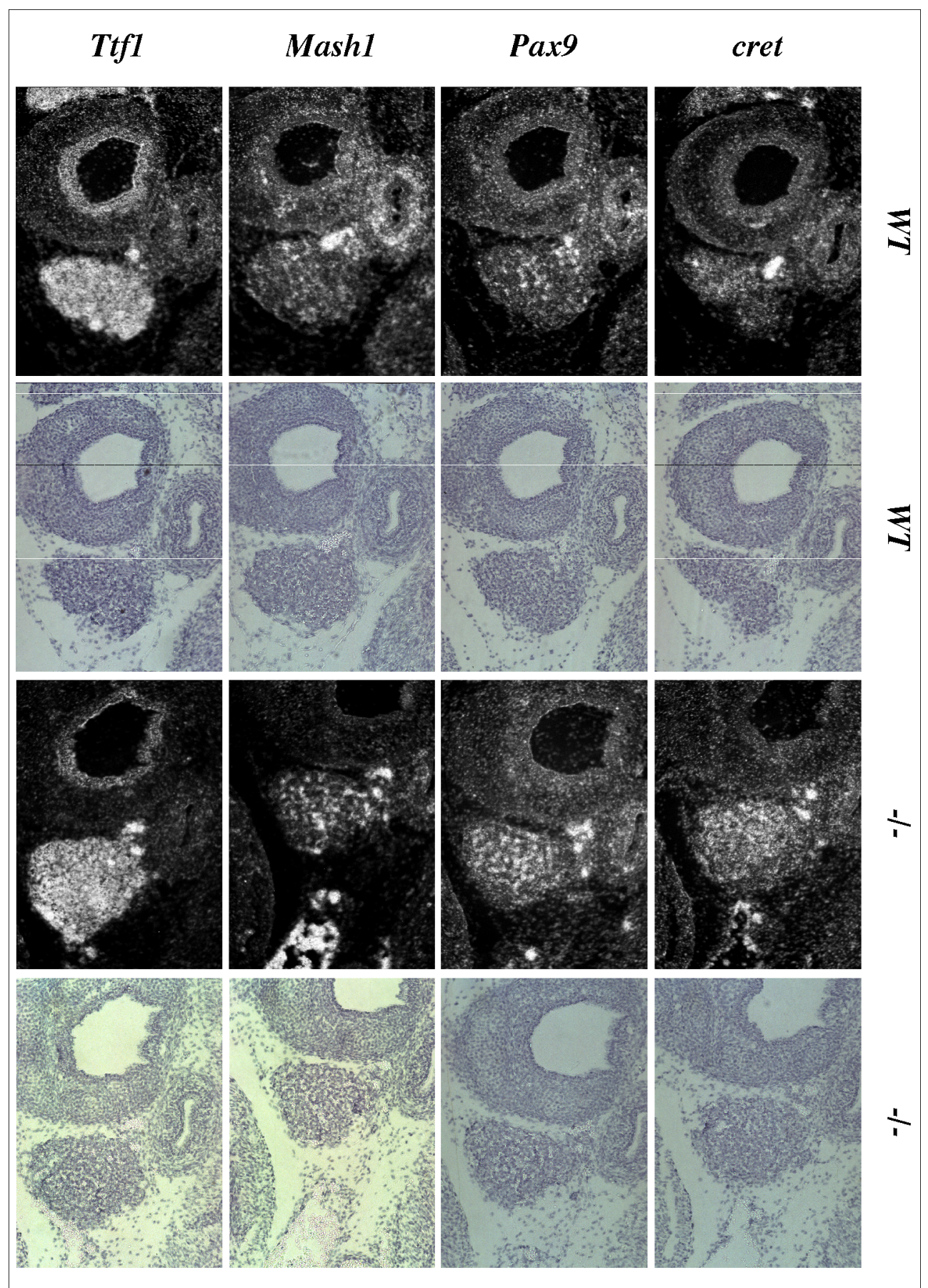

Abb. 37: Genexpressions- und Strukturnachweis in Wildtyp-Mäusen und homozygoten Mash1-Mutanten in transversalen Schnitten.

Die Struktur des Thyroids wird deutlich in der Expression des Ttf1-Gens. Die morphologische Gestalt ist in der Mutante nicht verändert. Alle untersuchten Gene zeigen Aktivität in der Schilddrüse der Mash1-Mutante. 
In der Mutante ist weder die Wanderung und noch die Integration der Mash1 positiven Zellen defizitär. Die fehlende Mashl-Funktion verhindert die Reifung der CZellen, so dass kein Calcitonin produziert wird. 


\section{DISKUSSION}

Im Forschungsgebiet der Entwicklungsbiologie führte die Kombination der Genetik, der Zell- und Molekularbiologie zu einem besseren Verständnis der Prozesse der Embryonalentwicklung. Die Entwicklung jedes Organismus steht unter der präzisen Kontrolle eines genetischen Programms, das sich unter anderem in der exakten Ausgestaltung des Körpers zeigt. Die Klärung der Funktion des Irx2-Gens als Vertreter der Iroquois-Genfamilie anhand der erstellten Verlustmutante steht im Mittelpunkt der hier beschriebenen Studie.

\section{DIE CHARAKTERISIERUNG DES IRX2-GENS IN DER MAUS}

\section{DIE IROQUOIS-GENFAMILIE DER MAUS}

Der Entdeckung der Iroquois-Gene in Drosophila melanogaster folgte unsere gezielte Suche nach homologen Sequenzen im Genom der Maus und die Identifizierung der Iroquois-Genfamilie (Bosse et al., 1997; Becker, 1997; Zülch, 1997). Diese Genfamilie besteht zum heutigen Zeitpunkt aus den sechs Mitgliedern Irxl bis Irx6 (Bosse et al., 1997; Bosse et al., 2000; Bruneau et al., 2000; Cohen et al., 2000; Peters et al., 2000).

Die Bestimmung der chromosomalen Lokalisation von Irx 1 und Irx2 auf Chromosom 13 und die duchgeführte Abstandsmessung weisen auf eine enggekoppelte Organisation mit nur $200 \mathrm{~Kb}$ Distanz hin. Diese Daten zeigen in Kombination die Lokalisation aller Mitglieder der Iroquois-Familie in einer geklusterten Abfolge der Gene Irx1, Irx2 und Irx4 auf Chromosom 13 und von Irx3, Irx5 und Irx6 auf Chromosom 8 (Peters et al., 2000; Bosse et al., 2000). Damit besteht jeder der beiden Kluster aus drei IroquoisGenen, deren Position zu einander streng konserviert ist.

Die Bestimmung der Sequenz der neugefundenen Mausgene machte eine phylogenetische Einteilung möglich, so konnten die Mitglieder der Iroquois- 
Genfamilien der Vertebraten in sechs orthologe Gruppen unterteilt werden. Ausgehend von den Ergebnissen der Sequenzuntersuchungen bilden jeweils zwei Gene eine paraloge Gruppe: Irx1 mit Irx3, Irx2 mit Irx5 und Irx3 mit Irx6. Da vergleichbare intergenische Abstände vorliegen, ist von einer singulären Verdopplung des Klusters auszugehen. Denn es ist unwahrscheinlich, dass bei drei einzelnen Duplikationen ebenfalls die Gesamtorganisation erhalten geblieben wäre. Da von allen untersuchten Wirbeltierarten mindestens vier orthologe Irx-Gene bekannt sind, welche die paralogen Gruppen abdecken. Der Zeitpunkt der Verdoppelung wird vor der Trennung der evolutiven Linien von Fisch, Amphibien, Vögeln und Säugern vermutet. Wahrscheinlich hat die Vervielfältigung des Iroquois-Kluster im Zuge der genomweiten Duplikation in der frühen Phase der Evolution der Vertebraten statt gefunden (Skrabanek and Wolfe, 1998).

Die Iroquois-Proteine bilden eine sehr konservierte Familie von Transkriptionsfaktoren, wie dem Vergleich der Aminosäuresequenzen der Iroquois2Proteine entnommen werden kann, mit den nahezu identischen Strukturmotiven der Homeo- und der Iro-Domäne.

Die Homeodomäne der Iroquois-Proteine gehört aufgrund ihrer Sequenz in die TALE-Gruppe (=three aminoacid loop extension Gruppe), die ein verwandtes Motiv zu dem homeodomänen-assozierten Motiv, genannt MEINOX, darstellt (Bürglin, 1997). Der erstaunliche Nachweis eines derart "alten" Motivs weist auf die Existenz eines UrGens dieser Familie hin, das schon vorhanden war in der gemeinsamen Entwicklungslinie von Pflanzen, Pilzen und Tieren. Die TALE Homeoboxgene sind demnach eine sehr "alte" Gruppe, die sich seit der Phase der Protozoenevolution von den typischen Homeodomänen getrennt entwickelt hat (Bürglin, 1997).

Der Aminosäuresequenzvergleich verweist auf eine zweite hochkonservierte Domäne in den Iroquois-Proteinen. Die Iro-box ist allen Iroquois-Genen gemein, und sogar in den orthologen Gene bei Fliege und Wurm vorhanden. Bisher kann diesem kurzen Motiv keine Funktion zugeordnet werden, aber theoretisch vorstellbar ist, dass es für ProteinProteininteraktion wichtig ist. In einem Yeast-Two-Hybrid-Screen wurde ein neues ZnFinger-Protein identifiziert, welches an die Iro-Domäne bindet (Gómez-Skarmeta, pers. Mitteilung). 
Das Irx2-Transkript enthält als einziges der sechs Mausgene am nicht-translatierten 3'-Ende (UTR, untranslated region) eine K-Box. Sie ist ein Sequenzmotiv, das bei den Genen des enhancer of split in Drosophila entdeckt und untersucht wurde (Lai et al., 1998). Zellinterne Prozesse steuern über Bindung an dieses Motiv die Weiterverarbeitung der mRNA und damit den Proteingehalt in der Zelle. Die Deletion der K-Box in den Genen des enhancer of split führt zur Transkriptanhäufung über das normale Maß hinaus und damit zu Phänotypen, die ebenfalls mit der Überexpression des entsprechenden Gens erzielt werden können. Die K-Box, die ebenfalls in den IroquoisGenen von Drosophila vorliegt, ist nur in der Sequenz des murinen Irx2-Gens bestehen geblieben. Es muß von Bedeutung sein, die $\mathrm{zu}$ bildenen Irx2-Proteinmenge in Abstimmung mit dem Notch-Signalweg (Lai et al., 1998) genau zu kontrollieren. Auffällig ist bei allen Untersuchungen auf RNA-Ebene gewesen, dass die detektierbare Transkriptmenge von Irx2 deutlich unter der anderer muriner Iroquois-Gene lag.

\section{EVO DEVO: DER VERGLEICH DER BISHER BEKANNTEN FUNKTIONEN DER IROQUOIS-GENE} IM TIERREICH

Die ausserordentlich hohe Identität der Aminosäuren der Irx2-Proteine auch außerhalb der bekannten konservierten Domänen läßt vermuten, dass die Proteine ähnliche Interaktionen eingehen können. Der Erhalt der Sequenz der K-Box in den Transkripten der Irx2-Gene kann auf gemeinsame funktionelle Aufgaben verweisen.

Ein Vergleich ist möglich mit Xiro2, von dem funktionelle Daten zur Verfügung stehen. Das Ortholog (Xiro2) des Frosches ist funktionell redundant mit Xiro und Xiro3. Sie markieren das dorsale Ektoderm in der Phase der Gastrulation (Gómez-Skarmeta et al., 2001), welches darauffolgend ein neurales Entwicklungsschicksal nimmt. In der ausgebildeten Neuralplatte kontrollieren sie die Menge der vorhandenen undifferenzierten neuralen Zellen und zu späterer Zeit die Entwicklung spezifischer Neuronen.

Die Frage nach einer möglichen funktionellen Übereinstimmung neben der konservierten Nukleotidsequenz ist vielschichtig zu beantworten. Zum einen zeigen die Irx-Gene in der Maus auch nicht miteinander überlappende Expressionsbereiche, in denen daher keine redundante Funktion $\mathrm{zu}$ erwarten ist. Zum anderen kann die beschriebene Funktion von Xiro2 nicht vollständig mit dem Funktionsbereich von Irx2 
der Maus korreliert werden, da Funktionen unter den Mausgenen aufgeteilt sind. Insbesondere die Aktiviät während der Gastrulation kann definitiv nicht von Irx2 ausgeführt werden, da zu diesem Zeitpunkt noch keine Irx2-Expression besteht. Diese Kontrolle über Zellschicksale wird bei der Bildung der drei Keimblätter in der Maus von Irxl ausgeübt (Zülch, 2001).

Bessere Vergleichsmöglichkeiten bestehen bei der Spezifizierung von neuralen Bereichen. Die territoriale Einteilung des Neuralektoderms in Xenopus entspricht der Regionalisierung der Gehirnanlage durch die Irx2-Expression. Irx2 setzt die regionale Ordnung des Organisators der Mittel-Hinterhirn-Grenze (MHB) um und definiert insbesondere mit seiner scharfen Expressionsgrenze das Hinterhirn. Vergleichbar ist diese Aktivität mit der Funktion der Iroquois-Gene in Drosophila, die in der AugenImaginalscheibe die aufgebaute Ordnung des dortigen Organisators umsetzen (Cavodeassi et al., 2001). Neueste Ergebnisse aus der Analyse von Überexpressionsexperimenten im Huhn zeigen, dass eine ektopische Genaktivität von cIrx2 im Mittelhirn dort Hinterhirnstrukturen entstehen lassen kann (Diaz del Coral, pers. Mitteilung).

Nun zeigen aber gerade die zentralnervösen Expressionsdomänen funktionellen Überlappungen zwischen den verschiedenen Genen des Iroquois-Familie der Maus. Eindeutige funktionelle Zuständigkeiten können daher nur von Mehrfachmutanten aufgedeckt werden.

Es bleibt festzuhalten, dass die Irx2-Gensequenz außerordentlich stark konserviert wurde in den Entwicklungslinien von Amphibien, Vögeln und Säugern. Bedacht werden muß der deutliche Unterschied zwischen der Redundanz der Iroquois-Proteine von Droxophila und Xenopus, der im Widerspruch steht zur funktionellen Ausgestaltung in der Maus. Für die Iroquois-Gene in der Maus wird eine Mischung an redundanten und singulären Funktionen erwartet (Zülch, 2001).

\section{Analyse des Phänotyps der IRX2-VERLUStMUtante.}

\section{UNTERSUCHUNG DER URSACHEN DES PERINATALEN TODES}

Der erste Aspekt des zu besprechenden Phänotyps ist der perinatale Tod der Mutanten. Noch im Stadium E18,5, also einen Tag vor der Geburt, können homozygote 
Tiere identifiziert werden. Die morphologische Analyse dieser deckte keinerlei anatomische Besonderheiten auf und doch sterben die Tiere. Dies ist ein deutlich Hinweis darauf, dass essentielle Körperfunktionen des Fötus gestört sind. Denn nach der Geburt muß er alle lebenserhaltenen Funktionen, wie das Atmen, den Elektrolyt- und Hormonhaushalt, das Kreislaufsystem und die Stoffwechselfunktionen selbst steuern und ausführen.

Verschiedene Veränderungen in den angesprochenen Lebensfunktionen führen $\mathrm{zu}$ Tieren, die zwar geboren werden, dann aber die ersten Stunden nicht überleben. Alle nicht lebensfähigen Babies werden von den Mütter nach der Geburt sofort aufgefressen. Die Tatsache, dass keine homozygoten Tiere postnatal detektiert werden konnten, läßt vermuten, dass der sofortige Tod aufgrund von Atemfehlfunktionen eintritt.

Für die lebenswichtige Respiration ist der anatomisch korrekt geformte Luftweg notwendig, damit die Luft ein- und auströmen kann. Desweiteren müssen funktionstüchtige Lungenbläschen vorliegen. Sowohl der Kehlkopf wie auch die Lunge sind prominente Ort der Irx2-Genaktivität. Der anatomische Aufbau läßt in der Mutante jedoch keine Veränderungen erkennen, so dass von einem funktionellen Versagen ausgegangen werden kann.

Die zentralnervöse Steuerung der Atemfunktion liegt im Hinstamm in den autonomen Atemzentren und wird über die branchial-motorischen und branchial-sensorische Reizleitungen reguliert. Das Atemzentrum entsteht medio-ventral in der Medulla oblongata, deren Entwicklung mit der Ausbildung des Rhombencephalons beginnt. Das Rhombencephalon zeigt im embryonalen Stadium E9,5 einen Aufbau aus sechs bis acht Kompartimenten. In diesen Rhombomeren ist Irx2 von Beginn an aktiv. Das Hinterhirn unterteilt sich in das kranial gelegene Metencephalon, aus dem Pons und Cerebellum hervorgehen, und das weiter kaudal liegende Myelencephalon, das sich zur Medulla oblongata ausbildet. In allen diesen Strukturen hat sich die rhombencephale Irx2Aktivität erhalten. Die Gliederung des embryonalen Neuralrohrs in Grund- und Flügelplatte (motorisch und sensibel) ist im Hinterhirn annähernd erhalten geblieben: In der Grundplatte sind vorwiegend motorische Hirnnervenkerne und weitere motorische Zentren zu finden, wohingegen die Flügelplatte im Dienst sensibler Verschaltung steht (Trepel, 1995). Die breite unspezifische Irx2-Expression verändert sich und ist mit zunehmender Differenzierung in distikten Strukturen erkennbar. Eine klare und deutlich 
abgegrenzte Aktivität zeigt Irx2 in der Medulla in den Hirnnervenkernen der branchialmotorischen Säule und in der Formatio reticularis (FR), welche aus einem Netz von Nervenzellen besteht, dass sich vom Hirnstammtegmentum bis ins Rückenmark zieht und die Hirnnervenkerne miteinander verschaltet. Sie koordinieren die Aufrechterhaltung des lebenswichtigen inneren Körpermilieus vom Schluckreflex bis hin zur Atmung.

Die Genexpression von Irx2 folgt der Entwicklung und Differenzierung der Strukturen des Hirnstamms, die an der nervösen Steuerung der Atemfunktionen beteiligt sind. Störungen im Netzwerk der Atemkontrolle aufgrund des Irx2-Genverlusts sind morphologisch nicht nachweisbar, werden aber im Verlust der Lebensfähigkeit aufgrund von Sauerstoffmangel resultieren.

Die Beweisführung der Todesursache kann oft erst nach Jahren der Analysen erfolgen. Zum Beispiel sterben die intensiv untersuchten Mashl-Mutanten kurz nach der Geburt (Guillemot et al., 1993). Die Mutanten verzeichnen einen großen Verlust autonomer Neuronen, doch die Ursache der Lethalität konnte bis heute nicht eindeutig geklärt werden. Angenommen wird, dass Fehlfunktionen des autonomen Nervensystems zum Tode führen (Sang et al., 1999). Aufgrund des Expressionmusters von Irx2 und des eingetretenen Phänotyps läßt sich postulieren, dass die Irx2-Mutanten an morphologisch nicht detektierbaren Atemwegsdysfunktionen sterben.

\section{GRUNDLAGEN DER MONOALLELISCHEN WEITERGABE DER IRX2-MUTATION}

Die Ergebnisse der Mutationsverteilung in den Nachkommen führte zu interessanten Folgerungen. Die eingeführte Mutation im Irx2-Gen wird abhängig von ihrer Herkunft unterschiedlich umgesetzt. Durchläuft sie die mütterliche Keimbahn, so scheint der Verlust der genetischen Information das Leben der Nachkommen nicht zu beeinflussen. Entstammt sie aber der väterlichen Keimbahn, so zeigt sich, dass transgene Söhne zu keinem untersuchten Zeitpunkt der Entwicklung nachweisbar sind.

Ein ersten Ansatz zum Verständnis der erzielten Daten besteht in der Untersuchung der Übereinstimmung von genotypischen und phänotypischem Geschlecht der Nachkommen. Im allgemeinen ist das Geschlecht der Mäuse ab einem Alter von drei Wochen an den Genitalien abzulesen. Bei "sex switch" Mutanten kann diese visuelle Bestimmung irreführen. In Mäusen, deren phänotypisches Geschlecht nicht zur 
genetischen Ausstattung paßt, treten sogenannte Ovo-Testis auf. In der embryonalen Anlage der Gonaden sind bis E14.5 keine geschlechtsspezifischen Unterschiede auszumachen, erst danach entwickeln sich aus den Anlagen entweder Ovarien oder Hoden (Testis) (Kaufmann and Bard, 1999). Ist die Regulation dieser Prozesse gestört, so entwickeln sich parallel sowohl Ovarien wie Hoden.

Die Untersuchung der Irx2-Mutante ergab keinen Hinweis auf das Vorliegen einer "sex switch" Mutation.

Festzuhalten bleibt, dass die Merkmalsausprägung durch zwei Faktoren bestimmt wird, nämlich durch das Geschlecht der Embryonen und die Herkunft der Mutation. Jedoch einen funktionelle Regulation zwischen dem X-Chromosom und den Genen des 13. Chromosoms ist nicht bekannt.

Das Vererbungsmuster weist auf einen Effekt mit genomischer Prägung hin und die meisten untersuchten Phänomene dieser Art zeichnen sich durch ein unterschiedliches Methylierungsmuster der beiden Allele aus. Methylierungen finden an CpGDinukleotide Nukleotiden statt (Sasaki et al., 1993). Im Genom sind die CpGDinukleotide keinesfalls zufällig verteilt, sondern sie treten häufig in sog. CpG-Inseln auf (Robertson, 2000). Diese "Inseln" sind Bereiche von mehr als 500bp, in denen eine weit über dem Durchschnitt liegende Anzahl von CpGs vorliegen (Reik and Walter, 2001). Sie bewirken eine besonders offene Chromatinstruktur auf und sind "hot spots" für Umlagerungen und Mutationen (Tazi and Bird, 1990). In diesen Bereichen finden beispielsweise 30\% aller Punktmutationen der Keimbahn statt, die zur Entstehung von Krebs führen (Greenblatt et al., 1994).

Der identifizierte Iroquois2-Lokus weist ebenfalls meherere CpG-Inseln auf, die zudem umgeben sind von repetitiven Sequenzen. Dies deutet auf eine chromosomale Region hin, die durch Methylierung stillgelegt werden kann (imprinting, genomische Prägung).

Allerdings zeigte sich bei der Analyse des Methylierungsmusters des Irx2-Lokus, dass diese Art der Regulation hier nicht vorliegt. Auch beim Mash2-Gen zeigte sich, dass die monoallelische Expression nicht durch eine Methylierung der CpG-Inseln erfolgt (Tanaka et al., 1999).

Interessanterweise liegt auch in Drosophila eine elternspezifische Vererbung vor (FlyBase, 2002). Sowohl die paternale wie auch die maternale Vererbung des 
Heterochromatinzustands ist beobachtet worden (Cavalli, 1998). Es wird die Existenz von zellulären Erinnerungsmodulen (CMM, cellular memory modules) postuliert, an die die Proteine der PcG (polycomb-Gruppe) und TrxG (trithorax-Gruppe) binden. Diese Module fungieren als "Schalterelemente" (switchable elements), die verschiedenen Formen der Chromatinkonformation induzieren und stabil weitergeben können. In diesem Zusammenhang ist es bemerkenswert, dass der Iroquois-Komplex Ziel einer solchen Inaktivierung, vermittelt durch die polycomb-Proteine, ist (Netter et al., 1998). Die Proteinen der polycomb-Gruppe verändern die Chromatinstruktur und beieinflussen so den Zugriff der Transkriptionsmaschinerie auf die DNA. (Brock and van Lohuizen, 2001). Diese epigentische Mechanismen bleiben stabil in der Entwicklung erhalten, wobei die Proteine der Polycomb Gruppe den stillgelegten Zustand eines Lokus auf Dauer erhalten können. Interessanterweise bindet beispielsweise das polycomb-Protein an Promotoren von homeotischen Genen in vivo erst, nachdem eine Reprimierung etabliert wurde, um sie dann in der Folge zu erhalten (Orlando et al., 1998). Dieser Regulatinsprozess, der auf der Wirkung von $P c G$ und $\operatorname{Tr} x G$ beruht, scheint nicht nur auf Drosophila beschränkt zu sein. Untersuchung in der Maus konnten zeigen, dass auch hier die orthologen Gene homologe Funktionen ausüben (Wang et al., 2001).

Der "Konflikt-Hypothese" (Moore, 1991) zufolge ist anzunehmen, dass das paternal aktiv Irx2-Gen für ein Protein mit wachstumsfördernder Funktion kodiert. Denn die Aktivität von Wachstumsinhibitoren werden der Hypothese entsprechend vom mütterlichen Genom reguliert werden. Postuliert wird so ein Kampf der Geschlechtern um die mütterlichen Ressourcen (Moore and Haig, 1991). Ein gutes Beispiel im Rahmen dieser Idee ist das Imprinting von $\operatorname{Ig} f 2$. Das $\operatorname{Ig} f 2$-Gen kodiert für einen Wachstumsfaktor und wird von väterlichen Chromosom transkribiert. Der unter maternaler Kontrolle stehende Igf2-Rezeptor bedingt hingegen eine Reduktion des im Cytoplasma vorliegenden Igf2-Proteins und vermindert so dessen wachstumsfördernde Funktion.

Abschließend läßt sich sagen, dass auch Irx2 einen monoallelischen Erbgang aufweist. Analog zur Regulation von Mash2 äußert sich die genomische Prägung nicht in einem differentiellen Methylierungsmuster. Zudem stehen auch schon die Gene des Iroquois-Komplexes von Drosophila unter epigentischer Kontrolle. 


\section{IMPLIKATIONEN DES IRX2-GENS IN DAS HUMANE SYNDROM CRI-DU-CHAT}

In dieser Arbeit wurde die humane chromosomale Lokalisation des Irx2- Gens bestimmt. Irx2 liegt auf dem kurzen Arm (p) des humanen Chromosoms 5 (5p15.3). Bei Funktionsverlust dieser Region (Deletionen, Translokationen)tritt das Cri-du-chatSyndroms (CDC, Katzenschrei Syndrom) auf. Zuerst wurde dieses Syndrom 1963 von LeJeune beschrieben. Dabei war ein hoher monochromatischer Geburtsschrei der betroffenen Kinder das Haupterkennungsmerkmal. Das Katzenschrei-Syndrom ist eine genetische Krankheit mit einer Auftrittswahrscheinlichkeit von 1:50000 Geburten.

Das Cri-du-chat-Syndrom umfaßt eine breit gefächerte Symptomatik mit einer dementsprechend variablen Lebenserwartung der heterozygoten Merkmalsträger. Die allgemeinen Symptome umfassen Gesichtsanomalien, Sprachschwierigkeiten und zum Teil sehr starke mentale Defizite, die ein eigenständiges Leben nicht ermöglichen. Ferner liegt der typische Katzenschrei im Frühkindalter vor. Als Zeichen der Variabilität des Phänotyps sei erwähnt, dass die älteste Patientin mit diagnostiziertem Katzenschrei 80 Jahre alt ist (Iwasa, 1998).

Es ist anzunehmen, dass an der Ausprägung der variablen Symptomatik mehrere Gene beteiligt sind. Die Identifikation und Analyse ist komplex, denn nur ca. 13\% der Patienten haben die Mutation geerbt. Eltern von Merkmalsträgern zeigen in sehr vielen Fällen eine balancierte Translokation im Bereich des kurzen Arms des Chromosoms 5. In der Keimbahn und damit in ihren Nachkommen wandelt sich die balancierte in eine nicht-balancierte Translokation um. Es ist augenscheinlich, dass die Region um die Lokalisation des Katzenschrei-Syndroms anfällig für genomische Umorganisation ist. Die Rekombinationsfreudigkeit des Lokus hängt von der Sequenz und der damit verbundenen offenen DNA-Konformation ab. Ein vermehrtes Auftreten von NukleotidWiederholungen und ein hoher GC-Gehalt, wie sie auch im Irx2-Gen der Maus vorliegen, erhöhen die Wahrscheinlichkeiten von Rekombinationsereignissen, die zu Translokationen führen könnten.

Die Cri-du-chat-Patienten zeigen eine deutliche Variabilität in der Zytogenetik ihres Karyotyps (Mainardi et al., 2001). 


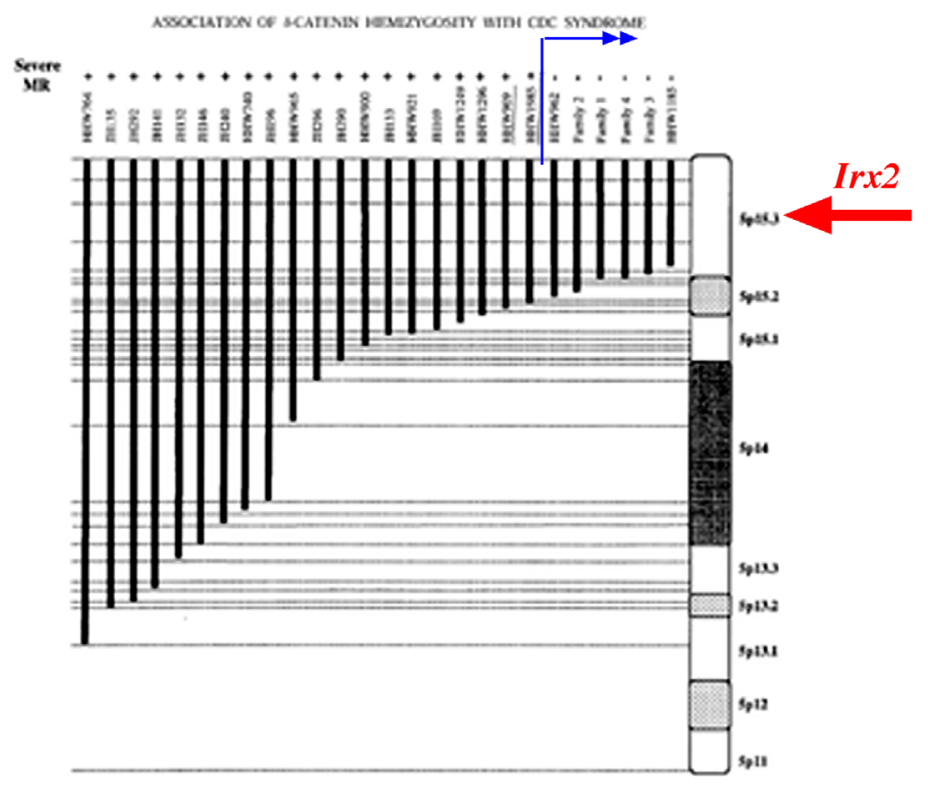

Abb. 38: Chromosomale Bruchpunktanalyse in Verbindung mit der mentalen Retardierung der CDC-Patienten, aus: (Mainardi et al., 2001)

Eine starke mentale Retardierung (severe $M R+$ ) geht einher mit einem Chromosomenverlust von $5 \mathrm{p} 13$ bis $5 \mathrm{p} 15.2$. Patienten mit Chromosomenaberrationen in 5p15.3 (roter Pfeil) zeigen keine Demenz (blauer Pfeil, MR-).

Die Analyse der chromosomalen Bruchpunkte, die zum Ausbruch der Krankheit geführt haben, verweist auf einen divergenten Ursprung der Mutation, die in den meisten Fällen de novo entstanden ist. In der untersuchten Patienten-Gruppe von Mainardi (Mainardi et al., 2001) zeigen 77,5\% eine terminale Deletion, bei der Genmaterial von 5 p13 bis 5 p15 verloren gegangen ist. In einigen Fällen sind die verkürzten Chromosomen über ihre Telomere fusioniert, und die neugeformten Ringchromosomen können die anstehende Meiose nicht korrekt durchlaufen. Durch doppelten Strangbruch und Verlust mittlerer chromosolmaler Bereiche entstehen bei 8,75\% interstizielle Deletionen mit entsprechendem Informationsverlust.

Die zytogenetische Analyse hat die auslösende Region auf zwei Megabasen im Abschnitt 5p15.2 bis 5p15.3 eingegrenzt (Overhauser et al., 1986). Seit Jahren wird nach relevanten Genen in den $48 \mathrm{Mb}$ (=Megabasen) des kurzen Arms des fünften Chromosoms, der etwa 1,5\% des Genoms des Menschen enthält, gesucht (Simmons et al., 1997). Bekannt sind einige wenige Gene in der kritischen Region, von denen bisher 
zwei möglicherweise in das CDC-Syndrom involviert sind. Delta-catenin (CTNND2) ist ein Adhäsionsprotein, welches in der neuralen Mausentwicklung aktiv und im Kontext der Zellmobilität von Bedeutung ist. Die genomische Lokalisation des humanen CTNND2-Gens entspricht der Position 5p15,2 (Medina et al., 2000). Ebenfalls dort liegt die genetische Information für das Semaphorin F-Gen. Es kodiert für einen Faktor, der im embryonalen Gehirn der Maus aktiv ist. Seine Funktion liegt in der Leitung von auswachsenden Neuronen (=axon guidance molecule) (Simmons et al., 1997).

Wegweisend sind die zytogenetischen Untersuchungen an einer Patientin gewesen, die die typische Stimmlage aufweist und leichte Lernverzögerungen zeigt, aber weder mental retardiert ist noch eine auffällige Gesichtsform besitzt (Sreekantaiah et al., 1999). Ihr Karyotyp zeigt eine de novo Deletion sowie eine zusätzliche invertierte Duplikation der 5p Region auf. Es wurde evident, dass ausschließlich ein Defizit genomischer Sequenz an 5p15.3 vorliegt. Diese Daten unterstützen die Idee, dass es zwei kritische Regionen gibt, von denen 5p15.3 für den Phänotyp des Katzenschreis (Dysphonie) und 5p15,2 für die starke mentale Beeinträchtigung verantwortlich ist (Goodart et al., 1994)(Gersh et al., 1997).

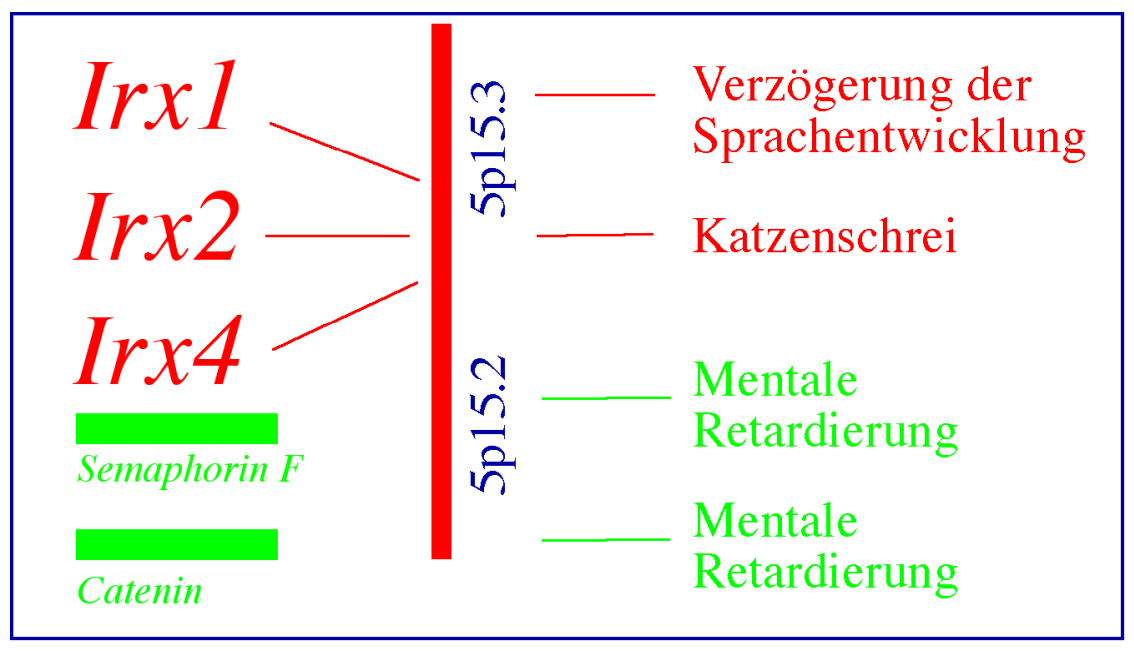

Abb. 39: Zuordnung der phänotypischen Ausprägung des CDC-Syndroms

Für eine korrekte Lebensprognose ist es unerläßlich, den Bruchpunkt so genau wie möglich bestimmen zu können. 
Verschiedene Formen von Dysphonien in Neugeborenen sind das Ergebnis von nicht ausgereifter Innervation des Larynx (Hirschberg, 1999). Die Ursachen der Dysphonie der Katzenschrei-Patienten ist nicht geklärt.

Die Analyse der murinen Irx2-Expression zeigte, dass dieses Gen während der Kehlkopfentwicklung der Maus von Bedeutung ist. So ist Irx2 ganz speziell in den Knorpeln des Larynx aktiv, welche die Stimmlage regulieren. Denn die ArytenoidKnorpel variieren über die Spannung der Stimmbänder die Ausprägung der Stimme. Neben der chromosomalen Lokalisation untermauert das murine Genaktivitätsmuster die herausragende Bedeutung von Irx2 als Kandidatengen für das Katzenschrei Syndrom.

Ein weiterer Aspekte der murinen Irx2-Funktion ist der perinatale Tod bei homozygotem Genverlust. In allen bekannten Fällen sind die CDC-Patienten ausschließlich heterozygote Merkmalsträger, d.h. es gibt auch hier keine lebenden homozygoten Erbträger.

Die Vererbung des CDC Syndroms gibt seit Jahren Rätsel auf. Bemerkenswert ist die ungleiche Verteilung der Merkmale abhängig vom Geschlecht der Nachkommen und der Weitergabe durch die mütterliche oder väterliche Keimbahn. Die Anzahl der untersuchten Patienten, die die krankheitsauslösende Mutation geerbt haben, ist zu gering, um statistisch klare Aussagen treffen zu können. Dennoch wurde festgehalten, dass mehr Mädchen als Jungen mit der Krankheit geboren werden (Ivison, 1999) und, dass in 90,2\% der Fälle das Chromosom 5 mit einer Deletion von Vater vererbt wird (Ivison, 1999). Auch in der Irx2-Mutantenanalyse gibt es einen klaren Überschuß an weiblichen transgenen Tieren und die Weitergabe durch die männliche Keimbahn verstärkt den Phänotyp.

Entsprechend der parentalen Herkunft des veränderten humanen Chromosoms 5 stellt sich die Frage, ob der CDC-Lokus der genomischen Prägung unterliegt (Church et al., 1995). Die Analyse einer Mutter und ihres Sohnes mit identischer doppelter, perizentrischer Inversion zeigt die Ausprägung unterschiedlicher Phänotypen. Dabei entwickelt ausschließlich der Sohn die CDC-Symptome, was bedeutet, das sich die Mutation geschlechtsspezifisch ausprägt. Die Inversion im Genom des Sohnes resultiert nicht in einem genetischen Informationsverlust, sondern in einer veränderten Regulation des CDC-Region. Diese Region zeigt je nach Geschlecht eine unterschiedliche Aktivität, 
was auf einen Effekt wie die genomische Prägung oder variable Penetranz hinweist (Goodart et al., 1996).

\section{DIE MAUS ALS MODELLORGANISMUS DER HUMANEN FORSCHUNG}

Die Maus ist der beste Modellorganismus für die Analyse humaner Krankheiten, da gezielte Verlustmutationen in ihren Genom verankert werden können. Obwohl ihre Entwicklung natürlich teilweise divergent von der menschlichen Entwicklung verläuft, so ist sie doch in eine Vertreterin der hochentwickelten Säuger. Alle säugerspezifischen Fragen, wie zum Beispiel die genomische Prägung können untersucht werden. Entscheidend ist die exzellente Vergleichbarkeit von physiologischen Vorgängen, die es ermöglichen, die Grundlagen von Krankheiten zu studieren.

Zusätzlich zeigte sich durch die Vergleiche von Nukleotidsequenzen und Genfamilien, dass nicht nur einzelne Gene in ihrem Aufbau konserviert wurden in der Evolution, sondern dass auch die Organisation der Gene auf den Chromosomen vergleichbar ist. Unter Verwendung von Krankheits-Syndromen wie Cri-du-chat als Marker wurden die Chromsomen von Säugern und Primaten untersucht (Tarazami et al., 1998). Das Chromosom 5 des Menschen ist z.B syntenisch mit Chromoson 4 von Schimpanse und Orang-Utan (Tarazami et al., 1998) und weiten Teilen des Chromosom 13 der Maus.

Hierin liegt ein weiterer Ansatz begründet, warum die Maus ein sehr gutes Tiermodell für die Untersuchung humaner Krankheiten ist. Über die Lokalisation des Mausgens kann potentiell die chromosomale Position des humanen Homologs vorhergesagt und damit das cytogentische Wissen der Humangenetik über diese Region genutzt werden.

\section{DIE HERAUSRAGENDE ROLLE VON MASH1 WÄHREND DER ENTWICKLUNG DER C-ZELLEN DES THYROIDS}

ANALYSE DER INTERAKTION DES MURINEN ORTHOLOGS DES PRONEURALEN ACHAETESCUTE KOMPLEX UND DEN IROQUOIS-GENEN

Die theoretische Grundlage einer Verbindung zwischen den Iroquois-Genen und dem achaete-scute Ortholog, Mash1, in der neuralen Entwicklung wird durch experimentale Daten untermauert, die in den Untersuchungen der genetischen Regulationskaskaden in Drosophila und Xenopus gewonnen wurden. Die späte Funktion der drei Gene des 
Iroquois-Komplexes (Iro-C) bedingt die Bildung sensorischer Organe auf dem Notum der Fliege. In der Iro-Mutante ist die Anzahl der sensorischen Borsten stark vermindert und diese Reduktion geht einher mit dem Verlust der Genexpression der achaete-scute(AS-C) Gene auf dem seitlichen Notum (Gómez-Skarmeta et al., 1996). Die achaetescute Gene zeigen proneurale Potenz, d.h. dass sie innerhalb ihrer Expressionsdomänen die Bildung von Sinnesorganen induzieren können. Folglich führt das Fehlen ihrer Aktivität zum Verlust dieser Sinnesorgane (Leyns et al., 1996). Der Funktionsverlust der einzelnen Iroquois-Gene bedingt die Deletion verschiedenen wie auch überlappender Expressionsdömanen der achaete-scute Gene. Demnach ist die Kombination der Iroquois-Genaktivitäten mit ihren singulären und redundanten Funktion die Voraussetzung für die Aktivität der proneuralen Gene. Dabei scheint es von Bedeutung zu sein, dass eine gegebene Intensität an Iroquois-Aktivität vorliegt. Die genetische Interaktion konnte in in vitro-Studien belegt werden, bei der das Protein des Gens araucan an ein konserviertes cis-Element im regulativen 5'-Bereich der achaete-scute Gene bindet (Gómez-Skarmeta and Modolell, 1996). Durch Überexpression von Iro-C vergrößert sich der Aktivitätsbereich der achaete-scute-Gene und damit kann eine aktivierende Funktion postuliert werden (Gómez-Skarmeta and Modolell, 1996). Allerdings weisen Folgeexperimente daraufhin, das die Interaktion in ihrer Form bei der Fruchtfliege indirekt ist, d.h. unter Zuhilfenahme weiterer Faktoren abläuft. Dazu steht im Gegensatz, dass die Ergebnisse aus Überexpression chimärer Proteine in Xenopus deutlich auf eine direkte, reprimierende Funktion der Transkriptionsfaktoren des Iroquois-Komplex hinweisen (Gómez-Skarmeta et al., 2001).

Die Untersuchung der genetischen Interaktionen zwischen den Orthologen Gene der eben beschrieben Regulation in der Maus wurde anhand einer Promotoraktivierungsstudie durchgeführt. Das Iroquois1- bzw. das Iroquois2- Protein der Maus wurde in COS-Zellen, die eine veränderte Form des Mash1-Promotors enthalten, überexprimiert. Dieser veränderte Promotor (Verma-Kurvari et al., 1998) wird nicht gefolgt von der kodierenden Sequenz des Mashl-Gens, sondern von der GFPMarkerkassette. Der Ansatz des Experimentes erfordert, das bei Aktivierung des Mash1Promotors GFP (green fluorescent protein) gebildet wird, welches anschließend visuell detektierbar ist. Allerdings konnte weder mit Irx1 (A. Zülch, pers. Mitteilung) noch mit Irx2 (Daten nicht gezeigt) das Promotorkonstrukt aktiviert werden. Diese Experimente 
belegen, dass in der Maus keine direkte positive Regulation zwischen Irx 1, Irx2 und Mashl besteht.

Für eine abschließende Interpretation hinsichtlich der Regulation zwischen den genannten Genen fehlen noch weitere Daten. Zum einen gibt es noch vier weitere IrxProteine, deren Interaktionen noch nicht untersucht sind und zum anderen existiert ein weiteres Ortholog des AS-Komplex in der Maus, nämlich Mash2. Es ist nicht definitiv auszuschließen, dass zwischen den weiteren Mitgliedern dieser Genfamilien direkte Interaktionen bestehen.

MASHI ZEIGT NEBEN DER NEURALEN EINE HOCHSPEZIFISCHE AKTIVIÄT IN DER ENTWICKLUNGSPHASE DES PHARYNX

Die orthologen Gene des AS-Komplex in der Maus, Mash1 und Mash2, kodieren für Transkriptionsfaktoren, die sehr unterschiedliche Funktionen ausüben. Mash2 wirkt in der Entwicklung der extraembryonalen Strukturen und wird monoallelisch exprimiert (Tanaka et al., 1999). Das Mash1-Gen kontrolliert die Differenzierung spezifischer neuraler Zelllinien (Guillemot et al., 1993) und ist aktiv im autonomen Nervensystem. Dort ist es essentiell für den korrekten Aufbau des sympathischen, parasympathischen und viszeralen Netzes (Lo et al., 1991; Guillemot et al., 1993). Mash1-defiziente Tiere sterben in den ersten Tagen nach der Geburt. Verschiedene Ansätze liefern Erklärungsansätze für den postnatalen Tod der Tiere. Es zeigt sich, dass sie kaum Nahrung aufnehmen bzw. verstoffwechseln können. Der mangelhaften Aufbau des peripheren Nervensystems resultiert in einer fehlerhaften viszeraler Innervation (Sang et al., 1999) und steht einem Überleben der Mutanten entgegen.

Ein weiterer prominenter Expressionsort des Mash1-Gens liegt in den Derivaten des vierten Schlundbogentasche, in den Ultimobranchialkörpern. Sie sind ein Bestandteil der entstehenden Schilddrüse (Thyroid), die aus den Thyroglobulin-produzierenden Zellen (Follikelzellen) und den Calcitonin-produzierenden Zellen (C-Zellen) zusammensetzt.

Die Entwicklung der Schilddrüse beginnt mit einer endodermalen Verdickung im Boden des Pharynx kaudal des entstehenden ersten Branchialbogens an Tag E8,5. Dieses endodermale Diverticulum wird die Thyroglobulin-produzierenden Zellen bilden. Desweiteren schnüren sich aus der vierten Schlundtasche die Ultimobranchialkörper (Ub) ab. Es wird seit Jahren diskutiert, ob dessen Zellen den epibranchialen Plakoden 
(Larsen, 1993), den mesenchymalen Komponenten der vierten Tasche (Fontaine, 1979) abstammen oder sich aus Neuralleistenzellen bilden. Neuere Publikationen gehen davon aus, dass sie der Neuralleistenzelllinie entstammen. Sie greifen damit die Hypothesen von LeLievre auf (Le Lievre and Le Douarin, 1975), der postuliert, dass sie in den vierten Schlundbogen kurz nach dessen Bildung einwandern (Kaufmann and Bard, 1999). Nach der Trennung bewegen sich die Ultimobranchialkörper kaudalwärts in Richtung der Schilddrüsenanlage. In der folgenden Entwicklung von E13,5 bis E15,5 löst sich die ovale Struktur auf und ihre Zellen fusionieren mit den Follikelzellen im anterioren und dorsalen Bereich. Es entsteht die Schilddrüse mit einer Mischung an Thyroglobulin-produzierenden und Calcitonin-prodizierenden Zellen, die mit der Hormonproduktion im Embryonalstadium E17,5 starten.

Der Entwicklung des vollständigen Organs liegen massive Zellwanderungen zugrunde, die den "Abstieg" der Schilddrüse entlang der rostrokaudalen Achse bedingen. Eine fehlerhafte Regulation dieses Prozesses resultiert in anatomischen Auffälligkeiten wie dem "lingualen" Thyroid oder "Zysten" im Halsbereich. Bei Menschen entsteht der linguale Thyroid, wenn das Organ nach der Bildung nicht wandert, sondern im dorsalen Teil der Zunge verbleibt. Häufiger treten Zysten auf, die Resten der Schilddrüsenanlage entsprechen, die nicht vollständig bis ins superioren Mediastinum vorgedrungen sind. Sie verbleiben auf dem Weg beispielsweise auf Höhe der ersten trachealen Ringe und bilden ektopisches Schilddrüsengewebe.

AUfSTELLUNG ANATOMISCHER UND MOLEKULARER ZUSAMMENHÄNGE DER THYROIDENTWICKLUNG ANHAND DER MASHI VERLUSTMUTANTE

Mashl-Aktivität ist sehr spezifisch im Vorderdarm der Maus zu finden, so dass eine Untersuchung der Ultimobranchialkörper in der Verlustmutante hochinteressant erschien. Bei der Ermittlung einer möglichen Funktionsstörung der Schilddrüse muß die schrittweise Entstehung bedacht werden, denn es kann sowohl die Wanderung, wie die Fusion oder die Reifung defizitär sein.

Die Untersuchung des Zeitpunkts der Fehlentwicklung erfolgtemittels in situ Analyse der Genaktivitäten von Ttf1, c-ret und Pax9. Die Genaktivität von Ttf1 ist in der Mutante nicht verändert, denn nach wie vor liegt sie in den Ultimobranchialkörper und in den Vorläufern der Follikelzellen. Dementsprechend ist die Bildung der 
Ultimobranchialkörper (Ub) durch den Verlust der Mash1-Aktivität nicht gestört. Der zweite kritische Schritt ist die Fusion der verschiedenen Zelltypen. Der molekulare Nachweis der Zellen aus den Ubs wird durch die Darstellung der Genaktivitäten von Ttf1 und $\operatorname{Pax} 9$ geliefert. Darüberhinaus konnte gezeigt werden, dass diese Zellen, wie auch in andere Neuralleistenzellen, das Gen c-ret aktiv ist. Den besten Beweis dafür, dass Zellen, die aus den Ubs entstanden sind, bis zum Tag E15,5 nicht verloren gehen, liefert die verwendete Mash1-Sonde. In der Verlustmutant liegt kein funktionstüchtiges Mash1Protein vor, aber es existiert eine verkürzte mRNA, die mit der in-situ-Hybridisierung detektiert werden kann. Somit kann klar demonstriert werden, dass die Mash1-positiven Zellen durch den Funktionsverlust in den frühen Phasen der Schilddrüsenentwicklung nicht beeinträchtigt sind. In der Mutante ist weder die Wanderung und noch die Integration der Mash1 positiven Zellen defizitär.

Die Untersuchung des korrekten Aufbaus eines Organs ist ein wichtiger Schritt in der Mutantenanalyse. Doch die Funktionsanalyse ist erst mit der Untersuchung der Differenzierung der Zellen abgeschlossen. Die Funktion der Schilddrüse beinhaltet unter anderem die Produktion der Hormone Calcitonin und Thyroglobulin. Der Verlust des Mash1-Gens prägt sich in der Unfähigkeit der Schilddrüse aus, Calcitonin zu produzieren. Die fehlende Genfunktion verhindert die Reifung der C-Zellen und bewirkt so, dass das lebenswichtiges Calcitonin nicht produziert werden kann.

Der Vergleich mit anderen Genen, die an der funktionellen Ausgestaltung der Schilddrüse beteiligt sind, macht die einzigartige Stellung des Mash1-Gens für die Bildung der C-Zellen deutlich. In der Ttf1-Verlustmutante entstehen weder die Follikelnoch die Calcitonin-produzierende Zellen (Lazzaro et al., 1991). In der Pax9-Mutante findet keine Bildung von Thymus und Parathyroid, den Derivaten der dritten Schlundbogentasche, statt (Peters, 1998). Das Gen Ttfl scheint demnach für die Bildung der Schilddrüse in der frühen Phase von Bedeutung zu sein (Lazzaro et al., 1991). Speziell wichtig Für die spezifische Entwicklung der Follikelzellen ist das Gen Pax8 (Mansouri et al., 1998). Denn in der Pax8-Verlustmutante bildet sich zwar eine Schilddrüse, diese besteht aber ausschließlich aus C-Zellen.

Die Reifung der C-Zellen ist die Vollendung eines Entwicklungsprogramm der Organogenese, dass mit der Bildung der Ultimobranchialkörper aus der vierten Schuldtasche beginnt. Die Ergebnisse der vorliegenden Funktionsanalyse belegen, das 
die molekularen Mechanismen, welche die Organogenese der Schilddrüse vollenden, abhängig sind von der Funktion des Mash1-Gens.

\section{REGULATION DES KALZIUM HAUSHALTS DER ZELLEN}

Das Hormon Calcitonin reguliert im Körper die Konzentration der Kalzium-Ionen $\left(\mathrm{Ca}^{2+}\right)$. Schon millimolare Änderungen der Konzentration im Blut und im extrazellulärem Plasma sind kritisch für die Organismen. Dies beruht auf der Rolle der Kalzium-Ionen als Regulatorsubstanz bei vielen Zellprozessen. Calcitonin wird von den C-Zellen der Schilddrüse als Antwort auf eine Hyperkalzämie sezerniert. Es unterdrückt den Calziumverlust aus den Knochen, die ein großes Reservoir von Kalzium- und Phosphat-Ionen bilden. Im Gegenspiel mit dem Parathyroidhormon, wird die körpereigene Konzentration eingestellt und kontrolliert.

Für das Verständnis von Krankheiten ist es notwendig die Schritte zu entschlüsseln, die zur Herstellung der Schilddrüsenhormone führen. Die humane Krankheiten des Hypothyroidismus tritt in 1:5000 bis 1:3000 Neugeborenen auf. Es ist absolut kritisch, die Krankheit früh zu diagnostizieren, da sie unbehandelte bei den betroffenen Kindern zu irreversiblen Schädigungen in der geistigen Entwicklung führt und Debilität und Cretinismus hervorruft.

Die funktionellen Analysen der Kontrollgene Irx2 und Mash1 haben die wichtigen Rollen dieser Gene in verschiedenen Aspekten der Säugerentwicklung aufgezeigt. Generell sind neben den singulären Funktionen der Gene insbesondere die Interaktionen innerhalb von Regulationskaskaden von Interesse. Abschließend kann gesagt werden, dass sowohl Irx2 als auch Mash1 innerhalb ihres genetischen Netzwerkes für die funktionelle Differenzierung lebenswichtiger Organe verantwortlich sind. 


\section{MATERIAL UND Methoden}

\section{IV.1. ORGANISMEN}

\section{IV.1.1 MÄUSE UND EMBRYONEN}

NMRI (Weibchen) und C57Bl/6/xSJL oder 129Sv Mäuse wurden vom Zentralinstitut für Versuchstierzucht Hannover bezogen. Zur Gewinnung von Embryonen für RNAPräparationen, in-situ-Hybridisierungen und Morula-Aggregationen wurden die Mäuse ü.N. verpaart und der Tag des Vaginalpfropfes als Tag 0,5 post coitum der Embryonalentwicklung (E0,5) gezählt.

Die anlysierte Mash1-Mausmutante wurden von F. Guillemot zur Analyse zur verfügung gestellt (Guillemot et al., 1993).

\section{IV.1.2 BAKTERIEN}

Transformationen wurden mit den E. coli-Stämmen DH5 $\alpha$ (Hanahan, 1985), XL-10Gold (Stratagene), SURE (Stratagene) durchgeführt. Als Wirt für $\lambda$ - Phagen wurde der Stamm LE392 oder C600 verwendet.

\section{IV.1.3 ES-ZELLEN}

Zur homologen Rekombination wurden die embryonalen Stammzellen der MPI II Linie verwendet. Sie entstammen dem genetischen Mausstamm 129Sv/J. 


\section{IV.2 MATERIALIEN}

\section{IV.2.1 CHEMIKALIEN}

Die genutzten Chemikalien wurden von den Firmen Sigma (München), Merck (Darmstadt), BRL (Bethesda Research Laboratories, Karlsruhe), Serva (Heidelberg), Fluka (Buchs, Schweiz), J.T. Baker (Deventer, Holland), Roth (Karlsruhe), Biomol (Ilvesheim) und Gibco Laboratories (Detroit, USA) bezogen. Phenol verschiedener pHWerte wurde zuerst von der Firma Amresco (Solan, Ohio) und im späteren Verlauf der Arbeit von Roth (Karlsruhe) bezogen, ohne dass qualitative Unterschiede zu beobachten waren. Alle Chemikalien besaßen den Reinheitsgrad "p.a." (zur Analyse).

\section{IV.2.2 RADIOCHEMIKALIEN}

Die Firma Amersham (Braunschweig) lieferte die im gesamten Verlauf der Arbeit genutzten Radiochemikalien ( ${ }^{32} \mathrm{P}-\mathrm{dCTP}$ und $\left.{ }^{35} \mathrm{~S}-\mathrm{dUTP}\right)$.

\section{IV.2.3 VERBRAUCHSMATERIAL}

Das Plastikmaterial wurde von den Firmen Falcon, Greiner, Eppendorf, Sarstedt und Nunc bezogen.

\section{IV.2.4 ENZYME}

Enzyme der Firmen Amersham-Buchler (Braunschweig), Stratagene (La Jolla), Gibco-BRL (Karlsruhe), Boehringer (Mannheim), Biolabs (Frankfurt), Promega () und Pharmacia (Freiburg) wurden verwandt.

\section{IV.2.5 REAKTIONSSETS (“KITS")}

Es wurden folgende Kits benutzt:

Kit

BigDye Terminator Cycle Sequencing Ready

Reaction Kit

Multiprime DNA labelling system

\section{Hersteller}

Perkin-

Elmer Corporation

Amersham Life Science 


$\begin{array}{ll}\text { Probe Quant G-50 Micro Columns } & \text { Amersham } \\ \text { Qiagen Plasmid Maxi Kit } & \text { Qiagen } \\ \text { QIAprep Spin Miniprep Kit } & \text { Qiagen } \\ \text { QIAquick PCR Purification Kit } & \text { Qiagen } \\ \text { QIAexII Gel Extraction Kit } & \text { Qiagen } \\ \text { Trizol } & \text { Life Technologies } \\ \text { Oligotex mRNA Kit } & \text { Qiagen }\end{array}$

\section{IV.2.6 MEMBRANEN}

Es wurde mit ungeladenen Nylon-Membranen der Firma Qiagen (Düsseldorf) gearbeitet, die sie ihrerseits von der Firma PAL erhalten.

\section{IV.2.7 DNA-BIBLIOTHEKEN}

genomische $\lambda$-Phagenbibliothek

Die genomische Bibliothek Ola129 wird seit einigen Jahren in unserem Labor verwendet.

\section{cDNA-Bibliothek}

Das Durchmustern verwchiedener Bibliotheken diente dazu, die Irx2-cDNA zu vervollständigen. Die ersten Fragmente wurden aus einer E8,5-cDNA-Bibliothek gewonnen (Becker, 1997), die freundlicherweise von Dr. B. Hogan (Fahrner et al., 1987) zur Verfügung gestellt wurde. Bei der zusätzlich verwendeten DNA-Bibliothek handelt es sich um die E10,5-Bibliothek der Firma Stratagene (Oligo-dT und Random-primed; E10,5; C57/B16; \#938303 ).

\section{IV.2.8 VEKTOREN}

Für Klonierungen wurden das Plasmid Bluescript II KS+ (Stratagene, USA), pGEMT oder pGEM-T-Easy (Promega) genutzt. Zur Erstellung des Knock-out Konstruktes wurde der pGNA-Vektor genutzt.

\section{IV.2.9 GRÖßENMARKER}

Für die DNA-Auftrennung wurden verschiedene Größenmarker verwandt:

a) $1 \mathrm{~kb}$-Marker (Biolabs): 
kb: 10,0, 8,0, 6,0, 5,0, 4,0, 3,0, 2,0, 1,5, 1,0, 0,5

b) 100 bp-Marker (Biolabs):

bp: $1517,1200,1000,900,800,700,600,500,400,300,200,100$

c) $\lambda$ - Marker:

bp: $14000,8000,7000,7500,6500,4300,3600,2400,1900,1300,1000,700$

Als Größenmarker für die RNA-Auftrennung wurde der RNA-Marker 0,28-6,58 $\quad \mathrm{kb}$ von Promega verwandt:

bp: $6583,4981,3638,2604,1908,1383,955,623,281$

\section{IV.2.10 OLIGONUKLEOTIDE}

Die Oligonukleotide dienten entweder als Sequenzierprimer oder sie wurden zur PCR benutzt. Sie wurden von den Firmen Eurogentec (Köln) oder NAPS (Göttingen) bezogen. Die folgende Aufzählung zeigt ausschließlich die wichtigsten Oigonukleotide:

T7-Primer (Stratagene) : 5'-CTA ATA CGA CTC ACT ATA GGG C-3'

T3-Primer (Stratagene) : 5'-AAT TAA CCC TCA CTA AAG GG-3'

Primer neoA: 5'- CGG ATC AAG CGT ATG ATG CAG CCG -3'

Primer neoB: 5' - CAA GAT GGA TTG CAC GCA GG- 3'

Primer lacZ1: 5' - TTGGCGTAAGTGAAGCGAC- 3'

Primer lacZ2: 5' - AGCGGCTGATGTTGAACTG- 3'

\section{IV.2.11 FILME}

Alle Farbfotografien wurden mit den Kunstlichtfilmen, Extrachrome $320 \mathrm{~T}$ und 64T der Firma Kodak gemacht. Die Autoradiogramme wurden auf XAR-3 oder BIOMAXFilmen (beide von der Firma Kodak) exponiert, und die in-situ-Hybridisierungen auf Gewebeschnitten wurde mittels Kodak NTB-2 Flüssigfilm visualisiert.

\section{IV.2.12 PHOTOARBEITEN UND SEQUENZBEARBEITUNG}

Die Photos der Embryonen bzw. Schnitte wurden mit Zeiss-Mikroskopen (Binokular und Axiophot) aufgenommen und digital weiterverarbeitet. DNA-Sequenzbearbeitung wurden mit den Computerprogrammen Sequencher, DNA-Strider, GCG (Genetics Computer Group Inc.), Multialign und BLAST (NCBI) durchgeführt.

Die Genbank-Nummern (Accession number) der bearbeiteten Iroquois-Sequenzen lauten: Irx1 (Y15002); Irx2 (Y15000); Irx3 (Y15001); Irx4 (AF124732); Irx5 (AF271053); Irx6 (AJ271055). 


\begin{tabular}{|c|c|c|}
\hline Kanamycin: & Tetracyclin: & Ampicillin: \\
\hline $\begin{array}{l}10 \mathrm{mg} / \mathrm{ml} \text { in } \mathrm{H}_{2} \mathrm{O} \text { gelöst und bei }-20^{\circ} \mathrm{C} \\
\text { gelagert }\end{array}$ & $\begin{array}{l}12,5 \mathrm{mg} / \mathrm{ml} \text { in Ethanol gelöst und } \\
\text { bei }-20{ }^{\circ} \mathrm{C} \text { gelagert }\end{array}$ & $\begin{array}{l}25 \mathrm{mg} / \mathrm{ml} \text { in } \mathrm{H}_{2} \mathrm{O} \text {, steril filtriert, } \\
\text { und bei }-20^{\circ} \mathrm{C} \text { gelagert }\end{array}$ \\
\hline Proteinase K: & Phenol/Chloroform/ & Zellkulturmedien \\
\hline $\begin{array}{l}\text { Proteinase } \mathrm{K} \text { (Boehringer) wurde mit } \\
\text { einer Endkonzentration von } 20 \mathrm{mg} / \mathrm{ml} \text { in } \\
\mathrm{H}_{2} \mathrm{O} \text { gelöst und bei }-20^{\circ} \mathrm{C} \text { aufbewahrt. }\end{array}$ & $\begin{array}{l}\text { Isoamylalkohol : } \\
\text { Mischung aus Phenol, } \\
\text { Chloroform und Isoamylalkohol } \\
\text { (PCI) im Volumenverhältnis } \\
25: 24: 1 \text {. }\end{array}$ & $\begin{array}{l}\text { Medien stammten von den } \\
\text { Firmen Gibco (Paisley, } \\
\text { England), Flow Laboratories } \\
\text { (Irvine, England) und Boehringer } \\
\text { (Mannheim). }\end{array}$ \\
\hline $\begin{array}{l}\text { EtBr-Lösung: } \\
100 \mathrm{mg} \text { Ethidiumbromid in } 10 \mathrm{ml} \mathrm{H}_{2} \mathrm{O} \\
\text { gelöst und im Dunkeln aufbewahrt; } \\
\text { verwendete Konzentration betrug } 2 \mathrm{mg} / \mathrm{ml} \text {. }\end{array}$ & $\begin{array}{l}\text { RNase A: } \\
10 \mathrm{mg} / \mathrm{ml} \text { in } 10 \mathrm{mM} \mathrm{Tris} / \mathrm{HCl} \\
(\mathrm{pH} 7,5), 15 \mathrm{mM} \mathrm{NaCl} \text { gelöst, } \\
\text { zur Inaktivierung der DNasen für } \\
15 \mathrm{Min} \text {. bei } 95^{\circ} \mathrm{C} \text { inkubiert und } \\
\text { langsam auf RT abgekühlt; bei - } \\
20^{\circ} \mathrm{C} \text { gelagert }\end{array}$ & \\
\hline
\end{tabular}

\section{IV.3 METHODEN}

Alle molekularbiologischen Standardmethoden, die nachfolgend nicht aufgeführt sind, wurden nach der Beschreibung von Sambroock oder Ausubel durchgeführt (Sambroock et al., 1989)(Ausubel et al., 1987).

\section{IV.3.1 ISOLIERUNG VON PLASMID-DNA AUS BAKTERIEN}

\section{PLASMIDPRÄPARATION MIT DEM QIAPREP SPIN MINIPREP KIT}

Zur schnellen Gewinnung kleiner Mengen hochreiner Plasmid-DNA wurde der "QIAprep Spin Miniprep Kit" (Qiagen, 2000) von der Firma Qiagen (Düsseldorf) verwendet. Hierbei handelt es sich um eine modifizierte Form der alkalischen Lyse (Birnboim and Doly, 1979) in Verbindung mit einer Affinitätsaufreinigung an einer Silicongelmembran, die bei hohen Salzkonzentrationen DNA bindet und bei niedrigen eluiert. Die jeweiligen Zusammensetzungen der Puffer P1, P2, N3, PB, PE und EB sind in den Herstellerangaben zu finden. 
Es wurden $5 \mathrm{ml}$ einer E. coli-Kultur ü.N. in LB-Medium mit Selektionsmarker bei $37^{\circ} \mathrm{C}$ angezogen. Die Kultur wurde $10 \mathrm{Min}$. mit $4.000 \mathrm{rpm}$ bei $4{ }^{\circ} \mathrm{C}$ pelletiert und der Überstand verworfen. Das Pellet wurde in $250 \mu 1$ Puffer P1 resuspendiert und die Lösung in ein Eppendorfgefäß überführt. Danach wurden $250 \mu$ Puffer P2 zugeben, durch vorsichtiges Schwenken gemischt und nach maximal 5 Min. Inkubation bei RT $350 \mu 1$ Puffer N3 zugegeben. Nach erneutem Mischen wurde 1 Min. mit $13.000 \mathrm{rpm}$ bei RT zentrifugiert und der Überstand auf die QIAprep Spin-Säule gegeben. Durch kurze Zentrifugation mit $13.000 \mathrm{rpm}$ bei RT wurde die DNA an die Säulenmatrix gebunden und mit 0,75 ml Puffer PE gewaschen. Die DNA wurde in ein sauberes Eppendorfgefäß eluiert, wozu $50 \mu 1$ Puffer EB auf die Säule gegeben, 1 Min. bei RT inkubiert und danach erneut 1 Min. mit $13.000 \mathrm{rpm}$ bei RT zentrifugiert wurden. Die erwartete DNA Konzentration entspricht 200-400 ng/ $\mu \mathrm{l}$.

\section{PLASMIDISOLATION MIT DEM QIAFILTER MAXIPREP KIT}

Zur Aufreinigung größerer Mengen hochreiner Plasmid-DNA wurde der "QIAfilter Plasmid Maxi Kit" (Qiagen, 2000) nach den Angaben des Herstellers verwendet. Der Kit arbeitet nach einer modifizierten Form der alkalischen Lyse (Birnboim and Doly, 1979), diesmal in Verbindung mit einer Anionen-Austauschersäule. Die jeweiligen Zusammensetzungen der Puffer P1, P2, P3, QBT, QC, QF und TE sind in den Herstellerangaben zu finden.

Es wurden $100 \mathrm{ml}$ E. coli-Kultur ü.N. in LB-Medium mit Selektionsmarker bei $37^{\circ} \mathrm{C}$ in einem Erlenmeyerkolben angezogen, wenn das verwendete Plasmid mit ca 200-500 Kopien pro Beakterienzelle vorkommt. Die Kultur wurde durch 10minütige Zentrifugation mit $4.000 \mathrm{rpm}$ bei $4^{\circ} \mathrm{C}$ pelletiert. Der Überstand wurde verworfen und das Pellet in $10 \mathrm{ml}$ kaltem P1-Puffer resuspendiert. Nach der Zugabe von $10 \mathrm{ml}$ P2-Puffer wurde 6 mal invertiert, 5 Min. bei RT inkubiert und $10 \mathrm{ml}$ gekühlter P3-Puffer zugegeben. Der Überstand wurde in die QIAfilter Cartridge gefüllt. Während der nun folgenden 10 Min. Inkubation bei RT wurden eine QIAGEN-tip 500-Säule mit $10 \mathrm{ml}$ QBT-Puffer äquilibriert. Das Zellysat wurde durch die QIAfilter Cartridge gedrückt und das klare Lysat auf die QIAGEN-tip 500-Säule auftragen. Es folgte zweimaliges Waschen der Säule mit je $30 \mathrm{ml}$ QC-Puffer. Die DNA wurde mit $15 \mathrm{ml}$ QF-Puffer eluiert, durch Zugabe von 10,5 ml eiskaltem Isopropanol gefällt und durch eine $30 \mathrm{Min}$. 
Zentrifugation bei $4{ }^{\circ} \mathrm{C}$ und 15.000 g pelletiert. Der Überstand wurde verworfen, die DNA mit 5 bis $10 \mathrm{ml} 70 \%$ igem Ethanol gewaschen und erneut durch Zentrifugation mit $15.000 \mathrm{~g}\left(4^{\circ} \mathrm{C}, 10 \mathrm{Min}\right.$.) pelletiert. Nach dem vollständigen Entfernen des Überstandes wurde die isolierte Plasmid-DNA an der Luft getrocknet ( ca 30 Min. RT) und in 1/10 TE resuspendiert.

\section{IV.3.2 KONZENTRATIONSBESTIMMUNG VON NUKLEINSÄUREN}

Konzentrationsbestimmungen von DNA und RNA wurden durch einen optischen Vergleich der Ethidiumbromidfluoreszenz von Standard-DNA und Probe in Agarosegelen durchgeführt (Sambroock et al., 1989) oder mit Hilfe eines Photospektrometers.

\section{IV.3.3 AGAROSE-GELELEKTROPHORESE}

Zur Trennung von DNA-Fragmente nach ihrer Größe wird die Agarosegelelektrophorese (Thorne, 1966) (Helling et al., 1974) (McDonell et al., 1977)(Johnson and Grossman, 1977)(Southern, 1975) verwendet, wobei die DNA entsprechend ihrer Größe und ihrer Form im elektrischen Feld zur Anode wandert.

Der aufzutrennenden Fragmentgröße entsprechend wurden 0,3 - 2 \%ige Agarosegele mit jeweils $0,1 \mu \mathrm{g} / \mathrm{ml}$ Ethidiumbromid versetzt verwendet. Als Laufpuffer diente $0,5 \mathrm{x}$ TBE. Die DNA wurde vor dem Auftragen mit Ladepuffer versetzt. Nach der Elektrophorese wurden die Gele bei kurzwelligem UV-Licht $(258 \mathrm{~nm})$ fotogafiert. Präparative Gele sollten, um die Bildung von Thymidin-Dimeren und Strangbrüche zu vermeiden, nur langwelligem, energieärmerem UV-Licht (Wellenlänge $>300 \mathrm{~nm}$ ) ausgesetzt werden. Für die Präperation von 0,3\%igen Gelen ist es zur Stabilisierung erforderlich, eine Unterlage aus einem 1\%igem Gel zu giessen. Für ein großes Gel wurden verwendet: 100ml 1\%iges Gel und 350ml 0,3\%igem Gel.

\section{IV.3.4 GEWINNUNG VON DNA-FRAGMENTEN AUS AGAROSEGELEN MIT DEM QIAEX GEL EXTRACTION KIT}

Die Gewinnung von DNA-Fragmenten aus Agaosegelen wurde mit Hilfe des "QIAEX Gel Extractions Kit" von der Firma Qiagen durchgeführt. Das Protokoll arbeitet nach dem Prinzip der selektiven Bindung von DNA an Selikon-Gel-Partikel in 
der Anwesenheit von hohen Salzkonzentrationen. Dabei macht man sich zunutze, dass DNA bei hohen Salzkonzentrationen an der Säulenmatrix haften bleibt, während Kontaminationen weggewaschen werden. Bei niedrigen Salzkonzentrationen kann die DNA eluiert werden. Die jeweiligen Zusammensetzungen der Puffer QX, PE und EB sind in den Herstellerangaben zu finden (Qiagen, 2000).

\section{IV.3.5 RESTRIKTIONSSPALTUNG VON DNA}

Das Restriktionsschneiden wurde gemäß den Angaben des Enzymherstellers durchgeführt. Restriktionsansätze mit mehreren Enzymen konnten gleichzeitig erfolgen, wenn die Enzyme dieselben Reaktionsbedingungen erforderten. Unterschieden sich die Reaktionspuffer nur in der $\mathrm{NaCl}$ Konzentration, wurde zuerst mit der niedrigeren Salzkonzentration und dem entsprechenden Enzym inkubiert, anschließend wurde die Salzkonzentration für das zweite Enzym eingestellt, bevor dieses zugegeben wurde. Benötigten die Enzyme unterschiedliche Ionen, mußte nach dem ersten Schneiden eine PCI-Extraktion (IV.3.6) mit anschließender Ethanolfällung (IV.3.7) durchgeführt werden, bevor mit dem zweiten Enzym geschnitten werden konnte. Die Reaktionsansätze wurden zum Teil zwischen verschiedenen Retsriktionsverdauen mit dem PCR-Purification Kit von Qiagen (28104) gereinigt.

\section{IV.3.6 AUfreinigung VON DNA-LÖSUNGEN MITTELS PHENOL/ CHLOROFORM-EXTRAKTION}

Bei der Phenol/Chloroform-Extraktion (Kirby, 1956)(Marmur, 1960)wurde zu einem Volumen einer wässrigen DNA-Lösung ein Volumen einer Mischung aus Phenol, Chloroform und Isoamylalkohol gegeben (Mengenverhältnis $25: 24: 1$ ). Nach intensivem Mischen auf dem Vortexer wurde die Emulsion zur Phasentrennung bei RT mit $13.000 \mathrm{rpm}$ für 5 Min. zentrifugiert. Danach befanden sich denaturierte Proteine, Membranbestandteile und organisch lösliche Moleküle in der unteren Phenol/ Chloroform-Phase und in der Interphase. Die DNA befand sich in der oberen wässrigen Phase. Zur einfacheren Handhabung bei der Phasentrennung wurde vor der Zentrifugation Wachs zugegeben, welches sich in der Interphase sammelte.

Die obere, wässrige Phase wurde vorsichtig abgenommen und in ein neues Röhrchen überführt. Je nach benötigtem Reinheitsgrad der DNA kann der Vorgang mehrmals 
wiederholt werden. Anschließend wurde, um Phenolspuren zu beseitigen, nach obigem Schema eine weitere Extraktion mit Chloroform/Isoamylalkohol (24:1) durchgeführt. Die DNA wurde in der Regel nach der Extraktion mit Ethanol (IV.3.7) gefällt.

\section{IV.3.7 ETHANOLFÄLLUNG VON DNA AUS WÄSSRIGEN LÖSUNGEN}

Es wurde zu der DNA-Lösung 1/10 ihres Volumens 5M Natriumacetat zugegeben. Danach wurden 2,5 Volumina des jetzigen Volumens absoluten (oder $96 \%$ igen) Ethanols zugegeben und gemischt. Die Fällung wurde für ca. $30 \mathrm{Min}$. bei $4{ }^{\circ} \mathrm{C}$ oder 5 Min. bei $-20{ }^{\circ} \mathrm{C}$ inkubiert. Zum Sedimentieren der gefällten DNA wurde für 5 bis 10 Min. bei $4{ }^{\circ} \mathrm{C}$ und $13.000 \mathrm{rpm}$ zentrifugiert und danach der Überstand abgenommen. Um die DNA zu waschen, z.B. um Salzreste zu entfernen, wurden $0,5 \mathrm{ml} 70 \%$ Ethanol in ein Eppendorfgefäß mit gefällter DNA gegeben und kräftig gemischt. Es folgte wieder eine Zentrifugation für 3 - 5 Min.. Der Überstand wurde vorsichtig entfernt. Nach dem Trocknen des Pellets wurde die DNA in 1/10 TE oder Wasser $(\mathrm{pH}>6.0)$ aufgenommen.

\section{IV.3.8 ISOPROPANOLFÄLLUNG VON DNA AUS WÄSSRIGEN LÖSUNGEN}

Eine Isopropanolfällung hat den Vorteil, dass zur Fällung nur weniger Isopropanol (als Ethanol im Vergleich) zugegeben werden muß und dass die DNA mit weniger Salz ausfällt. Nachteile der Isopropanolfällung sind die geringere Flüchtigkeit des Isopropanols und das weniger feste und durchsichtigere Pellet nach der Zentrifugation.

Anstatt Ethanol wurden 0,7 Volumina Isopropanol zur DNA-Lösung zugegeben. Die Methodik ist analog zur Ethanolfällung.

\section{IV.3.9 LIGATION VON DNA-FRAGMENTEN}

Das Enzym T4-DNA-Ligase katalysiert die Bildung einer Phosphodiesterbindung zwischen der 3'-OH-Gruppe am Ende eines DNA-Stranges und der 5'-Phosphatgruppe am Ende eines anderen DNA-Stranges. Zum Ablaufen dieser endergonischen Reaktion ist ATP erforderlich. Die Produkte einer Ligation wurden in E. coli transformiert und so vermehrt.

Ligationen wurden mit 10 - 100 ng Vektor und dem 3-fachen molaren Überschuß des entsprechenden Fragments in Ligase-Puffer mit $1 \mathrm{mM}$ ATP und 1 U T4-DNA-Ligase 
angesetzt. Überhang-Ligationen (,sticky ends”) wurden 3 h. bei $20^{\circ} \mathrm{C}$ oder ü.N. bei 14 ${ }^{\circ} \mathrm{C}$, Ligationen mit stumpfen Enden (,,blunt ends”) stets ü.N. bei $14{ }^{\circ} \mathrm{C}$ inkubiert.

10X LIGASE-PUFFER:

$660 \mathrm{mM}$ Tris $/ \mathrm{HCl}(\mathrm{pH} 7,6)$

$66 \mathrm{mM} \mathrm{MgCl}_{2}$

$0,1 \mathrm{M}$ DTT

\section{IV.3.10. „BLUNT END"-KLONIERUNG}

Sollten Fragmente mit überhängenden 5'- oder 3'- Enden in einen „blunt end"-Vektor kloniert wurden, so wurden:

- 5' Überhänge mit Klenow-Fragment der DNA-Polymerase I (Boehringer Mannheim) und den entsprechenden Nukleotidmix direkt im Reaktionsansatz aufgefüllt (Klenow arbeitet in den meisten Puffern zufriedenstellend).

- 3' Überhänge mit T4-Polymerase (stärkere 3' - 5' Exonukleaseaktivität als Klenow) abgebaut.

\section{IV.3.11 TRANSFORMATION VON BAKTERIEN}

\section{HERSTELLUNG ELEKTROKOMPETENTER BAKTERIEN}

Bei der Elektroporation wird eine Mischung aus Bakterien und DNA einem kurzen, aber intensiven elektrischen Feld von 1,8 kV, welches einen exponentiellen Abfall zeigt, ausgesetzt (Dower et al., 1988). Dies führt zur vorübergehenden Bildung von Poren in der Membran von lebenden Zellen (Calvin and Hanawalt, 1988), durch welche die DNA in die Zelle gelangen kann. Die Porenentstehung ist vermutlich darauf zurückzuführen, dass sich die Membranmoleküle der Phospholipiddoppelschicht in einem elektrischen Feld als Dipol verhalten und die Struktur der Membran so verändert wird (Neumann et al., 1982).

Zur Herstellung elektrokompetenter Bakterien wurden E. coli auf einer LB-Platte ausgestrichen und ü.N. bei $37{ }^{\circ} \mathrm{C}$ inkubiert. Von dieser Platte wurde eine einzelne Kolonie in $5 \mathrm{ml}$ LB-Medium angeimpft und $5 \mathrm{~h}$ bis ü.N. bei $37^{\circ} \mathrm{C}$ leicht geschüttelt. Mit diesen $5 \mathrm{ml}$ wurde $11 \mathrm{LB}-L o ̈ s u n g ~ a n g e i m p f t$ und bei $37{ }^{\circ} \mathrm{C}$ geschüttelt (300 rpm), bis eine $\mathrm{OD}_{600}$ von 0,6 erreicht wurde. Nun wurde das Wachstum gestoppt, indem die Bakterien ca. 15 - 30 Min. in einem Eiswasserbad abgekühlt wurden. Hiernach wurden die Zellen durch ein 15 Min. Zentrifugieren $\left(4200 \mathrm{rpm}, 4{ }^{\circ} \mathrm{C}\right)$ pelletiert. Die Bakterien 
wurden in 11 eiskaltes $\mathrm{ddH}_{2} \mathrm{O}$ aufgenommen und nach dem Lösen wie bereits beschrieben erneut pelletiert. Dieser Waschschritt wurde mehrfach wiederholt, doch jedesmal wurde das Pellet nur kleineren Mengen $\mathrm{ddH}_{2} \mathrm{O}$ aufgenommen. Die letzten Schritte entsprechen 0,5 $1 \mathrm{ddH}_{2} \mathrm{O}$ bzw. $20 \mathrm{ml} 10 \%$ Glycerinlösung aufgenommen. Nach erneuter Zentrifugation wurde das nun erhaltene Pellet in 2 - $3 \mathrm{ml} 10 \%$-Glycerinlösung aufgenommen und gut gemischt. Die Konzentration betrug nun in etwa $3 * 10^{10}$ Zellen/ ml. Danach wurden die Bakterien aliquotiert und bei $-70{ }^{\circ} \mathrm{C}$ gelagert. Die Zellen sind nun fertig für eine Elektroporation und können nach Bedarf aufgetaut werden. Generell ist es besser einige Zellen während der Präperation zu verlieren, als sie zu lange von $4{ }^{\circ} \mathrm{C}$ zu nehmen oder sie zu stark zu zentrifugieren. Weniger ist mehr.

\section{TRANSFORMATION DURCH ELEKTROPORATION}

Die kompetenten Bakterien (ca. $50 \mu \mathrm{l}$ ) wurden auf Eis aufgetaut und mit dem Ligationsansatz gemischt. Danach wurden die Bakterien in kalte Elektroporationsküvetten überführt und der Elektroporationapparat eingestellt $(1,8 \mathrm{kV}$, $25 \mathrm{mF}$ und $200 \mathrm{~W}$ beim Pulskontroller). Nach der Elektroporation wurde direkt $1 \mathrm{ml}$ SOC-Medium zu den Bakterien gegeben. Die Bakterienlösung wurde in ein steriles Reaktionsgefäß transferiert und ca. 30 Min. bei $37{ }^{\circ} \mathrm{C}$ leicht geschüttelt, bevor sie auf Selektivagar ausplattiert wurde.

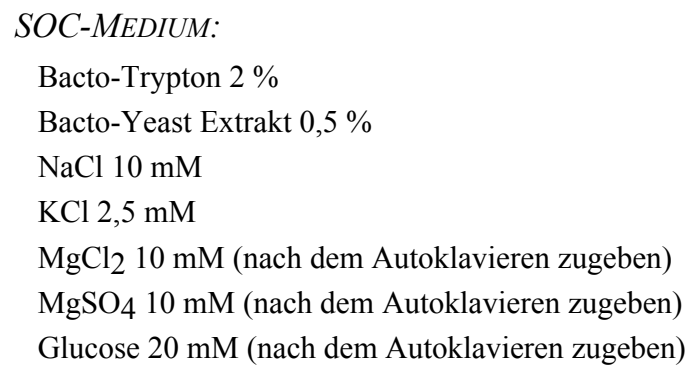

\section{IV.3.12 SEQUENZIERUNG ("CYCLE SEQUENCING")}

Zum Sequenzieren der DNA wurde ein Verfahren benutzt, das auf der kontrollierten Unterbrechung der DNA-Synthese beruht (Sanger et al., 1977) (Tabor and Richardson, 1987). Einzelsträngige DNA dient dabei als Matrize für die Synthese eines neuen Stranges. Es wurden variable Primer zugegeben, die mit der DNA hybridisieren kann. DNA-Polymerasen benötigen für ihre Syntheseaktivität einen kurzen Abschnitt doppelsträngiger DNA. Zusätzlich zu den Desoxyribonukleotiden wurden auch 
Didesoyribonukleotide (ddNTPs) in den Reaktionsansatz gegeben. Werden die ddNTPs in den neuen DNA-Strang eingebaut, so stoppt das Kettenwachstum, da keine weitere Phosphodiesterbindung geknüpft werden kann. Über die unterschiedliche Länge der neu entstandenen DNA-Stränge läßt sich die Basenabfolge nach einer gelelektrophoretischen Auftrennung ermitteln. Längenunterschiede von einem Basenpaar können aufgelöst werden. Die ddNTPs sind je nach Base unterschiedlich fluoreszenz-markiert, so dass nach einer Gel-Elektrophorese jedes DNA-Fragment mit einer Laserapparatur detektiert werden kann.

Die Bestimmung der Nukleotidsequenzen wurde auf einem ABI PRISM-377 DNA Sequencer durchgeführt. Im Reaktionsansatz wurden 300 - 400 ng DNA, 10 pmol Primer und 4,5 ml Big Dye Terminator Cycle Sequencing Kit-Lösung zugegeben. Die Reaktion fand in einem Gesamtvolumen von 11,5 - 13,5 ml statt. Das Cycle sequencingProgramm $\left(30^{\prime \prime} 95^{\circ} \mathrm{C}, 10^{\prime \prime} 50^{\circ} \mathrm{C}, 4^{\prime} 60^{\circ} \mathrm{C}, 25\right.$ Zyklen) wurde in einem Biometra TrioThermoblock durchgeführt. Nach der Reaktion wurde der Ansatz mit Ethanol gefällt und im Big Dye-Auftragspuffer aufgenommen. Die Reaktion wurde dann auf das Sequenziergel aufgetragen. Die Integrale werden mit der Computersoftware Sequencer ausgewertet.

\section{IV.3.13 POLYMERASE-KETTENREAKTION (PCR)}

(Saiki et al., 1985)(Saiki et al., 1986)(Saiki et al., 1988)(Mullis et al., 1986)

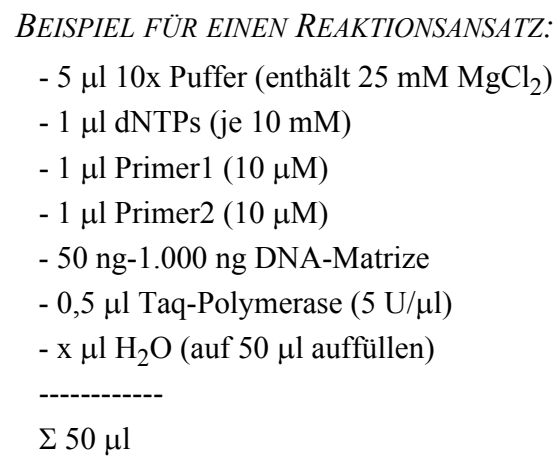




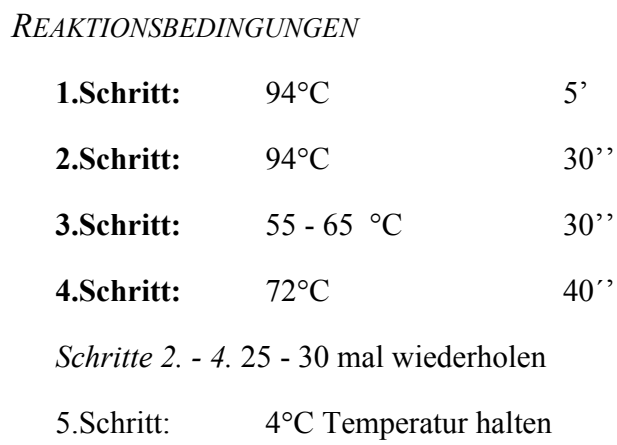

GENOTYPISIERUNGS-PCR:

Zum Genotypisieren wurde zum einen eine Irx2-WT-PCR, die den deletierten Intronbereich zwischen dem dritten und dem vierten Exon (Primer $\mathrm{F}+\mathrm{V}$ oder $\mathrm{B}+\mathrm{Z}$ ) erfaßt, und zum anderen eine Neomycin- oder lacZ-PCR durchgeführt. Das Geschlecht embryonaler Tiere wurde durch eine PCR auf das SRY-Gens des Y-Chromosoms ermittelt.

\begin{tabular}{|c|c|c|}
\hline IRX2-WT-PCR & NEO-PCR & $L A C Z-P C R$ \\
\hline Ansatz (wie oben beschrieben) & Ansatz (wie oben beschrieben) & Ansatz (wie oben beschrieben) \\
\hline Primer: FV + BZ & Primer: neoA + neoB & Primer: lacZ1 + lacZ2 \\
\hline Protokoll (wie oben beschrieben) & Protokoll (wie oben beschrieben) & Protokoll (wie oben beschrieben) \\
\hline Annealingtemperatur: $65^{\circ} \mathrm{C}$ & Annealingtemperatur: $65^{\circ} \mathrm{C}$ & Annealingtemperatur: $65^{\circ} \mathrm{C}$ \\
\hline Zyklenzahl: 30x & Zyklenzahl: $25 \mathrm{x}$ & Zyklenzahl: 30x \\
\hline
\end{tabular}

Die PCR-Reaktion wurde in einem Biometra Trio-Thermoblock mit Deckelheizung durchgeführt.

\section{IV.3.14 SOUTHERN-BLOT-ANALYSE}

Die nachfolgend aufgeführt Analyse wurde nach der Beschreibung von Southern oder Chomczynski durchgeführt (Southern, 1975)(Chomczynski and Quasba, 1984).

Mit Restriktionsenzymen geschnittene DNA wurde in Agarosegelen aufgetrennt, gefärbt und mit einem Längenmaß fotogafiert. Das Gel wurde 15 Min. lang unter Schütteln mit 0,25 M HCl behandelt (Depurinisierung; reduziert die Größe der DNAFragmente im Gel und verbessert dadurch die Effizienz, mit der große Fragmente auf die Filter transferiert werden können) und anschließend mit VE-Wasser gespült. Da ausschließlich Nylon-Memranen verwendet wurden, konnte der Transfer der DNA unter alkalischen Bedingungen erfolgen (,alkalisches Blotting”). Hierzu wurde die DNA für 
mindestens 30 Min. in Denaturierungslösung denaturiert und anschließend ca. 30 Min. in der Neutralisierungslösung geschwenkt. Zum Blotten wurde der Aufbau nach Southern verwendet. Als Transferlösung diente 20x SSC. Der Transfer dauerte 12-16 h, je nach Größe der Fragmente und Menge der DNA in dem Gel. Nach dem Blotten wurde die Membran in 2x SSC gespült, luftgetrocknet und bei $80^{\circ} \mathrm{C}$ für $1 \mathrm{~h}$ gebacken. Anschließend wurde die DNA durch Bestrahlung mit langwelligem UV-Licht $\left(0,3 \mathrm{~J} / \mathrm{cm}^{2}\right)$ kovalent auf dem Filter fixiert.

DENATURIERUNGSLSG.:
$0,5 \mathrm{M} \mathrm{NaOH}$
$1,5 \mathrm{M} \mathrm{NaCl}$

DENATURIERUNGSLSG.:

$1,5 \mathrm{M} \mathrm{NaCl}$

\author{
NEUTRALISIERUNGSLSG.: \\ $1,5 \mathrm{M} \mathrm{NaCl}$ \\ $0,5 \mathrm{M}$ Tris \\ $\mathrm{HCl}(\mathrm{pH} 7,2)$
}

\section{IV.3.15 RADIOAKTIVE MARKIERUNG VON DNA- UND RNA-BLOTS}

\section{RADIOAKTIVE MARKIERUNG VON DNA-FRAGMENTEN}

Die radioaktive Markierung von DNA-Fragmenten erfolgte mit dem "Multiprime DNA labelling system" von Amersham. Bei diesem System (Feinberg and Vogelstein, 1983) wird doppelsträngige DNA bei $95^{\circ} \mathrm{C}$ zu Einzelstrang-DNA denaturiert. Zu der ssDNA (>50ng) werden Klenow-Enzym, Zufallssequenz-Hexamerprimer, dNTPs und ${ }^{32} \mathrm{P}$-markiertes dCTP gegeben. Bei der Polymerisation werden neben normalen dNTPs auch ${ }^{32} \mathrm{P}-\mathrm{dCTP}$ in den Strang eingebaut.

Um die Reaktion zu stoppen, wurde die Probe auf $50 \mathrm{ml}$ mit STE aufgefüllt und über eine G-50-Mikrosäule (Sephadex G-50 Probe Quant; Pharmacia) gegeben. Die Präparation der Säule umfaßt kurzes vortexen sowie das Aufbrechen der Ausflußöffung. Die Säule wurde in ein Eppendorfgefäß gestellt und bei 735 xg 1 Min. zentrifugiert, das Eluat wird verworfen. Die Reaktionsmischung wird vorsichtig auf die Säule pipettiert und für zwei Min. bei 735 xg zentrifugiert. Der Durchfluß enthält die aufgereinigte Sonde, die freien Nukleotide wurden von der Säule zurückgehalten.

Um die Qualität der Sonde zu prüfen, wurden $1 \mu \mathrm{l}$ von $50 \mu$ l Säulendurchfluß für eine Szintillationszählung eingesetzt. Das Gesamtvolumen der Sonde sollte ein Signal von 15 - 25 Millionen counts liefern. Die Sonde wurde für 10 Min. bei $95^{\circ} \mathrm{C}$ denaturiert und sofort danach in die Hybridisierungslösung gegeben. 
Bei der Genotypisierung kam es bei einigen Sonden zu starkem Signal-Hintergrund. In diesem Fall wurde die Sonde mit großen Mengen denaturierter WT-DNA abgesättigt. Nach der Denaturierung von DNA und Sonde wurden beide für 20 Min. bei $65^{\circ} \mathrm{C}$ inkubiert und erst dann zur Membran gegeben.

\section{HYBRIDISIERUNG DER MEMBRANEN}

Die Prähybridisierung, Hybridisierung und das Waschen der Membran erfolgte in Hybridisierungsflaschen, die im $65^{\circ} \mathrm{C}$-Schrank kontinuierlich gedreht wurden.

Die Membranen wurden zunächst für mindestens 1 Stunde (meist ca. 2 h) mit $20 \mathrm{ml}$ Hybridisierungspuffer prähybridisiert. Nach der Prähybridisierung wurde die vorbereitete, radioaktiv markierte DNA-Sonde für 10 Min. im Heizblock bei $95^{\circ} \mathrm{C}$ denaturiert und sofort in $12 \mathrm{ml}$ Hybridisierungslösung (auf $65^{\circ} \mathrm{C}$ vorgewärmt) gegeben. Die Konzentration der Sonde sollte ungefähr $10^{6}$ counts $/ \mathrm{ml}$ betragen. Nach Verwerfen der Prähybridisierungslösung wurde die radioaktive Hybridisierungslösung in die Hybridisierungsflasche gefüllt. Die Hybridisierung wird im $65^{\circ} \mathrm{C}$-Schrank über Nacht durchgeführt. Die Membranen wurden mehrmals je 30 Min. bei $65{ }^{\circ} \mathrm{C}$ gewaschen, wobei die Salzkonzentrationen der Waschlösungen konstant abnahmen.

Die Exposition erfolgte mit einem Biomax-Film bei $-70{ }^{\circ} \mathrm{C}$. Die Expositionsdauer betrugt meistens ein bis drei Tage, bei der externen Sonde auf genomischer DNA allerdings 14 Tage. Die Entwicklung des Films wurde mit einer Entwicklermaschine durchgeführt.

\section{GENOTYPIEREN DER IRX2-MAUSMUTANTEN MITTELS SOUTHERN-BLOT ANALYSE}

Das Genotypisieren der Irx2-Mausmutanten erfolgte ab dem embryonalen Alter von E10,5 mittels Southern-Blot-Analyse. Die genomische DNA wurde enzymatisch mit BamHI verdaut. Die Hybridisierung erfolgte dann mit der radioaktiv markierten extSonde. Drei Modifikationen haben sich dabei als sinnvol herausgestellt. Zum einen wurde die markierte Sonde mit WT-DNA gegenhybridisiert, die Membran mit FischSperma-DNA in der Prähybridisierung abgesättigt und zum anderen hat sich der Hybridisierungspuffer der Fa. Stratagene (Quickhyb-Solution) als signalverstärkend erwiesen. 


$\begin{array}{lll}\text { Waschschritte: } & & \\ \text { Zeit: } & \text { Lösungen: } & \text { Temperatur: } \\ 2 \text { x } 15 \text { Min. } & 2 \times \mathrm{SSC} / 0,1 \% \mathrm{SDS} & \mathrm{RT} \\ 1 \times 30 \mathrm{Min} . & 0,1 \times \mathrm{SSC} / 0,1 \% \mathrm{SDS} & 65^{\circ} \mathrm{C}\end{array}$

\section{IV.3.16 DURCHMUSTERN EINER CDNA- ODER GENOMISCHEN MAUS-DNA- BIBLIOTHEK NACH REKOMBINANTEN BAKTERIOPHAGEN UND DEREN ISOLIERUNG}

Das nachfolgend aufgeführte Durchmustern einer DNA-Bank, wurde nach der Beschreibung von Ausubel durchgeführt (Ausubel et al., 1995).

\section{VORBEHANDLUNG DER WIRTSBAKTERIEN}

Von dem Bakterienstamm LE392/C600 wurde eine 100 ml-ü.N. Kultur in LBMedium mit 0,2 \% Maltose und $10 \mathrm{mM} \mathrm{MgSO} 4$ angesetzt. Am nächsten Tag wurden die Bakterien mit $4.000 \mathrm{rpm}$ bei $4{ }^{\circ} \mathrm{C}$ für $10 \mathrm{~min}$ abzentrifugiert. Das Pellet wurde in der Hälfte des ursprünglichen Volumens in $10 \mathrm{mM} \mathrm{MgSO}_{4}$ aufgenommen. Diese Bakterien waren nun für eine Infektion mit Lambda-Phagen kompetent. Die Bakterien wurden bei $4{ }^{\circ} \mathrm{C}$ aufbewahrt und blieben etwa eine Woche verwendbar.

\section{TITERBESTIMMUNG EINER PHAGENBIBLIOTHEK}

Die Ausplattierung einer genügend hohen Anzahl von Phagen aus einer Bibliothek war Voraussetzung für die erfolgreiche Identifizierung eines bestimmten Klons. Daher mußte der aktuelle Titer der verwendeten Bibliothek bekannt sein. Hierzu wurde jeweils eine Verdünnungsreihe in SM-Puffer angesetzt, um den Titer der Bibliothek durch Auszählen von Phagenplaques bestimmen zu können. Diese Reihe umfaßte in der Regel fünf Verdünnungen von $1: 10^{2}$ bis $1: 10^{6}$. Aus der Anzahl der Plaques unter Berücksichtigung der Verdünnungsfaktoren ließ sich die Zahl der infizierenden Phagen pro Volumeneinheit der Bibliothek errechnen.

\section{AUSPLATTIEREN DER PHAGENBIBLIOTHEK}

Die Phagen wurden mit einer Dichte ausplattiert, die gerade noch Einzelphagen erkennen ließ. Die gewünschte Phagenzahl wurde mit der entsprechenden Menge 
Bakterien 30 Min. bei $37^{\circ} \mathrm{C}$ inkubiert. Danach wurden die infizierten Bakterien mit ca. $46{ }^{\circ} \mathrm{C}$ warmem Topagar gemischt und auf $37{ }^{\circ} \mathrm{C}$ vorgewärmte Agarplatten plattiert. Nach Erstarren des Topagar wurden die Platten umgekehrt für ca. 5 - 9 h bei $37{ }^{\circ} \mathrm{C}$ inkubiert, bis die Plaques einen Durchmesser von ca. 1,0 $\mathrm{mm}$ erreicht hatten. Anschließend wurden die Platten bis zum Herstellen der Filter bei $4{ }^{\circ} \mathrm{C}$ aufbewahrt.

\section{TRANSFER DER PHAGEN AUF NYLON-MEMBRANEN UND HyBRIDISIERUNG}

Trockene ungeladene Nylonmembranen wurden in passender Größe beschriftet und mit der unbeschrifteten Seite auf den Phagenrasen gelegt und die Markierungen auf den äußeren Plattenboden übertragen. Nach ca. 1 Min. wurde der Filter abgezogen. Von der Platte konnten mehrere Filter nacheinander gezogen werden. Die Filter wurden mit der DNA-Seite nach oben in getränktes Whatman mit folgenden Lösungen gelegt:

1. DENATURIEREN:

5 Min. $1,5 \mathrm{M} \mathrm{NaCl}, 0,4 \mathrm{M} \mathrm{NaOH}$

2. NEUTRALISIEREN

5 Min. $1 \mathrm{M}$ Tris/ $\mathrm{HCl}(\mathrm{pH} 8), 1,5 \mathrm{M} \mathrm{NaCl}$

3. ÄQUILIBRIEREN

5 Min. 2x SSC

4. LUFTTROCKNEN

Zuletzt wurde die Phagen-DNA durch UV-Bestrahlung (300 m J/cm², $302 \mathrm{~nm})$ an die Nylonmembran kovalent gebunden. Mittels radioaktiver Hybridisierung konnten die positiven Phagenklone ermittelt werden.

\section{ISOLIERUNG REKOMBINANTER PHAGENKLONE}

Die Markierungen der hybridisierten Filter wurden auf die entwickelten Röntgenfilme entsprechend ihrer Lage übertragen, um die Signale den Phagen-Plaques auf den Agarplatten zuordnen zu können. Die ausgewählten Phagen-Plaques wurden mit sterilen Pipettenspitzen ausgestochen und in SM-Puffer transferiert. Die Phagen wurden ü.N. bei $4{ }^{\circ} \mathrm{C}$ oder 3 - 4 h. bei Raumtemperatur eluiert. In den folgenden Selektionsrunden („Rescreenings”) wurden die im ersten Durchgang erhaltenen Phagen in verschiedenen Verdünnungen ausplattiert, die Phagen-DNA wurde, wie oben beschrieben, auf Nylonmembranen transferiert, diese dann mit der radioaktiven Sonde hybridisiert und die entsprechenden positiven Phagenplaques ausgestochen. Dieses Nachmustern wurde solange wiederholt, bis eindeutige Einzelphagen isoliert werden konnten. 


\section{ANLEGEN EINEN PHAGENSTOCKS}

Mit dieser Methode wurde eine hochkonzentrierte Lösung ("high titer stock") der isolierten Phagen hergestellt, die als Grundstock für präparative Plattenlysate diente. Die Phagen wurden in einer Dichte ausplattiert, die eine konfluente Lyse ergab. Die Lysate wurden mit $10 \mathrm{ml} \mathrm{SM}$ (bei $15 \mathrm{~cm}$ Plattendurchmesser) überschichtet, und langsam bei 4 ${ }^{\circ} \mathrm{C}$ üN geschüttelt. Bakterien oder Agarosestücke wurden durch 10 min Zentrifugieren mit 3.000 rpm abgetrennt. Zur Abtötung der Bakterien wurde der Überstand mit einigen Tropfen Chloroform versetzt und bei $4{ }^{\circ} \mathrm{C}$ aufbewahrt. Die Phagen sind in dieser Lösung mehrere Monate bis Jahre haltbar, wenn auch mit deutlich fallendem Titer.

\section{DNA-ISOLIERUNG AUS LAMDA-PHAGEN (PLATTENLYSAT-METHODE)}

Der entsprechende Phagenklon wurde auf einer $150 \mathrm{~mm}$ Petrischale konfluent ausplattiert. Anschließend wurden die Phagen mit $10 \mathrm{ml}$ SM und einigen Tropfen Chloroform ü.N. bei $4{ }^{\circ} \mathrm{C}$ von der Platte gewaschen. Der Überstand wurde unter Zugabe von DNase und RNase (Endkonzentrationen jeweils $10 \mu \mathrm{g} / \mathrm{ml}$ ) $30 \mathrm{~min}$ bei $37^{\circ} \mathrm{C}$ in $50 \mathrm{ml}$ Röhrchen (Falcon) verdaut, zentrifugiert (3.500 rpm, $30 \mathrm{~min}$, Minifuge T) und der Überstand mit gleichem Volumen $20 \%$ Polyethylenglykol-6.000/2 M NaCl für $2 \mathrm{~h}$ (4 ${ }^{\circ} \mathrm{C}$ ) präzipitiert. Die Phagen wurden pelletiert (3.500 rpm, $30 \mathrm{~min}$ ), getrocknet, in $500 \mu 1$ SM gelöst und in ein Reaktionsgefäß überführt. Mit weiteren $200 \mu \mathrm{SM}$ wurden die Falcon-Röhrchen einmal nachgewaschen. Nach einer Chloroformextraktion erfolgte ein weiterer RNase-Verdau (Endkonzentration $20 \mu \mathrm{g} / \mathrm{ml} ; 15 \mathrm{~min}$ bei $37^{\circ} \mathrm{C}$ ) und ein Proteinase-K-Verdau (Endkonzentration von $10 \mu \mathrm{g} / \mathrm{ml}$; nach Zugabe von $5 \mu 110 \%$ SDS und $5 \mu 1$ 0,5 M EDTA-Lösung; $15 \mathrm{~min}$ bei $37^{\circ} \mathrm{C}$ ). Abschließend wurde eine Phenol- und Chloroform-Isoamylalkohol-Extraktion (nicht vortexen) der Phagen-DNA durchgeführt, diese mit dem gleichen Volumen Isopropylalkohol oder Ethanol gefällt und 30 min bei 13.000 rpm zentrifugiert. Die Phagen DNA wurde mit 70 \% Ethanol gewaschen, in 100 $\mu 1 \mathrm{TE}$ gelöst und bei $4{ }^{\circ} \mathrm{C}$ aufbewahrt.

SM-PUFFER:

$\mathrm{NaCl} 100 \mathrm{mM}$

$\mathrm{MgSO}_{4} 10 \mathrm{mM}$

Tris/HCl, pH 7,5 $50 \mathrm{mM}$

Gelatine $0,01 \%$ 


\section{IV.3.17 PRÄPARATION GENOMISCHER MAUS-DNA}

Das Gewebe (ca. $1 \mathrm{~cm}$ Schwanz oder embryonales Gewebe) wurde in $450 \mu 1$ Proteinase K-Puffer, der $50 \mu 1$ Proteinase K $(10 \mathrm{mg} / \mathrm{ml})$ enthielt, gegeben und über Nacht bei $56{ }^{\circ} \mathrm{C}$ inkubiert. Die unverdauten Haare und Knochen wurden am nächsten Tag abzentifugiert (5 Min., $13.000 \mathrm{rpm}$, Heraeus Biofuge A), die genomische DNA im Überstand mit $500 \mu 1$ Isopropanol gefällt und zentrifugiert (5 min, $13.000 \mathrm{rpm}$, Heraeus Biofuge A). Das DNA Pellet wurde einmal mit $70 \%$ Ethanol gewaschen und in $100 \mu 1$ TE gelöst (bei $37^{\circ} \mathrm{C}$ unter leichtem Schütteln). Für Embryonen jünger als E8,5 muß der gesamte Embryo zur PCR Analyse benutzt werden.

PROTEINASE-K-PUFFER:

$\mathrm{NaCl} 200 \mathrm{mM}$

Tris/HCl, pH $8.5100 \mathrm{mM}$

EDTA $5 \mathrm{mM}$

SDS $0,2 \%$

\section{IV.3.18 ARBEITEN MIT RNA}

\section{VORBEREITUNGEN FÜR DAS ARBEITEN MIT RNA}

Voraussetzung für das erfolgreiche Arbeiten mit RNA ist die Minimierung der RNAse-Aktivität sowie die Vermeidung von RNAse-Kontaminationen. Zu diesem Zweck wurden bei der Gewebepräparation sowie bei allen anderen Arbeiten mit RNA stets Handschuhe getragen. Das frisch präparierte Gewebe wurde bei $-70{ }^{\circ} \mathrm{C}$ aufbewahrt. Die Arbeitsfläche wurde vor Beginn gründlich mit Ethanol gereinigt. Sämtliche Glasgeräte wurden für $2 \mathrm{~h}$ bei $220^{\circ} \mathrm{C}$ gebacken und das Wasser für alle Lösungen mit 0,1 \% Diethylpyrocarbonat (DEPC) behandelt. Alle Lösungen wurden zusätzlich autoklaviert. Der Versuchsansatz wurde während der RNA-Präparation, wenn möglich, auf Eis gehalten. Verwendete Gelkammern, Schlitten und Kämme wurden vorher gründlich mit Seife bzw. 0,1 \% SDS gereinigt, in 0,25 M NaOH eingeweicht, dann mit DEPC-Wasser und nochmal mit 100 \%igem EtOH gespült.

ISOLIERUNG VON GESAMT-RNA AUS EMBRYONALGEWEBE MIT TRIZOL (LIFE TECHNOLOGIES)

Bei dem TRIzol-Protokoll wurde das Gewebe in einer monophasischen Mischung aus saurem Guanidiniumthiocyanat, saurem Phenol und Chloroform homogenisiert 
(Chomczynski and Sacchi, 1987)(Chomczynski, 1993). Guanidiniumthiocyanat ist ein sehr effektives Mittel zur Proteindenaturierung (Chomczynski and Sacchi, 1987); Extraktion mit saurem Phenol und Chloroform ermöglicht nach Zentrifugation die effektive Trennung von RNA in der wässrigen Phase von DNA und Protein in der Phenol/Chloroformphase.

Dazu wurden Embryonen verschiedenen Alters, Mausgehirne bzw. Lungen von 1 Tag und älteren Mäusen in PBS (mit DEPC) präpariert und sofort in flüssigem Stickstoff eingefroren. Das Gewebe wurde bei $-80{ }^{\circ} \mathrm{C}$ gelagert. Zur RNA-Präparation wurde eingefrorenes Gewebe direkt aus dem $-80{ }^{\circ} \mathrm{C}$-Schrank in ein steriles Greinerröhrchen mit Trizol gegeben. Es wurde $1 \mathrm{ml}$ Trizol pro 50 - $100 \mathrm{mg}$ Gewebe eingesetzt. Das Gewebe wurde solange homogenisiert, bis keine Gewebeteilchen mehr sichtbar sind. Die homogenisierte Probe wurde für 5 Min. bei Raumtemperatur inkubiert, um die vollständige Dissoziation von Nucleoproteinkomplexen zu ermöglichen. Nach Zugabe von $0,2 \mathrm{ml}$ Chloroform pro $1 \mathrm{ml}$ Trizol wurde das Röhrchen für 15 Sek. intensiv geschüttelt. Es schloß sich eine Inkubation bei Raumtemperatur für 2 - 3 Minuten an. Die Probe wurde zur Phasentrennung mit $12.000 \mathrm{~g}$ bei $4{ }^{\circ} \mathrm{C}$ für $15 \mathrm{Min}$. zentrifugiert. Die farblose obere Phase enthielt die RNA und wurde in ein neues Greinerröhrchen überführt. Die rote untere Phase enthielt DNA und Proteine und wurde verworfen. Zur RNA-Fällung wurden 0,5 ml Isopropanol pro eingesetztem $1 \mathrm{ml}$ Trizol zugegeben. Die Probe wurde für 10 Min. bei Raumtemperatur inkubiert und anschließend mit $12.000 \mathrm{~g}$ bei $4{ }^{\circ} \mathrm{C}$ für $10 \mathrm{Min}$. zentrifugiert. Die ausgefällte RNA bildete ein Pellet am Boden des Röhrchens. Der Überstand wurde entfernt und das Pellet mit mindestens $1 \mathrm{ml} 75 \%$ Ethanol pro $1 \mathrm{ml}$ eingesetztem Trizol gewaschen. Die Probe wurde mit einem Vortexer gemischt und mit $7.500 \mathrm{~g}$ bei $4{ }^{\circ} \mathrm{C}$ für 5 Min. zentrifugiert. Der Überstand wurde abgenommen und das Pellet getrocknet. Das Pellet wird in RNase-freiem DEPC- $\mathrm{H}_{2} \mathrm{O}$ aufgenommen. Damit sich die RNA besser löste, konnte sie für $10 \mathrm{Min}$. bei $50{ }^{\circ} \mathrm{C}$ inkubiert werden. Die RNA wurde bei $-80{ }^{\circ} \mathrm{C}$ gelagert.

ISOLIERUNG VON POLYA+ ${ }^{+}$RNA AUS GESAMT-RNA MIT DEM OLIGOTEX MRNA-KIT (MINIPRÄPARATION)

Der Oligotex-Kit von Qiagen beruht auf der Bindung von mRNA mit polyadenylierten 3'-Enden an Oligo-dT-Primer, die an eine Festphasenmatrix gekoppelt 
sind. Die Bindung erfolgt in einem Hochsalzpuffer, die Elution bei Niedrigsalzbedingungen (Qiagen, 2000).

Dazu wurde die Oligotex-Suspension auf $37{ }^{\circ} \mathrm{C}$, der Elutionspuffer auf $70{ }^{\circ} \mathrm{C}$ erwärmt. Die RNA wurde in $250 \mu \mathrm{l}$ DEPC- $\mathrm{H}_{2} \mathrm{O}$ gelöst. Dazu wurden $250 \mu \mathrm{l} 2 \mathrm{x}$ Bindepuffer und $15 \mu$ l Oligotex-Suspension gegeben und das ganze 3 Min. bei $65{ }^{\circ} \mathrm{C}$ inkubiert, um RNA-Sekundärstrukturen aufzulösen. Zur Hybridisierung der RNA an die Oligo-dT-Primer wurde 10 Min. bei RT inkubiert. Danach wurde 2 Min. mit $13.000 \mathrm{rpm}$ bei RT zentrifugiert und der Überstand verworfen. Das Pellet wurde in $400 \mu$ OW2 Waschpuffer resuspendiert und die Suspension auf Spin-Säule gegeben. Diese wurde 30 Sek. mit $13.000 \mathrm{rpm}$ bei RT zentrifugiert. Danach wurde ein zweites Mal mit $400 \mu \mathrm{l}$ OW2 Waschpuffer gewaschen. Nach erneuter Zentrifugation (30 Sek., 13.000 rpm, RT) wurde die Spin-Säule in RNase-freies Eppendorfgefäß gestellt und mit 30 - $50 \mu 1$ vorgeheiztem $\left(70{ }^{\circ} \mathrm{C}\right)$ Elutionspuffer durch eine 30 sekündige Zentrifugation mit 13.000 rpm bei RT eluiert. Zur besseren Ausbeute kann der Elutionsschritt nochmals wiederholt werden. Die Lagerung der polyA ${ }^{+}-\mathrm{RNA}$ erfolgte bei $-80{ }^{\circ} \mathrm{C}$.

\section{IV.3.19 NORTHERN BLOT}

Bei einem Northern Blot wird die RNA in einem denaturierenden FormaldehydAgarosegel aufgetrennt und danach mittels Kapillarkräften auf eine Nylonmembran übertragen und dort fixiert. Die Membran kann dann für eine Hybridisierung mit einer spezifischen Sonde benutzt werden.

\section{NORTHERN BLOT: ELEKTROPHORESE}

Um ein RNA-Gel mit einem Volumen von $100 \mathrm{ml}$ zu gießen, wurden $88 \mathrm{ml}$ DEPC$\mathrm{H}_{2} \mathrm{O}$ mit $1 \mathrm{~g}$ Agarose aufgekocht und die Flüssigkeit auf $55^{\circ} \mathrm{C}$ abgekühlt. Erst dann wurden $10 \mathrm{ml}$ 10x MOPS-Puffer und 1,8 ml Formaldehyd zugegeben und das Gel gegossen. Die Elektrophorese wurde 1x MOPS-Puffer als Laufpuffer zugegeben. Für die Probendenaturierung wurden 4,5 $\mu \mathrm{l}$ RNA-Lösung (ca. $20 \mu \mathrm{g}$ Gesamt-RNA oder 1-3 $\mu \mathrm{g}$ polyA ${ }^{+}-$RNA) mit 2,0 $\mu \mathrm{l}$ 10x MOPS-Puffer, 3,5 $\mu \mathrm{l}$ Formaldehyd und 10,0 $\mu \mathrm{l}$ deionisiertem Formamid versetzt. Die Mischung wurde für $15 \mathrm{Min}$. bei $55^{\circ} \mathrm{C}$ inkubiert und danach auf Eis abgekühlt. Nach Zugabe von $2 \mu$ l Auftragspuffer und $1 \mu$ EtBr wurden die Proben in die Geltaschen geladen. Der aufgetragene RNA-Marker wurde 
genauso behandelt. Der Gellauf erfolgte für ca. 3 Stunden bei 100 Volt, bis die Bromphenolblau-Bande ungefähr 2/3 des Gels durchlaufen hatte.

Nach dem Gellauf wurde auf dem UV-Tisch mit einem fluoreszierenden Lineal neben der Markerspur fotografiert, damit sich später die Größe der Marker-Banden bestimmen läßt. Dann wurde das Gel für 20 Min. in 20x SSC inkubiert. MOPS-Puffer, verwendetes $\mathrm{H}_{2} \mathrm{O}$ und sonstige Lösungen müssen RNase-frei sein.

\section{NORTHERN BLOT: TRANSFER}

Der Aufbau und der Ablauf des Northern Blots entsprechen dem des Southern Blots. Allerdings bedarf die bereits einzelsträngig vorliegende RNA keiner Denaturierung und Neutralisierung. Nach dem Blotten wurde die RNA durch UV-Bestrahlung $(300 \mathrm{~m} \mathrm{~J} /$ $\mathrm{cm}^{2}, 366 \mathrm{~nm}$ ) kovalent auf der Membran fixiert.

\section{NORTHERN BLOT: HYBRIDISIERUNG}

Prähybridisierung, Hybridisierung und Waschschritte wurden in rotierenden Hybridisierungsflaschen in Wärmeschränken analog zur Hybridisierung von DNABlots durchgeführt:

\section{PRÄHYBRIDISIERUNG \\ bei $65^{\circ} \mathrm{C}$ für 2 Stunden \\ HYBRIDISIERUNG \\ bei 63 - $65{ }^{\circ} \mathrm{C}$ ü.N. mit radioaktiver Sonde (ca. $10^{6}$ counts $/ \mathrm{ml}$ )}

\section{NORTHERN BLOT: WASCHSCHRITTE UND EXPOSITION}

Northernblots wurden auf folgende Weise gewaschen:

Waschschritt 1: frische Prähybridisierungslösung, 30 Min. bei $60{ }^{\circ} \mathrm{C}$

Waschschritt 2 - 4: Waschpuffer 20 Min. bei $60^{\circ} \mathrm{C}$

Danach wurde die Membran noch feucht in Plastikfolie eingeschweißt oder in Frischhaltefolie eingeschlagen und mit Klebebändern in einer Expositionskassette befestigt. Es wurden immer zwei Filme aufgelegt, wobei der eine nach 3 Tagen und der zweite je nach Stärke des Signals nach 1,5 - 3 Wochen entwickelt wurde. Die Exposition wurde bei $-80^{\circ} \mathrm{C}$ durchgeführt. Als Filmmaterial wurden Biomax-Filme benutzt. Die Entwicklung des Films erfolgte mit einer Entwicklermaschine. 


\section{IV.3.20 RADIOAKTIVE MRNA IN-SITU-HYBRIDISIERUNG AN SCHNITTEN}

Das nachfolgend aufgeführte radioaktive in-situ-Hybridisierung wurde nach der Beschreibungen von McDougall, Manning, Wilkinson und Hogan durchgeführt (McDougall et al., 1972)(Manning et al., 1975)(Wilkinson, 1992)(Hogan et al., 1994).

\section{ALLGEMEINES ZUR RADIOAKTIVEN IN-SITU-HYBRIDISIERUNG}

Die in-situ-Hybridisierung ist eine Methode, die zur Analyse von Expressionsmustern von Genen genutzt wird. Bei der radioaktiven mRNA-in-situ-Hybridisierung wird eine radioaktiv markierte RNA-Sonde hergestellt, die zur im Gewebe vorhandenen mRNA komplementär ist, an diese hybridisiert und sie so erkennbar macht. Ein Überziehen der Schnitte mit einer Filmemulsion und anschließendes Exponieren und Entwickeln läßt das radioaktive Signal als eine weiß erscheinende Färbung im Dunkelfeldmikroskop sichtbar werden. Zusätzlich werden die Schnitte einer histologischen Färbung (Giemsa oder HE) unterzogen, welche im Hellfeldmikroskop betrachtet werden kann.

Diese Methode ermöglicht organ-, gewebe- und unter Umständen auch zellspezifische Analyse des Expressionsmusters eines Gens. Zudem können im Gegensatz zum Whole-mount-in-situ-Hybridisierungsverfahren auch ältere Embryonen und adultes Gewebe ohne penetrationsprobleme bearbeitet werden.

\section{HERSTELLUNG EINER MATRIZE FÜR DIE IN-VITRO-TRANSKRIPTION}

Die entsprechenden Fragmente befanden sich in einem pBluescriptKS+ -Plasmid, das jeweils flankierend zum Polylinker hochspezifische Bakteriophagen-Promotoren besitzt (T3- und T7-Promotoren). Die $1 \mu \mathrm{g}$ Plasmid-DNA wurden mit einem geeigneten Restriktionsenzym linearisiert. Es ist für die spätere in-vitro-Transkription von Vorteil, wenn der Restriktionsverdau eine stumpfe Schnittstelle ergibt. Die Vollständigkeit der Enzymreaktion wurde auf einem Minigel kontrolliert. Nach einer Phenol- und Chloroformextraktion wurde eine Ethanolfällung durchgeführt. Die DNA wurde anschließend in $10 \mu 1$ DEPC-behandeltem Wasser aufgenommen.

\section{IN-VITRO-TRANSKRIPTION DER RNA-SONDEN}

Es wurde der Transkriptionskit von Boehringer (Ingelheim) verwendet. Folgender Transkriptionsansatz wurde bei RT pipettiert und danach 60 Min. bei $37{ }^{\circ} \mathrm{C}$ inkubiert: 


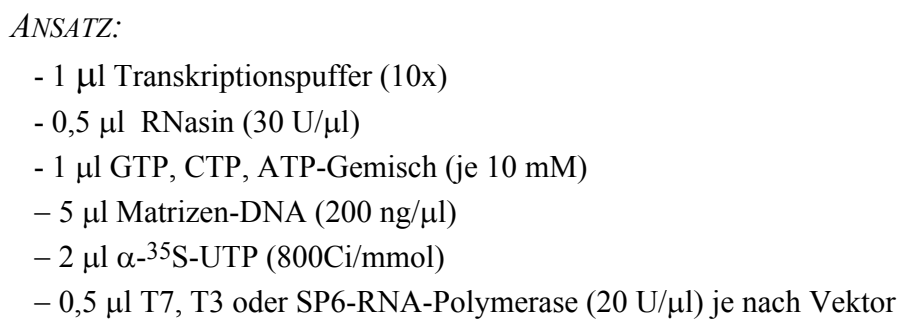

Die Gegenstrang-Sonde hybridisierte als Komplement an die zelluläre mRNA und bildete so stabile Hybride, die die Position der zellulären mRNA anzeigten. Die SinnSonde war dagegen nicht in der Lage, mit dem zellulären Transkript zu hybridisieren, da sie der zellulären mRNA entsprach, und diente so als Kontrolle für eventuelle Hintergrundreaktionen.

\section{AUFREINIGUNG DER RNA-SONDEN}

Nach der in-vitro-Transkription wurde die DNA-Matrize auf ein Volumen von $50 \mu 1$ aufgefüllt und zur Aufreinigung auf eine vorbereitete G-50-Mikrosäule (Sephadex Probe-Quant; Pharmacia) gegeben und 2 Min. mit 735 g bei RT zentrifugiert. Die bei der Transkription nicht eingebauten Nukleotide wurden dadurch entfernt. Zur RNA-Sonde, die sich im Eluat befand, wurden $50 \mu$ deionisiertes Formamid gegeben und $1 \mu 1$ der Sonde mit einer Szintillationslösung im Szintillationszähler gemessen.

\section{PRÄPARIEREN DER EMBRYONEN UND GEHIRNE FÜR DIE RNA-IN-SITU-ANALYSE}

Die Embryonen wurden in 1x PBS frisch aus den Uteri präpariert und ü.N. in $4 \%$ PFA in 1x PBS bei $4{ }^{\circ} \mathrm{C}$ fixiert. Am nächsten Tag wurden die Embryonen oder Gehirne mehrmals in 1x PBS gewaschen und danach folgendermaßen behandelt:

Ablauf:

\begin{tabular}{|c|c|c|}
\hline a. $1 \times$ PBS & $24 \mathrm{~h}$ & $\begin{array}{l}\text { h. } 75 \% \text { Isopropanol } \\
\text { Toluol }\end{array}$ \\
\hline b. $0,86 \% \mathrm{NaCl}$ (Saline) & $24 \mathrm{~h}$ & $\begin{array}{l}\text { i. } 50 \% \text { Isopropanol } \\
\text { Toluol }\end{array}$ \\
\hline c. $70 \%$ Ethanol & $24 \mathrm{~h}$ & $\begin{array}{l}\text { j. } 25 \% \text { Isopropanol } \\
\text { Toluol }\end{array}$ \\
\hline d. $80 \%$ Ethanol & $24 \mathrm{~h}$ & k. $100 \%$ Toluol \\
\hline e. $90 \%$ Ethanol & $24 \mathrm{~h}$ & 1. Paraplast-Plus, $60^{\circ} \mathrm{C}$ \\
\hline
\end{tabular}




$\begin{array}{llll}\text { f. } 100 \% \text { Ethanol } & 24 \mathrm{~h} & \text { m. Paraplast-Plus, } 60{ }^{\circ} \mathrm{C} & 24 \mathrm{~h} \\ \text { g. } 100 \% \text { Isopropanol } & 24 \mathrm{~h} & \text { n. Paraplast-Plus, } 60^{\circ} \mathrm{C} & 24 \mathrm{~h}\end{array}$

Nach der Dehydrierung wurden die Embryonen in der gewünschten Orientierung mit Hilfe einer Einbettmaschine in Paraffin eingebettet und bis zur Herstellung der Schnitte bei RT gelagert.

$4 \%$ PFA IN 1 X PBS:

$40 \mathrm{~g}$ Paraformaldehyd (PFA)

ad $1.000 \mathrm{ml}$ mit 1x PBS

bei $60{ }^{\circ} \mathrm{C}$ gelöst

\section{HERSTELLUNGVON PARAFFINSCHNITTEN}

Dazu wurde der in Paraffin eingebettete Embryo in ein Mikrotom der Firma Leica eingespannt und geschnitten. Die 8 - $15 \mu \mathrm{m}$ dicken Schnitte wurden anschließend auf der Wasseroberfläche eines $45{ }^{\circ} \mathrm{C}$-Wasserbades entspannt und von dort auf einen Superfrost-Objektträger der Firma Menzel Gläser (Braunschweig) aufgenommen. Diese geringe Schnittstärke ist von Vorteil, da sie eine zelluläre Analyse erlaubt. Die Schnitte wurden für $1 \mathrm{~h}$ auf eine $37{ }^{\circ} \mathrm{C}$-Wärmeplatte gelegt, ü.N. bei $37{ }^{\circ} \mathrm{C}$ getrocknet, am darauffolgenden Tag bei RT bis zur Verwendung gelagert.

\section{PRÄHYBRIDISIERUNG}

Die Prähybridisierung dient dem Entparaffinieren der Schnitte, außerdem zum Vorbereiten der Hybridisierung.

Ablauf:

$\begin{array}{llll}\text { a. } 100 \% \text { Xylolersatz } & 10 \text { Min. } & \text { o. } 10 \mathrm{mg} / \mathrm{ml} \text { Proteinase-K } & 7 \text { Min. } \\ \text { b. } 100 \% \text { Xylolersatz } & 10 \text { Min. } & \text { p. } 1 x \text { PBS } & 5 \text { Min. } \\ \text { c. } 100 \% \text { Ethanol } & 2 \text { Min. } & \text { q. } 4 \% \text { PFA } & 20 \text { Min. } \\ \text { d. } 95 \% \text { Ethanol } & 2 \text { Min. } & \text { r. } 1 x \text { PBS } & 5 \text { Min. } \\ \text { e. } 90 \% \text { Ethanol } & 2 \text { Min. } & \text { s. Acetyl.-Mix. } & 10 \text { Min. } \\ \text { f. } 80 \% \text { Ethanol } & 2 \text { Min. } & \text { t. } 1 \text { PBS } & 5 \text { Min. } \\ \text { g. } 70 \% \text { Ethanol } & 2 \text { Min. } & \text { u. } 0,86 \% \mathrm{NaCl}(\text { Saline) } & 5 \text { Min. } \\ \text { h. } 50 \% \text { Ethanol } & 2 \text { Min. } & \text { v. } 30 \% \text { Ethanol } & 2 \text { Min. } \\ \text { i. } 30 \% \text { Ethanol } & 2 \text { Min. } & \text { w. } 50 \% \text { Ethanol } & 2 \text { Min. } \\ \text { j. } 0,86 \% \mathrm{NaCl} \text { (Saline) } & 5 \text { Min. } & \text { x. } 70 \% \text { Ethanol } & 2 \text { Min. }\end{array}$




$\begin{array}{llll}\text { k. } 1 \text { x PBS } & 5 \text { Min. } & \text { y. } 80 \% \text { Ethanol } & 2 \text { Min. } \\ \text { 1. } 4 \% \text { PFA } & 20 \text { Min. } & \text { z. } 90 \% \text { Ethanol } & 2 \text { Min. } \\ \text { m. } 1 \text { PBS } & 5 \text { Min. } & \text { aa. } 95 \% \text { Ethanol } & 2 \text { Min. } \\ \text { n. } 1 \text { x PBS } & 5 \text { Min. } & \text { bb. } 100 \% \text { Ethanol } & 2 \text { Min. }\end{array}$

Anschließend wurden die Objektträger mit den Schnitten für ca. 30 Min. bei RT getrocknet.

$$
\begin{aligned}
& \text { ACETLYL.-MIX: } \\
& \text { 0,1 M Triethanolamin } \\
& \text { 0,05 M Acetanhydrid }
\end{aligned}
$$

\author{
PROTEINASE-K-PUFFER: \\ $20 \mathrm{mM}$ Tris/HCl, $\mathrm{pH} 7,5$ \\ $1 \mathrm{mM}$ EDTA, $\mathrm{pH} 8,0$
}

\section{HYBRIDISIERUNG DER SCHNITTE}

Die RNA-Sonde wurde mit in-situ-Hybridisierungspuffer auf 1 x $10^{5} \mathrm{cpm} / \mu \mathrm{l}$ verdünnt. Vor dem Auftragen wurde der Hybridisierungsmix 2 Min. bei $80{ }^{\circ} \mathrm{C}$ denaturiert. Für jeden Schnitt wurden ca. $10 \mu$ l Hybridisierungsmix benötigt. Der Tropfen mit der Hybridisierungslösung wurde mit einem silikonisierten Deckgläschen möglichst luftblasenfrei abgedeckt. Die Hybrisierung erfolgte ü.N. bei $50{ }^{\circ} \mathrm{C}$ in einer dicht abschließbaren Plastikschüssel, die durch 50 \% Formamid/2x SSC feucht gehalten wurde und eine gesättigte Atmosphäre schaffte.

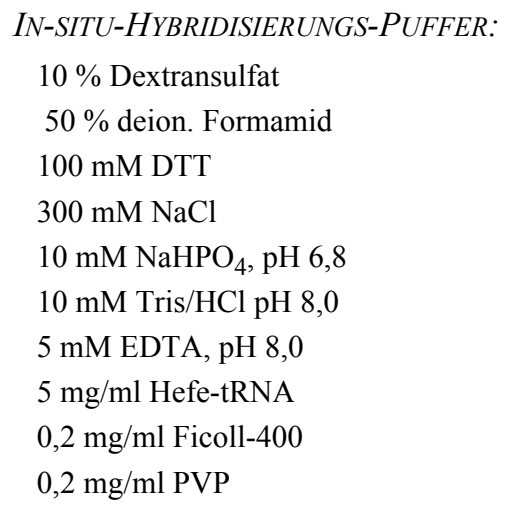

\section{WASCHEN DER OBJEKTE}

Die Objektträger wurden in Träger einsortiert und $20-30$ Min. bei $65-70{ }^{\circ} \mathrm{C}$ in Waschpuffer bewegt, je nach der erforderten Stringenz. Anschließend wurden die Schnitte 3 - 5 h unter leichtem Schütteln bei $37^{\circ} \mathrm{C}$ gewaschen. Zur RNase-Behandlung wurden die Objektträger jeweils 15 Min. im NTE ohne RNase, dann 15 Min. im NTE mit $20 \mathrm{mg} / \mathrm{ml}$ RNase A und nochmals $15 \mathrm{Min}$. ohne RNase jeweils bei $37^{\circ} \mathrm{C}$ behandelt. Danach wurden die Schnitte 30 Min. in Waschpuffer bei $37^{\circ} \mathrm{C}$ und jeweils 15 Min. in 2x 
SSC und 0,1x SSC bei RT gewaschen. Anschließend erfolgte eine Dehydrierung der Schnitte in einer aufsteigenden Alkoholreihe $(30 \%, 50 \%, 70 \% 80 \%, 90 \%, 95 \%$ und $100 \%$ Ethanol, jeweils 2 Min.). Nachdem die Schnitte gut getrocknet waren, wurden sie in einer Röntgenfilmkassette ü.N. auf Standard-Röntgenfilm (BIOMAX, Firma Kodak) exponiert, um die Stärke des Signals für die Expositionszeit abschätzen zu können.

$\begin{array}{ll}\text { WASCHPUFFER: } & \text { NTE: } \\ 50 \% \text { Formamid } & 0,5 \mathrm{M} \mathrm{NaCl} \\ 2 \mathrm{x} \text { SSC } & 0,01 \mathrm{M} \text { Tris- } \mathrm{HCl}(\mathrm{pH} 7,5) \\ 0,01 \mathrm{M} \beta \text {-Mercaptoethanol } & 1 \mathrm{mM} \text { EDTA }\end{array}$

\section{EXPONIEREN, ENTWICKELN UND FÄRBEN DER IN-SITU-HYBRIDISIERUNGEN}

In einer Dunkelkammer (ohne Rotlicht) wurden die Objektträger in eine 1:1 mit Wasser verdünnte Kodak NTB-2 Emulsion getaucht, die auf $42{ }^{\circ} \mathrm{C}$ erwärmt wurde, und $2 \mathrm{~h}$ bei RT getrocknet. Die Objektträger wurden dann in eine lichtdichte Plastikbox einsortiert. Die Objektträger wurden so bei $4{ }^{\circ} \mathrm{C} 10$ Tage exponiert. Schließlich wurden die Objektträger in der Dunkelkammer (ohne Rotlicht) 3 Min. in D19 Entwickler (80 g/ $500 \mathrm{ml}$ ) der Firma Kodak entwickelt. Es folgten 1 Min. Behandlung in $1 \%$ iger Essigsäure, 3 Min. Fixierung in 30 \%iger Natriumthiosulfatlösung und mehrmaliges Waschen in $\mathrm{dH}_{2} \mathrm{O}$ (2x 10 Min. bei RT, 5 Min. bei $42{ }^{\circ} \mathrm{C}, 10$ Min. bei RT und 30 Min. bei RT). Eine Färbung wurde für 20 Min. in einer gefilterten Giemsa-Lösung durchgeführt. Die gefärbten Objektträger wurden vorsichtig, aber gründlich mit Leitungswasser (nicht deionisiert) gespült. Nach dem Trocknen wurden die Schnitte mit Einschlußmittel (Eukitt) unter Deckgläschen eingedeckelt. Fotografien wurden mit einem Leitz Labovert Hellfeld-Dunkelfeld-Mikroskop und einem Kunstlichtfilm (Fa. Kodak, 320T) gemacht.

GIEMSA-STOCKLÖSUNG:
$0,75 \mathrm{~g}$ Giemsa
$50 \mathrm{ml}$ Methanol
$50 \mathrm{ml}$ Glycerin

GIEMSA FÄRBELÖSUNG:

$8 \mathrm{ml}$ Giemsa-Stocklösung

$4 \mathrm{ml} \mathrm{Na-Phosphat-Puffer} \mathrm{(0,2} \mathrm{M;} \mathrm{pH} \mathrm{6,0)}$

$188 \mathrm{ml} \mathrm{ddH} \mathrm{H}_{2} \mathrm{O}$

\section{IV.3.21 MRNA-IN-SITU-HYBRIDISIERUNG AN GANZEN EMBRYONEN (,WHOLE-MOUNT"-HYBRIDISIERUNGSTECHNIK)}

Die whole-mount-in-situ-Hybridisierungstechnik erlaubt die Lokalisierung einer spezifischen mRNA in Geweben und ganzen Embryonen. Die whole-mount-in-situ- 
Hybridisierung wurde nach dem Protokoll von Wilkinson durchgeführt (Wilkinson, 1992).

\section{VORBEREITUNG DER EMBRYONEN UND GEHIRNE}

Die Embryonen wurden in 1x PBS bei RT präpariert und direkt in 4 \% PFA/1x PBS überführt. Über Nacht wurden sie dann bei $4{ }^{\circ} \mathrm{C}$ in der PFA-Lösung fixiert. Am nächsten Tag wurden die Embryonen auf folgende Weise dehydriert:

$\begin{array}{lll}1 \text { x PBT } & 5 \text { Min. } & 4{ }^{\circ} \mathrm{C} \\ 1 \text { x PBT } & 5 \text { Min. } & 4{ }^{\circ} \mathrm{C} \\ 25 \% \mathrm{MeOH} / \mathrm{PBT} & 5 \mathrm{Min} . & \\ 50 \% \mathrm{MeOH} / \mathrm{PBT} & 5 \mathrm{Min} . & \\ 75 \% \mathrm{MeOH} / \mathrm{PBT} & 5 \mathrm{Min} . & \\ 100 \% \mathrm{MeOH} & 5 \mathrm{Min} . & \end{array}$

Schließlich wurden die Embryonen in frisches Methanol überführt, wo sie bei -20 ${ }^{\circ} \mathrm{C}$ mehrere Tage aufbewahrt werden konnten.

\section{HERSTELLUNG DER IN-VITRO-RNA-SONDE}

Das Herstellen einer DNA-Matrize zur in-vitro-RNA-Synthese erfolgte wie oben beschrieben.

\section{In-vitro-Transkription}

Folgender Transkriptionsansatz wurde $2 \mathrm{~h}$ bei $37^{\circ} \mathrm{C}$ inkubiert:

$\begin{array}{lc}\text { Transkriptionsansatz: } & \\ \text { DEPC-H} 2 \mathrm{O} & 11 \mu \mathrm{l} \\ \text { 10x Transkriptionspuffer } & 2 \mu \mathrm{l} \\ \text { DTT }(0,1 \mathrm{M}) & 2 \mu \mathrm{l} \\ \text { 10x DIG-Nukleotid-Mix } & 1 \mu \mathrm{l} \\ \text { linearisiertes Plasmid }(1 \mu \mathrm{g} / \mu \mathrm{l}) & 1 \mu \mathrm{l} \\ \text { RNasin }(30 \mathrm{U} / \mu \mathrm{l}) & 1 \mu \mathrm{l} \\ \text { RNA-Polymerase }(10-50 \mathrm{U} / \mu \mathrm{l}) & 1 \mu \mathrm{l}\end{array}$

Nach Entnahme eines $1 \mu$ Aliquots für ein Analysegel (1 \% Agarose/TBE Gel) wurde der Ansatz unter Zugabe von $2 \mu$ DNase (20 U/ml, RNase-frei) weitere $15 \mathrm{~min}$ 
bei $37{ }^{\circ} \mathrm{C}$ inkubiert, mit $100 \mu \mathrm{l}$ TE aufgefüllt und mittels G50-Säulen (Pharmacia) aufgereinigt..

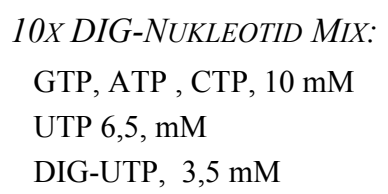

10X TRANSKRIPTIONSPUFFER:

Tris/ $\mathrm{HCl}(\mathrm{pH} 7,5), 400 \mathrm{mM}$

$\mathrm{MgCl}_{2}, 60 \mathrm{mM}$

\section{HYBRIDISIERUNG, ANTIKÖRPERINKUBATION UND FÄRBUNG}

Sämtliche Waschschritte wurden, wenn nicht anders vermerkt, bei RT für 5 Min. durchgeführt.

\section{Hybridisierung}

Zur Hybridisierung der Sonde wurden die Embryonen zunächst durch eine abfallende Methanolreihe (75\% in PBT, $50 \%$ in PBT, $25 \%$ in PBT) rehydriert. Nach zweimaligem Waschen in 1x PBT wurden die Embryonen in $6 \% \mathrm{H}_{2} \mathrm{O}_{2} / \mathrm{PBT}$ für $1 \mathrm{~h}$ bei RT gebleicht. Anschließend wurden sie dreimal in PBT gewaschen. Die Embryonen wurden je nach Alter unterschiedlich lange mit Proteinase K behandelt, wodurch die Zugänglichkeit der Sonde und des Antikörpers erhöht wurde. Hierfür wurden die Embryonen in $10 \mu \mathrm{g}$ Proteinase-K/ml PBT gemäß folgenden Richtzeiten bei RT inkubiert.

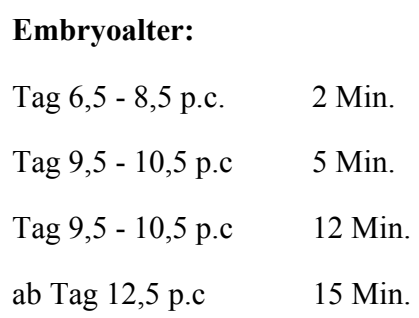

Der Proteinaseverdau wurde durch Waschen mit 2 mg Glycin/ml PBT gestoppt. Nach zweimaligem Waschen in 1x PBT wurden die Embryonen in 0,2 \% Glutaraldehyd in $4 \%$ PFA/PBT für 20 min refixiert. Anschließend wurden die Embryonen zweimal in 1x PBT gewaschen, bevor sie für $1 \mathrm{~h}$ bei $70^{\circ} \mathrm{C}$ in Prähybridisierungslösung äquilibriert wurden. Die Hybridisierung erfolgte bei $70{ }^{\circ} \mathrm{C}$ ü.N. durch Zugabe der RNA-Sonde $(0,1 \mathrm{mg} / \mathrm{ml})$. 
(PR̈̈-) HYBRIDISIERUNGSLÖSUNG:

SDS, $1 \%$

Formamid, $50 \%$

Heparin, $50 \mu \mathrm{g} / \mathrm{ml}$

Hefe-tRNA, $50 \mu \mathrm{g} / \mathrm{ml}$

$\mathrm{SSC}(\mathrm{pH} 4,5), 5 \mathrm{x}$

\section{Waschschritte}

Nach der Hybridisierung wurden die Embryonen wie folgt gewaschen und die nichthybridisierte RNA abgebaut.

\begin{tabular}{|c|c|c|}
\hline \multicolumn{3}{|l|}{ Ablauf: } \\
\hline a. Lösung 1 & $30 \mathrm{Min}$. & $70^{\circ} \mathrm{C}$ \\
\hline b. Lösung 1 & 30 Min. & $70^{\circ} \mathrm{C}$ \\
\hline c. Lösung 1/2 & $10 \mathrm{Min}$. & $70{ }^{\circ} \mathrm{C}$ \\
\hline d. Lösung 2 & 5 Min. & \\
\hline e. Lösung 2 & 5 Min. & \\
\hline $\begin{array}{l}\text { f. Lösung 2/ } \\
\text { RNAseA }\end{array}$ & 5 Min. & $37^{\circ} \mathrm{C}$ \\
\hline $\begin{array}{l}\text { g. Lösung 2/ } \\
\text { RNAseA }\end{array}$ & 5 Min. & $37^{\circ} \mathrm{C}$ \\
\hline
\end{tabular}

$\begin{array}{lll}\text { h. Lösung } 2 & 5 \mathrm{Min} . & \\ \text { i. Lösung } 3 & 5 \mathrm{Min} . & \\ \text { j. Lösung } 3 & 30 \mathrm{Min} . & 65^{\circ} \mathrm{C} \\ \text { k. Lösung3 } & 30 \mathrm{Min} . & 65^{\circ} \mathrm{C} \\ \text { 1. TBST } & 5 \mathrm{Min} . & \\ \text { m. TBST } & 5 \mathrm{Min} . & \\ \begin{array}{l}\text { n. TBST/ } \\ 10 \% \text { FCS }\end{array} & 90 \mathrm{Min} . & \end{array}$

LÖSUNG 1
Formamid, 50\%
SDS, $1 \%$
SSC (pH 4,5), 5x
LÖSUNG 2
NaCl, $0,5 \mathrm{M}$
Tris/HCl, pH 7,5,
$10 \mathrm{mM}$
Tween-20, $0,1 \%$
ggf. RNase, $20 \mathrm{mg} / \mathrm{ml}$

\section{LÖSUNG 3:}

Formamid, $50 \%$

SSC (pH 4,5), 2x

10X TBST (100ML):

$\mathrm{NaCl}, 8 \mathrm{~g}$

$\mathrm{KCl}, 0,2 \mathrm{~g}$

Tris/ $\mathrm{HCl}(\mathrm{pH} 7,5), 1 \mathrm{M}$

Tween-20, $10 \mathrm{ml}$

vor Gebrauch Verdünnung auf $1 \mathrm{x}$ und

Zugabe von $0,48 \mathrm{mg} / \mathrm{ml}$

Levamisol
PBT:

$0,1 \%$ Tween-

20 in $1 x$ PBS

\section{Antikörperinkubation}

Die Sonde war mit DIG-dUTP markiert. Nach der Inkubation mit dem gegen die Digoxygenin-markierte RNA gerichteten Antikörper konnte die Farb-Enzym-Reaktion gestartet werden. 
Um unspezifische Bindung des Antikörpers mit embryonalen Proteinen zu vermeiden, wurde der Antikörper vorbehandelt. Hierfür wurden 3 mg Embryo-Pulver in 0,5 ml TBST für $30 \mathrm{~min}$ bei $70^{\circ} \mathrm{C}$ inkubiert. Nach Abkühlung auf Eis wurden $5 \mu \mathrm{FCS}$ zugegeben. $1 \mu 1$ Anti-DIG-Antikörper-AP (Boehringer-Mannheim) wurden anschließend für $1 \mathrm{~h}$ bei $4{ }^{\circ} \mathrm{C}$ in dem Ansatz inkubiert. Nach 10 min Zentrifugation (4 ${ }^{\circ} \mathrm{C}, 13.000 \mathrm{rpm}$, Heraeus Biofuge A) wurde der Überstand mit 1\% FCS/TBST auf $2 \mathrm{ml}$ aufgefüllt. In dieser Lösung wurden die Embryonen ü.N. bei $4{ }^{\circ} \mathrm{C}$ leicht schwenkend inkubiert.

Embryo-Pulver: $1 \mathrm{~g}$ embryonales Gewebe wurde in 4 Volumina Aceton $\left(4{ }^{\circ} \mathrm{C}\right) \mathrm{mit}$ einem Polytron-Mixer homogenisiert und für $30 \mathrm{~min}$ auf Eis gehalten. Nach $10 \mathrm{Min}$. Zentrifugation (1500 rpm, Heraeus Biofuge A) wurde das Pellet mit kaltem Aceton gewaschen, wieder zentrifugiert und abschließend das Pellet zu einem feinem Pulver zerstoßen. Das Pulver wurde bei $4{ }^{\circ} \mathrm{C}$ gelagert.

\section{Entfernen des Antikörpers}

Um überschüssige Antikörper zu entfernen, sowie die Embryonen für die Färbung zu äquilibrieren (pH-Wert und Salzkonzentration), wurde am Tag nach der Antikörperinkubation wie folgt bei RT gewaschen:

$\begin{array}{ll}\text { Ablauf: } & \\ \text { TBST } & 5 \text { Min. } \\ \text { TBST } & 5 \text { Min. } \\ \text { TBST } & 5 \text { Min. } \\ \text { TBST } & 60 \text { Min. } \\ \text { TBST } & 60 \text { Min. } \\ \text { TBST } & 60 \text { Min. } \\ \text { TBST } & 60 \text { Min. } \\ \text { NTMT } & 5 \text { Min. } \\ \text { NTMT } & \text { ü.N. }\end{array}$




\section{Färbung und Analyse}

Zur Färbung wurden die Embryonen dreimal für 10 Min. in NTMT gewaschen. Anschließend wurde mit $200 \mu \mathrm{l}$ NBT/BCIP-Stammlösung (Boehringer-Mannheim) in $10 \mathrm{ml}$ NTMT bei RT (abgedunkelt) gefärbt. Nach 3 h bis ü.N. wurde die Farbreaktion durch Überführung der Embryonen in 1x PBT gestoppt. Anschließend wurden die Embryonen nochmals in PBT gewaschen (>15 Min.), über $50 \%$ Glyzerin/PBT in $80 \%$ Glyzerin/PBT überführt und bei $4{ }^{\circ} \mathrm{C}$ gelagert. Nun waren sie für weitere Untersuchungen und zum Fotografieren fertig.

Digoxygenin ist ein natürliches, im Fingerhut vorkommendes Steroid. Dig-dUTP wird anstelle von dTTP in die DNA inkorporiert. An digoxygenierte DNA oder DNA/ RNA bindet ein mit alkalischer Phosphatase konjugierter, gegen Digoxygenin gerichteter Antikörper. Die alkalische Phosphatase katalysiert die Oxidation des farblosen Substrates BCIP (5-Bromo-4-chloro-3-indolylphosphat) zu Indigo (blau). In gekoppelter Reaktion wird farbloses NBT (Nitroblautetrazoliumchlorid) zu blauem Diformazan reduziert.

Die enzymatische Blaufärbung der Gehirne bzw. Embryonen gibt den spezifischen Ort der Hybridisierung zwischen zellulärer RNA und in-vitro- transkribierter Gegenstrang-Sonde wieder. Folglich ist so eine räumliche Aussage über die Expression des Transkripts möglich.

\section{VIBRATOMSCHNEIDEN VON WHOLE-MOUNT-GEFÄRBTEN EMBRYONEN BZW. GEHIRNEN}

Das Schneiden der durch die in-situ-Hybridisierung gefärbten Embryonen bzw. Gehirnen ermöglichte es, auch die Organstrukturen $\mathrm{zu}$ analysieren. Es wurden Embryonen der Stadien E9,5 und E10,5 und die Gehirne der embryonalen Stadien E13,5 bis E18,5 untersucht. Die Embryonen wurden sagital und quer geschnitten, die Gehirne E13,5 bis E17,5 horizontal und das E18.5-Gehirn koronal.

Um das Gewebe näher $\mathrm{zu}$ untersuchen, welches das Gen exprimiert, wurden Vibratomschnitte von $40 \mu \mathrm{m}$ angefertigt. Sie ermöglichten es, einen Eindruck von tieferliegenden Gewebeschichten zu erhalten und auch dreidimensionalen Eindruck von der Schnittebene zu erhalten. Zunächst wurden die Embryonen bzw. Gehirne aus dem 80 $\%$ Glycerol/PBT, über $50 \%$ Glycerol/PBT und schließlich in PBT überführt. Dann wurde das Gewebe in die Gelatine-Albumin-Lösung gelegt, damit das Gewebe 
physiologisch ausgeglichen ist. Parallel wurden $2 \mathrm{ml}$ der Gelatine-Albumin-Lösung mit $80 \mu \mathrm{l}$ einer 50 \%igen Gluteralaldehydlösung gemischt. Dies wurde leicht angetrocknet bevor der Embryo auf diesem Block in der gewünschten Position plaziert wurde. Nun wurden $2 \mathrm{ml}$ einer frisch angemischten Gelatine-Albumin-Lösung mit $80 \mu 1$ einer 50 \%igen Gluteralaldehydlösung dazugegeben. Nach 30 minütigem Aushärten, wurde der

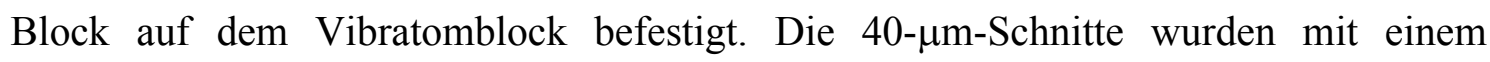
Vibratomschneidegerät („Pelco-1.000”) unter Wasser durchgeführt. Die Schnitte wurden einzeln auf vorbehandelte Objektträger (s. mRNA-in-situ-Hybridisierung) aufgezogen und mit einer Lösung (Moviol, Fa. Hoechst) eingedeckelt.

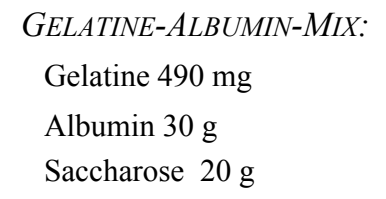

\section{IV.3.22 NACHWEIS VON ß-GALAKTOSIDASE (X-GAL-FÄRBUNG)}

Embryonen bzw. Gehirne des gewünschten Alters wurden in 1x PBS präpariert und bei $4{ }^{\circ} \mathrm{C}$ in Fixierlösung für $30 \mathrm{Min}$. fixiert. Anschließend wurden die Embryonen/ Gehirne zweimal bei RT in 1x PBS für 20 Min. gewaschen. Zum Nachweis der $\beta$ Galaktosidase wurden die Embryonen in X-Gal-Färbelösung bei $30^{\circ} \mathrm{C}$ für mindestens 12 $\mathrm{h}$ inkubiert.

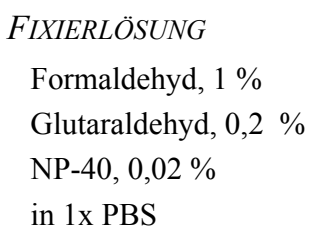

Nach erfolgter $\beta$-Galaktosidase-Färbung wurden die Embryonen/Geirne in PBS gewaschen und anschließend in einer ansteigenden Glycerin/PBS-Reihe (30\%, $50 \%, 80$ \%) aufgeklärt. In jeder Lösung wurden die Embryonen für 1 - 2 Tage belassen.

\section{IV.3.23 METHODEN ZUR ARBEIT MIT EUKARYOTISCHEN ZELLEN}

Das nachfolgend aufgeführte Arbeiten mit eukaryotischen Zellen, wurde nach der Beschreibung von A. Mansouri durchgeführt (Mansouri, 2001). 
Generell wurden die Zellen in wassergesättigter Atmosphäre unter $5 \% \mathrm{CO}_{2}$ bei 37 ${ }^{\circ} \mathrm{C}$ kultiviert. Medien und Lösungen wurden, wenn nicht anders angegeben, auf $37{ }^{\circ} \mathrm{C}$ vorgewärmt. Alle Arbeiten wurden mit Plastikmaterial (Pipetten, Gewebekulturschalen und -platten) durchgeführt.

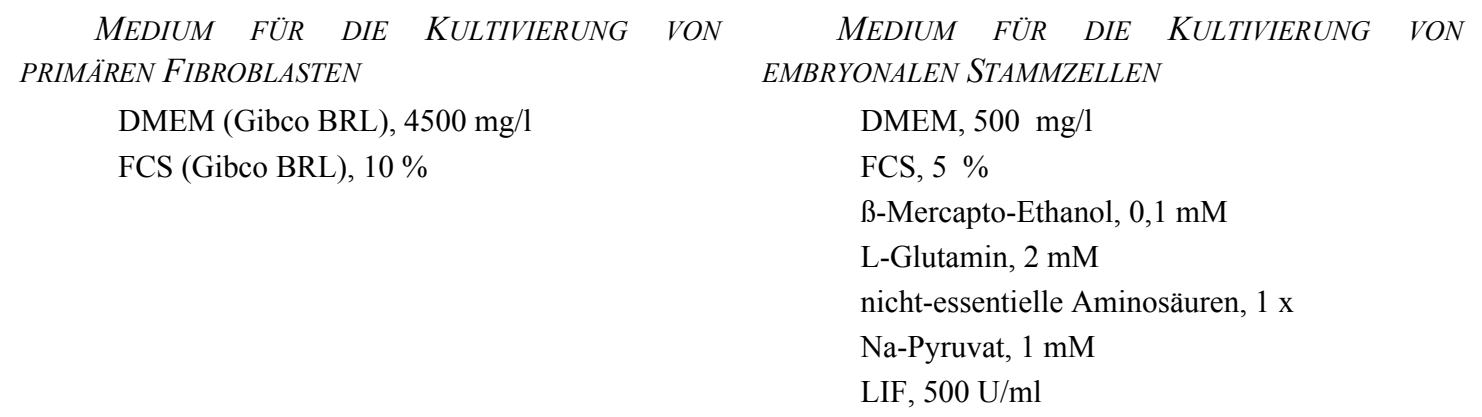

PRÄPARATION VON PRIMÄREN NEOMYCIN-BZW. PUROMYCIN-RESISTENTEN FIBROBLASTEN

Zehn Tage 13 - 15 p.c. Embryonen neomycin- bzw. puromycin-resistenter Mäuse wurden präpariert und mit 1x PBS gewaschen. Der Kopf wurde abgetrennt, Herz, Leber und andere Organe aus den Embryonen entfernt. Das Gewebe wurde mehrmals in 1x PBS gewaschen, um das Blut zu entfernen. Das Embryonengewebe wurde in einem sterilen Erlenmeyerkolben mit $50 \mathrm{ml}$ 0,25 \%igem Trypsin und sterilen Glasperlen (ø 4-5 mm) 30 Min. bei $37{ }^{\circ} \mathrm{C}$ gerührt. Die Zellen wurden pelletiert (5 Min., $1.200 \mathrm{rpm}$ ), der Überstand abgesaugt, das Pellet in Medium resuspendiert und die Zelldichte mit einer Neubauer-Zählkammer bestimmt. Die Fibroblasten wurden auf 14,5-cmZellkulturschalen plattiert und kultiviert.

\section{MITOTISCHE INAKTIVIERUNG VON FIBROBLASTEN}

Konfluente Mausfibroblasten wurden unmittelbar vor Benutzung als FibroblastenZellen durch Behandlung mit Mitomycin C mitotisch inaktiviert. Dazu wurde dem Fibroblastenmedium Mitomycin C zugesetzt (100 mg/ml) und die Mitomycin CBehandlung 2,5 h bei $37^{\circ} \mathrm{C}$ durchgeführt. Das Medium wurde abgesaugt, die Zellen 2x mit 1x PBS gewaschen und trypinisiert. Anschließend wurden die Zellen in einer Dichte von 8 x 104 Zellen/ $\mathrm{cm}^{2}$ ausplattiert. Die Gewebekulturschalen waren zuvor mit einer 0,1 \%igen Gelatine-Lösung für 15 Min. behandelt worden. 


\section{TRYPSINBEHANDLUNG VON ZELLEN}

Das Medium wurde von der Gewebekulturschale abgesaugt und die Zellen einmal mit 1x PBS gewaschen. Die Zellen wurden ca. 5 Min. mit 0,05\% Trypsin/EDTA bei $37{ }^{\circ} \mathrm{C}$ bis zur Abrundung der Zellen (mikroskopische Kontrolle) inkubiert. Die Reaktion wurde durch Zugabe von Medium gestoppt, die Zellen durch mehrfaches Aufsaugen mit der Pipette vereinzelt, die Zellzahl pro ml mit der Neubauer-Zählkammer bestimmt. Die Zellen wurden in der gewünschten Dichte ausgesät.

\section{KULTIVIERUNG EMBRYONALER STAMMZELLEN (ES-ZELLEN)}

Embryonale Stammzellen wurden auf Fibroblasten-Zellrasen aus mitotisch inaktivierten Mausfibroblasten kultiviert. Die Zellen wuchsen in scharf abgerundeten Kolonien und wurden täglich mikroskopisch kontrolliert. Dem Medium wurden $15 \%$ FCS zugesetzt und täglich gewechselt. Die Zugabe von LIF (Leukemia Inhibiting Factor) blockiert eine Differenzierung der embryonalen Stammzellen.

\section{DNA-TRANSFER IN EMBRYONALE STAMMZELLEN DURCH ELETROPORATION}

Die embryonalen Stammzellen wurden nach der Trypsinbehandlung gezählt und zweimal mit PBS gewaschen. Ca. 1,5 x 107 Zellen wurden in 0,8 ml PBS suspendiert, mit $25 \mathrm{mg}$ den Rekombinationskonstruktes sorgfältig gemischt und in die Elektroporationsküvette (Biorad; $4 \mathrm{~mm}$ Elektrodenabstand) überführt. Die Zellsuspension wurde für $5 \mathrm{Min}$. bei RT inkubiert und anschließend die Zellen mit einem Impuls von $500 \mu \mathrm{F}$ und $250 \mathrm{~V}$ elektroporiert. Mittels dieses Strompulses werden die ESZellen mit dem Rekombinationskonstrukt transformiert. Die Zellen wurden nach dem Strompuls für 5 Min. nicht bewegt, anschließend in ES-Zellmedium aufgenommen und auf den vorbereiteten Fibroblasten-Zellrasen ausplattiert.

SELEKTION EMBRYONALER STAMMZELLEN NACH ELEKTROPORATION, UM IRX2-KO-PURO POSITIVE ES-ZELLEN ZU ISOLIEREN.

\section{Irx2-KO-puro}

Das Medium elektroporierter ES-Zellen wurden $24 \mathrm{~h}$ nach der Elektroporation gegen ein mit G418 und Puromycin Dihydrochlorid enthaltendes Selektionsmedium ausgewechselt (4 $\mu \mathrm{g} / \mathrm{ml}$ Puromycin Dihydrochlorid; $2 \mathrm{mM}$ Gancyclovier). Das 
Selektionsmedium wurde täglich erneuert. Ab dem fünften Tag wurde nur noch mit Puromycin Dihydrochlorid selektioniert.

\section{GEWINNUNG VON ES-ZELL-EINZELKLONEN}

Etwa am 8. Tag nach der Elektroporation konnten einzelne ES-Zellklone isoliert werden. Dazu wurden die Zellklone unter dem Stereomikroskop mit einer sterilen gestopften Pipettenspitze isoliert. Die Zellen eines ES-Zellklons wurden in $40 \mu 1$ Trypsin/EDTA in ein Loch einer 96-Loch-Platte überführt, 5 Min. bei RT inkubiert und durch mehrmaliges Aufziehen mit einer Pipette vereinzelt. Die Trypsinierung wurde durch Überführung der Zellen in eine mit inaktivierten Fibroblasten-Zellen vorbereitete 24-Loch-Gewebekulturplatten gestoppt. Die vereinzelten ES-Zellen wurden bis zum konfluenten Wachstum kultiviert. Danach wurden die Klone wiederum trypsiniert, die eine Hälfte in DMSO-haltigem Medium weggefroren und die andere Hälfte zur Gewinnung von genomische DNA weiterkultiviert. Die ES-Zell-DNA wurde mit Hilfe von Southern-Blot-Analysen auf homologe Rekombinationsereignisse untersucht.

\section{EINFRIEREN UND AUFTAUEN VON EUKARYONTISCHEN ZELLEN}

\section{Primäre Fibroblasten}

Die Fibroblastenzellen wurden mit Trypsin behandelt, in Medium aufgenommen und 5 Min. bei $1.500 \mathrm{rpm}$ pelletiert. Nach Absaugen des Überstandes wurden die Zellen in 1 $\mathrm{ml}$ Einfriermedium resuspendiert, in Kryoröhrchen überführt und langsam ü.N. auf -70 ${ }^{\circ} \mathrm{C}$ abgekühlt und dann in flüssigem Stickstoff gelagert.

\section{Embryonale Stammzellen}

Die ES-Zellen wurden mit Trypsin behandelt, in Medium aufgenommen und pelletiert. Der Überstand wurde abgesaugt und das Zellpellet in Einfriermedium aufgenommen. In Gefrierröhrchen wurden die ES-Zellen langsam ü.N. auf $-70{ }^{\circ} \mathrm{C}$ abgekühlt und dann in flüssigem Stickstoff gelagert.

MEDIUM FÜR FIBROBLASTEN:
Zellkulturmedium
$+10 \%$ DMSO

MEDIUM FÜR FIBROBLASTEN:

$+10 \%$ DMSO
MEDIUM FÜR ES-ZELLEN:
ES-Zellmedium
$+10 \%$ FCS
$+10 \%$ DMSO 


\section{Auftauen von Zellen}

Nach der Entnahme des Kryoröhrchens aus dem flüssigem Stickstoff wurden die Zellen bei $37{ }^{\circ} \mathrm{C}$ aufgetaut. Die Zellsuspension wurde entnommen, in $5 \mathrm{ml}$ Medium überführt und die Zellen in der Labofuge pelletiert (1.500 rpm, 5 Min.). Der Überstand wurde abgesaugt, die Zellen in Medium aufgenommen und ausplattiert. Am nächsten Tag wurde das Medium gewechselt, um Reste von DMSO zu entfernen.

\section{IV.3.24 MAUS-FISH-ANALYSE DER TRANSGENEN ES-ZELLEN}

Die DNA-Sonden wurden bei $15{ }^{\circ} \mathrm{C}$ für $1 \mathrm{~h}$ mittels des BioNick labeling Kits am dATP biotinyliert (Gibco BRL) (Heng et al., 1992).

Der Ablauf der FISH-Detektion erfolgte nach Heng et al, 1992, und Heng und Tsui 1993. Dabei wurde die Chromosomen auf den Objektträgern für $1 \mathrm{~h}$ bei $55^{\circ} \mathrm{C}$ gebacken. Nach RNase-Behandlung wurden die Objekte bei $70{ }^{\circ} \mathrm{C}$ für 2 Min. in $70 \%$ Formamid/ 2xSSC denaturiert, gefolgt von einer Dehydrierung mittels einer EtOH-Reihe. Die Sonden wurden für 5 Min. in einem Hybridisierungsmix aus $50 \%$ Formamid/10 \% Dextransulfat bei $75{ }^{\circ} \mathrm{C}$ denaturiert. Die entsprechende Sonde wurde dann auf die denaturierten Chromosomen-Objektträgern aufgetragen und so ü.N. hybridisiert. Danach wurden die Objekte gewaschen und das Signal amplifiziert und detektiert. Die FISHSignale und das DAPI-Bandenmuster wurde separat analysiert und fotogafiert. Das Herstellen der FISH-Kartierungs-Daten wurde durch Überlagerung der FISH-Signale und der DAPI-Chromosomen-Bandemuster erreicht (Heng and Tsui, 1993).

Als Material für die Maus-FISH-Analyse wurde Maus-ES-Zellen benutzt und für die humane Analyse Blutzellen.

\section{IV.3.25 HERSTELLUNG VON MAUS-CHIMÄREN AUS ES-ZELLEN DURCH MORULAAGGREGATION}

Das nachfolgend aufgeführte Arbeiten mit ES-Zellen, wurde nach der Beschreibung von A. Mansouri durchgeführt (Mansouri, 2001).

\section{GEWINNUNG VON 8-ZELLSTADIEN (MORULAE) AUS TRÄCHTIGEN MÄUSEN}

Superovulierte C57Bl/6J- oder NMRI-Weibchen, die am Tag E2,5 trächtig waren, wurden nach Betäubung mit $\mathrm{CO}_{2}$ durch eine zervikale Dislokation getötet. Die Tiere 
wurden auf den Rücken gelegt, das Abdomen mit 70 \% Ethanol desinfiziert und der Bauchraum geöffnet. Der Uterus wurde mit einer stumpfen Pinzette gefaßt, und mit einer spitzen Pinzette wurden Mesometrium und Fettgewebe abgestreift. Das Ovidukt wurde zwischen Uterus und Ovar abgetrennt und bis zur Durchspülung in M2 Medium bei RT inkubiert. Die 8-Zellstadien, die sich zum Zeitpunkt der Präparation im Ovidukt befanden, wurden folgendermaßen gewonnen: Unter dem Binokular wurde das Fimbrium mit einer feinen, stumpfen Pinzette über ein Glasschälchen gehalten, eine 2,5 $\mathrm{ml}$ Spritze mit einer 27g-Kanüle vorsichtig in das Lumen Fimbriums eingeführt, und die 8-Zellstadien unter leichtem Druck herausgespült. Anschließend wurden die 8Zellstadien unter dem Binokular mit einer ausgezogenen Pasteurpipette (über einen Schlauch mit Mundstück) aufgesaugt und die 8-Zellstadien mehrfach in M2 Medium gespült und in M16 Medium abgelegt. Alle weiteren Arbeitsschritte wurden unter dem Binokular durchgeführt.

$\begin{array}{lc}\text { M2 Medium: } & \\ \text { 10x Hank's Puffer } & 3 \mathrm{ml} \\ \mathrm{NaHCO}_{3} 7,5 \% & 141 \mu \mathrm{l} \\ \text { Hepes-Puffer 1 M } & 630 \mu \mathrm{l} \\ \text { Na-Pyruvat } 100 \mathrm{mM} & 99 \mu \mathrm{l} \\ \text { Pen/Strep10.000 U/ml } & 300 \mu \mathrm{l} \\ \text { NaOH 1 M } & 30 \mu 1 \\ \text { BSA } & 120 \mathrm{mg} \\ \text { Na-Lactat } & 78 \mathrm{mg} \\ \text { ad } \mathrm{H}_{2} \mathrm{O} & 30 \mathrm{ml}\end{array}$

$\begin{array}{ll}\text { M16 Medium: } & \\ 10 \times \text { Earle's-Puffer } & 1 \mathrm{ml} \\ \mathrm{NaHCO}_{3} 7,5 \% & 270 \mu \mathrm{l} \\ \text { Na-Pyruvat100 mM } & 33 \mu \mathrm{l} \\ \text { Pen/Strep10.000 U/ml } & 100 \mu \mathrm{l} \\ \text { BSA } & 40 \mathrm{mg} \\ \text { Na-Lactat } & 26 \mathrm{mg} \\ \text { ad } \mathrm{H}_{2} \mathrm{O} & 10 \mathrm{ml} \\ \text { M16 Medium: } & \\ 10 \times \text { Earle's-Puffer } & 1 \mathrm{ml}\end{array}$

Die Medien wurden 1x pro Woche frisch angesetzt, sterilfiltriert und bei $4{ }^{\circ} \mathrm{C}$ gelagert.

\section{VORBEREITUNG DER ES-ZELLEN FÜR MORULA-AGGREGATION}

Die ES-Zellen einer 3,5-cm-Gewebekulturplatte wurden trypsiniert und in ES-ZellMedium aufgenommen. Der Überstand mit den ES-Zellen wurde abgenommen und die Zellen pelettiert (1.300 rpm, 5 Min.). Diese wurden erneut in frischen ES-Zellmedium aufgenommen. Unter dem Binokular wurden anschließend ES-Zellaggregate geeigneter Größe mit einer ausgezogenen Pasteurpipette isoliert, mehrfach in M16 Medium gewaschen und auf die Aggregationsplatte übertragen. 


\section{AGGREGATION VON ES-ZELLEN MIT 8-ZELLSSTADIEN}

Bevor 8-Zellstadien mit ES-Zellen aggregiert werden konnten, mußte die Zona pellucida von den 8-Zellstadien entfernt werden. Dazu wurden die 8-Zellstadien nacheinander in Tyrode's Säure gewaschen, wodurch die Zona pellucida sich auflöste. Anschließend wurden die 8-Zellstadien mehrfach in M16 Medium gut gewaschen und in die Vertiefungen einer Aggregations-platte in M16 Medium abgelegt. In den Vertiefungen der Aggregationsplatte wurde ein Zellhaufen aus ca. 4 - 15 ES-Zellen an das 8-Zellstadium aggregiert und beides ü.N. bei $5 \% \mathrm{CO}_{2}$-Atmosphäre und $37{ }^{\circ} \mathrm{C}$ inkubiert. Am nächsten Tag wurden die aggregierten Embryonen in einem Tropfen M16 Medium gewaschen, gesammelt und in pseudoschwangere Weibchen (Fostermäuse) übertragen.

$\begin{array}{ll}\text { Tyrode's Säure: } & \mathrm{g} / 100 \mathrm{ml} \\ \mathrm{NaCl} & 0,800 \\ \mathrm{KCl} & 0,020 \\ \mathrm{CaCl}_{2} \times \mathrm{x}^{2} \mathrm{H}_{2} \mathrm{O} & 0,024 \\ \mathrm{MgCl}_{2} \times 2 \mathrm{H}_{2} \mathrm{O} & 0,010 \\ \mathrm{Glukose} & 0,100 \\ \text { Polyvenylpyrrolidone (PVP) } & 0,400\end{array}$

Die Lösung wird mit $5 \mathrm{M} \mathrm{HCl}$ auf $\mathrm{pH}$ 2,5 eingestellt und sterilfiltriert.

\section{TRANSFER AGGREGIERTER EMBRYONEN IN PSEUDOSCHWANGERE FOSTERMÄUSE}

Pseudoschwangere Fostermäuse wurden durch Verpaarung mit vasektomierten Männchen erzeugt. Zur Injektionsnarkose pseudoschwangerer Fostermäuse wurden 0,7 $0,8 \mathrm{ml}$ Avertin intraperitoneal injiziert. Die Maus wurde auf den Bauch gelegt und der Rücken wurde zwischen Rippenbogen und Beckenkamm mit 70 \% Ethanol desinfiziert. Die Haut wurde mit einem sagitalen Schnitt $(1 \mathrm{~cm})$ neben der Wirbelsäule, unmittelbar unter dem Rippenbogen eröffnet. Der Hautschnitt wurde über den Fettkörper oberhalb des Uterus verschoben, die Bauchdecke mit einer spitzen Pinzette gefaßt und mit einem Schnitt eröffnet. Der am Ovar anliegende Fettkörper wurde aufgesucht, mit einer stumpfen Pinzette gefaßt und zusammen mit Ovar, Ovidukt und Uterushorn aus der Bauchhöhle herausgehoben. Der Fettkörper wurde mit einer Arterienklammer fixiert. Der Uterus wurde mit einer feinen Pinzette kurz vor dem Übergang in das Ovidukt 
fixiert und mit einer 26 g-Kanüle unterhalb der Pinzette perforiert. In diese Öffnung wurde eine Glaskapillare eingeführt, in die zuvor die aggregierten Embryonen (in ca. 10$20 \mu 1$ M16-Medium) aufgenommen worden waren. Die Embryonen wurden durch leichten Druck in das Lumen des Uterus eingespült. Die Arterienklemme wurde entfernt, der Uterus mit Ovidukt, Ovar und Fettkörper zurückgelegt und der Hautschnitt mit einer Wundklammer versorgt. Die Fostermäuse wurden bis zum Aufwachen aus der Narkose auf einer Wärmeplatte vor Unterkühlung geschützt.

$\begin{array}{ll}\text { Avertin: } & \\ \text { Tribromethanol } & 0,5 \mathrm{~g} \\ \text { Tert-Amylalkohol } & 0,25 \mathrm{~g} \\ \mathrm{H}_{2} \mathrm{O} & 39,5 \mathrm{~g} \\ \text { bei } 42{ }^{\circ} \mathrm{C} 4 \text { h lösen, sterilfiltrieren } & \end{array}$

\section{IV.3.26 ZELLBIOLOGISCHE METHODEN}

\section{REPORTER PLASMIDKONSTRUKTE}

Das Irx2-Gen wurde zum einen in einen pcDNA1.1-Vektor (Invitrogen) mit $C M V$ Promotor (Irxl-pcDNA) und zum anderen in einen pTRACER ${ }^{T M-C M V 2-V e k t o r}$ (Invitrogen) mit $C M V$-Promotor und Green-Fluorenzent-Protein (GFP) (Irx2pTRACER) kloniert. Beide Klonierungen erfolgten über eine EcoRI-Klonierung.

\section{DNA-GEWINNUNG AUS HUMANEN FIBROBLASTEN}

Tiefgefrorene humane Fibroblasten wurden mit Medium $(\alpha$-MEM $+10 \%$ FCS) aufgetaut und plattiert. Alle 2 -3 Tage wurden die Zellen mit Trypsin (1x Trypsin, 3 min., $37^{\circ} \mathrm{C}$ ) behandelt, in neuem Medium aufgenommen und gesplittet. Eine $10 \mathrm{~cm}^{2}-$ Schale an humanen Fibroblasten ergab ca. 15 $\mu$ g DNA. Zur DNA-Gewinnung wurden die Zellen mit Proteinase $K$ behandelt (ü.N. bei $56^{\circ} \mathrm{C}$ ). Alle weiteren Schritte sind analog zur Gewinnung aus Mausbiopsien oder ES-Zellen.

\section{CO-TRANSFEKTION MITTELS LIPOFECTAMIN (GIBCO,BRL)}

Drei Tage vor der Transfektion wurden die Zellen gesplittet, so dass die Schalen 0,2 0,3 x $10^{6}$ Zellen pro Platte aufwiesen. Das entsprechende Mash1-Promotorkonstrukt (1

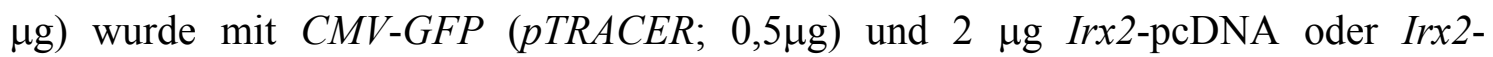


pTRACER cotransformiert. Die Transfektion erfolgte mittels Lipofectamin (Gibco/ BRL). Nach 48 h wurde die $\beta$-Galactosidase-Aktivierung des Mash1-Promotors mittels lacZ-Färbung ermittelt.

\section{IV.3.27 HERSTELLUNG VON ANTISERA (IRX2-ANTIKÖRPER)}

\section{REINIGUNG VON IRX2-PROTEIN AUS E. COLI}

Zur Affinitätsreinigung der synthetisierten Oligonucleotide wurden die am Aminoterminus mit einem Histidinhexamer-Tag versehenen, löslichen Fusionsproteine auf eine Nickelsäule (NiNTA, Qiagen; $5 \mathrm{ml}$ Bettvolumen) gegeben. Die Säule wurde mit 10 Bettvolumen Waschpuffer gewaschen und das Protein mit $10 \mathrm{ml}$ Elutionspuffer durch einen $\mathrm{pH}$-Sprung eluiert. Die $1 \mathrm{ml}$ große Fraktionen wurden aufgefangen und mit jeweils $100 \mu \mathrm{l}$ 1M Tris- $\mathrm{HCl}(\mathrm{pH} \mathrm{8,0)}$ neutralisiert. Zum Nachweis des Fusionsproteins wurden Aliquots der Fraktionen in einem 10 \%igen SDS-Gel aufgetrennt und mit CoomassieBlau gefärbt. Zur Quantifizierung wurde zu $5 \mu$ Proteinlösung $1 \mathrm{ml}$ verdünnte BradfordReagenzlösung (Biorad; $1: 5$ in $\mathrm{H}_{2} \mathrm{O}$ ) gegeben und die $\mathrm{OD}_{595}$ gemessen.

PHOSPHATPUFFER
$20 \quad \mathrm{mM}$ Na-Phospat
$(\mathrm{pH} 7,8)$
$500 \mathrm{mM} \mathrm{NaCl}$

PHOSPHATPUFFER

$500 \mathrm{mM} \mathrm{NaCl}$

WASCHPUFFER
$20 \quad \mathrm{mM}$ Na-Phospat
$(\mathrm{pH} 6,0)$
$500 \mathrm{mM} \mathrm{NaCl}$

\author{
ELUTIONSPUFFER \\ $20 \mathrm{mM} \quad$ Na-Phospat \\ $(\mathrm{pH} 4,0)$ \\ $500 \mathrm{mM} \mathrm{NaCl}$
}

\section{IMMUNISIERUNG UND BLUTABNAHME}

Für jedes Peptid-Konjugat wurden je zwei Chinchilla-Bastard-Kaninchen immunisiert. Zur Injektion wurden je $250 \mu$ Konjugat in einem Gesamtvolumen von 250 $\mu 1$ mit $250 \mu \mathrm{l}$ komplettem Freund'schen Adjuvants gemischt und die Suspension durch vortexen und wiederholtes Aufziehen und Ausspritzen durch eine 25G-Kanüle homogenisiert. Dieses Gemisch wurde intramuskulär in den Oberschenkel injiziert. Immunisierungen wurden alle sechs Wochen wiederholt. Blut wurde jeweils ca. 10 Tage nach der Injektion aus der äußeren Ohrvene entnommen (max. $50 \mu$ je Tier). Das Rohblut wurde zum Gerinnen über Nacht in den Kühlraum gestellt und am nächsten Tag abzentrifugiert (Sorvall HB-4 Rotor, 20 Min. bei 8.000 U/Min.), das resultierende Serum aliquotiert und bei $-20{ }^{\circ} \mathrm{C}$ gelagert. Diese Arbeit wurde in der Fa. Bioscience (Göttingen) durchgeführt. 


\section{REINIGUNG VON ANTISERUM}

Zur Reinigung des Serums wurde eine Antigenaffinitätssäule hergestellt, um Antigenspezifische Antikörper zu isolieren. Dazu wurde das Fusionsprotein an eine Säulenmatrix gekoppelt. Affi-Gel10 (Biorad) besteht aus, durch UV-Bestrahlung miteinander verbundenen Agarosekügelchen, die N-Hydroxysuccinimid-Estergruppen trägt. Liganden, die freie Alkylamino- oder Arylaminogruppen tragen, koppeln unter milden, wäßrigen Bedingungen spontan über die Estergruppen und bilden eine stabile Amid-Bindung zu den Kügelchen aus.

Die Proteinlösung wurde mehrfach gegen Kopplungspuffer dialysiert (HEPES, pH 7,5), um Tris und andere Substanzen $\mathrm{zu}$ entfernen, die mit ihren Aminogruppen interagieren könnten. Weiterhin wurde das Säulenmaterial mit drei Bettvolumen eiskaltem $\mathrm{dH}_{2} \mathrm{O}$ gewaschen. Das dialysierte Protein wurde zur Kopplung zur feuchten Matrix gegeben und $4 \mathrm{~h}$ bei $4{ }^{\circ} \mathrm{C}$ unter leichtem Schütteln inkubiert. Nachdem die Lösung entfernt wurde, wurde die Matrix wie folgt gewaschen:

$\begin{array}{ll}\text { Tris- } \mathrm{HCl}, 10 \mathrm{mM}, \mathrm{pH} 7,5 & 200 \mathrm{ml} \\ \text { Tris-HCl, } 10 \mathrm{mM}, \mathrm{pH} 7,5 & 200 \mathrm{ml} \\ 1 \mathrm{M} \mathrm{NaCl} & \\ \text { Glycin } 100 \mathrm{mM} \text {, ph 2,5; } 1 \mathrm{M} \mathrm{NaCl} & 200 \mathrm{ml} \\ \text { Tris-HCl } 10 \mathrm{mM}, \mathrm{pH} 8,8 & \\ \text { bis Eluat neutral } & \\ \text { Triethylamin } 100 \mathrm{mM}, \mathrm{pH} 11,5 ; & \\ 1 \mathrm{M} \mathrm{NaCl} & \\ \text { Tris- } \mathrm{HCl} 10 \mathrm{mM}, \mathrm{pH} 8,8 & \\ \text { bis Eluat neutral } & \end{array}$

Die fertige Säule wurde bei $4^{\circ} \mathrm{C}$ stehend gelagert. Zur Reinigung wurden jeweils ca. 5 $\mathrm{ml}$ Serum dreimal hintereinander über die Säule gegeben, um eine vollständige Bindung von spezifischen Antikörpern an die Säule zu erhalten. Danach wurde wie folgt gewaschen und eluiert: 


$\begin{array}{lc}\text { Tris- } \mathrm{HCl}, 10 \mathrm{mM} \text {, pH 7,5 } & 100 \mathrm{ml} \\ \text { Tris- } \mathrm{HCl}, 10 \mathrm{mM} \text {, pH 7,5 } & 100 \mathrm{ml} \\ 0,5 \mathrm{M} \mathrm{NaCl} & \\ \text { Glycin } 100 \mathrm{mM}, \text { ph 2,5; } 1 \mathrm{M} \mathrm{NaCl} & 50 \mathrm{ml} \\ \text { Tris- } \mathrm{HCl} 10 \mathrm{mM}, \mathrm{pH} 7,5 & \\ \text { bis Eluat neutral } & \end{array}$

Die Antikörper wurden durch einen pH-Sprung mit dem Glycin-Puffer eluiert, mit Tris-HCl (10 ml 1M, pH 7,5) neutralisiert und gefällt. Zur Fällung wurde ein äquivalentes Volumen gesättigter Ammoniumsulfatlösung unter Rühren langsam zugegeben und die Lösung für $6 \mathrm{~h}$ bei $4{ }^{\circ} \mathrm{C}$ aufbewahrt. Danach wurde abzentrifugiert (Sorvall HB4-Rotor 30 Min., 8.000 U/Min.). Das Pellet wurde in PBS resuspendiert, gegen PBS dialysiert und der gereinigte Antikörper in Aliquots bei $-20^{\circ} \mathrm{C}$ gelagert.

\section{IV.3.28 WESTERN-BLOT}

Die nachfolgend aufgeführte Proteinanalyse, wurde nach der Beschreibung von Towbin durchgeführt (Towbin et al., 1979).

\section{SDS-POLYACRYLAMID-GELELEKTROPHORESE}

Proben wurden in Laemmli-Ladepuffer gelöst, für 5 Min. auf $95{ }^{\circ} \mathrm{C}$ erhitzt und abzentrifugiert (Laemmli, 1970). Gewebeproben wurden im Ladepuffer mit Hilfe eines Branson-Cell Disruptors zerschallt, bis eine nichtvisköse Lösung entstanden war. Zur Herstellung eines kleinen Gels (Trenngel 6 x 11 x 0,1 cm) wurde die Trenngellösung angesetzt und zum Auspolymerisieren zwischen gereinigte, zusammengeklammerte Glasplatten gegossen und mit Isopropanol überschichtet. Nach dem Polymerisieren wurde das Isopropanol weggewaschen, die Sammelgellösung zugegossen und der Kamm zum Formen der Taschen eingeschoben. Nach dem Auspolymerisieren des Sammelgels wurde der Kamm herausgezogen und das Gel in eine vertikale Gelkammer eingespannt. Als Laufpuffer wurde Laemmli-Laufpuffer verwendet. Die Proben wurden mit einer Hamilton-Spritze geladen. Elektrophoretisiert wurde bei max. $150 \mathrm{~V}$ für 2-3 h, bis die Lauffront (Bromphenolblau) den unteren Rand des Geles erreicht hat. 


\begin{tabular}{|c|c|c|}
\hline LAEMMLI-LADEPUFFER: & TRENNGEL: & ACRYLAMIDMIX: \\
\hline SDS, $2 \%$ & $\mathrm{H}_{2} \mathrm{O}, 2 \mathrm{ml}$ & Acrylamid, 29,2\% \\
\hline Glycerol, $10 \%$ & Acrylamidmix $1,7 \mathrm{ml}$ & Methylenbisacrylamid \\
\hline Tris-HCl, $\mathrm{pH}$ 6,8, $60 \mathrm{mM}$ & Tris-HCl, $\mathrm{pH} 8,8,1,5 \mathrm{M}$, & $0,8 \%$ \\
\hline DTT, $100 \mathrm{mM}$ & $1,3 \mathrm{ml}$ & in $\mathrm{H}_{2} \mathrm{O}$ \\
\hline \multirow[t]{3}{*}{ Bromphenolblau 0,01 \% } & SDS (10\%), $50 \mathrm{ml}$ & \\
\hline & APS $(10 \%), 50 \mathrm{ml}$ & \\
\hline & TEMED, $2 \mathrm{ml}$ & \\
\hline SAMMELGEL: & LAEMMLI-LAUFPUFFER: & ACRYLAMIDMIX: \\
\hline $\mathrm{H}_{2} \mathrm{O} 2,1 \mathrm{ml}$ & Tris-HCl, $\mathrm{pH} \mathrm{8,3,} 25 \mathrm{mM}$ & Acrylamid, 29,2 \% \\
\hline Acrylamidmix, $0,5 \mathrm{ml}$ & Glycin, $250 \mathrm{mM}$ & Methylenbisacrylamid \\
\hline Tris-HCl, pH 6,3, 1 M 0,38 & SDS, $0,1 \%$ & $0,8 \%$ \\
\hline $\mathrm{ml}$ & & in $\mathrm{H}_{2} \mathrm{O}$ \\
\hline \multicolumn{3}{|l|}{ SDS (10\%), $30 \mathrm{ml}$} \\
\hline APS $(10 \%), 30 \mathrm{ml}$ & & \\
\hline
\end{tabular}

Das Irx2-Protein wurde durch in-vitro-Translation mittels des Transkriptions- und Translationssystems (TNT, Promega) hergestellt.

\section{ELEKTROBLOTTEN VON PROTEINGELEN}

Das nachfolgend aufgeführte Elektroblotten von Proteingelen, wurde nach der Beschreibung von Khysen-Anderson durchgeführt (Khysen-Anderson, 1984).

Nach der Trennung der Proteine durch die SDS-Polyacrylamid-Gelelektrophorese wurden die Proteine durch elektrophoretischen Transfer auf Kunststoffmembranen (Immobilon, Millipore) übertragen. Dazu wurde folgender Aufbau verwendet:

ELEKTROBLOT:

Elektrode (-)

Drei Lagen Filtrierpapier in Transferpuffer

Membran

Polyacrylamid-Gel

Drei Lagen Filtrierpapier in Transferpuffer

Elektrode $(+)$

Zum Blotten wurde das Gerät "Novablot Electrophoretic Transfer Kit" der Firma LKB verwendet. Es wurde bei $0,8 \mathrm{~mA} / \mathrm{cm}^{2}$ Gelfläche $1,5 \mathrm{~h}$ lang geblottet. Nach dem Transfer wurden die Proteine reversibel mit Ponceau-Rot gefärbt, um die Position der 
Größenstandardproteine auf die Membran zu übertragen und die Qualität des Transfers zu beurteilen.

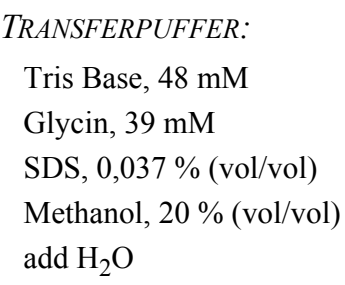

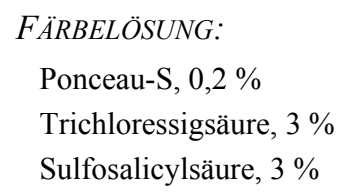

Zum Entwickeln wurde die Membran nach dem Blotten eine Stunde unter ständiger Bewegung in Blockierungslösung inkubiert, um unspezifische Absorption von Antikörpern an der Membran zu verhindern.

Danach wurde das in Blockierungslösung verdünnte Antiserum zugegeben. Das Ganze wurde in einem Plastikbeutel eingeschweißt und die Inkubation erfolgte auf einem Schütteltisch ü.N. bei $4{ }^{\circ} \mathrm{C}$. Anschließend wurde der Blot viermal je 5 Min. lang bei Raumtemperatur in PBS gewaschen und für eine Stunde mit dem 1:200 in Blockierungslösung verdünnten Schwein-Anti-Kaninchenimmunglobulin-PeroxidaseKonjugat (DAKO No. P217) inkubiert. Nach erneutem Waschen (2x 5 Min., 2x 15 Min. PBS) wurde der Blot mit dem ECL-Chemiluminiszenz-Reagenz (Amersham) nach den Vorschriften des Herstellers entwickelt. Die gewaschene Membran wurde für 1 Min. in der frisch angesetzten Entwicklungslösung inkubiert, kurz mit Filtrierpapier abgetupft, in Haushaltsfolie eingeschlagen und sofort auf Kodak-XAR Röntgenfilmen exponiert. Die Exponierungszeit betrug in der Regel nur wenige Sekunden. Alternativ wurden Blots mit Diaminobenzidin oder Chlornaphtol als Substrat entwickelt (Harlow and Lane, 1988). Zur Größenbestimmung wurden die Rf-Werte der Markerproteine gegen den Logarithmus der bekannten Molekulargewichte aufgetragen. Die Größe des zu bestimmenden Proteins wurde duch Interpolation aus dem gemessenen Rf-Wert berechnet. 


\section{IV.3.29 IMMUNHISTOCHEMIE}

\section{HERSTELLEN VON GEFRIERSCHNITTEN}

Gefrierschnitte wurden auf einem Kryostaten (Leitz) angefertigt. Dazu wurde zunächst eine Schicht Einbettmittel (Tissue-Tec; Miles) auf einem auf Trockeneis liegenden Objekthalter aufgetragen und angefroren. Nach nochmaligem Auftragen von Tissue-Tec wurde der gefrorene Embryo auf der noch flüssigen Schicht in die zum Schneiden gewünschte Position gebracht. Langsam wurde schichtweise mehr Einbettmittel um den Embryo aufgetragen bis dieser vollständig umhüllt war (Embryo sollte beim Einbetten nicht auftauen).

Es wurden $5 \mathrm{~mm}$ dicke Schnitte angefertigt, die vom Messer mit einem mit Gelatine und Chromalaun beschichteten Objektträger aufgenommen wurden. Die Schnitte wurden 15 Min. bei $50^{\circ} \mathrm{C}$ auf einer Wärmeplatte getrocknet und dann in einem mit Klebeband versiegelten Plastibrand-Objektträgerkasten trocken bei $-20^{\circ} \mathrm{C}$ aufbewahrt.

\section{IMMUNFÄRBUNG VON GEFRIERSCHNITTEN}

Die Gefrierschnitte wurden im Objektträgerkasten aufgetaut und in Färbegestelle einsortiert. Darin wurden die Schnitte mit Aceton nachfixiert (30 s, Raumtemperatur), die endogene Peroxidase inhibiert $\left(0,5 \% \mathrm{H}_{2} \mathrm{O}_{2}\right.$ in Methanol für $30 \mathrm{Min}$.) und mehrmals in PBS gewaschen. Danach wurden die Objektträger einzeln herausgenommen, PBS durch Papiertücher, der Antikörper, 1:200 verdünnt in Blockierungslösung, aufgetragen und für $6 \mathrm{~h}$ bei Raumtemperatur in einer feuchten Kammer inkubiert. Danach wurde viermal je 5 Min. in PBS gewaschen und der Nachweisantikörper (Ziege-AntiKaninchen-Immunglobulin-Peroxidasekonjugat DAKO No. P744) wie oben angegeben (1:200 verdünnt) aufgetragen. Nach 60 Min. Inkubation wurde erneut gewaschen und mit DAB-Lösung 5 Min. lang entwickelt.

$\begin{array}{cc}\text { BLOCKIERUNGSLÖSUNG } & \text { DAB-ENTWICKLUNGSLÖSUNG } \\ 5 \% \text { Milchpulver in PBS } & 0,5 \mathrm{mg} / \mathrm{ml} \text { DAB (Sigma) } \\ & \text { filtriert } \\ & 0,05 \% \mathrm{H}_{2} \mathrm{O}_{2}\end{array}$


Danach wurde erneut mit PBS gewaschen, mit einer Alkoholreihe dehydriert, in Eukitt eingedeckelt und im Lichtmikroskop mit Nomarski-Interferenzkontrast beobachtet.

\section{IV.3.30 HISTOLOGISCHE METHODEN}

\section{HÄMATOXILIN-EOSIN-F̈̈RBUNG}

Die Hämatoxilin-Eosin-Färbung wurde zur histologischen Untersuchung der Embryonen benutzt. Hämatoxilin bewirkt eine Blaufärbung der Zellkerne, während das Zytoplasma durch Eosin rot gefärbt wird. Die Schnitte werden wie o.a. als Paraffinschnitte hergestellt.

Ablauf:

\begin{tabular}{|c|c|c|c|}
\hline a. Xylolersatz & 3 Min. & 1. $\mathrm{dH}_{2} \mathrm{O}$ & $1 \mathrm{Min}$. \\
\hline b. Xylolersatz & 3 Min. & m. Eosin & 2 - 3 Min. \\
\hline c. $100 \% \mathrm{EtOH}$ & 2 Min. & n. $\mathrm{dH}_{2} \mathrm{O}$ & $1 \mathrm{Min}$. \\
\hline d. $96 \% \mathrm{EtOH}$ & 2 Min. & o. $50 \% \mathrm{EtOH}$ & 2 Min. \\
\hline e. $90 \% \mathrm{EtOH}$ & 2 Min. & p. $70 \% \mathrm{EtOH}$ & 2 Min. \\
\hline f. $80 \% \mathrm{EtOH}$ & 2 Min. & q. $80 \% \mathrm{EtOH}$ & $2 \mathrm{Min}$. \\
\hline g. $70 \% \mathrm{EtOH}$ & 2 Min. & r. $90 \% \mathrm{EtOH}$ & 2 Min. \\
\hline h. $50 \% \mathrm{EtOH}$ & 2 Min. & s. $96 \%$ EtOH & 2 Min. \\
\hline i. $\mathrm{dH}_{2} \mathrm{O}$ & einmal kurz eintauchen & t. $100 \% \mathrm{EtOH}$ & 2 Min. \\
\hline j. Hämatoxilin (Harris) & 5 - 7 Min. & u. Xylolersatz & 2 Min. \\
\hline k. HCl-Alkohol & $3 \times 10-30 s$. & v. Xylolersatz & $2 \mathrm{Min}$. \\
\hline
\end{tabular}

Im Anschluß wurden die Schnitte mit Eukitt-Einbettmedium eingedeckelt und ü.N. getrocknet.

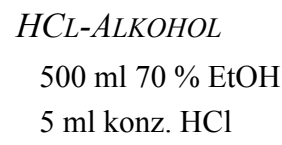

EOSIN:

$0,5 \mathrm{~g}$ Eosin in $500 \mathrm{ml} \mathrm{dH}_{2} \mathrm{O}$ lösen unter Zugabe von zwei Tropfen konz. Essigsäure, filtrieren
HÄMATOXYLIN:

fertige Lösung, filtrieren 


\section{GlOSSAR, ABKÜRZUNGEN UND SYMBOLE}

\section{GLOSSAR}

Die Bedeutung einiger Fachwörter ist hier nochmals aufgeführt.

Aktivator: Molekül, das die Aktivität eines Gens anschaltet

Allel: Zustandsform eins Gens

Blastozyste: Embryonalstadium der Säugetiere, das der Blastula anderer Tierembryonen entspricht und in dem die Einnistung in die Uterus-schleimhaut erfolgt (Wolpert et al., 1999); die Blastozyste stellt den Tag E4.0 der Mausembryogenese dar

Blotting: Unter Blotting versteht man den Übertrag (Transfer) von elektrophoretisch aufgetrennten DNA-, RNA- oder Proteingemischen auf spezielle Filter oder Membranen, die den spezifischen Nachweis einer bestimmten Nukleinsäuresequenz oder Proteinspezies erlauben

cDNA: komplementäre DNA; wird in der Gentechnik in vitro und mit Hilfe des Enzyms Reverse Transkriptase an isolierter, polyadenylierter, eukaryotischer mRNA, die als Matrize dient, erzeugt

detektieren: nachweisen, erkennen

downstream: wörtlich: stromabwärts; in einer Kaskade: unterhalb, als nachgeschalteter Faktor; bei einem Gen: weiter 3' gelegen

Embryo: Frühstadium der Entwicklung mit embryonalem und extra-embryonalem Bereich 
Enhancer: DNA-Sequenzen in 5'-Richtung vor eukaryotischen Promotoren, deren Funktion die Erhöhung der Transkriptionsrate ist

ES-Zellen (embryonale Stammzellen): pluripotente Stammzellen, die aus der Mausblastozyste hergestellt werden und sich in vivo zu allen Geweben, einschließlich der Keimbahnzellen, differenzieren

generieren: herstellen

Gen-Knock-out (KO): gezielte Deletion oder Inaktivierung (eines Gens)

Genexpression: Aktivität eines Gens

Homologe Gene: siehe orthologe Gene; In der Entwicklungsbiologie werden orthologe Gene häufig als homologe Gene bezeichnet, obwohl Ihre Homologie sich in erster Linie auf die Sequenz bezieht.

Homologe Rekombination: Rekombination zweier DNA-Moleküle an einer bestimmten Stelle, an denen sich ihre Sequenzen ähneln (Wolpert et al., 1999); Erzeugung neuer Kombinationen des genetischen Materials durch Austausch von Nukleinsäuremolekülen

Insert: Insert-DNA, Passagier-DNA, Fremd-DNA

in-situ-Hybridisierung: Technik, mit deren Hilfe man nachweisen kann, wo im Embryo bestimmte Gene exprimiert werden

Keimbahn: Zellen, die sich zu Spermien und Eizellen entwickeln

Kluster: Abfolge von Genen, die zumeist Kontrollelemente teilen

Konservierung: evolutive Erhaltung

Konstrukt: DNA-Molekül, das durch in-vitro-Verknüpfung verschiedener DNAMoleküle entstanden ist

lacZ-Gen: $\beta$-Galaktosidase-kodierendes Cistron des Lac-Operons von E. coli

Mauschimären: Mäuse, die mittels ES-Zell-Aggregation oder ES-Zell-Injektion in Blastozysten hergestellt werden. Diese haben Organe und Gewebe welche ES-Zelloder "Gastembryo"-Ursprungs sind. Weiterhin zeigt die Fellfarbe eine Mischfarbe, welche einen Hinweis auf den Grad des Chimärismus gibt

Morula: frühes Stadium des Säugerembryos ab ca. 8 Zellen (Blastomere) oder mehr. Sie zeigt die Gestalt einer Beere (Morula)

Northern-Blot: RNA-Blot, RNA-Transfer 
Orthologe Gene: Gene verschiedener Spezies, die signifikante Ähnlichkeiten in ihrer Nukleotidsequenz besitzen, da sie von einem gemeinsamen Ur-Gen abstammen

Paraloge Gene: Gene, die durch Duplikationen aus einanderder hervorgegangen sind im Genom eines Organismus.

Pluripotenz: Fähigkeit der Zellen, sich in die meisten Zelltypen des Organismus zu entwickeln. So entwickeln sich die Maus-ES-Zellen sich zu allen Geweben bis auf die Plazenta. Totipotente Zellen können sich dagegen in alle Zelltypen entwickeln.

Primer: jede Oligonukleotidsequenz, die nach Hybridisierung mit einer einzelsträngigen Nukleinsäure einen kurzen doppelsträngigen Bereich mit freier 3'- OH-Gruppe liefert und damit ein weiteres Auffüllen über DNA-Polymerasen oder Reverse Transkriptasen ermöglicht

Probe: Sonde (durch Denaturieren einzelsträngiger RNA oder DNA), welche zum Hybridisieren benutzt wird

Promotor: RNA-Polymerase-Bindungsstelle, Ort der Initiation der Transkription Repressor: Molekül, das die Aktivität eines Gens unterdrückt

Reportergen: Im Gegensatz zu selektierbaren Markergenen, die eine Auslese rekombinanter Klone oder transgener Organismen gestatten, kann ein erfolgreicher Gentransfer auch über Reportergene anhand eines leicht erkennbaren Phänotyps erfolgen (z. B. $\beta$-Galaktosidase-Färbung)

Selektionsmarker: Bezeichnung für eine DNA-Sequenz, die es ermöglicht, ein Auswahlverfahren für Organismen, die einen veränderten Geno- oder Phänotyp haben, durchzuführen

Southern-Blot: DNA-Blot, DNA-Transfer

transgene Maus: Maus mit verändertem Genom durch z. B. stabile Integration eines neuen Gens oder die Inaktivierung eines bestimmten Gens

Translokation: Übertragung von chromosomalen Bereichen auf andere Chromosomen

upstream: wörtlich: stromaufwärts; in einer Kaskade: oberhalb, als vorgeschalteter Faktor; bei einem Gen: weiter 5' gelegen

Western-Blot: Protein-Blot, Protein-Transfer

whole-mount-Hybridisierung: in-situ-Hybridisierung auf ganzen Embryonen whole-mount-in-situ-Hybridisierung: Gesamtkörper-in-situ-Hybridisierung 


\section{ABKÜRZUNGEN UND SYMBOLE}

Neben den konventionellen physikalischen Einheiten, chemischen Symbolen und dem Ein- und Dreibuchstabencode für Aminosäuren finden folgende Abkürzungen und Symbole Verwendung:

\begin{tabular}{|c|c|}
\hline Abb. & Abbildung \\
\hline Ac & Acetat \\
\hline Amp & Ampicillin \\
\hline AP & alkalische Phosphatase \\
\hline APS & Ammoniumpersulfat \\
\hline As & Aminosäure \\
\hline ATP & Adenosintriphosphat \\
\hline bp & Basenpaar \\
\hline cDNA & complementary DNA \\
\hline $\mathrm{Ci}$ & Curie \\
\hline $\mathrm{CI}$ & Chloroform/Isoamylalkohol (24:1) \\
\hline CIP & Phosphatase aus Kälberdarm (calf intestinal phosphatase) \\
\hline cpm & radioaktive Zerfälle pro Minute (counts per minute) \\
\hline $\mathrm{d}$ & Tag \\
\hline $\mathrm{ddH}_{2} \mathrm{O}$ & bidestilliertes Wasser (Millipore) \\
\hline dATP & desoxy-Adenosintriphosphat \\
\hline $\mathrm{dCTP}$ & desoxy-Cytidintriphosphat \\
\hline dGTP & desoxy-Guanosintriphosphat \\
\hline dTTP & desoxy-Thymidintriphosphat \\
\hline DMEM & Dulbecco's Modified Eagle's Medium \\
\hline dNTP & desoxy-Nukleotidtriphosphate \\
\hline DEPC & Diethylpyrocarbonat \\
\hline DMF & Dimethylformamid \\
\hline DMSO & Dimethylsulfoxid \\
\hline DNS & Desoxyribonukleinsäure \\
\hline DNase & Desoxyribonuklease \\
\hline ds & doppelsträngig \\
\hline
\end{tabular}




\begin{tabular}{|c|c|}
\hline DTT & Dithiothreitol \\
\hline EDTA & Ethylendiamintetraacetat \\
\hline $\mathrm{EtBr}$ & Ethidiumbromid \\
\hline ES-Zellen & embryonale Stammzellen \\
\hline FCS & ötales Kälber Serum (fetal calf serum) \\
\hline g & Gramm \\
\hline $\mathrm{h}$ & Stunde \\
\hline HEPES & N-2-Hydroxyethylpiperazin-N'-2-Ethansulfonsäure \\
\hline IPTG & Isopropylthio- $\beta$-D-Galaktosid \\
\hline LB & Luria-Bertani-Medium \\
\hline LIF & Leukaemia Inhibiting Faktor \\
\hline Lsg. & Lösung \\
\hline$\mu$ & micro \\
\hline $\mathrm{m}$ & milli \\
\hline M & molar \\
\hline Min. & Minuten \\
\hline MOPS & Morpholinopropansulfonsäure \\
\hline Neo & Neomycin \\
\hline mRNA & messenger RNA \\
\hline OD & optische Dichte \\
\hline p.a. & pro analysis \\
\hline PAA & Polyacrylamid \\
\hline PBS & Phosphat-gepufferte Salzlösung (phosphate buffered saline) \\
\hline p.c. & post coitum \\
\hline PCI & Phenol/Chloroform/Isoamylalkohol (25:24:1) \\
\hline PEG & Polyethylenglykol \\
\hline Pen/Strep & Penicillin/Streptomycin \\
\hline $\mathrm{pfu}$ & infektiöse Partikel (plaque forming units) \\
\hline PIPES & Pipazarin-N-N'-bis(2-Ethansulfonsäure) \\
\hline PVP & Polyvenyl-Pyrrolidon \\
\hline RNS & Ribonukleinsäure \\
\hline RNase & Ribonuklease \\
\hline $\mathrm{rpm}$ & Umdrehungen pro Minute (rounds per minute) \\
\hline RSA (BSA) & Rinderserumalbumin (bovine serum albumin) \\
\hline RT & Raumtemperatur \\
\hline S & Sekunden \\
\hline
\end{tabular}


SDS

ST I

Ss

SSC

TBE

TE

TEMED

Tris

tRNA

$\mathrm{U}$

ü.N.

V

Vol.

VE-Wasser

wt

X-Gal
Natriumdodecylsulfat (sodiumdodecylsulfate)

Standard-I Nährmedium/Agar

einzelsträngige

$\mathrm{NaCl} / \mathrm{NaCitrat}$ (standard saline citrate solution)

Tris-Borat-EDTA Puffer

Tris-EDTA Puffer

$\mathrm{N}, \mathrm{N}, \mathrm{N}^{\prime}, \mathrm{N}^{\prime}$-Tetramethylethylendiamin

Tris(hydroxymethyl)-aminomethan

transfer RNA

unit

über Nacht

Volt

Volumen

vollentsalztes Wasser

Wildtyp

5-Bromo-4-chloro-3-indolyl- $\beta$-D-galaktosid 


\section{ZUSAMMENFASSUNG}

Die Entwicklung der Organismen wird durch die koordinierte Funktion von Entwicklungskontrollgenen gesteuert, die ihrerseits den Aktivitätsstatus anderer Gene regulieren.

Bei der Suche nach neuen, entwicklungsrelevanten Genen in der Maus wurde das Irx2-Gen identifiziert und als Mitglied der Iroquois-Genfamilie in die Gruppe der Transkriptionsfaktoren eingeordnet. Das Irx2-Gen enthält hochkonservierte Sequenzmotive und stammt wahrscheinlich von einem Ur-Gen ab, das bereits in der gemeinsamen Entwicklungslinie von Pflanzen, Pilzen und Tieren existierte.

Die Herstellung der Verlustmutante ist die Grundlage für die funktionelle Analyse des Irx2-Gens. Mittels gezielter homologer Rekombination in embryonalen Stammzellen wurden die funktionellen Bereiche des Irx2-Gens deletiert.

Drei Aspekte der Funktionsanalyse sind bemerkenswert. Die Irx2-Mausmutante zeigt keine offensichtlichen morphologischen Defekte, dennoch versterben die Föten bei der Geburt. Dies läßt auf das Versagen lebenswichtiger Organe schließen. Desweiteren weisen die Ergebnisse der Funktionsanalyse auf eine ungleiche Ausprägung des Phänotyps, abhängig vom Geschlecht der Tiere und der Abstammung des mutierten Allels, hin. Die Untersuchung der genomischen Prägung des Irx2-Lokus läßt einen methylierungs-unabhängigen Mechanismus der epigenetischen Kontrolle postulieren.

Die chromosomale Lokalisation des Irx2-Gens in der Maus und im Menschen zeichnet es als ein relevantes Kandidatengen des Cri-du-Chat-Syndroms aus. Die vorhandene Genaktivität von Irx2 in den murinen Arytenoid-Knorpeln des Kehlkopfes weist auf eine mögliche Ursache der veränderten Stimmbildung der humanen Katzenschrei-Patienten hin. Die Entdeckung von Irx2 erlaubt die genetische Trennung zwischen den Symptomen der mentalen Fehlfunktion und der gestörten Stimmbildung. 
Die Evo-Devo-Studien aus Drosophila und Xenopus verweisen auf eine Interaktion der Iroquois-Gene mit den Mitgliedern des achaete-scute-Komplexes. Eine direkte Regulation konnte für die orthologen Gene in der Maus nicht bestätigt werden. Die Zunahme der murinen Mitglieder innerhalb der Genfamilie gegenüber dem IroquoisKomplex der Fliege bringt eine Aufteilung konservierter Funktionen mit, so dass regulative Interaktionen zwischen den Iroquois-Genen und den Orthologen des achaetescute-Komplexes dennoch existieren können.

Die Analyse der Mash1-Mutante zeigt die essentielle Funktion des Gens in der Differenzierung der Calcitonin-produzierenden C-Zellen in der Schilddrüse der Maus. Calcitonin reguliert die Kalziumkonzentration des Körpers, die schon bei millimolaren Änderungen schwere physiologische Schäden hervorruft.

Die funktionellen Analysen des Irx2- und des Mash1-Gens lassen für beide Gene lebenswichtige Einzelfunktionen in der Embryonalentwicklung erkennen. Die Funktionsanalysen in dem Modellorganismus Maus sind daher wichtige Grundlagen für die Erforschung humaner Krankheiten. 


\section{LITERATURVERZEICHNIS}

Ausubel, F. M., Brent, R., Kingston, R. E., Moore, D. D., Seidman, J. G., Smith, J. A., and Struhl, K. (1987). Current protocolls in molecular biology. I + II (New York: John Wiley \& Sons).

Ausubel, F. M., Brent, R., Kingston, R. E., Moore, D. D., Seidman, J. G., Smith, J. A., and Struhl, K. (1995). Short protocols in molecular biology, 3rd Edition (New York: John Wiley \& Sons).

Bao, Z. Z., Bruneau, B. G., Seidman, J. G., Seidman, C. E., and Cepko, C. L. (1999). Regulation of chamber-specific gene expression in the developing heart by Irx4. Science 283, $1161-4$

Becker, M. B. (1997). Struktur- und Funktionsanalyse eines Iroquois-verwandten Gens der Maus -Irx3-. In Dept. Moleculare Cell Biology, MPIBPC (Göttingen: University of Göttingen).

Becker, M. B., Zülch, A., and Gruss, P. (2001). Irx2 and Irxl expression in early lung development. Mech. Dev. 106, 155-158.

Bellefroid, E. J., Kobbe, A., Gruss, P., Pieler, T., Gurdon, J. B., and Papalopulu, N. (1998). Xiro3 encodes a Xenopus homolog of the Drosophila Iroquois genes and functions in neural specification. EMBO J. 17, 191-203.

Birnboim, H. C., and Doly, J. (1979). A rapid alkaline extraction procedure for screening recombinant plasmid DNA. Nucleic. Acids Res. 7, 1512-1523. 
Borges, M., Linnoila, R., van de Velde, H., Chen, H., Nelkin, B., Mabry, M., Baylin, S., and Ball, D. (1997). An achaete-scute homologue essential for neuroendocrine differentiation in the lung. Nature $386,852-855$.

Bosse, A., Stoykova, A., Nieselt-Struwe, K., Chowdury, K., Copeland, N. G., Jenkins, N. A., and P, G. (2000). Identification of a novel mouse Iroquois homeobox gene, Irx5, and chromosomal localization of all members of the mouse Iroquois gene family. Dev. Dyn. 218, 160-174.

Bosse, A., Zülch, A., Becker, M. B., Torres, M., Gomez-Skarmeta, J. L., Modolell, J., and Gruss, P. (1997). Identification of the vertebrate iroquois homeobox gene family with overlapping expression during early development of the nervous system. Mech. Dev. 69, 169-181.

Brock, H. W., and van Lohuizen, M. (2001). The polycomb group - no longer an exclusive club? Current Opinion in Genetics \& Development 11, 175 - 181.

Bronson, S., and Smithies, O. (1994). Altering mice by homologous recombination using embryonic stem cells. J Biol Chem 269, 27155-8.

Bruneau, B., Bao, Z., Tanaka, M., Schott, J., Izumo, S., Cepko, C., Seidman, J., and Seidman, C. (2000). Cardiac expression of the ventricle-specific homeobox gene Irx4 is modulated by Nkx2-5 and dHand. Dev. Biol. 217, 266-277.

Bürglin, T. R. (1997). Analysis of TALE superclass homeobox genes (MEIS, PBX, KNOX, Iroquois, TGIF) reveals a novel domain conserved between plants and animals. Nucleic Acids Res. 25, 4173-4180.

Calvin, N. M., and Hanawalt, P. C. (1988). High-efficiency transformation of bacterial cells by electroporation. J. Bacteriol. 170, 2796-2801. 
Capecchi, M. R. (1989). Altering the mouse genome by homologous recombination. Science 244, 1288-1292.

Cavalli, A. (1998). Structural requirements of DNA-transcription. DNA Cell Biol. 20, 381-391.

Cavodeassi, F., Modolell, J., and Gomex-Skarmeta, J. L. (2001). The Iroquois family of genes: from body building to neural patterning. Development 128, 2847 - 2855.

Chomczynski, P. (1993). A reagent for the single-step simultaneous isolation of RNA, DNA, and proteins from cell and tissue samples. Biotech. 15, 532-536.

Chomczynski, P., and Quasba, P. K. (1984). Alkaline transfer of DNA to plastic membrane. Biochem. Biophys. Res. Comm. 122, 340-344.

Chomczynski, P., and Sacchi, N. (1987). Single-step method of RNA isolation by acid guanidinium thiocyanate-phenol-chloroform extraction. Anal. Biochem. 162, 156159.

Chou, and Fasman (1978). Prediction of the secondary structure of proteins from their amino acid sequence. Adv. in Enzymol. 47, 45-178.

Church, D. M., Bengtsson, U., Nielson, K. V., Wasmuth, J. J., and Niebuhr, E. (1995). Molecular definition of deletions of different segments of distal $5 \mathrm{p}$ that result in distinct phenotypic features. Am. J. of Human Genetics 56, 1162 - 1172.

Cohen, D. R., Cheng, C. W., Cheng, S. H., and Hui, C. C. (2000). Expression of two novel mouse Iroquois homeobox genes during neurogenesis. Mech.Dev. 91, 317-321.

Dambly-Chaudière, C., and Leynes, L. (1992). The determination of sense organs in Drosophila : a search for interactimg genes. Int. J. Dev. Biol. 36, 85-91. 
Doetschman, T., Maeda, N., and Smithies, O. (1988). Targeted mutation of the Hprt gene in mouse embryonic stem cells. Proc Natl Acad Sci U S A 85, 8583-7.

Dower, W. J., Miller, J. F., and Ragsdale, C. W. (1988). High efficiency transformation of E. coli by high voltage electroporation. Nucleic. Acids Res. 16, 61276145 .

Fahrner, K., Hogan, B. L. M., Flavell, R. A., and 1265-1271., T. o. H.-a. Q. g. i. e. a. a. m. (1987). Transcription of H-2 and Qa genes in embryonic and adult mice. EMBO J. $6,1265-1271$.

Feinberg, A. P., and Vogelstein, B. (1983). A technique for radiolabelling DNA restriction endonuclease fragments to high specific activity. Anal. Biochem. 132, 6-13.

FlyBase (2002). Polycomb. http://flybase.bio.indiana.edu.

Fontaine, J. (1979). Multistep migration of calcitonin cell precursors during ontogeny of the mouse pharynx. Gen. Comp. Endocrinol. 37, 81 - 92.

Funayama, N., Sato, Y., Matsumoto, K., Ogura, T., and Takahashi, Y. (1999). Coelom formation: binary decision of the lateral plate mesoderm is controlled by the ectoderm. Development 126, 4129-38.

Garnier, J., Osguthorpe, D. J., and Robson, B. (1978). Analysis of the accuracy and implications of simple methods for predicting the secondary structure of globular proteins. J. Mol. Biol. 120, 97-120.

Gehring, W. J. (1994). Guidesbook to the Homeobox Genes., D. Duboule, ed. (Oxford: Oxford University Press).

Gehring, W. J. (1985). Homeotic genes, the homeo box, and the genetic control of development. Cold Spring Harb. Symp. Quant. Biol. 50, 243-251. 
Gersh, M., Grady, D., Rojas, K., Lovett, M., Moyzis, R., and Overhauser, J. (1997). Development of diagnostic tools for the analysis of $5 p$ deletions using interphase FISH. Cytogenetics \& Cell Genetics 77, 246 - 251.

Gómez-Skarmeta, J. L., del lel Calle-Mustiemces, E., and Modolell, J. (2001). The Wnt-activated Xirol gene encodes a repressor that is essential for neural development and downregulates Bmp4. Development 128, 551-560.

Gómez-Skarmeta, J. L., Diez del Corral, R., del lel Calle-Mustiemces, E., FerrésMarcó, M. D., and Modolell, J. (1996). araucan and caupolitan, two members of the novel Iroquois complex, encode homeoproteins that control proneural and vein forming genes. Cell 85, 95-105.

Gómez-Skarmeta, J. L., Glavic, A., del lel Calle-Mustiemces, E., Modolell, J., and Mayor, R. (1998). Xiro, a Xenopus homolog of the Drosophila Iroquois complexgenes, controls development at the neural plate. EMBO J. 17, 181-190.

Gómez-Skarmeta, J. L., and Modolell, J. (1996). araucan and caupolitan provide a link between compartment subdivisions and patterning of sensory organs and veins in the Drosophila wing. Genes. Dev. 10, 2935-2945.

Gómez-Skarmeta, J. L., Rodríguez, I., Martínez, C., Culí, J., Ferrés-Marcó, M. D., Belmonte, D., and Modolell, J. (1995). Cis-regulatorion of achaete and scute : Shared enhancer-like elements drive their coexpression in proneural clusters of the imaginal discs. Genes Dev. 9, 1869-1882.

Goodart, S. A., Butler, M. G., and Overhauser, J. (1996). Familial double pericentric inversion of chromosome 5 with some features of cri-du-chat syndrome. Human Genetics 97, 802 - 807. 
Goodart, S. A., Simmons, A. D., Grady, D., Rojas, K., Moyzis, R. K., Lovett, M., and Overhauser, J. (1994). A yeast artificial chromosome contig of the critical region for cridu-chat syndrome. Genomics 24, 63 - 68 .

Goriely, A., Diez del Corral, R., and Storey, K. G. (1999). c-Irx2 expression reveals an early subdivision of the neural plate in the chick embryo. Mech. Dev. 87, 203-6.

Greally, A., and John, M. (2000). The undelible mark of the genome. J. of the American Academy of Child and Adolescent Psychiatry April.

Greenblatt, M. S., Bennett, W. P., Hollstein, M., and Harris, C. C. (1994). Mutations in the p53 tumor suppressor gene: Clues to cancer etiology and molecular pathogenesis. Cancer res. 54, $4855-4878$.

Grindley, J. C., Bellusci, S., Perkins, D., and Hogan, B. L. (1997). Evidence for the envolvement of the Gli gene family in embryonic mouse lung development. Dev Biol $188,337-348$.

Guillemot, F., Lo, L. C., Johnson, J. E., Auerbach, D. J., Anderson, D. J., and Joyner, A. L. (1993). Mammalian achaete-scute homolog 1 is required for the early development of olfactory and autonomic neurons. Cell 75, 463-476.

Hanahan, D. H. (1985). Techniques for transformation of E. coli., D. M. Glover, ed. (Oxford: IRL Publisher).

Harlow, E., and Lane, D. (1988). Antibodies. A labratory manual., C. S. Harbour, ed. (New York: Cold Spring Harbour Labratory).

Heitzler, P., Bourouis, M., Ruel, L., Cateret, C., and Simpson, P. (1996). Genes of the Enhancer of Split and achaete-scute complexes are required for a regulatory loop between Notch and Delta during lateral signalling in Drosophila. Development 122, 161-171. 
Helling, R. B., Goodman, H., and Boyer, H. W. (1974). Analysis of endonuclease R EcoRI fragments of DNA from lambdoid bacteriophages and other viruses by agarosegel electrophoresis. J. of Virology 14, 1235-1244.

Heng, H. H. Q., Squire, J., and Tsui, 1.-C. (1992). High resolution mapping of mammalian genes by in situ hybridization to free chromatin. Proc. Natl. Acad. Sci. USA 89, 9509-9513.

Heng, H. H. Q., and Tsui, 1.-C. (1993). Modes of DAPI banding and simultaneous in situ hybridization. Chromosoma 102, 325-332.

Hirschberg, J. (1999). Dysphonia in infants. Int. J. of Pediatric Otorhinolaryngology 49, $293-296$.

Hogan, B., Beddington, R., Constantini, F., and Lacy, E. (1994). Manipulating the Mouse Embryo. A Labratory Manual., 2nd Edition (New York: Cold Spring Harbour Labratory Press).

Hogan, B. L. (1996). Bone morphogenetic proteins: Multifunctional regulators of vertebrate development. Genes. Dev. 10, 1580-1594.

Hogan, B. L., and Yingling, J. M. (1998). Epithelial/mesenchymal interactions and branching morphogenesis of the lung. Curr.Opin. Gene Dev. 8, 481-486.

Ivison, B. (1999). Cri du Chat support group of Australia Inc. Internet:http:// home.vicnet.net.au/-criduch/what.htm\#Message.

Iwasa, Y. (1998). The conflict theory of genomic imprinting: How much can be explained? Curr.Topics in Developmental Biology 40, 255 - 293. 
Johnson, P. H., and Grossman, L. I. (1977). Electrophoresis of DNA in agarose gels. Optimizing separations of conformational isomers of double- and single-stranded DNAs. Biochemistry 16, 4217-4225.

Kaufmann, M. H., and Bard, J. B. L. (1999). The anatomical basis of mouse development. (London: Academic Press).

Khysen-Anderson, J. (1984). Electroblotting of multiple gels: a simple apparatus without buffer tank for rapid transfer of proteins from polyacrylamide to nitrocellulose. J. Biochem. Biophys. Methods 10, 203-209.

Killian, J. K., and al., e. (2001). Divergent evolution in M6P/IGF2R imprinting from the Jurassic to the Quaternary. Hum Mol Genetics 10, 1721-1728.

Killian, J. K., Buckley, T. R., Stewart, N., Munday, B. L., and Jirtle, R. L. (2001). Marsupials end eutherians reunited: genetic evidence for the Theria hypothesis of mammalian evolution. Mammalian Genome 12, 513-517.

Kirby, K. S. (1956). A new method for the isolation of desoxyribonucleic acids: evidence on the nature of bonds between deoxyribonucleic acid and protein. Biochem. $\mathrm{J}$. $66,495-504$.

Laemmli, E. K. (1970). Cleavage of structural proteins during the assembly of the head if bacteriophage T4. Nature 227, 680-685.

Lai, E. C., Burks, C., and Posakony, J. W. (1998). The K box, a conserved 3'UTR sequence motif, negatively regulates accumulation of enhancer of split complex transcripts. Development-Suppl. 125, 4077 - 4088.

Larsen, W. J. (1993). Human Embryology, Volume 1st. (New York: Churchill Livingstone). 
Lazzaro, D., Price, M., De felice, M., and Di Lauro, R. (1991). The transcriptionfactor Ttf-1 is expressed at the onset of Thyroid and lung morphogenesis an in restricted regions of the foetal brain. Development 113, 1093 - 1104.

Le Lievre, C. S., and Le Douarin, N. M. (1975). Mesenchymal derivativesof the neural crest: analysis of chimaeric quail and chick embryos. J. Embryol. Exp. morph. 34, $125-154$.

Lewis, M. T., Ross, S., Strickland, P. A., Snyder, C. J., and Daniel, C. W. (1999). Regulated expression patterns of IRX-2, an Iroquois-class homeobox gene, in the human breast. Cell \& Tissue Research 296, 549-54.

Leyns, L., Gomez-Skarmeta, J., and Dambly-Chaudiere, C. (1996). iroquois: a prepattern gene that controls the formation of bristles on the thorax of Drosophila. Mech. Dev. 59, 63-72.

Lo, L. C., and Anderson, D. J. (1995). Postmigratory neural rest cells expressiong cRET display restricted developmental and proliferative capacities. Neuron 15, 527 - 539.

Lo, L. C., Johnson, J. E., Wuenschell, C. W., Saito, T., and Anderson, D. J. (1991). Mammalian achaete-scute homolog 1 is transiently expressed by spatially-restricted subsets of early neuroepithelial and neural crest cells. Genes Dev 5, 1524 - 1537.

Mainardi, P. C., Perfumo, C., Cali, A., Coucourde, G., Pastore, G., Cavani, S., Zara, F., Overhauser, J., Pierluigi, M., and Bricarelli, F. D. (2001). Clinical and molecular characterization of 80 patients with $5 p$ deletion: genotype-phenotype correlation. J. of Medical Genetics 38, 151 - 158.

Manning, J. E., Hershey, N. D., Broker, T. R., Pellegrini, M., Mitchell, H. K., and Davidson, N. (1975). A new method of in situ hybridization. Chromosoma 53, 107-117. 
Mansouri, A. (2001). Determination of gene function by homologous recombination using embryonic stem cells and knockout mice., Volume 175, P. M. Starkey and R. Elaswarapu, eds. (Totowa, NY: Humana Press Inc.).

Mansouri, A. (2000). Mouse Knockouts, 2nd Edition: Macmillian Refernce Ltd.).

Mansouri, A., Chowdhury, K., and Gruss, P. (1998). Follicular cells of the thyroid gland require Pax8 gene function. Nature genetics 19, 87 - 90.

Marmur, J. (1960). A procedure for the isolation of deoxyribonucleic acid from micro-organisms. J. Mol. Biol. 3, 208-218.

Marshall, L. G. (1979). Evolution of metatherian end eutherian (mammalian) characters: a review based on cladistic methology. Zool J Linnean Soc 66, 369-410.

McDonell, M. W., Simon, M. N., and Studier, F. W. (1977). Analysis of restriction fragments of T7 DNA and determination of molecular weights by electrophoresis in neutral and alkaline gels. J. Mol. Biol. 110, 119-146.

McDougall, J. K., Dunn, A. R., and Jones, K. W. (1972). In situ hybridization of adenovirus RNA and DNA. Nature 236, 346-348.

McGinnis, W. (1985). Homeo box sequences of the Antennapedia class are conserved only in higher animal genomes. Cold Spring Harb. Symp. Quant. Biol. 50, 263-270.

McGinnis, W., and Krumlauf, R. (1992). Homeobox genes and axial patterning. Cell $68,283-302$.

McGinnis, W., Levine, M. S., Hafen, E., Kuroiwa, A., and Gehring, W. J. (1984). A conserved DNA sequence in homeotic genes of the Drosophila antennapedia and bithorax complexes. Nature 308, 428-433. 
McNeill, H., Yang, C. H., Brodsky, M., Ungos, J., and Simon, M. A. (1997). mirror encodes a novel $P B X$-class homeoprotein that functions in the definition of the dorsalventral border in the Drosophila eye. Genes Dev. 11, 1073-1082.

Medina, M., Marinescu, R. C., Overhauser, J., and Kosik, K. S. (2000). Hemizygosity of delta-catenin (CTNND2) is associated with severe mental retardation in cri-du-chat syndrome. Genomics 63, 157 - 164.

Mo, R., Freer, A. M., Zinyk, D. L., Crackower, M. A., Michaud, J., Heng, H. H., Chik, K. W., Shi, X. M., Tsui, L. C., and Cheng, S. H. (1997). Specific and redundant functions of Gli2 and Gli3 zinc finger genes in the skeletal patterning and development. Development 124, 113-123.

Moore, T., and Haig, D. (1991). Genomic imprinting in mammalian develoment: a parental tug-of-war. Trends Genet 7, 45 - 49.

Motoyama, J., Liu, J., Mo, R., Ding, Q., Post, M., and C.C., H. (1998). Essential function of Gli2 and Gli3 in the formation of the lung, trachea and oesophagus. [see comments]. Nat. Genet. 20, 54-57.

Mullis, K., Faloona, F., Scharf, S., Saiki, R., Horn, G., and Erlich, H. (1986). Specific enzymatic amplification of DNA in vitro: the polymerase chain reaction. Nature 292, 635-638.

Netter, S., Fauvarque, M. O., Diez del Corral, R., Dura, J. M., and Coen, D. (1998). white + transgene insertions presenting a dorsal/ventral pattern define a single cluster of homeobox genes that is silenced by the polycomb group proteins in Drosophila melanogaster. Genetics 149, 257 - 275.

Neumann, E., Schaefer-Ridder, M., Wang, Y., and Hofschneider, P. H. (1982). Gene transfer into mouse lyoma cells by electroporation in high electric fields. EMBO J. 1, 841-845. 
Orlando, V., Jane, E. P., Chinwalla, V., Harte, P. J., and Paro, R. (1998). The binding of trithorax and polycomb proteins to the bithorax complex: dynamic changes during early Drosophila embryogenesis. Embo J. 17, 5141 - 5150.

Overhauser, J., Beaudet, A. L., and Wasmuth, J. J. (1986). A fine structure physical map of the short arm of chromosome 5. Am. J. of Human Genetics 39, 562 - 572.

Peters, H., Neubüser, A., Kratochwil, K. und Balling, R. (1998). Pax9-deficient mice lach pharyngeal pourch derivatives and teeth and exhibit cranialfacial and limb abnormalities. Genes Dev 12, 2735 - 2747.

Peters, T., Dildrop, R., Ausmeier, K., and Rüther, U. (2000). Organization of mouse Iroquois homeobox genes in two clusters suggests a conserved regulation and function in vertebrate development. Genome Res. 10.

Posakony, J. W. (1994). Nature versus nature: Asymmetric cell divisions in Drosophila bristle development. Cell 76.

Reik, W., and Walter, J. (2001). Genommic imprinting: parental influence on the genome. Nature reviews 2, 21 - 32 .

Robertson, E. J. (1987). Embryo-derived stem cell lines, in Tertocarcinomas and Embryonic Stem Cells., E. J. Robertson, ed. (Oxford: IRL).

Robertson, K. D. (2000). DNA methylation in health and disease. Nature 1, 11-19.

Saiki, R. K., Bugawan, T. L., Horn, G. T., Mullis, K. B., and Erlich, H. A. (1986). Analysis of enzymatically amplified b-globin and HLA-DQa DNA with allele-specific oligonucleotide probes. Nature 324, 163-166. 
Saiki, R. K., Gelfand, D. H., Stoffel, S., Scharf, S. J., Higuchi, R., Horn, G. T., Mullis, K. B., and Erlich, H. A. (1988). Primer-directed enzymatic amplification of DNA with a thermostable DNA polymerase. Science 239, 487-491.

Saiki, R. K., Scharf, S., Faloona, F., Mullis, K. B., Horn, G. T., Erlich, H. A., and Arnheim, N. (1985). Enzymatic amplification of b-globin genomic sequences and restriction site analysis for diagnosis of sickle cell anemia. Science 230, 1350-1354.

Sambroock, J., Fritsch, E. F., and Maniatis, T. (1989). Molecular cloning: a laboratory manual, 2nd Edition, C. S. H. Laboratory, ed. (New York: Cold Spring Harbor Laboratory Press).

Sang, Q., Ciampoli, D., Greferath, U., Sommer, L., and Young, H. M. (1999). Innervation of the esophagus in mice that lack Mash1. J. of Comp. Neurology 408, 1 10.

Sanger, F., Nicklen, S., and Coulsen, A. R. (1977). DNA sequencing with chaintermination inhibitors. Proc. Natl. Acad. Sci. USA 74, 5463-5467.

Sasaki, H., Allen, N. D., and Surani, M. A. (1993). DNA methylation and genomic imprinting in mammals. In: "DNA methylation: Molecular biology and biological significance." Birkhäuser, Basel, 469 - 486.

Simmons, A. D., Overhauser, J., and Lovett, M. (1997). Isolation of cDNAs from the cri-du-chat critical region by direct screening of a chromosome 5-specific cDNA library. PCR Methods \& Applications 7, 118 - 127.

Simpson, P. (1997). Notch signalling in development: on equivalence groups and asymmetric developmental potential. Curr. Opin. Genet. Dev. 7.

Skrabanek, L., and Wolfe, K. H. (1998). Eukaryote genome duplivation - where's the evidence? Curr. Opin. Genet. Dev. 8, 694 - 700. 
Sosa-Pineda, B., Chowdhury, K., Torres, M., Oliver, G., and Gruss, P. (1997). The Pax4 gene is essential for the differentiation of insuline-producing beta-cells in mammalian pancreas. Nature 386, 399-402.

Southern, E. M. (1975). Detection of specific sequences among DNA fragments separated by gel electrophoresis. J. Mol. Biol. 98, 503-517.

Spooner, B. S., Hartman, P., and Paulsen, A. (1994). Gravity in mammalian organ development. J Exp Zool 269, 212-222.

Sreekantaiah, C., Kronn, D., Marinescu, R. C., Goldin, B., and Overhauser, J. (1999). Characterization of a complex chromosomal rearrangement in a patient with a typical catlike cry and no other findings of the cri-du-chat syndrome. Am. J. Med. Genet. 86, $264-268$.

St. Onge, L., Sosa-Pineda, B., Chowdhury, K., Mansouri, A., and Gruss, P. (1997). Pax6 is required for differentiation of glucagon-producing alpha-cells in mouse pancreas. Nature 387, 406-409.

Tabor, S., and Richardson, C. C. (1987). DNA sequence analysis with a modified bacteriophage T7 DNA polymerase. Proc. Natl. Acad. Sci. USA 84, 4767-4771.

Tam, P. P. L., and Behringer, R. R. (1997). Mouse gastrulation: the formation of a mammalian body plan. Mech. Dev. 68, 3-25.

Tan, J. T., Korzh, V., and Gong, Z. (1999). Expression of a zebrafish iroquois homeobox gene, Ziro3, in the midline axial structures and central nervous system. Mech. Dev. $87,165-8$.

Tanaka, M., Puchyr, M., Ggertsenstein, M., Harpal, K., Jaenisch, R., Rossant, J., and Nagy, A. (1999). Parental origin-specific expression of Mash2 is established at the time of implantation with its imprinting mechanism highly resistant to genome-wide demethylation. Mech.Dev. 87, 129 - 142. 
Tarazami, S. T., Kringstein, A. M., Conte, R. a., and Verma, R. S. (1998). Comparative mapping of the cri du chat and DiGeorge syndrome regions in the great apes. Genes Genet Syst 73, 135 - 136.

Tazi, J., and Bird, A. (1990). Alternative chromatin structure at CpG islands. Cell 60, $909-920$.

Ten Have-Opbroek, A. (1991). Lung development in the mouse embryo. Experimental Lung Research 17, 111-130.

Thomas, K. R., and Capecchi, M. R. (1987). Site-directed mutagenesis by gene targeting in mouse embryo-derived stem cells. Cell 51, 503-512.

Thorne, H. V. (1966). Electrophoretic characterization and fractionation of polyoma virus DNA. J. Mol. Biol. 24, 203-211.

Towbin, H., Staehelin, T., and Gordon, J. (1979). Electrophoretic transfer of proteins from polyacrylamide gels to nitrocellulose sheets: procedure and some applications. Proc. Natl. Acad. Sci. USA 76, 4350-4353.

Treisman, J., Gonczy, P., Vashishtha, M., Harris, E., and Desplan, C. (1989). A single amino acid can determine the DNA binding specificity of homeodomain proteins. Cell $59,553-562$.

Trepel, M. (1995). Neuroanatomie, Struktur und Funktion. Urban \& Schwarzenberg Verlag.

Verma-Kurvari, S., Savage, T., Smith, D., and Johnson, J. E. (1998). Multiple elements regulate Mash1 expression in the developing CNS. Dev. Biol. 197, 106-116. 
Wang, J., Mager, J., Chen, Y., Schneider, E., Cross, J. C., Nagy, A., and Magnuson, T. (2001). Imprinted X inactivation maintained by a mouse polycomb group gene. Nature Genetics 28, 371-375.

Weisblat, D. (1994). Evolution of developmental mechanisms. In Curr. Topics in Developmental Biology, R. A. Pedersen, ed., pp. 103-134.

Wilkinson, D. G. (1992). in situ hybridisation; a practical approach. (London: Oxford University Press).

Wolpert, L., Beddington, R., Brockes, J., Jessel, T., Lawrence, P., and Meyerowitz, E. (1999). Entwicklungsbiologie (Heidelberg, Berlin: Spektrum Akademischer Verlag).

Zülch, A. (2001). Funktionsanalyse des Irxl-Gens der Maus. In MPIBPC, Dept. Mol. Cell Biology (Göttingen: Universität Göttingen).

Zülch, A. (1997). Struktur- und Funktionsanalyse eines Iroquois-verwandten Gens der Maus -Irx2-. In Dept. Moleculare Cell Biology, MPIBPC (Göttingen: University of Göttingen). 


\section{DANKSAGUNG}

An dieser Stelle möchte ich mich bei allen bedanken, die durch ihre eigene Motivation und Begeisterungsfähigkeit mir den Laboralltag spannend und persönlich angenehm gemacht haben.

Mein besonderer Dank gilt Herrn Prof. Dr. Peter Gruss für die Möglichkeit an diesem hochinteressanten Thema arbeiten zu können. Sein stetes Interesse an den Ergebnissen und dem Fortgang meines Projektes, der Aufdeckung der Funktionen der IroquoisGenfamilie hat mich motiviert und begeistert.

Ich danke Herrn Prof. Dr. U. Ehlers für die hilfreichen und freundlichen Gespräche und für die Übernahme der Begutachtung. Ich bedanke mich auch bei allen Mitgliedern der Prüfungskommission für ihr Entgegenkommen.

Meinen großen Dank möchte ich Armin Zülch aussprechen. Unsere fachlichen Diskussionen waren hilfreich und hoch produktiv.

Ich habe mich sehr gefreut, dass Frau Dr. Anastassia Stoykova mir mit ihrem Fachwissen immer zur Seite stand.

Ich richte meinen Dank an Dieter Treichel, Joachim Berger, Nora Speer, Wencke Armsen, Silke Eckaert und Barbara Meyer für ihre tolle Unterstützung in allen fachlichen Fragen.

Auf keinen Fall vergessen möchte ich den Spaß, den ich mit Marjo Salminen, Francesco Cecconi und Viktor Tarabykin beim Skifahren und den abendlichen wisenschaftlichen Diskussionen in Klosters und Val Thorens hatte.

In sehr guter Erinnerung habe ich auch die Hilfe von Luc St.Onge unteranderem im Moment der Entscheidung über die weitere Analyse meines ersten Knock-outs.

Weiterhin möchte ich mich bei meinen Kolleginnen und Kollegen im Labor Maria Belaoussoff, Nicole Andrejewski, Guy Goudrou, Sharif Masour, Jens Krull, Sabine 
Geisendorf, Alexandra Driehorst und Heike Fett bedanken, die durch ihre Hilfsbereitschaft mit zu dieser Arbeit beigetragen haben.

Danken möchte ich auch der " Iroquois-Gruppe" mit Juan Modolell, José Luis Gómez-Skarmeta, Roberto Mayor, Ruth Diaz del Coral und Peter Gruss für die vielen Ideen und Diskussionen, die in der Iroquois-Gruppe entstanden sind.

Marianne Schuster möchte ich für die vielen großen und kleinen Hilfen danken, die sie trotz ihrer vielen eigenen Arbeit übernommen hat und mir so das Leben sehr erleicherte.

Hilfe in letzter Stunde bei Rechtschreibkorrekturen und dem Drucken der Arbeit kam von Armin Zülch, Anne Becker, Nicole Andrejewski und Joachim Berger. Vielen Dank!

Mein Dank gilt meinen geliebten Eltern und meinen Schwestern, die mich immer in jeder erdenklichen Weise unterstützt und gefördert haben.

Das sich meine Erinnerungen an die Doktorarbeit nicht ausschließlich auf fachliche Fragen beschränken, habe ich Armin Zülch zu verdanken. Wir haben zusammen an der Entschlüsselung der Iroquois-Funktionen gearbeitet und dabei wunderschöne Momente erlebt. Danke! 


\section{Publikationen}

Bosse, A., Zülch, A., Becker, M. B., Torres, M., Gomez-Skarmeta, J. L., Modolell, J., and Gruss, P. (1997). Identification of the vertebrate iroquois homeobox gene family with overlapping expression during early development of the nervous system. Mech. Dev. 69, 169-181.

Becker, M. B., and Gruss, P. (2000). Functional analysis of two gene trap lines 5A-89 and 5A-97. AMGEN report, 216-224.

Treichel, D., Becker, M. B., and Gruss, P. (2001). The novel transcription factor gene Sp5 exhibits a dynamic and highly restricted expression pattern during mouse embryogenesis, Mech. Dev. 103, 150-155

Becker, M. B., Zülch, A., and Gruss, P. (2001). Irx2 and Irx1 expression in early lung development. Mech. Dev. 106, 155-158

Zülch, A., Becker, M. B., and Gruss, P. (2001). Expression pattern of Irx1 and Irx2 during mouse digit development. Mech. Dev. 106, 159-162

Becker, M. B., Zülch, A., Guillemot, F., and Gruss, P. (2002). The proneural gene Mash1 is essential for C-cell differentiation. in Vorbereitung.

Zülch, A., Becker, M.-B., and Gruss, P. (2002). Irxl, a prepattern gene essential during murine gastrulation. in Vorbereitung.

Becker, M. B., Zülch, A., and Gruss, P. (2002). Irx2 ko . Functional analyis of the Irx2 gene in mouse. in Vorbereitung 
deutschsprachige Arbeiten:

Becker, M. B. ( 1997). Struktur- und Funktionsanalyse eines Iroquois-verwandten Gens der Maus -Irx3. Diplomarbeit in der Abt. Molekulare Zellbiologie am MPIBPC (Göttingen: Universität zu Göttingen)

Becker, M.-B., Zülch, A. und Gruss, P. (2001). Von der undifferenzierten Zelle zum komplexen Organismus. Biologie in unserer Zeit 2, 88-97.

Becker, M. B., Zülch, A. und Gruss, P. (2002) Ontogenie: Wie wir werden, was wir sind. Brockhaus, akzeptiert, im Druck. 


\section{LEBENSLAUF}

Persönliche Daten:

$1982-1991$

1991

$1991-1997$

1993

$1993-1996$

1996

$1996-1997$

1997

$1998-2002$
May-Britt Becker

Am Weendespring 24A

37077 Göttingen

*15.09.1971 in Köln

ledig, deutsche Staatsbürgerin

Besuch des Gymnasiums "An der Stenner" in Iserlohn

Abschluß: Allgemeine Hochschulreife

3-monatiger Sprachaufenthalt in Nordamerika

Studium der Biologie an der Universität Göttingen

Diplomvorprüfung: Molekulare Genetik, Zoologie, Anorganische Chemie und Physikalische Chemie; Note: "sehr gut"

Hauptstudium mit Schwerpunkt in Molekularer Genetik

Mündliche Diplomhauptprüfung im Hauptfach Molekulare Genetik und den Nebenfächern Zoologie und Organische Chemie

Diplomarbeit am Max-Planck-Institut für Biophysikalische Chemie, Abt. Molekulare Zellbiologie, Prof. Dr. Peter Gruss.

Thema: "Struktur- und Funktionsanalyse eines Iroquois-verwandten Gens der Maus - Irx3 "

Verleihung des Hochschulgrades Diplom-Biologin an der Universität Göttingen;

Note: "sehr gut"

Doktorarbeit am Max-Planck-Institut für Biophysikalische Chemie, Abt. Molekulare Zellbiologie, Prof. Dr. Peter Gruss.

Thema: "Funktionsanalyse der Entwicklungskontrollgene Irx2 und Mash1 in der Maus" 